UNIVERSIDADE DE SĂO PAULO

FACULDADE DE ARQUITETURA E URBANISMO

MARIANA DE CILLO MALUFE SPIGNARDI

A INFLUÊNCIA DO MICROCLIMA URBANO NA DECISĀO PELO USO DA BICICLETA COMO MEIO DE TRANSPORTE NO CENTRO EXPANDIDO DA

CIDADE DE SÃO PAULO

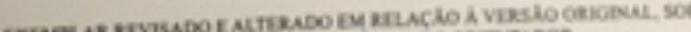

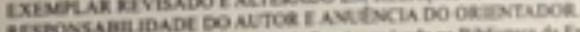

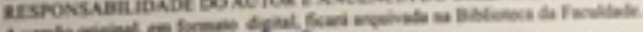

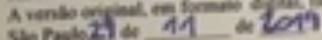

SĀO PAULO

2019 



\section{A INFLUÊNCIA DO MICROCLIMA URBANO NA DECISÃO PELO USO DA BICICLETA COMO MEIO DE TRANSPORTE NO CENTRO EXPANDIDO DA CIDADE DE SÃO PAULO}

Dissertação de Mestrado apresentada à Faculdade de Arquitetura e Urbanismo da Universidade de São Paulo, para obtenção do Título de Mestre em Arquitetura e Urbanismo.

Área de concentração: Tecnologia da Arquitetura

Orientador Prof. Dr. Leonardo Marques Monteiro

SÃO PAULO

2019 
Autorizo a reprodução e divulgação total ou parcial deste trabalho, por qualquer meio convencional ou eletrônico, para fins de estudo e pesquisa, desde que citada a fonte.

Catalogação na Publicação

Serviço Técnico de Biblioteca

Faculdade de Arquitetura e Urbanismo da Universidade de São Paulo

Spignardi, Mariana de Cillo Malufe

A INFLUÊNCIA DO MICROCLIMA URBANO NA DECISÃO PELO USO DA BICICLETA COMO MEIO DE TRANSPORTE NO CENTRO EXPANDIDO DA CIDADE DE SÃO PAULO / Mariana de Cillo Malufe Spignardi; orientador Leonardo Marques Monteiro. - São Paulo, 2019. $158 \mathrm{p}$.

Dissertação (Mestrado) - Faculdade de Arquitetura e Urbanismo da Universidade de São Paulo. Área de concentração: Tecnologia da Arquitetura.

1. Microclima Urbano. 2. Mobilidade. 3. Bicicleta. I. Monteiro, Leonardo Marques, orient. II. Título. 
Nome: SPIGNARDI, Mariana de Cillo Malufe

Título: A influência do microclima urbano na decisão pelo uso da bicicleta como meio de transporte no centro expandido da cidade de São Paulo

Dissertação de Mestrado apresentada à Faculdade de Arquitetura e Urbanismo da Universidade de São Paulo, para obtenção do Título de Mestre em Arquitetura e Urbanismo.

Aprovada em:

Banca Examinadora

Prof. Dr.

Instituição:

Julgamento:

Prof. Dr.

Instituição:

Julgamento:

Prof. Dr.

Instituição:

Julgamento: 

À Clara e ao Pedro. 



\section{AGRADECIMENTOS}

Agradeço ao Francisco e à minha família, pelo apoio incondicional.

Ao meu orientador, Leonardo Marques Monteiro, pela atenção e generosidade em compartilhar seu conhecimento.

O presente trabalho foi realizado com apoio da Coordenação de Aperfeiçoamento de Pessoal de Nível Superior - Brasil (CAPES) - Código de Financiamento 001 



\section{RESUMO}

A bicicleta encaixa-se na definição de transporte ambientalmente sustentável. Contribui com a redução dos congestionamentos, da poluição, da emissão de Gases de Efeito Estufa-GEE, otimiza o uso dos espaços urbanos e melhora a qualidade de vida dos habitantes. Proporciona ainda benefícios físicos e econômicos aos usuários. Apesar das políticas brasileiras de mobilidade urbana priorizarem os deslocamentos não motorizados e da bicicleta ser uma opção viável aos caóticos sistemas de mobilidade, na cidade de São Paulo ela representa menos de $10 \%$ dos deslocamentos para o trabalho. Diversos fatores influenciam os ciclistas em potencial a optar diariamente pela bicicleta como meio de transporte, entre eles os aspectos climáticos e microclimáticos. $O$ presente trabalho apresenta a correlação entre aspectos ambientais e o fluxo de bicicletas em duas escalas: A do centro expandido da cidade de São Paulo, por meio dos dados de um sistema de compartilhamento de bicicletas, e a da ciclovia ao longo da Avenida Faria Lima. O índice de Temperatura Equivalente Percebida - TEP é aplicado aos ciclistas, buscando investigar como a sensação e preferência térmica dos ciclistas, ou seja as condições de conforto/desconforto térmico, influenciam sua decisão pelo uso da bicicleta nos deslocamentos para o trabalho. 



\begin{abstract}
The bicycle fits into the definition of a sustainable and environmentally friendly transport mode. It contributes to the reduction of congestions, air pollution, the emission of Greenhouse Gases-GHG and the rational use of the urban spaces. It provides physical and economic benefits to it's users, improving their health and quality of life. The Brazilian policies of urban mobility prioritizes non-motorizes modes of transport, but in Sao Paulo bicycles represent less that $10 \%$ of commuting to work, even though it is a viable option for the city's chaotic mobility system. Several aspects influence potential cyclists to commute by bike, including climate and microclimatic conditions. The aim of this work is to verify how the climate and microclimatic conditions influence their decision to use the bicycle to commute in the city center of Sao Paulo. Climate and microclimate aspects and cycling data were analysed with a field survey and the identification of microclimate variables and the flow of cyclists in a specific location and period. The present work presents the correlation between environmental aspects and the bicycle flow in two scales: That of the expanded center of the city of São Paulo, using data from a bicycle sharing system, and that of the bike path along Avenida Faria Lima. The Perceived Equivalent Temperature Index - TEP is applied to cyclists, seeking to investigate how cyclists' thermal sensation and preference influence their decision to use the bicycle when commuting to work.
\end{abstract}





\section{LISTA DE FIGURAS}

Figura 1 - Localização do Parque de Ciência e Tecnologia da USP - CIENTEC e da Av. Faria Lima, no Município de São Paulo ... 42

Figura 2 - Localização do Parque de Ciência e Tecnologia da USP - CIENTEC e da

Av. Faria Lima 43

Figura 3 - Localização das bases de medição na ciclovia da Av. Faria Lima 47

Figura 4 - Localização ampliada da estação de medição na ciclovia da Av. Faria Lima 47

Figura 5 - Bases de medição na ciclovia da Av. Faria Lima. 48

Figura 6 - Foto grande angular nas bases de medição 01 - à sombra. 51

Figura 7 - Foto grande angular no ponto de medição 02 - ao sol. 51

Figura 8 - Aplicação do questionário aos ciclistas durante as medições de campo 53 Figura 9 - Questionário aplicado aos ciclistas durante as medições de campo ....... 54

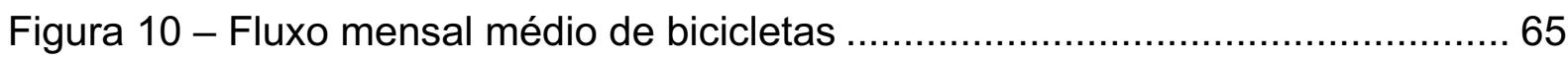

Figura 11 - Fluxo médio de bicicletas, entre 6:00 e 10:00am .................................. 65

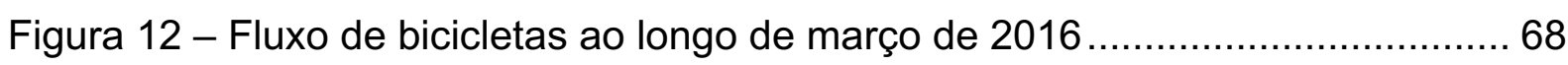

Figura 13 - Fluxo de bicicletas aos sábados, domingos e feriados em março de 2016 69

Figura 14 - Fluxo de bicicletas nos dias úteis em março de 2016. 69

Figura 15 - Correlação entre fluxo de bicicletas e temperatura média, entre 6:00 e 10:00 em 2016 



\section{LISTA DE TABELAS}

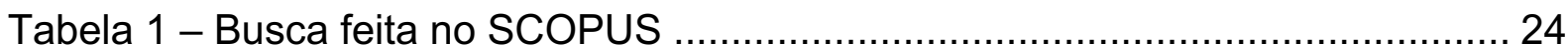

Tabela 2 - Busca feita no Web of Science ......................................................... 24

Tabela 3 - Síntese da revisão da literatura: Escala de abordagem, contexto social, variáveis ambientais e outras variáveis............................................. 27

Tabela 4 - Síntese da revisão da literatura: Coleta e análise de dados ................... 28

Tabela 5 - Síntese da revisão da literatura: Resultados........................................ 29

Tabela 6 - ISO 7726 (1998): Características requeridas e desejáveis dos instrumentos

Tabela 7 - Gasto energético estimado para atividades de ciclismo de diferentes intensidades 52

Tabela 8 - Índice de resistência térmica dos ciclistas, consolidado com vestimentas identificadas no levantamento experimental de campo 62

Tabela 9 - Gasto energético estimado para atividades de ciclismo de diferentes intensidades

Tabela 10 - Faixas interpretativas de percepção de índices de percepção de sensação térmica

Tabela 11 - Temperatura Equivalente Percebida, faixas interpretativas e respostas dos questionários aplicados aos ciclistas no levantamento de campo .. 72

Tabela 12 - Valores-limite de taxa metabólica para o índice TEP .73 



\section{SUMÁRIO}

1 INTRODUÇÃO

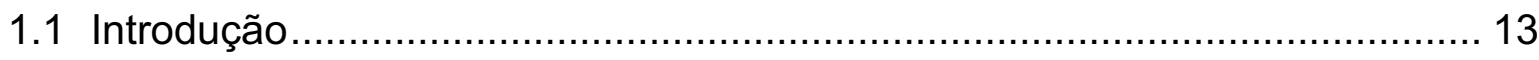

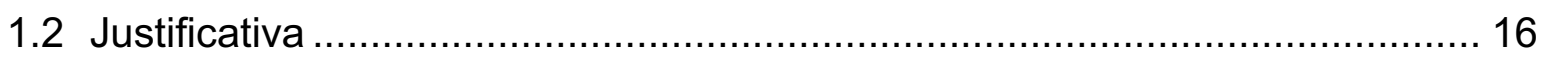

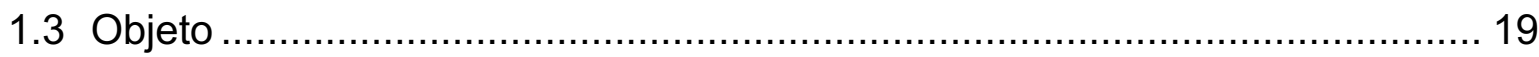

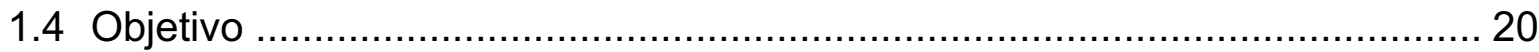

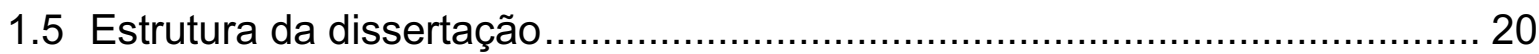

2 REVISÃO DA LITERATURA SOBRE A CORRELAÇÃO ENTRE CLIMA E MICROCLIMA URBANO E O USO DA BICICLETA...................................... 22

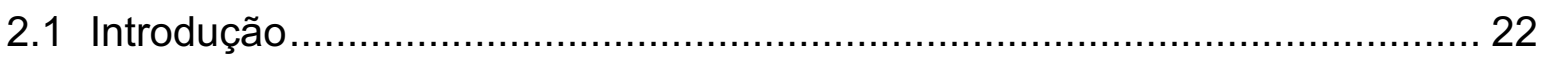

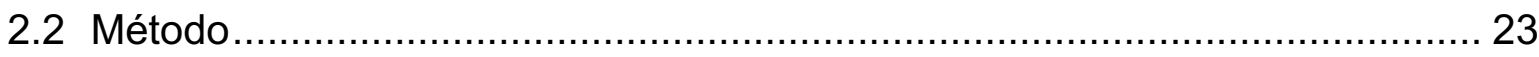

2.2.1 Identificação e seleção dos artigos ................................................... 23

2.2.2 Análise sistemática do conteúdo ...................................................... 25

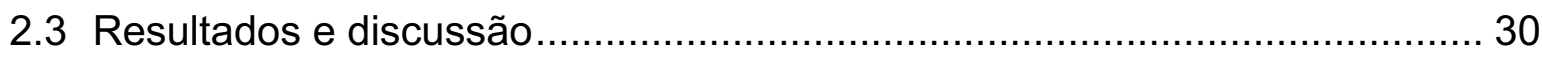

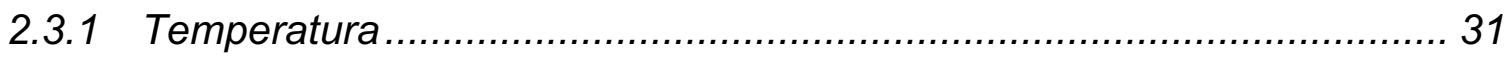

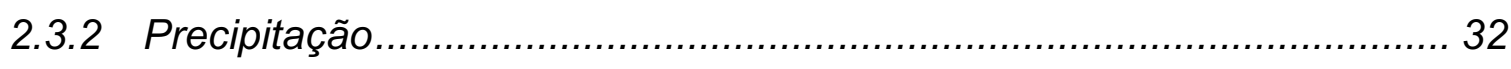

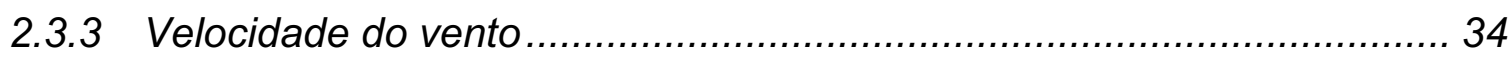

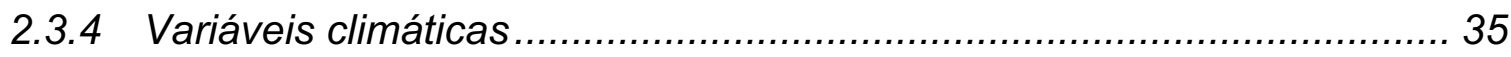

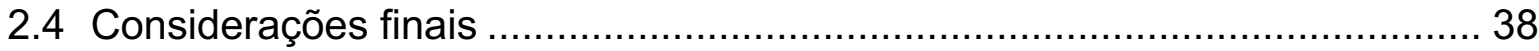

\section{MÉTODO DA PESQUISA PARA O LEVANTAMENTO DE DADOS}

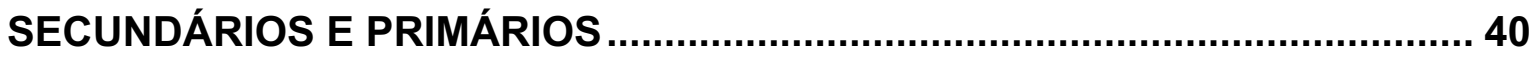

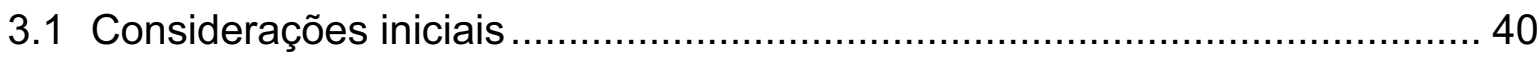

3.2 Levantamento de dados secundários.......................................................... 41

3.2.1 Dados climáticos da cidade de São Paulo ......................................... 41

3.2.2 Sistema de compartilhamento de bicicletas BIKE SAMPA ................... 43

3.2.3 Contador eletrônico da Companhia de Engenharia de Tráfego de São

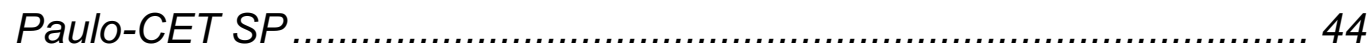

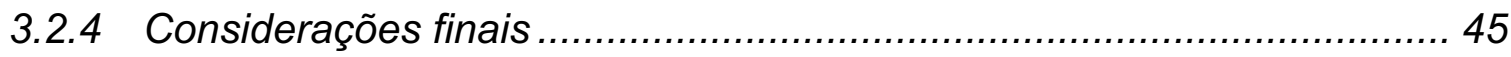

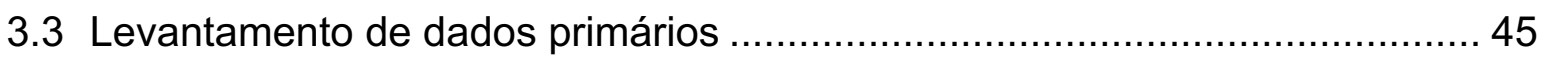

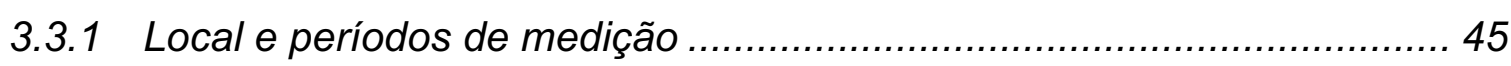

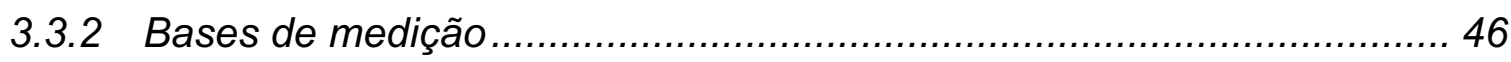

3.3.3 Procedimento do levantamento de dados primários .............................. 48

3.3.3.1 Variáveis ambientais .................................................................... 49 


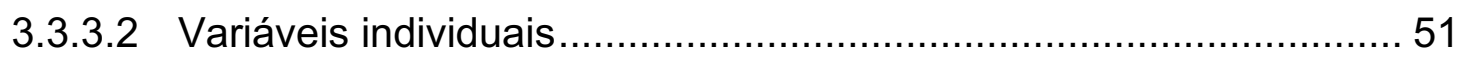

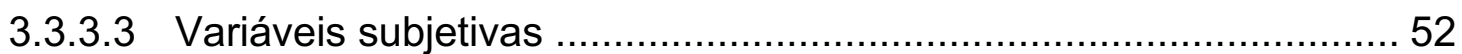

\section{TRATAMENTO DOS DADOS SECUNDÁRIOS E PRIMÁRIOS DA PESQUISA 55}

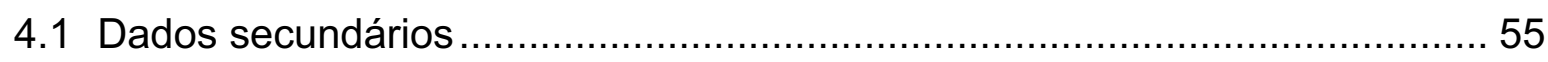

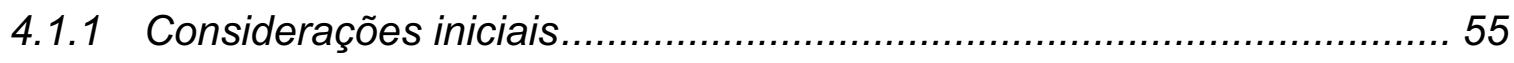

4.1.2 Dados climáticos da Estação Meteorológica do IAG ........................... 55

4.1.3 Dados sobre o fluxo de bicicletas.............................................. 56

4.1.4 Identificação de padrões no fluxo de bicicletas no centro expandido de São Paulo

4.1.5 Identificação de padrões no fluxo de bicicletas na ciclovia da Av. Faria Lima.

4.1.6 Correlações entre dados climáticos e os dados sobre contagem de bicicletas. 58

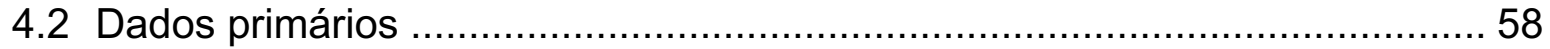

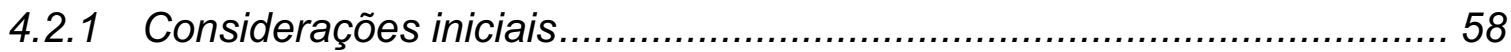

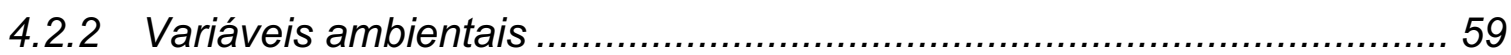

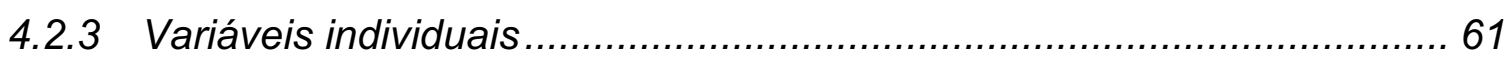

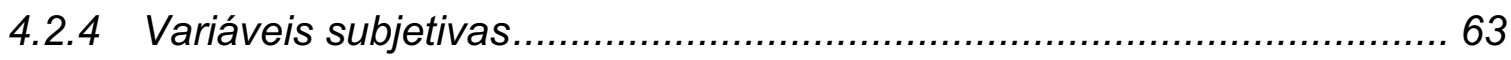

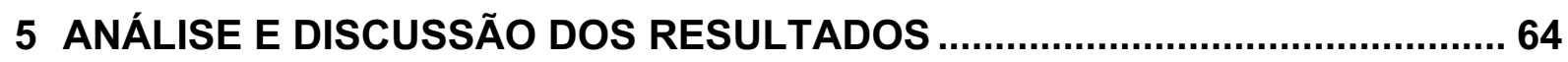

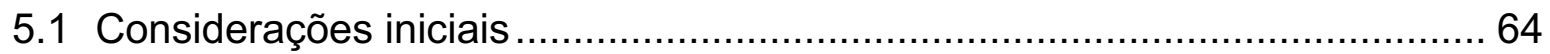

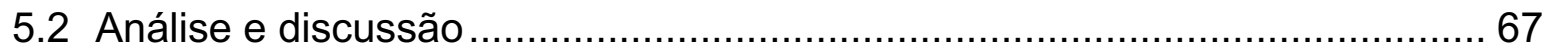

5.3 Análise qualitativa do levantamento de campo .................................. 73

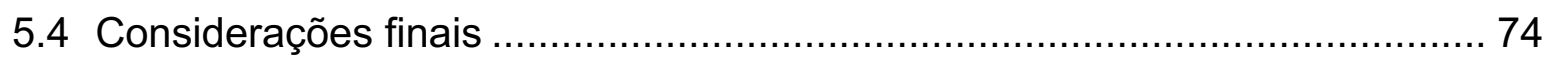

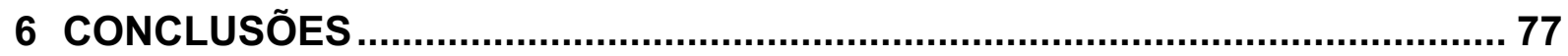

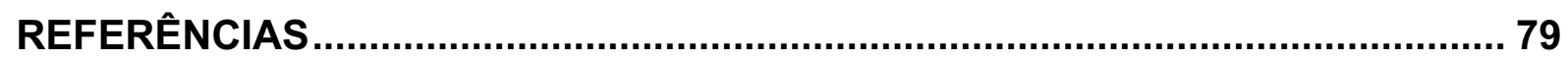

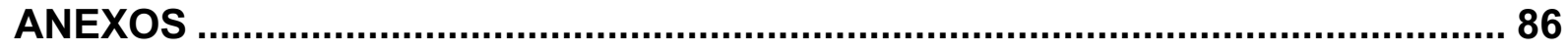

Anexo A_- Tabelas com os dados mensais de temperatura e umidade relativa do ar. 86

APÊNDICES.

Apêndice A - Consolidação das informações coletadas por meio do sistema de compartilhamento de bicicletas BIKE SAMPA.

Apêndice B - Gráficos do fluxo anual de bicicletas do sistema de bikesharing . 111 Apêndice C - Fluxo de bicicletas na ciclovia ao longo da Av. Faria Lima em Março de 2016 . 
Apêndice D - Tabela com dados consolidados mensalmente de temperatura e umidade relativa do ar, da Estação Meteorológica do IAG, e com dados do fluxo de bicicletas em duas escalas .............................. 114

Apêndice E - Dados brutos do levantamento de campo ................................. 127

Apêndice $\mathrm{F}$ - Descrição das vestimentas utilizadas pelos ciclistas no levantamento dos dados primários ........................................... 128

Apêndice G - Cálculos da Temperatura Equivalente Percebida - TEP ............. 133

Apêndice $\mathrm{H}$ - Questionários aplicados aos ciclistas ....................................... 134 



\section{INTRODUÇÃO}

\subsection{Introdução}

A bicicleta pode ser um meio de deslocamento eficaz e agradável, principalmente nas cidades sufocadas pelos congestionamentos. Além do ciclismo de lazer, existe o que chamamos de ciclismo quotidiano, em que o uso da bicicleta substitui ou é combinado a outros meios de transporte. Os benefícios do uso da bicicleta em centros urbanos são inúmeros. Do ponto de vista econômico, tem o potencial de reduzir os custos da posse de um carro e das horas gastas nos congestionamentos, gerando mais renda disponível para os indivíduos. Como consequência, existe um potencial aumento no PIB municipal (TORRES-FREIRE; CALLIL; CASTELLO, 2018).

Do ponto de vista ambiental, o impacto é significativo. Entre veículos automotores, ônibus, trens e aviões, a bicicleta é o único meio de transporte que não gera poluição, não emite gases de efeito estufa e não consome energia primária (INSTITUTO DE ENERGIA E MEIO AMBIENTE, 2010). Atualmente, os ciclistas de São Paulo são responsáveis por uma redução de $3 \%$ de todo o $\mathrm{CO} 2$ emitido com transporte de passageiros na cidade. Foi verificado que do total das viagens realizadas de ônibus, $9 \%$ são pedaláveis ${ }^{1}$ e $22 \%$ são facilmente pedaláveis ${ }^{2}$. Já entre as viagens de automóvel, $10 \%$ são pedaláveis e $33 \%$ são facilmente pedaláveis. Desta forma, ao fazermos uso do potencial da bicicleta para os deslocamentos urbanos em São Paulo, teríamos uma redução $8 \%$ e $10 \%$ do $\mathrm{CO}_{2}$ emitido por estes meios de transporte, respectivamente. Desta forma, o potencial ciclável da cidade de São Paulo corresponde a uma redução de até $18 \%$ da emissão de $\mathrm{CO}_{2}$ oriunda de seu sistema de transporte (TORRES-FREIRE; CALLIL; CASTELLO, 2018).

Além da redução das emissões de Gases de Efeito Estufa-GEE, o uso da bicicleta para deslocamentos quotidianos reduz a poluição urbana, melhorando a qualidade do ar. Em cidades como São Paulo, as emissões de poluentes dos veículos automotores respondem pela maior parte da poluição atmosférica (COMPANHIA DE

\footnotetext{
${ }^{1}$ Viagens pedaláveis: são aquelas de até $8 \mathrm{~km}$, realizadas entre $6 \mathrm{~h}$ e $20 \mathrm{~h}$, por pessoas com até 50 anos.

${ }^{2}$ Viagens facilmente pedaláveis: são aquelas de até $5 \mathrm{~km}$, realizadas entre $6 \mathrm{~h}$ e $20 \mathrm{~h}$, por pessoas com até 50 anos.
} 
TECNOLOGIA DE SANEAMENTO AMBIENTAL, 2008), que por sua vez gera graves problemas de saúde pública, como doenças respiratórias e cardíacas, onerando os sistemas de saúde.

A adoção deste meio de transporte também tem impacto na redução de gastos do Sistema Único de Saúde - SUS com doenças circulatórias e cardiovasculares. Ao considerarmos a adoção dos potenciais ciclistas por este meio de transporte, considerando as viagens pedaláveis e facilmente pedaláveis citadas acima, existe uma potencial redução do número de indivíduos com chance de ter diabetes ou doenças do aparelho circulatório, em função de um maior nível de atividade física. Isto porque o percentual de pessoas que não praticam atividades físicas regularmente é reduzido de $25 \%$ para $3 \%$ no caso destes indivíduos tornarem-se ciclistas cotidianos, refletindo em uma redução de gastos no SUS com essas doenças, e podendo gerar um impacto de mais de $\mathrm{R} \$ 34$ milhões $^{3}$ em economia anual somente na cidade de São Paulo (TORRES-FREIRE; CALLIL; CASTELLO, 2018).

De acordo com Rogers e Gumuchdjian (2001), foi o automóvel o principal responsável pela deterioração da coesa estrutura social da cidade, destruindo a qualidade dos espaços públicos e estimulando a expansão urbana para bairros distantes. Sob esta ótica, o uso da bicicleta em larga escala pode otimizar a ocupação das áreas urbanas destinadas à circulação e melhorar a qualidade ambiental dos espaços de acesso público, consolidando-se como um instrumento para que estas áreas sejam melhor aproveitadas e ocupadas pelos cidadãos. O espaço de uma faixa de trânsito de 3,5m de largura pode acomodar, por hora, 2.000 pessoas utilizando automóveis ou 9.000 pessoas utilizando ônibus. Este mesmo espaço seria ocupado por 14.000 pessoas de bicicleta (BOTMA; PAPENDRECHT, 1991).

A cidade de São Paulo, cujo centro expandido é altamente adensado e carente de áreas públicas e verdes, poderia ser amplamente beneficiada por uma mudança na mobilidade urbana baseada na prioridade aos transportes ativos. Seja pela redução da poluição do ar, pela liberação de espaços urbanos que poderiam ter seu uso resignificado, ou pela otimização dos investimentos de recursos públicos. Contribuir para o entendimento dos aspectos que influenciam a tomada de decisão pelo modo de transporte para ir ao trabalho foi a principal motivação desta pesquisa.

\footnotetext{
${ }^{3}$ Cálculo feito para o ano de 2016.
} 
Havendo a infraestrutura necessária, a bicicleta pode contribuir com outros modais de transporte, como ônibus, trens e metrôs, tornando-os mais atraentes para os usuários. A velocidade do ciclista é aproximadamente 4 vezes maior que a do pedestre. Enquanto o pedestre percorre aproximadamente 0,8km em 10 minutos de caminhada, o ciclista pode percorrer $3,2 \mathrm{~km}$ no mesmo espaço de tempo, em velocidades médias de 5 e $20 \mathrm{~km} / \mathrm{h}$ respectivamente. Com isso a área de abrangência de uma estação modal passa de 2 para $32 \mathrm{~km}^{2}$, permitindo maior acessibilidade aos transportes de massa. Em percursos de até $5 \mathrm{~km}$, a bicicleta é o meio de transporte que demonstra maior ganho de tempo, se comparada a automóveis, ônibus e metrôs (INSTITUTO DE ENERGIA E MEIO AMBIENTE, 2010). Além de aumentar a acessibilidade dos sistemas de transporte coletivo, os pedestres dispostos a usá-la podem percorrer distancias mais longas, contribuindo com a revitalização de centros urbanos degradados.

Do ponto de vista político, destaca-se a redução da dependência energética de recursos renováveis, uma das mais complexas questões ambientais da atualidade. Socialmente, o uso da bicicleta como meio de transporte reforça a democratização da mobilidade e do acesso aos espaços urbanos (COMISSÃO EUROPEIA, 2000). A União Européia, em seu Programa de Mudanças Climáticas, vislumbra a melhoria do transporte público e a revalorização do espaço urbano, incorporando o uso integrado da bicicleta como uma das estratégias de redução das emissões de gases de efeito estufa, da poluição do ar e dos congestionamentos (COMISSÃO EUROPEIA, 2000). De acordo com o documento, o conceito de transporte ambientalmente sustentável foi definido como os transportes que não colocam em perigo a saúde pública ou os ecossistemas e têm necessidades consistentes com uma taxa de utilização de recursos não renováveis inferior à sua (dos recursos) taxa de regeneração e com um ritmo de utilização dos recursos não renováveis inferior ao ritmo de desenvolvimento de substitutos renováveis.

A bicicleta aparece como um ótimo exemplo de transporte ambientalmente sustentável, sendo eleita como o transporte ecologicamente mais sustentável do planeta pela Organização das Nações Unidas - ONU (Jornal Oeste, 2010). Diversos países estão investindo em políticas e infraestrutura urbana para fomentar seu uso. No Brasil, as legislações sobre mobilidade urbana instituídas pelo Ministério das Cidades nas últimas décadas ilustram um grande avanço evidenciado pelos princípios da Política Nacional de Mobilidade Urbana-PNMU (BRASIL, 2012) que objetivam: 
Diminuir a necessidade de viagens motorizadas; repensar o desenho urbano; reconhecer a importância do deslocamento de pedestres; reduzir os impactos ambientais da mobilidade urbana; desenvolver meios não motorizados de transporte, entre outros.

No mesmo sentido, outros documentos como a Política Nacional de Mobilidade Urbana Sustentável (BRASIL, 2004), O PlanMob Construindo a Cidade Sustentável Caderno de Referencia para elaboração de Plano de Mobilidade Urbana (BRASIL, 2007); O Programa Brasileiro de Mobilidade por Bicicleta - Bicicleta Brasil e o Caderno de referência para elaboração de Plano de Mobilidade por Bicicleta nas Cidades (2007) reforçam a importância de mudar o paradigma de mobilidade nas grandes cidades brasileiras, onde o veículo individual ainda é o principal protagonista. A bicicleta responde por apenas $4 \%$ da divisão modal brasileira, enquanto em países como a Holanda, Dinamarca e Suíça a bicicleta responde por mais de $30 \%$ dos deslocamentos urbanos. Salienta-se que dos $4 \%$ de usuários de transportes ativos da cidade de São Paulo, a maioria concentra-se nas regiões periféricas e fazem uso de transportes ativos pela impossibilidade de arcar com os custos do transporte público. No centro expandido, os custos dos sistemas públicos e privados de transporte parecem ter um impacto menor sobre a decisão dos usuários, e é neste contexto que a presente pesquisa busca entender a correlação entre o clima e o microclima urbano e os ciclistas em potencial.

\subsection{Justificativa}

No Brasil, em torno de $40 \%$ das viagens cotidianas nas cidades são feitas em transportes ativos, cerca de $36 \%$ das viagens são realizadas por pedestres e apenas $4 \%$ de bicicleta. Na Cidade de São Paulo, a representatividade dos ciclistas urbanos quotidianos na divisão modal também é pequena. Além de pequena, esta representatividade está concentrada nas regiões periféricas, como o extremo sul da cidade, onde a bicicleta aparece como uma alternativa aos custos de deslocamentos por transportes coletivos para a população menos favorecida.

A população de maior poder aquisitivo, cujos deslocamentos "casa-trabalho" estão concentrados no centro expandido de São Paulo, e são o recorte desta pesquisa, estão fazendo uso da bicicleta como meio de transporte como uma alternativa aos congestionamentos, tendência crescente em São Paulo e outras 
metrópoles. Em São Paulo, as questões relativas à mobilidade urbana são mais intensas do que na maioria das cidades brasileiras. Aspectos decorrentes de um sistema de mobilidade que prioriza os deslocamentos por automóveis, incluem altos índices de poluição no ar, escassez de áreas públicas e ajardinadas, impactos econômicos e na saúde dos usuários. Neste sentido, entender os entraves da necessária mudança no sistema de mobilidade urbano Paulistano, incluem investigações acerca das decisões pelos transportes ativos, como a bicicleta, motivação da presente pesquisa.

Entre 2007 e 2012, cerca de 7\% dos deslocamentos foram feitos de bicicleta (BRASIL, 2015). Embora o recurso à bicicleta dependa naturalmente da escolha individual, é essencial entendermos o processo complexo e dinâmico que fortalece ou enfraquece as iniciativas dos ciclistas para incentivar efetivamente o uso da bicicleta como meio de transporte. O caderno Bicicleta Brasil (BRASIL, 2007) salienta aspectos que contribuem negativamente com o uso da bicicleta como meio de transporte no país:

- Vulnerabilidade física do ciclista: Falta de infraestrutura para garantir a segurança do ciclista, agravada pelo comportamento inadequado de alguns motoristas.

- Vulnerabilidade ao furto: Falta de estacionamentos seguros em locais públicos e modais de transporte, e de policiamento adequado em ciclovias e rodovias.

- Raio de ação limitado: Pela locomoção ser baseada no esforço físico, o raio de alcance depende da capacidade e condicionamento físico do usuário e de características como topografia, clima e infra-estrutura viária.

- Exposição as Intempéries e a Poluição: De todos os usuários de veículos em áreas urbanas, o ciclista é o que está mais vulnerável a aspectos climáticos, como a chuva e a intensidade do vento, No Centro-Sul do Brasil, está exposto ao frio intenso dos dias de inverno; no Norte e Nordeste, à insolação e ao calor ao longo do ano.

Os dois primeiros aspectos estão ligados à infraestrutura necessária e ao espaço disponível nas cidades para implementá-la. Os outros dois aspectos possuem relação direta com a forma urbana e o microclima ao longo dos percursos. O uso de vestimenta adequada e estratégias de arborização nos trajetos pode atenuar os efeitos microclimáticos sobre os ciclistas, mas faz-se necessário um entendimento 
sobre a extensão desta interação, de forma a contribuir com políticas e intervenções urbanas.

Os estudos feitos pela União Européia confirmam a importância de uma infraestrutura adequada mostrando pesquisas onde $70 \%$ das pessoas utilizariam a bicicleta com mais frequência se houvessem melhores pistas, acessos, atalhos e desvios para ciclistas. Porém o referido documento salienta a importância de uma abordagem mais ampla para incentivar efetivamente o uso da bicicleta, que considere:

a) Aspectos subjetivos: Imagem, aceitação social, sentimento de insegurança, reconhecimento da bicicleta como meio de transporte de adultos, preparo físico gradual, apreciação do prazer de pedalar e aspectos sociológicos e culturais;

b) Aspectos objetivos: Rapidez dos traslados, topografia e clima da cidade, segurança contra acidentes e furtos, e aspectos práticos que facilitem o dia-a-dia dos ciclistas como bicicletários e vestiários.

Quando estamos em áreas externas, o microclima do local é interpretado pelo nosso corpo como confortável ou desconfortável, o que pode nos deixar mais ou menos dispostos a permanecer nele (BROWN, 1995). No caso dos traslados feitos por meios de transporte não motorizados, a sensação térmica pode incentivar ou desencorajar os deslocamentos.

Foi identificada uma correlação entre as variáveis ambientais e o fluxo de bicicletas em centros urbanos. Alguns estudos identificaram ciclos anuais de fluxo de bicicletas em áreas urbanas de climas frios, concentrando o maior número de viagens durante o verão, apresentando um movimento crescente na primavera e decrescente no outono, e atingindo os menores volumes durante o inverno (AHMED; ROSE; JAKOB, 2010; BERGSTROM; MAGNUSSON, 2003; MIRANDA-MORENO; NOSAL, 2011; NANKERVIS, 1999; RICHARDSON, 2000).

Os aspectos climáticos são decisivos na escolha da bicicleta para o traslado, principalmente pela exposição às intempéries e ao eventual desconforto térmico. A influência sobre os ciclistas se mostra maior do que sobre os pedestres, visto que são afetados por temperaturas abaixo de $15^{\circ} \mathrm{C}$ e $5^{\circ} \mathrm{C}$, respectivamente (SANEINEJAD; ROORDA; KENNEDY, 2012). A variação na temperatura do ar é o aspecto ambiental que exerce maior influência na decisão pelo uso da bicicleta (EMMERSON; RYLEY; DAVIES, 1998; FLYNN et al., 2012; GALLOP; TSE, 2012; HANSON; HANSON, 1977; THOMAS; JAARSMA; TUTERT, 2009, 2013), especialmente as temperaturas muito baixas e muito altas (NANKERVIS, 1999; NOSAL; MIRANDA-MORENO, 2014). 
Segundo a União Européia (COMISSÃO EUROPEIA, 2000) os únicos elementos climáticos que exercem uma verdadeira influência dissuasiva sobre os ciclistas são a neve, a chuva intensa ou o sol abrasador. Mas deve-se considerar que, para curtas distâncias em trajetos urbanos, um vestuário adequado e uma infraestrutura apropriada no local de destino reduzem fortemente o inconveniente das condições climáticas.

O clima brasileiro é propicio à utilização da bicicleta para traslados, uma vez que os ciclistas não precisam enfrentar temperaturas excessivamente baixas ou o risco de nevascas. As temperaturas superiores a $30^{\circ} \mathrm{C}$, que poderiam causar desconforto para os ciclistas, concentram-se em períodos de menor fluxo, visto que a maior parte dos deslocamentos para o trabalho ocorrem no início e no final do dia, quando as temperaturas são menos severas. Em relação às chuvas, se muito intensas, podem apenas obrigar o ciclista a parar ou a ter de esperar até que a chuva diminua (INSTITUTO DE ENERGIA E MEIO AMBIENTE, 2010).

Considerando o impacto cada vez mais relevante dos aspectos climáticos no bem-estar dos indivíduos e a tendência em ampliar o uso da bicicleta como meio de transporte nos centros urbanos, faz-se necessário um aprofundamento no entendimento da influência das variáveis climáticas e microclimáticas na decisão pelo uso da bicicleta como meio de transporte. A percepção e preferência térmica dos ciclistas no meio urbano, podem ser exploradas por índices como o de Temperatura Equivalente Percebida - TEP, aplicado pela autora nesta pesquisa.

Investigações na América do Sul, e principalmente no Brasil, podem contribuir com esta investigação de forma relevante, visto que as pesquisas existentes concentram-se em países da Europa, América do Norte e Austrália.

\subsection{Objeto}

Inúmeros aspectos influenciam o ciclista em potencial a usar a bicicleta como meio de transporte em São Paulo. Além das questões sociológicas, que não serão diretamente abordadas nesta pesquisa, as condições microclimáticas, e o consequente conforto/desconforto térmico do ciclista ao longo do percurso, podem ser decisivos para encorajar ou desencorajar os deslocamentos de bicicleta. 
O objeto desta pesquisa é a relação entre as condições climáticas e a tomada de decisão pelo uso da bicicleta como meio de transporte no percurso para o trabalho no centro expandido da Cidade de São Paulo.

\subsection{Objetivo}

O objetivo da pesquisa é verificar a correlação entre variáveis climáticas e microclimáticas e a tomada de decisão pelo uso da bicicleta como meio de transporte no percurso para o trabalho no centro expandido da Cidade de São Paulo. O recorte da pesquisa é feito em duas escalas: A do centro expandido da cidade de São Paulo, e a da ciclovia ao longo da Avenida Faria Lima, caracterizada como ciclovia predominantemente funcional no período levantado.

\subsection{Estrutura da dissertação}

A dissertação está estruturada da seguinte forma:

O primeiro capítulo apresenta a bicicleta como um meio de transporte que está ganhando importância nos centros urbanos, principalmente nas cidades que buscam um desenvolvimento mais sustentável. São colocados aspectos sobre mobilidade urbana e a importância de uma presença maior dos modos de transporte ativos na divisão modal dos sistemas de transporte urbanos na busca por cidades com menor impacto ambiental. São colocados conceitos sobre transportes ativos, em especial a bicicleta, seu potencial em endereçar aspectos ambientais, econômicos, de qualidade de vida e saúde, entre outros. São apresentados o objeto e os objetivos da pesquisa.

O capítulo 2 apresenta a revisão da literatura sobre a correlação entre clima e microclima urbano e o uso da bicicleta. As pesquisas dos artigos identificados concentram estudos na América do Norte, Europa e Oceania. Outras regiões apresentam estudos pontuais, mas não apresentam uma linha contínua de pesquisa. Na revisão bibliográfica foi identificada uma correlação entre variações climáticas e o fluxo de bicicletas e as variáveis de maior impacto são temperatura média do ar e presença de precipitação, ambos apresentando uma influência não linear. E que os percursos recreativos são mais influenciados pelo clima do que os percursos funcionais, como a ida ao trabalho. 
O capítulo 3 apresenta o método da pesquisa para o levantamento de dados secundários e primários. Os dados secundários levantados são dados climáticos da cidade de São Paulo e do fluxo de bicicletas tanto no centro expandido, como em uma ciclovia de com alto fluxo de bicicletas. Os dados referentes ao fluxo de bicicletas no centro expandido de São Paulo foram obtidos por meio de um sistema de compartilhamento e bicicletas com mais de 270 estações e os dados de fluxo na ciclovia ao longo da Av. Faria Lima foram obtidos por meio do contador eletrônico de bicicletas da Companhia de Engenharia de Tráfego - CET de São Paulo.O levantamento de dados primários foi feito na ciclovia ao longo da Av. Faria Lima com estação de medição, que pertence ao Laboratório de Conforto e Eficiência Energética LABAUT-FAUUSP. Foram aplicados questionários aos ciclistas para identificar a sensação e preferência térmica durante os períodos de medição.

O capítulo 4 apresenta o tratamento dos dados secundários e primários da pesquisa. $O$ tratamento dos dados secundários apresenta a correlação entre as variações climáticas e o fluxo de bicicletas, por meio de gráficos e análises. $O$ tratamento dos dados primários analisa os dados levantados em dias representativos de inverno e de verão na ciclovia ao longo da Av. Faria Lima, na cidade de São Paulo.

No capítulo 5 são analisados e discutidos os resultados encontrados por meio do tratamento dos dados secundários e os resultados do tratamento dos dados primários. Este capítulo estabelece uma correlação entre os levantamentos de dados secundários e primários de forma a contribuir com as pesquisas que estabelecem uma relação entre as variações climáticas e o uso da bicicleta em centros urbanos.

No capítulo 6 são apresentadas as conclusões. 


\section{REVISÃO DA LITERATURA SOBRE A CORRELAÇÃO ENTRE CLIMA E MICROCLIMA URBANO E O USO DA BICICLETA}

\subsection{Introdução}

O uso da bicicleta como meio de transporte é uma peça-chave na construção de sistemas de mobilidade urbana mais sustentáveis e no desenvolvimento de centros urbanos de menor impacto ambiental. Os transportes ativos, em especial a bicicleta, são uma opção saudável e de baixo custo para os usuários, contribuindo inclusive com a democratização do acesso aos sistemas de transporte. Pode não ser a melhor opção para vencer longas distâncias, mas pode ser muito útil para percursos de até 5 km. Sabir (2011) coloca que, em grande parte dos centros urbanos, aproximadamente $75 \%$ dos percursos para o trabalho são de até $5 \mathrm{~km}$.

A escolha diária por um meio de transporte para se deslocar ao trabalho é influenciada por atitudes pessoais, aspectos socioeconômicos e fatores demográficos, características dos percursos como distância e topografia, e por variações climáticas (BERGSTROM; MAGNUSSON, 2003). Aaheim e Hauge (2005) e Ahmed, Rose e Jakob (2010) entendem as variáveis climáticas como um dos aspectos que mais influenciam os hábitos de viagem dos usuários dos diversos modos de transporte. Aaheim e Hauge (2005) apontam ainda para mudanças significativas na divisão modal de transportes, fruto de pequenas mudanças em variáveis ambientais. Sabir (2011) identifica uma correlação entre o aumento da precipitação e velocidade do vento e o aumento no uso do transporte público, em especial do metrô, em detrimento de outros meios de transporte como a bicicleta.

Assim, apesar do potencial da bicicleta em contribuir com centros urbanos mais sustentáveis e das inúmeras iniciativas de fomento espalhadas pela Europa, América do Norte e Oceania, os ciclistas são influenciados por diversos aspectos, entre eles, as variações microclimáticas.

Considerando essa problemática, a presente revisão bibliográfica objetiva identificar em que extensão a literatura científica identifica correlações entre as variáveis microclimáticas e a decisão do ciclista pelo uso da bicicleta em centros urbanos. 


\subsection{Método}

Este processo de revisão da literatura divide-se em duas etapas: (i) identificação e seleção dos artigos, e (ii) análise sistemática do conteúdo.

\subsubsection{Identificação e seleção dos artigos}

Durante a fase de desenvolvimento do projeto de pesquisa, foi feita a leitura de artigos e publicações identificados através de um processo de busca não sistematizado. Essa primeira aproximação ao tema, feita em bancos de dados que concentram periódicos nacionais, internacionais e anais de eventos, permitiu a identificação de:

a. Bancos de dados que concentram as publicações mais relevantes sobre o tema e bancos de dados nacionais;

b. Palavras-chave, utilizadas para refinar a busca sistematizada.

A identificação dos artigos foi baseada na análise sistemática dos bancos de dados SCOPUS, WEB OF SCIENCE, INFOHAB e anais dos eventos PLURIS, ENCAC e ELACAC.

Para entender a correlação entre o microclima urbano e o uso da bicicleta como meio de transporte, foram definidas sete palavras-chave, sendo quatro para identificar os aspectos relacionados às questões climáticas (\#weather, \#climate, \#environmental factors, \#thermal comfort) e três para identificar aspectos relacionados às questões ligadas ao uso da bicicleta (\#cycling, \#bicycle, \#active transportation). As buscas continham no título, resumo ou como palavra-chave uma das quatro palavras-chave ligadas às questões climáticas e uma das três palavras-chave ligadas ao uso da bicicleta, totalizando 12 buscas em cada um dos bancos de dados. Para as buscas em bancos de dados nacionais, também foram utilizadas quatro palavras-chave na língua portuguesa para a identificação de aspectos climáticos (\#microclima, \#clima, \#variáveis ambientais, \#conforto térmico) e três para o uso da bicicleta (\#ciclismo, \#bicicleta, \#transporte ativo).

Na busca feita no SCOPUS, foram consideradas publicações de todos os tipos de documentos listados, publicados até junho de 2017. Em uma segunda etapa, cada 
busca foi limitada às disciplinas relacionadas ao tema (engineering e environmental science) e posteriormente foram selecionadas as publicações que seriam estudadas. Para cada busca contendo duas palavras-chave, a quantidade de documentos identificados nas três etapas foi a seguinte (Tabela 1):

Tabela 1 - Busca feita no SCOPUS

\begin{tabular}{|l|c|c|c|}
\hline \multicolumn{1}{|c|}{ palavras-chave } & \multicolumn{3}{|c|}{ SCOPUS } \\
\hline & $\begin{array}{c}\text { documentos } \\
\text { identificados na } \\
\text { primeira etapa }\end{array}$ & $\begin{array}{c}\text { documentos } \\
\text { identificados na } \\
\text { segunda etapa }\end{array}$ & $\begin{array}{c}\text { documentos } \\
\text { selecionados } \\
\text { para leitura }\end{array}$ \\
\hline Weather AND Cycling & 727 & 337 & 19 \\
\hline Weather AND Bicycle & 217 & 127 & 25 \\
\hline Weather AND Active Transportation & 136 & 79 & 6 \\
\hline Climate AND Cycling & 5.461 & 2.727 & 7 \\
\hline Climate AND Bicycle & 241 & 94 & 14 \\
\hline Climate AND Active Transportation & 160 & 89 & 4 \\
\hline Environmental Factors AND Cycling & 3.057 & 1.531 & 2 \\
\hline Environmental Factors AND Bicycle & 504 & 201 & 8 \\
\hline Environmental Factors AND Active Transportation & 341 & 116 & 2 \\
\hline Thermal Comfort AND Cycling & 90 & 31 & 1 \\
\hline Thermal Comfort AND Bicycle & 51 & 18 & 1 \\
\hline Thermal Comfort AND Active Transportation & 11 & 7 & 1 \\
\hline
\end{tabular}

Fonte: a autora.

Foram selecionados 90 documentos e eliminados aqueles que apareceram em mais de uma busca, resultando em um total de 56 documentos.

Na busca feita no WEB OF SCIENCE, foram consideradas publicações de todos os tipos de documentos listados, publicados até junho de 2017. Em uma segunda etapa, as buscas foram limitadas às disciplinas relacionadas ao tema (Engineering Environmental, Transportation, Engineering Multidisciplinary, Behavioral Sciences) e posteriormente foram selecionadas as publicações que seriam estudadas. Foram feitas 12 buscas, fazendo uso das mesmas palavras-chave da pesquisa feita no SCOPUS. A quantidade de documentos identificados foi a seguinte (Tabela 2):

Tabela 2 - Busca feita no Web of Science

\begin{tabular}{|l|c|c|c|}
\hline \multicolumn{1}{|c|}{ palavras-chave } & \multicolumn{3}{c|}{ WEB OF SCIENCE } \\
\hline & $\begin{array}{c}\text { documentos } \\
\text { identificados na } \\
\text { primeira etapa }\end{array}$ & $\begin{array}{c}\text { documentos } \\
\text { identificados na } \\
\text { segunda etapa }\end{array}$ & $\begin{array}{c}\text { documentos } \\
\text { selecionados } \\
\text { para leitura }\end{array}$ \\
\hline Weather AND Cycling & 10.535 & 340 & 10 \\
\hline Weather AND Bicycle & 152 & 77 & 21 \\
\hline Weather AND Active Transportation & 16 & 6 & 2 \\
\hline Climate AND Cycling & 41.024 & 1.715 & 9 \\
\hline Climate AND Bicycle & 135 & 53 & 16 \\
\hline Climate AND Active Transportation & 15 & 3 & 3 \\
\hline Environmental Factors AND Cycling & 3.689 & 144 & 1 \\
\hline Environmental Factors AND Bicycle & 81 & 22 & 2 \\
\hline Environmental Factors AND Active Transportation & 32 & 5 & --- \\
\hline Thermal Comfort AND Cycling & 418 & 52 & 2 \\
\hline Thermal Comfort AND Bicycle & 38 & 10 & --- \\
\hline Thermal Comfort AND Active Transportation & 2 & --- & --- \\
\hline
\end{tabular}

Fonte: a autora. 
No INFOHAB foram feitas 12 buscas, fazendo uso das mesmas palavras-chave na língua inglesa. Em seguida foram feitas outras 12 buscas com palavras-chave na língua portuguesa, relacionando \#microclima, \#clima, \#variáveis ambientais e \#conforto térmico com \#ciclismo, \#bicicleta e \#transporte ativo, porém não foi encontrado nenhum documento. Foi feito um refinamento da busca, usando apenas uma palavra-chave relativa ao uso da bicicleta (\#ciclismo, \#bicicleta, \#transporte ativo), e apenas na busca com a palavra-chave \#bicicleta foram encontrados três artigos indiretamente relacionados ao tema. Foi feita uma busca nos anais de todas as edições dos eventos PLURIS, ENCAC e ELACAC, onde não foram encontrados artigos abordando diretamente a correlação entre condições microclimáticas e/ou climáticas e o uso de bicicletas.

Foram selecionados 69 documentos. A busca identificou um número maior de documentos, mas alguns apareceram em mais de um processo de busca ou abordam as palavras-chave de forma indireta. Foi feita uma análise do conteúdo dos referidos artigos e da relevância dos mesmos para o trabalho. Foram analisados sistematicamente neste artigo apenas aqueles que tratam diretamente do tema.

Em seguida, teve início a etapa de identificação de publicações referenciadas na bibliografia dos artigos selecionados, que resultaram em uma busca pontual em outros bancos de dados.

\subsubsection{Análise sistemática do conteúdo}

Durante a leitura e análise dos artigos, foram selecionados os temas e conteúdos abordados relevantes para o entendimento da correlação entre microclima e o uso da bicicleta como meio de transporte.

As principais abordagens dos artigos selecionados foram agrupadas de acordo com os seguintes assuntos:

a. Escala de abordagem, que identifica a escala física da pesquisa e varia entre a escala local, com medições microclimáticas, escalas regionais, entre cidades, e nacionais;

b. Contexto social, considerando a região em que os estudos foram realizados; 
c. Variáveis ambientais consideradas, como temperatura e umidade relativa do ar, níveis de precipitação, velocidade do vento, horas de sol por dia, entre outros;

d. Outras variáveis, como dados socioeconômicos, de morfologia e tipologia urbana, infraestrutura cicloviária, propósito da viagem, entre outros;

e. Método de coleta de dados, identificando se os dados foram coletados por estações meteorológicas, medições de campo, contagem eletrônica de bicicletas ou informações de agências de transporte, por exemplo;

f. Processo de análise de dados, indicando se as variáveis ambientais foram avaliadas de forma isolada ou combinada, se os dados climáticos e de fluxo de bicicletas foram consolidados por hora ou por dia, entre outros;

g. Resultados, que consolida os principais entendimentos dos autores sobre o tema, muitas vezes opostos ou discordantes, mas que permite consolidar os entendimentos que estão mais presentes nos artigos.

Foram elaboradas as Tabelas 3, 4 e 5, que sintetizam as principais abordagens, métodos de coleta e análise de dados e apontamentos de cada artigo. 
Tabela 3 - Síntese da revisão da literatura: Escala de abordagem, contexto social, variáveis ambientais e outras variáveis

\begin{tabular}{|c|c|c|c|c|c|c|c|c|c|c|c|c|c|c|c|c|c|c|c|c|c|c|c|c|}
\hline & \multicolumn{4}{|c|}{ Escala de Abordagem } & \multicolumn{4}{|c|}{ Contexto Social } & \multicolumn{9}{|c|}{ Variáveis Ambientais } & \multicolumn{7}{|c|}{ Outras Variáveis } \\
\hline & 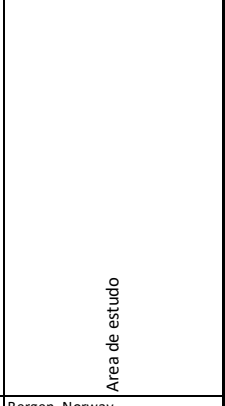 & 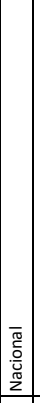 & 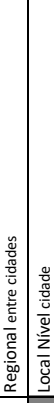 & 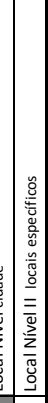 & 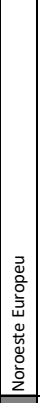 & 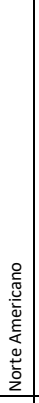 & & & & 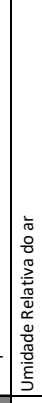 & 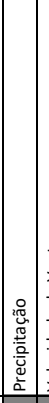 & 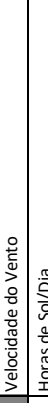 & 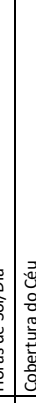 & 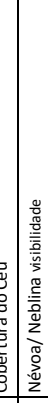 & 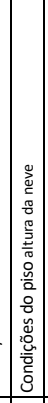 & 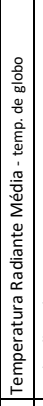 & 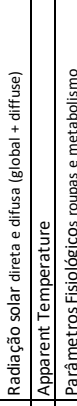 & 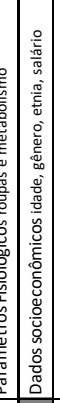 & 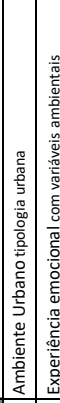 & 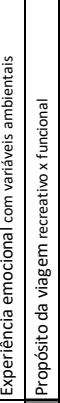 & 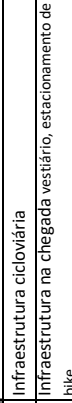 & 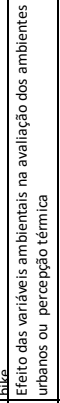 & 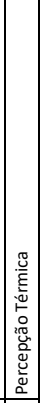 & 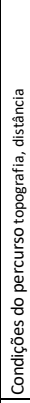 \\
\hline \begin{tabular}{|l|} 
AAHEIM, H.A.; HAUGE, K. $(2005)$ \\
AHMED, F.; ROSE, G; JAKOB, C (2010) \\
\end{tabular} & \begin{tabular}{|l|} 
Bergen, Norway \\
Melborne, Austrália \\
\end{tabular} & & & & & & & & & & & & & & & & & - & & & & & & \\
\hline $\begin{array}{l}\text { ARMED, F; ROSE, G.; HGLIOLCL, M.; JAROB, C. } \\
\text { (2012) }\end{array}$ & $\begin{array}{l}\text { Pourtland, EUAs e Brisbane, } \\
\text { Auustrália }\end{array}$ & & & & & & & & & & & & & & & & & & & & & & & \\
\hline AHMED, F.; ROSE, G.; JAKOB, C. (2013a) & Victoria, Australia & & & & & & & & & & & & & & & & & & & & & & & \\
\hline AHMED, F.; ROSE, G.; JAKOB, C. (2013b) & Victoria, Australia & & & & & & & & & & & & & & & & & & & & & & & \\
\hline $\begin{array}{l}\text { AMIRI, M.; ; ADEGHPOUR, F. (2013) } \\
\text { AMIIL M. SADEGPOUR F. (2015) }\end{array}$ & 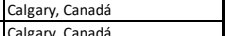 & & & & & & & & & & & & & & & & & & & & & & & \\
\hline 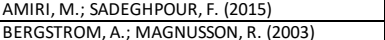 & \begin{tabular}{|l|} 
Calgary, Canadá \\
Lulea e Linkoping, Suécia
\end{tabular} & & & & & & & & & & & & & & & & & F & & & & & & \\
\hline BOCKER, L.; DIIST, M.; PRILLWITZ, J. (2013) & 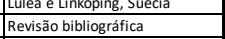 & & & & & & & & & & & & & & & & & 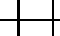 & & & & & & \\
\hline BOCKER, L; PRILLWITZ, I.; DISST, M. (2013b) & Regiäo de Rotterdam, Holanda & & & & & & & & & & & & & & & & & 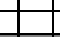 & & & & & & \\
\hline 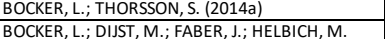 & Regiäo de Rotterdam, Holanda & & & & & & & & & & & & & & & & & & & & & & & \\
\hline $\begin{array}{l}\text { BOCER, L.; DIJST, M.; FABER, J.; HELBICH, M. } \\
\text { (2014b) }\end{array}$ & Regiäo de Rotterdam, Holanda & & & & & & & & & & & & & & & & & & & & & & & \\
\hline 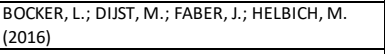 & Regiäo de Rotterdam, Holanda & & & & & & & & & & & & & & & & & & & & & & & \\
\hline $\begin{array}{l}\text { BRANDENBURG, C.; MATZARAKIS, A.; } \\
\text { ARNBERGER, A. (2004) }\end{array}$ & Vienna, Austria & & & & & & & & & & & & & & & & & & & & & & & \\
\hline $\begin{array}{l}\text { BRANDENBURG, C.; MATZARAKIS, A.; } \\
\text { ARNBERGER, A. (2007) }\end{array}$ & Vienna, Austria & & & & & & & & & & & & & & & & & & & & & & & \\
\hline \begin{tabular}{|l|l|} 
CLIFTON, K.; CHEN, R. (2011) \\
COPON, (201)
\end{tabular} & Regiäo de Sydney, Austrália & & & & & & & & & & & & & & & & & -1 & & & & & & \\
\hline $\begin{array}{l}\text { CORCOANA, J.; et al (2014) } \\
\text { EL-ASSI, W.; et al (2017) }\end{array}$ & \begin{tabular}{|l|l|} 
Brisbane, Australia \\
Toronto, Canadáa
\end{tabular} & & & & & & & & & & & & & & & & & & & & & & & \\
\hline EMMERSON, P.; RYLEY, T.J.; DAVIES, D.G. (1998) & $\begin{array}{l}\text { Chingford e Bidston, Reino } \\
\text { Unido }\end{array}$ & & & & & & & & & & & & & & & & & & & & & & & \\
\hline ENGBERS, L.H.; HENDRIKSEN, I.J.M. (2010) & Holanda & & & & & & & & & & & & & & & & & & & & & & & \\
\hline $\begin{array}{l}\text { FLYNN, B.S.; DANA, G.S.; SEARS, J.; AULTMAN- } \\
\text { HALL, L. (2012) }\end{array}$ & Vermont, EUA & & & & & & & & & & & & & & & & & & & & & & & \\
\hline GALLOP, C.; TSE, C. (2012) & Vancouver, Canadá & & & & & & & & & & & & & & & & & & & & & & & \\
\hline GEBHART, K.; NOLAND, R.B. (2013) & Washington DC, EUA & & & & & & & & & & & & & & & & & & & & & & & \\
\hline $\begin{array}{l}\text { HANSON, S.; HANSON, P. (1977) } \\
\text { HEINEE, E.; VAN WEE, B; MAAT, K. (2010) }\end{array}$ & \begin{tabular}{|l|l|} 
Uppsala, Súciaia \\
Revišab bibliográfica
\end{tabular} & & & & & & & & & & & & & & & & & & & & & & & \\
\hline 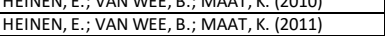 & 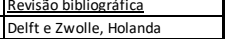 & & & & & & & & & & & & & & & & & & & & & & & - \\
\hline HELBICH, M.; BOCKER, L.; DIJST, M. (2014) & Região de Rotterdam, Holanda & & & & & & & & & & & & & & & & & & & & & & & \\
\hline LIU, C.; et al. (2015) & Suécia & & & & & & & & & & & & & & & & & & & & & & & \\
\hline MATHISEN, T.; KROESEN, M. (2015) & Bodo, Noruega & & & & & & & & & & & & & & & & & & & & & & & \\
\hline MENG, M.; ZHANG, J.; WONG,Y.D. (2016) & Cingapura & & & & & & & & & & & & & & & & & & & & & & & \\
\hline MIRANDA-MORENO, L.F.; NOSAL, T. (2011) & Montreal, Canadá & & & & & & & & & & & & & & & & & & & & & & & \\
\hline $\begin{array}{l}\text { MIRANDA-MORENO, L.; NOSAL, T.; SCHNEIDER, } \\
\text { R.J. PROULX, F. (2014) }\end{array}$ & \begin{tabular}{|l|} 
Montreal, ottawa, Portland, são \\
Francisco, Vancouver
\end{tabular} & & & & & & & & & & & & & & & & & & & & & & & \\
\hline MOTOAKI, Y,; DAZIANO, R.A. (2015) & \begin{tabular}{|l|l|l|l} 
Nova York, EUA \\
\end{tabular} & & & & & & & & & & & & & & & & & & & & & & & \\
\hline NANKERVIS, M. (1999) & Melbourne, Austrália & & & & & & & & & & & & & & & & & & & & & & & \\
\hline NOSAL, T.; MIRANDA-MORENO, L.F. (2014) & $\begin{array}{l}\text { Montreal, OOtawa, Portland, } \\
\text { vancouver, Quuebec }\end{array}$ & & & & & & & & & & & & & & & & & & & & & & & \\
\hline PARKIN, I, WARDMAN, M.; PAGE, M. (2008) & & & & & & & & & & & & & & & & & & & & & & & & \\
\hline PHUNG, J.; ROSE, G. (2008) & Melbourne, Austrália & & & & & & & & & & & & & & & & & & & & & & & \\
\hline PUCHER, J.; BUEHLER, R. (2006) & Canadáe EUA & & & & & & & & & & & & & & & & & & & & & & & \\
\hline PUCHER, J; BUEHLER, R. (2008a) & \begin{tabular}{|l|l} 
Holanda, Dinamarca e \\
Alemanha
\end{tabular} & & & & & & & & & & & & & & & & & & & & & & & \\
\hline PUCHER, J.; BUEHLER, R. (2008b) & $\begin{array}{l}\text { Holanda, Dinamarca e } \\
\text { Alemanha }\end{array}$ & & & & & & & & & & & & & & & & & & & & & & & \\
\hline $\begin{array}{l}\text { RICHARDSON, A.J. (2000) } \\
\end{array}$ & Melbourne, Austrália & & & & & & & & & & & & & & & & & & & & & & & \\
\hline SABIR, M. (2011) & Holanda & & & & & & & & & & & & & & & & & & & & & & & \\
\hline 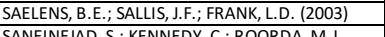 & \begin{tabular}{|l} 
('näo define) \\
\end{tabular} & & & & & & & & & & & & & & & & & & & & & & & \\
\hline $\begin{array}{l}\text { SANEINEJAD, S.; KENNEDY, C.; ROORDA, M.J. } \\
\text { (2010) }\end{array}$ & Toronto, Canadá & & & & & & & & & & & & & & & & & & & & & & & \\
\hline $\begin{array}{l}\text { SANEINEJAD, S.; ROORDA, M.J.; KENNEDY, C. } \\
\text { (2012) }\end{array}$ & Toronto, Canadá & & & & & & & & & & & & & & & & & & & & & & & \\
\hline $\begin{array}{l}\text { SEARS, J.; FLYNN, B.S.; AULTMAN-HALL, L.; DANA, } \\
\text { G.S. (2012) }\end{array}$ & Vermont, EUA & & & & & & & & & & & & & & & & & & & & & & & \\
\hline $\begin{array}{l}\text { SILVEIRA, M.; MAIA, M. (2015) } \\
\text { SMITH, M.S.; KAUERMANN, G. (2011) }\end{array}$ & \begin{tabular}{|l} 
(não define) \\
Melbourne, Austrália
\end{tabular} & & & & & & & & & & & & & & & & & & & & & & & \\
\hline $\begin{array}{l}\text { SMITH, M.S.; KAUERMANN, G. (2011) } \\
\text { SPENCER, P.; WATTS, R.; VIVANCO, L.; FLYNNN, B. }\end{array}$ & Melbourne, Austrália & & & & & & & & & & & & & & & & & & & & & & & \\
\hline (2013) & Veermont, EUA & & & & & & & & & & & & & & & & & & & & & & & \\
\hline $\begin{array}{l}\text { THOMAS, T.; JAARSMA, R.; TUTERT, B. (2009) } \\
\text { THOMAS, T.; JAARSMA, R.; TUTERT, B. (2013) }\end{array}$ & \begin{tabular}{|l|} 
Gouda e Ede, Holanda \\
Holanda
\end{tabular} & & & & & & & & & & & & & & & & & & & & & & & \\
\hline $\begin{array}{l}\text { TIN TIN, S.; WOODWARD, A. ROBINSON, E.; } \\
\text { AMERATUNGA, S. (2012) }\end{array}$ & Auckland, Nova Zelândia & & & & & & & & & & & & & & & & & & & & & & & \\
\hline $\begin{array}{l}\text { AMERAUNG, S. (2012) } \\
\text { WADUD, Z. (2013) }\end{array}$ & London, UK & & & & & & & & & & & & & & & & & & & & & & & \\
\hline WARDMAN, M.; TIGHT, M.; PAGE, M. (2007) & Reino Unido & & & & & & & & & & & & & & & & & & & & & & & \\
\hline $\begin{array}{l}\text { WINTERS, M.; FRIESEN, M.C.; KOEHOORN, M.; } \\
\text { TESCHKE, K. (2007) }\end{array}$ & Canadá & & & & & & & & & & & & & & & & & & & & & & & \\
\hline $\begin{array}{l}\begin{array}{l}\text { WINTERS, M.; DAVIDSON, G.; KAO, D.; TESCHKE, } \\
\text { K. (2011) }\end{array} \\
\end{array}$ & Vancouver, Canadá & & & & & & & & & & & & & & & & & & & & & & & \\
\hline
\end{tabular}

Fonte: a autora. 
Tabela 4 - Síntese da revisão da literatura: Coleta e análise de dados

\begin{tabular}{|c|c|c|c|c|c|c|c|c|c|c|c|c|c|c|c|c|c|c|c|c|c|c|c|c|c|c|}
\hline & & & & & eta & de & $\mathrm{tac}$ & & & & & & & & & & & lise & de & dac & & & & & & \\
\hline & 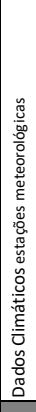 & 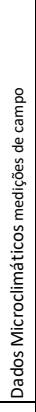 & 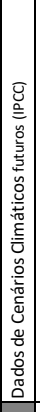 & 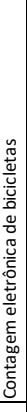 & 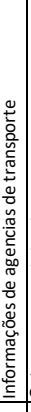 & & 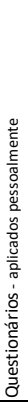 & 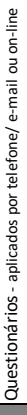 & 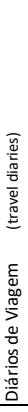 & 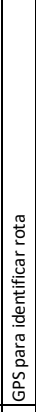 & 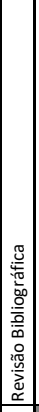 & 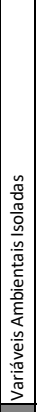 & 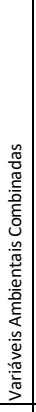 & 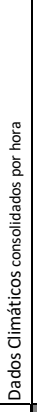 & 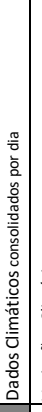 & 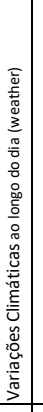 & 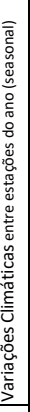 & 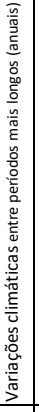 & 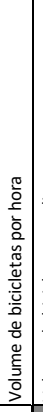 & 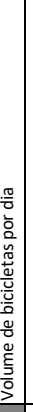 & 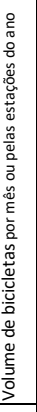 & 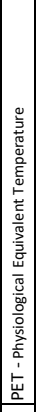 & 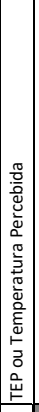 & 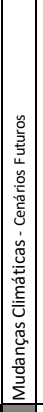 & 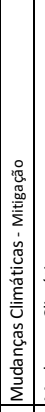 & \\
\hline $\begin{array}{l}\text { AAHEIM, H.A.; HAUGE, K. (2005) } \\
\text { AHMED, F.; ROSE, G; JAKOB, C (2010) } \\
\text { AHMED, F.; ROSE, G.; FGLIOZZI, M.; } \text { AAKOB, C. }\end{array}$ & & & & & & & & & & & & & & & & & & & & & & 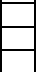 & 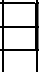 & & & \\
\hline & & & & & & & & & & & & & & & & & & & & & & & & & & \\
\hline $\begin{array}{l}\text { AHMED, F.; ROSE, G.; JAKOB, C. (2013a) } \\
\text { AHMED, F; ROSE, G.; JAKOB, C. (2013b) }\end{array}$ & & & & & & & & & & & & & & & & & & & & & & & & & & \\
\hline AMIRI, M.; SADEGHPOUR, F. (2013) & & & & & & & & & & & & & & & & & & & & & & 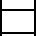 & & & & \\
\hline $\begin{array}{l}\text { AMIRI, M.; SADEGHPOUR, F. (2015) } \\
\text { BERGSTROM, A.; MAGNUSSON, R. (2003) }\end{array}$ & & & & & & & & & & & & & & & & & & & & & & & & & & \\
\hline BOCKER, L.; DIJST, M.; PRILLWITZ, J. (2013) & & & & & & & & & & & & & & & & & & & & & & L & & & & \\
\hline BOCKER, L.; PRILLWITZ, J.; DIJST, M. (2013b) & & & & & & & & & & & & & & & & & & & & & & & & & & \\
\hline 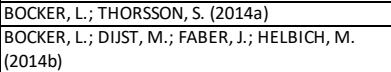 & & & & & & & & & & & & & & & & & & & & & & 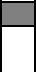 & & & & \\
\hline $\begin{array}{l}\text { BOCKER, L.; DIJST, M.; FABER, J.; HELBICH, M. } \\
\text { (2016) }\end{array}$ & & & & & & & & & & & & & & & & & & & & & & & & & & \\
\hline $\begin{array}{l}\text { BRANDENBURG, C.; MATZARAKIS, A.; } \\
\text { ARNBERGER, A. (2004) }\end{array}$ & & & & & & & & & & & & & & & & & & & & & & & & & & \\
\hline $\begin{array}{l}\text { BRANDENBURG, C.; MATZARAKIS, A.; } \\
\text { ARNBERGER, A. (2007) }\end{array}$ & & & & & & & & & & & & & & & & & & & & & & & & & & \\
\hline CLIFTON, K.; CHEN, R. (2011) & & & & & & & & & & & & & & & & & & & & & & & & & & \\
\hline 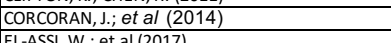 & & & & & & & & & & & & & & & & & & & & & & & & & & \\
\hline EL-ASSI, W.; et al (2017) & & & & & & & & & & & & & & & & & & & & & & & & & & \\
\hline EMMERSON, P.; RYLEY, T.J.; DAVIES, D.G. (1998) & & & & & & & & & & & & & & & & & & & & & & & & & & \\
\hline ENGBERS, L.H.; HENDRIKSEN, I.J.M. (2010) & & & & & & & & & & & & & & & & & & & & & & & & & & \\
\hline $\begin{array}{l}\text { FLYNNN, B.S.; DANA, G.S.; SEARS, J.; AULTMAN- } \\
\text { HALL, L. (2012) }\end{array}$ & & & & & & & & & & & & & & & & & & & & & & & & & & \\
\hline GALLOP, C.; TSE, C. (2012) & & & & & & & & & & & & & & & & & & & & & & & & & & \\
\hline GEBHART, K.; NOLAND, R.B. (2013) & & & & & & & & & & & & & & & & & & & & & & & & & & \\
\hline HANSON & & & & & & & & & & & & & & & & & & & & & & & & & & \\
\hline , B.; MAAT, K. (2010) & & & & & & & & & & & & & & & & & & & & & & & & & & \\
\hline EE, B.; MAAT, K. (2011) & & & & & & & & & & & & & & & & & & & & & & & & & & \\
\hline ; BOCKER, L.; DIJST, M. (2014) & & & & & & & & & & & & & & & & & & & & & & & & & & \\
\hline LIU, C,; & & & & & & & & & & & & & & & & & & & & & & & & & & \\
\hline ESEN, M. (2015) & & & & & & & & & & & & & & & & & & & & & & & & & & \\
\hline MENG, M.; $Z$ ZHANG, J.; WONG, Y & & & & & & & & & & & & & & & & & & & & & & & & & & \\
\hline \begin{tabular}{|l|} 
MIRANDA-MORENO, L.F.; NOSAL, T. (2011) \\
MIRANDA-MORENO, L.; NOSAL, T.; SCHNEIDER,
\end{tabular} & & & & & & & & & & & & & & & & & & & & & & & & & & \\
\hline $\begin{array}{l}\text { R.J. PROUL } \\
\text { MOTOAKI, }\end{array}$ & & & & & & & & & & & & & & & & & & & & & & & & & & \\
\hline NANKERV & & & & & & & & & & & & & & & & & & & & & & & & & & \\
\hline MORENO, L.F. (2014) & & & & & & & & & & & & & & & & & & & & & & & & & & \\
\hline M.; PAGE, M. (2008) & & & & & & & & & & & & & & & & & & & & & & & & & & \\
\hline PHUNG, J; ROSE, G. (2) & & & & & & & & & & & & & & & & & & & & & & & & & & \\
\hline PUCHER & & & & & & & & & & & & & & & & & & & & & & & & & & \\
\hline (2008a) & & & & & & & & & & & & & & & & & & & & & & & & & & \\
\hline PUCHER, J.; BUE & & & & & & & & & & & & & & & & & & & & & & & & & & \\
\hline $\begin{array}{l}\text { RICHARDSON, A.J. (2 } \\
\text { SABIR, M. (2011) }\end{array}$ & & & & & & & & & & & & & & & & & & & & & & & & & & \\
\hline SAELENS, B.E.; SALLIS, J.F.; FRANK, L.D. (2003) & & & & & & & & & & & & & & & & & & & & & & & & & & \\
\hline $\begin{array}{l}\text { SANEINEJAD, S.; KENNEDY, C.; ROORDA, M.J. } \\
(2010)\end{array}$ & & & & & & & & & & & & & & & & & & & & & & & & & & \\
\hline $\begin{array}{l}\text { SANEINEJAD, S.; ROORDA, M.J.; KENNEDY, C. } \\
(2012)\end{array}$ & & & & & & & & & & & & & & & & & & & & & & & & & & \\
\hline $\begin{array}{l}\text { SOART, I.; FLYNN, B.S.; AULTMAN-HALL, L.; DANA, } \\
\text { G.S. (2012) }\end{array}$ & & & & & & & & & & & & & & & & & & & & & & & & & & \\
\hline M.; MAIA, M. (2015) & & & & & & & & & & & & & & & & & & & & & & & & & & \\
\hline G. (2011) & & & & & & & & & & & & & & & & & & & & & & & & & & \\
\hline $\begin{array}{l}\text { SPENCER, P.; WATTS, R.; VIVANCO, L.; FLYNN, B. } \\
(2013)\end{array}$ & & & & & & & & & & & & & & & & & & & & & & & & & & \\
\hline THOMAS, T.; JA & & & & & & & & & & & & & & & & & & & & & & & & & & \\
\hline THOMAS, T.; JAARSMA, R.; TUTERT, B. (2013) & & & & & & & & & & & & & & & & & & & & & & & & & & \\
\hline $\begin{array}{l}\text { TIN TIN, S.; WOODWARD, A. ROBINSON, E.; } \\
\text { AMERATUNGA, S. (2012) }\end{array}$ & & & & & & & & & & & & & & & & & & & & & & & & & & \\
\hline WADUD, 2 & & & & & & & & & & & & & & & & & & & & & & & & & & \\
\hline WARDMAN, M.; TIGHT, M.; PAGE, M. (2007) & & & & & & & & & & & & & & & & & & & & & & & & & & \\
\hline $\begin{array}{l}\text { WINTERS, M.; FRIESEN, M.C.; KOEHOORN, M.; } \\
\text { TESCHKE, K. (2007) }\end{array}$ & & & & & & & & & & & & & & & & & & & & & & & & & & \\
\hline $\begin{array}{l}\text { WINTERS, M.; DAVIDSON, G.; KAO, D.; TESCHKE, } \\
\text { K. (2011) }\end{array}$ & & & & & & & & & & & & & & & & & & & & & & & & & & \\
\hline
\end{tabular}

Fonte: a autora. 
Tabela 5 - Síntese da revisão da literatura: Resultados

\begin{tabular}{|c|c|c|c|c|c|c|c|c|c|c|c|c|c|c|c|c|c|c|c|c|c|c|c|c|c|c|c|c|c|c|}
\hline & \multicolumn{30}{|c|}{ Resultados } \\
\hline & 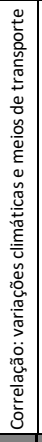 & 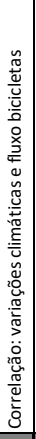 & 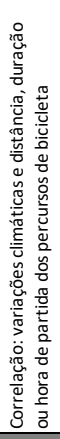 & 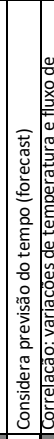 & & 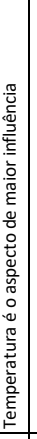 & 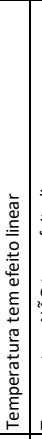 & 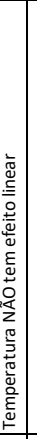 & 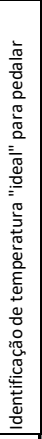 & 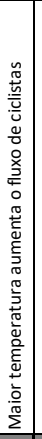 & 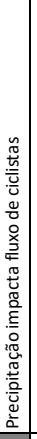 & 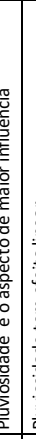 & 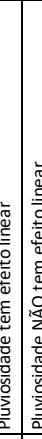 & 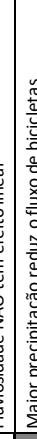 & 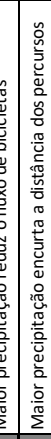 & 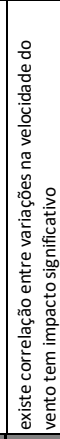 & 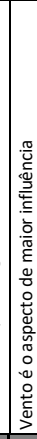 & 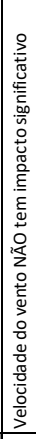 & 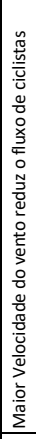 & 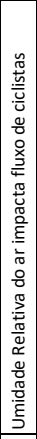 & 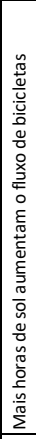 & 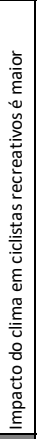 & 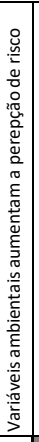 & 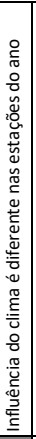 & 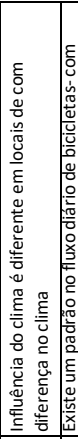 & 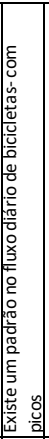 & 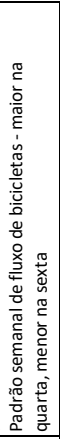 & 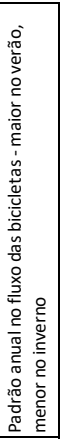 & 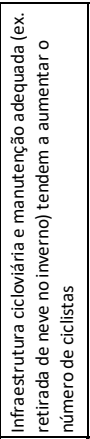 & 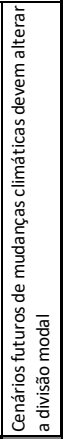 \\
\hline \multicolumn{31}{|l|}{ 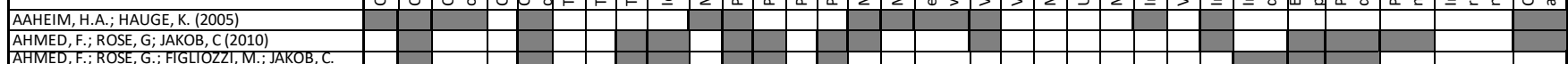 } \\
\hline $\begin{array}{l}\text { AAMMED, F.; ROSE, G.; FGLIOZZI, M.; JAKOB, C. } \\
\text { (2012) }\end{array}$ & & & & & & & & & & & & & & & & & & & & & & & & & & & & & & \\
\hline \\
\hline \multicolumn{31}{|l|}{\begin{tabular}{|l|} 
AHMED, F.; ROSE, G.; JAKOB, C. (2013b) \\
AMRIM. SADEGHPOBR F (2013)
\end{tabular}} \\
\hline \multicolumn{31}{|l|}{\begin{tabular}{|l|} 
AMIRI, M.; SADEGHPOUR, F. (2013) \\
AMIRI, M.; SADEGHPOUR, F. (2015)
\end{tabular}} \\
\hline BERGSTROM, A.; MAGNUSSON, R. (2003) & & & & & & & & & & & & & & & & & & & & & & & & 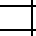 & & & & & & \\
\hline BOCKER, L.; DIJST, M.; PRILLWITZ, J. (2013) & & & & & & & & & & & & & & & & & & & & & & & & 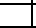 & & & & & & \\
\hline $\begin{array}{l}\text { BOCKER, L.; PRILLWITZ, J.; DIJST, M. (2013b) } \\
\text { BOCKER, L; THORSSON, S. (2014a) }\end{array}$ & & & & & & & & & & & & & & & & & & & -3 & 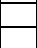 & - & & 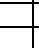 & 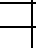 & & & & & & \\
\hline 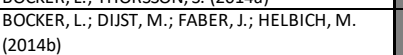 & & & & & & & & & & & & & & & & & & & & & & & & & & & & & & \\
\hline $\begin{array}{l}\text { BOCKER, L.; DIST, M.; FABER, J.; HELBICH, M. } \\
\text { (2016) }\end{array}$ & & & & & & & & & & & & & & & & & & & & & & & & & & & & & & \\
\hline $\begin{array}{l}\text { BRANDENBURG, C.; MATZARAKIS, A.; } \\
\text { ARNBERGER A. (2004) }\end{array}$ & & & & & & & & & & & & & & & & & & & & & & & & & & & & & & \\
\hline $\begin{array}{l}\text { BRANDENBURG, C.; MATZARAKIS, A.; } \\
\text { ARNBERGER, A. (2007) }\end{array}$ & & & & & & & & & & & & & & & & & & & & & & & & & & & & & & \\
\hline 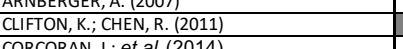 & & & & & & & & & & & & & & & & & & & & & & & & & & & & & & \\
\hline \begin{tabular}{|l} 
CORCORAN, J.; et al (2014) \\
EL-ASSI, W.; et al (2017)
\end{tabular} & & & & & & & & & & & & & & & & & & & & & & & & & & & & & & \\
\hline EMMERSON, P.: RYLEY, T.J.; DAVIES, D.G. (1998) & & & & & & & & & & & & & & & & & & & & & & & & & & & & & & \\
\hline ENGEERS, L.H.; HENDRIKSEN, I.J.M. (2010) & & & & & & & & & & & & & & & & & & & & & & & & & & & & & & \\
\hline $\begin{array}{l}\text { FLYNN, B.S.; DANA, G.S.; SEARS, J; AULTMAN- } \\
\text { HALL, L. (2012) }\end{array}$ & & & & & & & & & & & & & & & & & & & & & & & & & & & & & & \\
\hline GALLOP, C.; TSE, C. (2012) & & & & & & & & & & & & & & & & & & & & & & & & & & & & & & \\
\hline GEBHART, K.; NOLAND, R.B. (2013) & & & & & & & & & & & & & & & & & & & & & & & & & & & & & & \\
\hline HANSON, S.; HANSON, P. (1977) & & & & & & & & & & & & & & & & & & & & & & & & & & & & & & \\
\hline HEINEN, E.; VAN WEE, B.; MAAT, K. (2010) & & & & & & & & & & & & & & & & & & & & & & & & & & & & & & \\
\hline HEINEN, E.; VAN WEE, B.; MAAT, K. (2011) & & & & & & & & & & & & & & & & & & & & & & & & & & & & & & \\
\hline HELBICH, M.; BOCKER, L.; DIJST, M. (2014) & & & & & & & & & & & & & & & & & & & & & & & & & & & & & & \\
\hline & & & & & & & & & & & & & & & & & & & & & & & & & & & & & & \\
\hline MATHISEN, T.; KROESEN, M. (2015) & & & & & & & & & & & & & & & & & & & & & & & & & & & & & & \\
\hline MENG, M.; ZHANG, J.; WONG, Y.D. (2016) & & & & & & & & & & & & & & & & & & & & & & & & & & & & & & \\
\hline MIRANDA-MRRENO, L.F.; NOSAL, T. (2011) & & & & & & & & & & & & & & & & & & & & & & & & & & & & & & \\
\hline $\begin{array}{l}\text { MIRANDA-MORENO, L.; NOSAL, T.; SCHNEIDER, } \\
\text { R.J. PROULX, F. (2014) }\end{array}$ & & & & & & & & & & & & & & & & & & & & & & & & & & & & & & \\
\hline MOTOAKL, Y.; DAZIANO, R.A. (2015) & & & & & & & & & & & & & & & & & & & & & & & & & & & & & & \\
\hline NANKERVIS, M. (1999) & & & & & & & & & & & & & & & & & & & & & & & & & & & & & & \\
\hline NOSAL, T.; MIRANDA-MORENO, L.F. (2014) & & & & & & & & & & & & & & & & & & & & & & & & & & & & & & \\
\hline PARIN, .; WARDMAN, M.; PAGE, M. (2008) & & & & & & & & & & & & & & & & & & & & & & & & & & & & & & \\
\hline $\begin{array}{l}\text { PHUNG, J.; ROSE, G. (2008) } \\
\end{array}$ & & & & & & & & & & & & & & & & & & & & & & & & & & & & & & \\
\hline PUCHER, J; BUEHLER, R. (2006) & & & & & & & & & & & & & & & & & & & & & & & & & & & & & & \\
\hline PUCHER, J.; BUEHLER, R. (2008a) & & & & & & & & & & & & & & & & & & & & & & & & & & & & & & \\
\hline PUCHER, J.; BUEHLER, R. (2008b) & & & & & & & & & & & & & & & & & & & & & & & & & & & & & & \\
\hline RICHARDSON, A.J. (2000) & & & & & & & & & & & & & & & & & & & & & & & & & & & & & & \\
\hline SABIR, M. (2011) & & & & & & & & & & & & & & & & & & & & & & & & & & & & & & \\
\hline SAELENS, B.E.; SALLIS, J.F.; FRANK, L.D. (2003) & & & & & & & & & & & & & & & & & & & & & & & & & & & & & & \\
\hline $\begin{array}{l}\text { SANEINEJAD, S.; KENNEDY, C.; ROORDA, M.J. } \\
(2010)\end{array}$ & & & & & & & & & & & & & & & & & & & & & & & & & & & & & & \\
\hline $\begin{array}{l}\text { SANEINEJAD, S.; ROORDA, M.J.; KENNEDY, C. } \\
\text { (2012) }\end{array}$ & & & & & & & & & & & & & & & & & & & & & & & & & & & & & & \\
\hline SEARS, J.; FLYNN, B.S.; AULTMAN-HALL, L.; DANA, & & & & & & & & & & & & & & & & & & & & & & & & & & & & & & \\
\hline 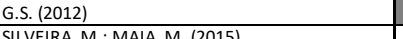 & & & & & & & & & & & & & & & & & & & & & & & & & & & & & & \\
\hline $\begin{array}{l}\text { SILVEIRA, M.; MAIA, M. (2015) } \\
\text { SMITH, M.S.; KAUERMANN G. (2011) }\end{array}$ & & & & & & & & & & & & & & & & & & & & & & & & - & & & & & & \\
\hline $\begin{array}{l}\text { SPENCER, P.; WATTS, R.; VIVANCO, L.; FLYNN, B. } \\
\text { SPEN3) }\end{array}$ & & & & & & & & & & & & & & & & & & & & & & & & & & & & & & \\
\hline$\frac{(2013)}{\text { THOMAS, T.j JAARSMA.R.; TUTERT B. (2009) }}$ & & & & & & & & & & & & & & & & & & & & & & & & & & & & & & \\
\hline THOMAS, T.; JAARSMA, R.; TUTERT, B. (2013) & & & & & & & & & & & & & & & & & & & & & & & & & & & & & & \\
\hline TIN TIN, S.; WOODWARD, A. ROBINSON, E.; & & & & & & & & & & & & & & & & & & & & & & & & & & & & & & \\
\hline $\begin{array}{l}\text { AMERATUNGA, S. (2012) } \\
\text { WADDD z (1013) }\end{array}$ & & & & & & & & & & & & & & & & & & & & & & & & & & & & & & \\
\hline & & & & & & & & & & & & & & & & & & & & & & & & & & & & & & \\
\hline 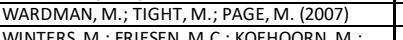 & & & & & & & & & & & & & & & & & & & & & & & & & & & & & & \\
\hline $\begin{array}{l}\text { WINTERS, M.; FRIESEN, M.C.; KOEHOORN, M.; } \\
\text { TESCHKE, K. (2007) }\end{array}$ & & & & & & & & & & & & & & & & & & & & & & & & & & & & & & \\
\hline $\begin{array}{l}\text { WINTERS, M.; DAVIDSON, G.; KAO, D.; TESCHKE, } \\
\text { K (T211) }\end{array}$ & & & & & & & & & & & & & & & & & & & & & & & & & & & & & & \\
\hline
\end{tabular}

Fonte: a autora. 


\subsection{Resultados e discussão}

Intuitivamente, somos menos propensos a pedalar em dias chuvosos, com temperaturas muito altas ou muito baixas. Umidade relativa do ar, ventos fortes, neve e gelo também parecem reduzir o uso da bicicleta (EMMERSON; RYLEY; DAVIES, 1998). Considerando as devidas limitações, é possível estabelecer uma correlação entre as variáveis climáticas e o uso da bicicleta em centros urbanos. Nesse sentido, alguns estudos identificaram ciclos anuais de fluxo de bicicletas em áreas urbanas de climas frios, concentrando o maior número de viagens durante o verão, apresentando um movimento crescente na primavera e decrescente no outono, e atingindo os menores volumes durante o inverno (AHMED; ROSE; JAKOB, 2010; BERGSTROM; MAGNUSSON, 2003; MIRANDA-MORENO; NOSAL, 2011; NANKERVIS, 1999; RICHARDSON, 2000).

Esse ciclo padrão de volume de bicicletas ao longo do ano é um indicador da influência das variações climáticas sobre a decisão individual pelo uso da bicicleta como meio de transporte (AAHEIM; HAUGE, 2005). Bergstrom e Magnusson (2003) comparam o uso de bicicletas para ir ao trabalho no verão (36\%) e no inverno (19\%), apresentando uma redução de 47\%. Tin Tin et al. (2012) identificaram um impacto significativo dos aspectos ambientais (velocidade do vento, chuva, temperatura do ar e horas de sol por dia) nos volumes horários e diários de bicicleta, concluindo que dias ensolarados e mais quentes aumentam o volume de bicicletas, enquanto dias chuvosos e com vento geram um impacto inverso. Ele coloca que as variações climáticas influenciam mais os padrões de volume diário $(56 \%)$ do que os volumes dos ciclos horários (23\%) de bicicletas. Ahmed, Rose e Jakob (2010) concluem que aproximadamente metade das variações no fluxo de bicicletas em Melbourne, Austrália, resulta de variações nas condições climáticas. Mais de $60 \%$ alternam o dia do percurso e 40\% alternam o horário de partida (AHMED; ROSE; JAKOB, 2013).

Na revisão da literatura, parte dos autores identificou a temperatura do ar como a variável ambiental de maior impacto e parte identificou a presença de precipitação como importante. Outros autores consideraram a velocidade do vento ou a umidade relativa do ar, como demonstrado na tabela 3 . Não foram identificados estudos na América do Sul e no Brasil, o que reforça a necessidade de pesquisas aplicadas ao contexto cultural e climático local. 


\subsubsection{Temperatura}

A variação na temperatura do ar é o aspecto ambiental que exerce maior influência na decisão pelo uso da bicicleta (EMMERSON; RYLEY; DAVIES, 1998; FLYNN et al., 2012; GALLOP; TSE, 2012; HANSON; HANSON, 1977; THOMAS; JAARSMA; TUTERT, 2009, 2013), especialmente as temperaturas muito baixas e muito altas (NANKERVIS, 1999; NOSAL; MIRANDA-MORENO, 2014). Alguns autores identificam essa correlação, mas não a reconhecem como sendo a de maior impacto, vide tabela 3. Em geral, os autores consideram a temperatura média do período de medição, mas Smith e Kauermann (2011) afirmam que a correlação mais significativa é estabelecida com as temperaturas máximas diárias, que normalmente ocorrem entre 14:00 h e 17:00 h em Melbourne, Austrália.

O aumento na temperatura média do ar em climas temperados é, em geral, atrativo para os ciclistas, influenciando positivamente o fluxo de bicicletas (EL-ASSI; MAHMOUD; HABIB, 2017; PARKIN; WARDMAN; PAGE, 2008; SABIR, 2011; THOMAS; JAARSMA; TUTERT, 2013; TIN TIN et al., 2012), seja na ida ao trabalho ou em percursos recreativos.

Miranda-Moreno e Nosal (2011) relacionam o aumento de 1\% na temperatura média do ar em Montreal, Canadá, a um acréscimo de aproximadamente 2,5\% no fluxo de bicicletas. Sears et al. (2012) relacionam que a intenção de utilizar a bicicleta em um percurso utilitário em Vermont, EUA, aumenta $3 \%$ a cada $0,5^{\circ} \mathrm{C}$ na temperatura durante a manhã. Ambos os estudos foram realizados em regiões de clima temperado frio, sem estação seca e com verão temperado. Para um aumento de $10 \%$ na temperatura média do ar, Nosal e Miranda-Moreno (2014) verificaram um aumento no fluxo de bicicletas de 3,4\% em rotas utilitárias e de 9,6\% em rotas recreativas. Tin Tin et al. (2012) avaliaram o impacto do aumento de $1{ }^{\circ} \mathrm{C}$ da temperatura no volume de bicicletas em um período de uma hora e de 24 horas, onde o volume de bicicletas aumentou 3,2\% e 2,6\%, respectivamente. Ahmed et al. (2012) verificaram que um aumento de $1{ }^{\circ} \mathrm{C}$ aumentaria em $8 \%$ o volume diário de bicicletas.

O intervalo térmico considerado confortável para pedalar é estabelecido através das temperaturas que influenciam positivamente o número de percursos feitos de bicicleta. Phung e Rose (2008) identificaram que esse intervalo está entre $14{ }^{\circ} \mathrm{C}$ e 
$40^{\circ} \mathrm{C}$ e que o fluxo atinge níveis máximos perto de $28^{\circ} \mathrm{C}$, que seria a temperatura "ideal para pedalar" em Melbourne, Austrália, onde o clima é temperado úmido, com verão temperado. Segundo Ahmed et al. (2012), a temperatura "ideal para pedalar" é de $24{ }^{\circ} \mathrm{C}$ em Portland, EUA, e $20^{\circ} \mathrm{C}$ em Brisbane, Austrália. Para Richardson (2000), o clima ideal em Melbourne é seco com temperatura de $25^{\circ} \mathrm{C}$ e esse foi o ponto de partida para sua simulação em busca da proporção de dias com "clima ideal" e "clima não ideal" para se pedalar ao longo de um ano. Os resultados evidenciam que as viagens utilitárias acontecem em maior número do que as viagens recreativas nos dias com "clima não ideal". Ahmed, Rose e Jakob (2010) identificaram a mesma correlação não linear para valores de temperatura aparente em Melbourne, onde as temperaturas relacionadas ao maior fluxo de bicicletas variaram entre $25^{\circ} \mathrm{C} \mathrm{em} \mathrm{St.} \mathrm{Georges} \mathrm{Road} \mathrm{e}$ $28^{\circ} \mathrm{C}$ em Canning street.

Sabir (2011) identificou que, em temperaturas baixas, abaixo de $0{ }^{\circ} \mathrm{C}$, a quantidade total de viagens não é alterada, mas que existe uma diferença na divisão modal: a demanda por viagens de bicicleta cai $7,7 \%$ e por transporte público aumenta $16,9 \%$, quando comparadas com o intervalo de temperaturas entre $0^{\circ} \mathrm{C}$ e $10^{\circ} \mathrm{C}$. Winters et al. (2007) identificaram uma redução de $9 \%$ no fluxo de ciclistas a cada grupo de 30 dias de temperaturas muito baixas no período de um ano. El-Assi, Mahmoud e Habib (2017) colocam que temperaturas mais altas e níveis mais baixos de umidade relativa do ar, assim como níveis baixos de neve no solo, são positivos para gerar e atrair viagens de bicicleta em Toronto, Canadá, cidade de clima temperado frio sem estação seca e com verão temperado.

\subsubsection{Precipitação}

A presença de precipitação é uma das variáveis ambientais que mais influencia o volume de bicicletas em centros urbanos, vide tabela 3. Segundo Meng et al. (2016), as condições climáticas tropicais de Singapura são relativamente estáveis ao longo de todo o ano, a precipitação é a variável mais importante ao decidir pelo uso da bicicleta. No seu entendimento, as chuvas frequentes e altas temperaturas associadas aos altos índices de umidade relativa do ar contribuem para os baixos índices de uso da bicicleta, em torno de $1 \%$. 
Nankervis (1999) avaliou o impacto das condições climáticas no fluxo de bicicletas em três universidades de Melbourne, Austrália, por meio do número de bicicletas no estacionamento da universidade, que nos dias de chuva forte foi reduzido pela metade. Ahmed et al. (2012) identificaram uma redução no volume de bicicletas de $70 \%$, se comparado aos períodos com ausência de precipitação, e que a chuva forte exerce o maior impacto, reduzindo o volume de bicicletas em $29 \%$, observando que a cada $1 \mathrm{~mm}$ de chuva houve uma redução de $3 \%$ no volume de bicicletas. Tin Tin et al. (2012) mostraram que a cada $1 \mathrm{~mm}$ de chuva houve uma redução de $10,6 \%$ no fluxo de bicicletas, em períodos de medição de uma hora, e uma redução de 1,5\% no volume diário de bicicletas. Richardson (2007) identificou que $8 \mathrm{~mm}$ de precipitação no dia reduzem o volume de bicicletas em $50 \%$, se comparado aos dias sem precipitação.

Além da intensidade, a duração da precipitação influencia a decisão sobre o uso da bicicleta, visto que 10 minutos de chuva reduzem a demanda por viagens em $1,6 \%$ e os percursos de bicicleta diminuem em $7 \%$, sugerindo que as pessoas trocam a bicicleta por transporte público ou automóvel (SABIR, 2011). Em uma perspectiva anual, Winters et al. (2007) mostram que, a cada 30 dias de chuva ao ano, existe uma redução de $16 \%$ no fluxo de bicicletas. A presença de precipitação em períodos anteriores ao início do percurso mostrou-se relevante na decisão dos ciclistas. Sears et al. (2012) verificaram que o número de ciclistas mais do que dobrou em dias sem precipitação no período da manhã.

A relação entre a intensidade da precipitação e o uso da bicicleta como meio de transporte não é linear (AHMED; ROSE; JAKOB, 2010; AHMED et al., 2012; LIU; SUSILO; KARLSTRÖM, 2015; MATHISEN; ANNEMA; KROESEN, 2015; NOSAL; MIRANDA-MORENO, 2014; PHUNG; ROSE, 2008; RICHARDSON, 2000; SANEINEJAD; ROORDA; KENNEDY, 2012). Ahmed, Rose e Jakob (2010) concluem que o impacto da chuva forte (acima de $10 \mathrm{~mm}$ diários) reduz o volume de ciclistas duas vezes mais do que o impacto da chuva fraca/garoa (entre 0,2 e $10 \mathrm{~mm}$ diários), visto que a chuva fraca reduz em $13 \%$ os percursos de bicicleta e a chuva forte reduz em 40\%. Ahmed et al. (2012) concluem que a chuva fraca reduz em 9\% o volume de bicicletas, enquanto a chuva forte tem impacto quatro vezes maior. A pesquisa de Phung e Rose (2008) em Melbourne mostra que a precipitação leve (com valores abaixo de $10 \mathrm{~mm}$ diários) reduziu o volume de bicicletas de $8 \%$ a $19 \%$, enquanto a chuva forte (acima de $10 \mathrm{~mm}$ diários) reduziu de $13 \%$ a $25 \%$, apenas um terço a mais. 
Além de reduzir o número de viagens, a precipitação encurta as distâncias percorridas de bicicleta, exceto em viagens utilitárias, como os percursos para o trabalho de Aaheim e Hauge (2005). Ahmed et al. (2012) colocam que a influência da chuva forte é significante nas duas cidades pesquisadas, mas a interferência é diferente, pois reduz em $23 \%$ o volume de bicicletas em Portland e $33 \%$ em Brisbane.

\subsubsection{Velocidade do vento}

O aumento na velocidade do vento apresentou um impacto negativo no número de viagens de bicicleta, vide tabela 3. Segundo Nankervis (1999), isso seria pelo maior esforço físico, devido ao aumento na dificuldade de pedalar. Ventos fortes tendem a agir mais sobre os ciclistas do que ventos mais fracos (THOMAS; JAARSMA; TUTERT, 2009; HEINEN; MATT; VAN WEE, 2011; FLYNN et al., 2012). Segundo Ahmed, Rose e Jakob (2010), os ventos fortes reduzem o fluxo de $15 \%$ a $20 \%$, dependendo do ponto de medição. Sears et al. (2012) apontam para uma redução de $5 \%$ na intenção de utilizar a bicicleta para um percurso utilitário para cada aumento de 1,6 km/h na velocidade do vento, enquanto Tin Tin et al. (2012) identificaram uma redução no fluxo de bicicletas de $1,4 \%$ nos ciclos de uma hora e de $0,9 \%$ nos ciclos diários para cada aumento de $1 \mathrm{~km} / \mathrm{h}$ na velocidade do vento.

Sabir (2011) conclui que o aumento na velocidade do vento influencia negativamente não apenas o número de viagens, como as distâncias percorridas. Os resultados de sua pesquisa mostram que ventos fortes reduzem a distância média percorrida em 2,3 km, uma redução equivalente a 7,4\% na média total de distâncias percorridas.

Aaheim e Hauge (2005) identificaram, a partir de questionários, que o vento é uma variável significativa, apesar da impossibilidade de correlacionar os dados pela indisponibilidade dos mesmos. Nankervis (1999) coloca que aparentemente o aumento da velocidade do vento influencia negativamente o número de ciclistas, mas não identificou uma clara relação entre a velocidade do vento e o fluxo de bicicletas, enquanto Richardson (2000) coloca que a velocidade do vento, assim como a cobertura do céu por nuvens, não tem qualquer ação sobre o fluxo de bicicletas. 


\subsubsection{Variáveis climáticas}

É um consenso que a influência das variáveis climáticas tem maior impacto sobre os ciclistas em percursos recreativos do que em percursos utilitários, como a ida ao trabalho ou à escola (AHMED; ROSE; JAKOB, 2010; BRANDENBURG; MATZARAKIS; ARNBERGER, 2007; HANSON; HANSON, 1977; SABIR, 2011; THOMAS et al., 2009; THOMAS; JAARSMA; TUTERT, 2013), visto que esses percursos em geral são obrigatórios e não podem ser postergados ou facilmente cancelados (RICHARDSON, 2000). Brandenburg, Matzarakis e Arnberger (2007) observaram que os ciclistas utilitários são menos sensíveis às baixas temperaturas e à chuva, e o estudo de Spencer et al. (2013) mostra que os mesmos apresentam maior faixa de aceitação em relação às variáveis climáticas.

Ahmed, Rose e Jakob (2013) salientam que os ciclistas casuais mudam o dia em que pedalam em função das condições climáticas em $90 \%$ dos casos e os ciclistas funcionais em 50\%. Amiri e Sadeghpour (2015) entrevistaram ciclistas sob baixas temperaturas e constataram que $96 \%$ dos entrevistados estavam usando a bicicleta para ir ao trabalho. Richardson (2000) coloca que os dois tipos de percurso são influenciados pelas condições ambientais, em especial temperaturas muito altas ou muito baixas, mas que o número de viagens recreativas é menor em ambos os casos. As viagens recreativas são afetadas pela presença de precipitação, independente do índice ser baixo ou alto, enquanto as viagens utilitárias não são afetadas por pequenas quantidades de precipitação. Em relação às mudanças na temperatura do ar, o mesmo acontece: com a temperatura de $15^{\circ} \mathrm{C}, 70 \%$ das viagens utilitárias continuam a acontecer, enquanto apenas $45 \%$ das viagens recreativas se mantêm.

É possível identificar a mesma dinâmica por meio da comparação entre rotas predominantemente utilitárias e rotas predominantemente recreativas, sendo o fluxo desta última mais sensível às variações de clima (BRANDENBURG; MATZARAKIS; ARNBERGER, 2007; RICHARDSON, 2000; THOMAS et al., 2009). Phung e Rose (2008) identificaram que a rota Bay Trail de Melbourne, com seu caráter claramente recreativo, é mais sensível a ventos e chuva do que as rotas predominantemente utilitárias. Ao avaliar o impacto da precipitação no fluxo de bicicletas em cinco cidades norte-americanas, Nosal e Miranda-Moreno (2014) verificaram que, nas rotas predominantemente funcionais, a redução no fluxo de bicicletas variou entre $-13 \%$ e - 
47\%. Na Green Route, em Quebec, Canadá, onde predominam ciclistas recreativos, o impacto no fluxo foi de $-70 \%$.

Diferenças de gênero, idade, cultura e/ou aclimatação fazem com que os indivíduos respondam de forma diferente às variações climáticas. Em geral, mulheres, indivíduos de idade mais avançada, baixos índices de escolaridade e maiores salários são associados com uma menor propensão para pedalar (WINTERS et al., 2007). As variações de temperatura influenciam mais as mulheres do que os homens (AHMED et al., 2013; BERGSTRÖM; MAGNUSSON, 2003; SANEINEJAD; ROORDA; KENNEDY, 2012). Saneinejad, Roorda e Kennedy (2012) apresentam a tendência de que as temperaturas baixas influenciam 1,5 vezes mais as mulheres do que os homens. Ahmed et al. (2013) contam que as mulheres afirmaram ser mais influenciadas pelas condições climáticas do que os homens, $47 \%$ e $35 \%$, respectivamente.

Wardman, Tight e Page (2007) afirmam que homens tendem a pedalar e caminhar mais do que as mulheres e a probabilidade de usar a bicicleta para ir ao trabalho diminui à medida que a idade dos indivíduos aumenta. Não foi identificada uma correlação entre o uso da bicicleta e o nível de escolaridade e formação dos indivíduos. Saneinejad, Roorda e Kennedy (2012) sugerem que ciclistas mais jovens são mais sensíveis ao frio do que os ciclistas com mais idade. Temperaturas abaixo de $20^{\circ} \mathrm{C}$ influenciam negativamente ciclistas abaixo de 55 anos, havendo maior interferência sobre ciclistas abaixo de 25 anos, aumentando gradativamente para grupos com mais idade. O mesmo acontece com a influência da chuva, que é maior no grupo de indivíduos abaixo de 25 anos, enquanto os outros não apresentam sensibilidade.

Ahmed, Rose e Jakob (2013) diferenciam as atitudes entre os ciclistas casuais, que fazem uso da bicicleta esporadicamente, e os ciclistas comprometidos. O primeiro grupo é mais vulnerável às alterações no clima (aproximadamente $75 \%$ dos entrevistados). No segundo grupo, $30 \%$ consideram as variações climáticas na decisão pelo uso da bicicleta e salientam aspectos que os impedem de pedalar. Amiri e Sadeghpour (2013), por meio da aplicação de um questionário em temperaturas muito baixas, identificam que $72 \%$ dos entrevistados eram ciclistas frequentes, pedalando mais de 10 vezes por semana ao longo do ano.

A análise dos ciclos semanais do fluxo de bicicletas evidência maior atuação das variáveis ambientais aos finais de semana, o que reforça a hipótese de que 
percursos recreativos são mais suscetíveis do que percursos utilitários. Esse efeito está presente em cenários de chuva, aumento da umidade relativa do ar e mudanças na temperatura. A neve exerce uma influência semelhante em ambos os tipos de percurso (WADUD, 2013). Também foi identificado um padrão para os volumes semanais de ciclistas, concentrando o maior fluxo entre terça-feira e quarta-feira e os menores volumes no início e final da semana, sendo a sexta-feira o dia com o menor número de ciclistas (AHMED; ROSE; JAKOB, 2010; AHMED et al., 2012; EMMERSON; RYLEY; DAVIES, 1998; GALLOP; TSE, 2012; MIRANDA-MORENO; NOSAL, 2011; MIRANDA-MORENO et al., 2014; NOSAL; MIRANDA-MORENO, 2014; PHUNG; ROSE, 2008).

Foram identificados também padrões de variação diária no volume de ciclistas utilitários, com períodos de pico comuns aos outros meios de transporte (AHMED; ROSE; JAKOB, 2010; MIRANDA-MORENO et al., 2014; SMITH; KAUERMANN, 2000; TIN TIN et al., 2012). Ahmed, Rose e Jakob (2010) verificaram que o pico ocorre entre 7:00 h e 9:00 h e entre 16:00 h e 18:00 h, sendo o primeiro deles mais expressivo. Smith (2000) identificou picos de ciclistas utilitários entre 06:00 h e 09:00 h e entre 16:00 h e 19:00 h. Tin Tin et al. (2012) identificaram picos entre 7:00 h e 8:00 h e entre 17:00 h e 18:00 h. Miranda-Moreno et al. (2014) avaliaram cinco cidades norteamericanas e constataram que as ciclovias prioritariamente utilitárias apresentam 0 mesmo padrão: picos diários, semelhantes aos picos de tráfego de veículos (em torno de 8:00 h e de 17:00 h) e fluxo mais intenso no meio da semana (quarta-feira). Ahmed et al. (2012) compararam duas cidades: Portland, EUA, e Brisbane, Austrália, e o horário de pico registrado foi entre 6:00 h e 9:00 h e entre 16:00 h e 19:00 h. O padrão de fluxo semanal segue os outros estudos, com maior fluxo na quarta-feira e menor fluxo na sexta-feira, com diferença de $17 \%$ entre esses dois dias.

Ciclistas com maior habilidade e experiência são menos afetados pelas condições climáticas desfavoráveis quando comparados aos ciclistas esporádicos. A chuva atua negativamente 2,5 vezes mais e a neve quatro vezes mais sobre ciclistas menos experientes (MOTOAKI; DAZIANO, 2015). 


\subsection{Considerações finais}

Sistemas de mobilidade urbana mais sustentáveis são essenciais na busca por cidades e economias de baixo carbono. A bicicleta tem um papel estratégico nesse cenário e as iniciativas de fomento a esse meio de transporte estão cada vez mais presentes. Porém, é importante entendermos quais aspectos influenciam a decisão pelo uso da bicicleta como meio de transporte.

Como mostra a revisão bibliográfica realizada, as variáveis microclimáticas influenciam, em maior ou menor escala, os usuários de transportes ativos, em especial os ciclistas. Os estudos foram realizados em cidades de clima temperado úmido ou temperado frio, onde as variações na temperatura média do ar e a presença de precipitação foram identificadas como os aspectos mais relevantes. Tanto a temperatura média como a presença de precipitação mostraram uma correlação não linear com o fluxo de bicicletas. Os estudos identificados foram realizados majoritariamente em regiões de clima temperado úmido com verão temperado ou quente, ou em clima temperado frio, sem estação seca e com verão temperado, onde a temperatura média no mês mais quente não passa dos $22^{\circ} \mathrm{C}$. As correlações identificadas não podem ser assumidas indiscriminadamente para outros climas, mas podem ser um ponto inicial de investigação para regiões com outros climas ou diferenças culturais intensas.

Em geral, os estudos avaliam o impacto individual de cada variável ambiental sobre o fluxo de bicicletas, mas a combinação das mesmas apresenta resultados ainda mais específicos. Como observado, o aumento na velocidade do vento exerce uma influência negativa no fluxo de bicicletas e a alta velocidade do vento associada à leve precipitação é o cenário de maior impedimento do uso da bicicleta. Os efeitos da temperatura, da umidade relativa do ar e do vento não deveriam ser analisados separadamente, visto que os indivíduos percebem a temperatura por meio da temperatura aparente/percebida, não da temperatura média do ar.

A percepção e o conforto térmico dos ciclistas são resultados da combinação de variáveis ambientais e determinantes na decisão do ciclista pelo uso da bicicleta. A revisão da literatura evidencia a influência individual das variáveis microclimáticas e aponta para a necessidade de um maior número de avaliações que as considerem em conjunto, estabelecendo uma relação com a sensação e preferência térmicas dos ciclistas. 
Foi identificada a necessidade de estudos em regiões com outros climas para uma avaliação mais ampla da influência das variáveis microclimáticas na decisão pelo uso da bicicleta em centros urbanos. Pesquisas na América do Sul, em especial no Brasil, podem contribuir com esta investigação, visto que as pesquisas identificadas se concentram em países da Europa, América do Norte e na Austrália. 


\section{MÉTODO DA PESQUISA PARA O LEVANTAMENTO DE DADOS SECUNDÁRIOS E PRIMÁRIOS}

\subsection{Considerações iniciais}

A partir do entendimento de que a bicicleta tem um papel relevante na busca por sistemas de mobilidade urbana mais sustentáveis, a investigação sobre a complexa combinação de fatores que influenciam a decisão pelo uso da bicicleta como meio de transporte faz-se necessária. Além de fatores ligados às condições de topografia e infraestrutura urbana, aspectos socioeconômicos, culturais e comportamentais, destaca-se a influência das variações climáticas na decisão dos ciclistas pelo uso da bicicleta, seja para percorrer percursos completos ou para utilizála de forma combinada a outros meios de transporte.

O levantamento de dados secundários foi direcionado para identificar a correlação entre variações climáticas e sua influência no fluxo de bicicletas em períodos onde predominam percursos funcionais ${ }^{4}$ na região do centro expandido da cidade de São Paulo. Foram investigados padrões de ciclos de fluxo de bicicletas em diversas escalas, tanto em períodos predominantemente funcionais, como em períodos predominantemente recreativos, permitindo a comparabilidade entre eles. Considerando que a decisão pelo uso da bicicleta para percursos funcionais acontece majoritariamente no início do dia, a investigação avançou no sentido de entender o fluxo de ciclistas no período matutino predominantemente funcionais permitindo uma correlação mais precisa com as variações climáticas. Foram utilizadas uma fonte de dados climáticos e duas fontes de dados para o fluxo de bicicletas, uma na escala do centro expandido de São Paulo e outra na escala local, na ciclovia da avenida Faria Lima. As variáveis climáticas ${ }^{5}$ levantadas foram temperatura média do ar e umidade relativa do ar, permitindo a identificação das ocorrências de precipitação.

Em um segundo momento da pesquisa foram levantados dados primários por meio de levantamento experimental de campo buscando estabelecer uma correlação entre o microclima urbano e o fluxo de bicicletas ao longo da ciclovia de estudo. As

\footnotetext{
${ }^{4}$ Percursos percorridos diariamente ou majoritariamente nos dias úteis, como de ida e volta ao trabalho ou a instituições de ensino.

${ }^{5}$ As variáveis climáticas descrevem as características gerais da região em termos de sol, nuvens, temperatura, ventos, umidade e precipitação.
} 
variáveis microclimáticas ${ }^{6}$ levantadas foram temperatura média do ar, umidade relativa do ar, velocidade e direção do vento, radiação solar e temperatura de globo. Os ciclistas que participaram da pesquisa tendem a morar e/ou trabalhar em regiões próximas à Av. Faria Lima, consideradas de médio e alto poder aquisitivo. Isto nos leva a identificar um perfil de ciclistas diferente dos ciclistas do extremo sul da cidade, que usam a bicicleta como alternativa ao impacto financeiro do uso do transporte coletivo. Para identificar essa correlação e a influência das variáveis ambientais na tomada de decisão pelo uso da bicicleta, foram aplicados questionários com ênfase na percepção e preferência térmica dos ciclistas.

Este capítulo apresenta os critérios de escolha e procedimentos realizados para os levantamentos de dados secundários e primários, apresentando ao final do capítulo os resultados obtidos.

\subsection{Levantamento de dados secundários}

\subsubsection{Dados climáticos da cidade de São Paulo}

Foram identificadas as seguintes Estações Meteorológicas para fornecimento de dados climáticos para a cidade de São Paulo:

a. Estações Meteorológicas dos aeroportos de São Paulo e Guarulhos - INPE;

b. Estação Meteorológica do Instituto Nacional de Meteorologia- INMET (Estação MIR Santana - número 83.781);

c. Estação Meteorológica do Instituto de Astronomia, Geofísica e Ciências Atmosféricas -IAG da USP, sediada no Parque CIENTEC.

Os dados das estações meteorológicas dos aeroportos (INPE) estavam indisponíveis. Os dados da Estação meteorológica do INMET (Santana) são disponibilizados com frequência diária, e os dados da estação meteorológica do IAGUSP são disponibilizados com frequência horária.

Foram considerados os dados registrados pela Estação Meteorológica da Seção Técnica de Serviços Meteorológicos do Instituto de Astronomia, Geofísica e Ciências Atmosféricas-IAG da Universidade de São Paulo, registrada junto à

\footnotetext{
${ }^{6}$ As variáveis microclimáticas descrevem o clima em uma escala mais próxima ao nível das edificações, de forma a identificar a influência de variáveis como a topografia e vegetação, a morfologia urbana e outros elementos urbanos.
} 
Organização Meteorológica Mundial sob o número 83004 e situada no Parque Estadual das Fontes do Ipiranga, no bairro da Água Funda, à latitude 23039'S e à longitude 46o37'W. O critério de escolha foi em função da longitude e latitude da estação meteorológica, como mostra imagem abaixo:

Figura 1 - Localização do Parque de Ciência e Tecnologia da USP - CIENTEC e da Av. Faria Lima, no Município de São Paulo

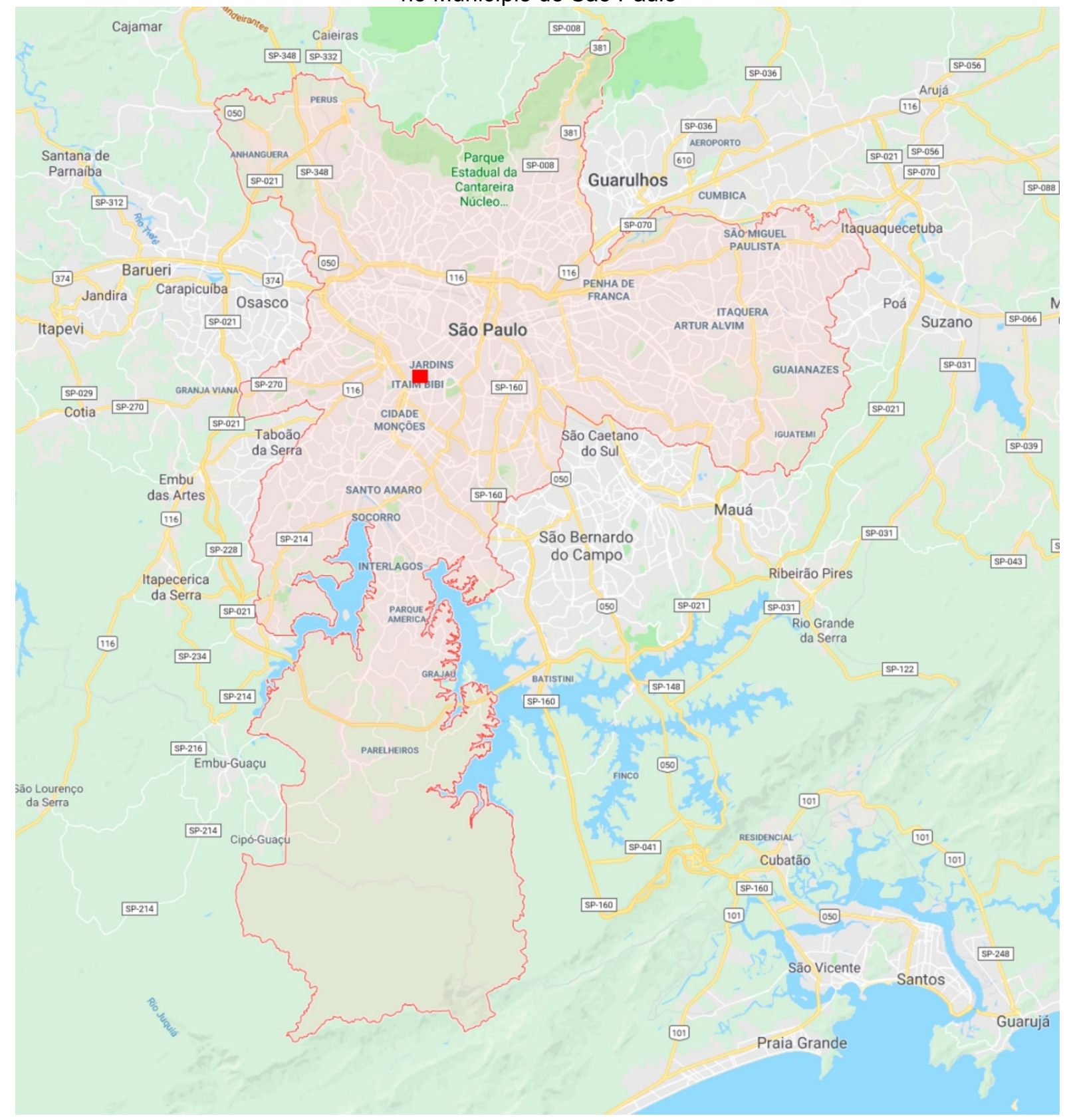

Fonte: Google Earth, 2017. 
Figura 2 - Localização do Parque de Ciência e Tecnologia da USP - CIENTEC e da Av. Faria Lima

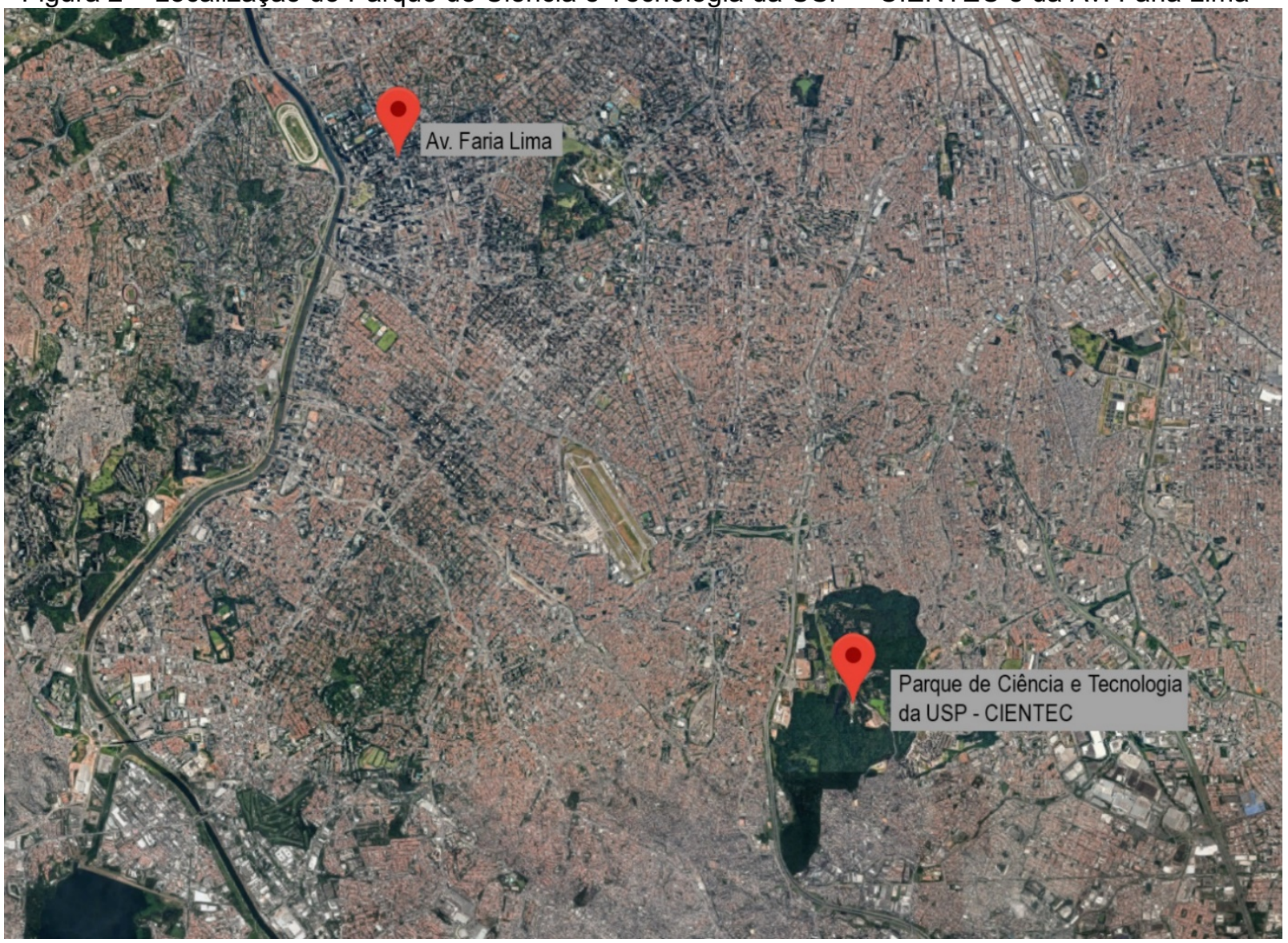

Fonte: Google Earth, 2017.

Outro aspecto considerado foi a disponibilidade de dados com periodicidade horária, tendo em vista que o objeto da pesquisa são ciclistas funcionais durante percursos de ida ao trabalho no período matutino e que dados com periodicidade horária permitiriam a utilização do mesmo recorte para os dados climáticos e para os dados relativos ao fluxo de bicicletas ${ }^{7}$. Os dados da Estação do INMET foram desconsiderados em função de sua periodicidade.

\subsubsection{Sistema de compartilhamento de bicicletas BIKE SAMPA}

Para a obtenção dos dados referentes ao fluxo de bicicletas na escala do centro expandido de São Paulo, foram identificados dois sistemas de bicicletas compartilhadas, o Bike-Sampa, que conta com 285 estações de retirada e entrega de bicicletas e o Ciclo-Sampa, que conta com 17 estações na região da Av. Faria Lima.

\footnotetext{
${ }^{7}$ Os dados climáticos foram solicitados e obtidos pelo e-mail estacao.aca@iag.usp.br
} 
Foram utilizados os dados do sistema de compartilhamento BIKE SAMPA pelo número de estações em funcionamento e pela área de abrangência e os dados do sistema de compartilhamento Ciclo-Sampa foram desconsiderados.

Os dados relativos ao sistema Bike-Sampa foram solicitados a representantes da equipe de comunicação do Banco Itaú, empresa patrocinadora da iniciativa, que indicaram um contato na empresa Serttel, responsável por gerenciar o sistema até o início de 2017. Após contato telefônico e por meio eletrônico com representantes da Serttel, foi enviada tabela de dados brutos do sistema de compartilhamento contendo data, horário, local e código de retirada das bicicletas e horário e local de entrega das mesmas.

\subsubsection{Contador eletrônico da Companhia de Engenharia de Tráfego de São Paulo- CET SP}

Para a contagem do número de bicicletas na área de estudo, foram utilizados os dados do contador eletrônico da Companhia de Engenharia de Tráfego de São Paulo-CETSP instalado na ciclovia da Av. Faria Lima. Inicialmente foi feito contato por e-mail com o Lab Prodam - Laboratório de Inovação Tecnológica da Prefeitura de São Paulo, e agendada uma reunião presencial. Na reunião foram obtidos dados do contador eletrônico de bicicletas instalado na Av. Faria Lima como iniciativa piloto do Lab Prodam. Porém, a iniciativa foi descontinuada e não forneceria a confiabilidade de dados necessária para a pesquisa. Os dados foram utilizados na fase inicial da pesquisa, mas foram desconsiderados na versão final. Por meio do site da Prefeitura de São Paulo foi possível obter os dados de um contador eletrônico de bicicletas instalado na Av. Faria Lima. Enquanto o contador do LabProdam foi instalado próximo ao Shopping Iguatemi, o contador da CET foi instalado próximo ao largo da Batata, em Pinheiros.

Os dados disponibilizados pela CET- Companhia de Engenharia de Tráfego de São Paulo - são consolidados diariamente e a demanda da pesquisa é por dados consolidados com periodicidade mínima a cada hora. Foi feito contato telefônico e por meio eletrônico fazendo uso da lei de acesso às informações públicas ${ }^{8}$ foram obtidos

\footnotetext{
${ }^{8}$ Lei n $12.527 / 2011$ que regulamenta o direito constitucional de acesso às informações públicas, que entrou em vigor em 16 de Maio de 2012. Esta Lei foi regulamentada pelo Decreto n 7.724/2012.
} 
os dados brutos, sem que estivessem consolidados por periodicidade horária, o que permitiu a consolidação dos mesmos de acordo com as necessidades da pesquisa.

\subsubsection{Considerações finais}

Inicialmente foram solicitados dados climáticos e referentes ao fluxo de bicicletas por 3 meses (entre agosto e outubro de 2016) para um pré-teste que objetivou a confirmação da disponibilidade das informações, a identificação dos procedimentos necessários para aquisição dos dados, a identificação do formato em que seriam disponibilizados, e a estruturação dos arquivos que permitiriam estabelecer uma correlação entre eles.

Foi feito o tratamento prévio dos dados coletados para entender se atenderiam à pesquisa. Na etapa de pré-teste de aquisição e tratamento dos dados foram avaliadas diversas formas de consolidação dos dados brutos, o que permitiu maior assertividade na consolidação dos dados utilizados na pesquisa. Após a conclusão da etapa de pré-teste foram solicitados às referidas fontes os dados entre 01 de janeiro e 31 de dezembro de 2016.

\subsection{Levantamento de dados primários}

\subsubsection{Local e períodos de medição}

Foram avaliadas ciclovias no centro expandido de São Paulo próximas a áreas com concentração de serviços e edifícios comerciais e a estações de transporte de massa. O objetivo foi identificar ciclovias com potencial de possuir padrão de uso predominantemente funcional durante os dias úteis, o que resultaria em altos índices de ciclistas funcionais. Após o mapeamento empírico, foi escolhida a ciclovia instalada no canteiro central da Av. Faria Lima, no centro expandido de São Paulo. A referida ciclovia recebe grande número de ciclistas aos finais de semana e feriados, podendo caracterizar-se como uma ciclovia de uso recreativo. Nos outros dias apresenta padrões de uso predominantemente utilitários, concentrando um alto fluxo de ciclistas no início da manhã e final da tarde, e pode ser considerada uma ciclovia de caráter misto. É uma ciclovia que faz parte da malha cicloviária de São Paulo, conectando bairros residenciais a áreas comerciais e de serviços com destinos de cultura e lazer. 
A ciclovia também faz a ligação entre importantes centros modais e distritos comerciais/ hubs de negócio, consolidando-se como um percurso utilitário de alto fluxo, considerando o perfil dos ciclistas que são objeto desta pesquisa.

Buscando identificar a influência do microclima urbano na decisão pelo uso da bicicleta para ir ao trabalho em São Paulo, o levantamento de campo foi direcionado para uma ciclovia com padrão de uso predominantemente funcional em dias úteis. Nestes períodos predominam altos índices de ciclistas em percursos de ida ao trabalho, instituições educacionais ou à atividades rotineiras. Foi escolhida a ciclovia da Av. Faria Lima, situada entre os bairros de Pinheiros, Jardim Europa, Jardim Paulistano e Itaim Bibi. Neste sentido os levantamentos foram feitos em dias úteis, representativos de inverno e de verão, entre junho de 2017 e março de 2018. Os levantamentos foram feitos entre 6:00am e 10:00am objetivando identificar o período de maior fluxo de bicicletas dentro deste intervalo.

\subsubsection{Bases de medição}

Foram realizadas medições microclimáticas em duas bases, uma em área sombreada e outra em área predominantemente ensolarada, distantes em 4 metros, buscando identificar com maior precisão o impacto da radiação direta. Entre as duas bases, junto ao data logger principal foram instalados sensores para medir a temperatura média e a umidade relativa do ar como um recurso complementar de medição. A estação foi localizada de acordo com critérios de segurança dos pesquisadores e equipamentos, proximidade com semáforo de bicicletas (permitindo uma abordagem aos ciclistas para colher informações de percepção e preferência térmica), presença de vegetação (que permitiu que as duas medições feitas entre uma distância de $4 \mathrm{~m}$, distância máxima alcançada em decorrência do cabeamento dos equipamentos), e facilidade para embarque e desembarque dos equipamentos. Abaixo está imagem da Av. Faria Lima e da ciclovia ao longo da avenida, onde as bases de medição foram localizadas. 
Figura 3 - Localização das bases de medição na ciclovia da Av. Faria Lima

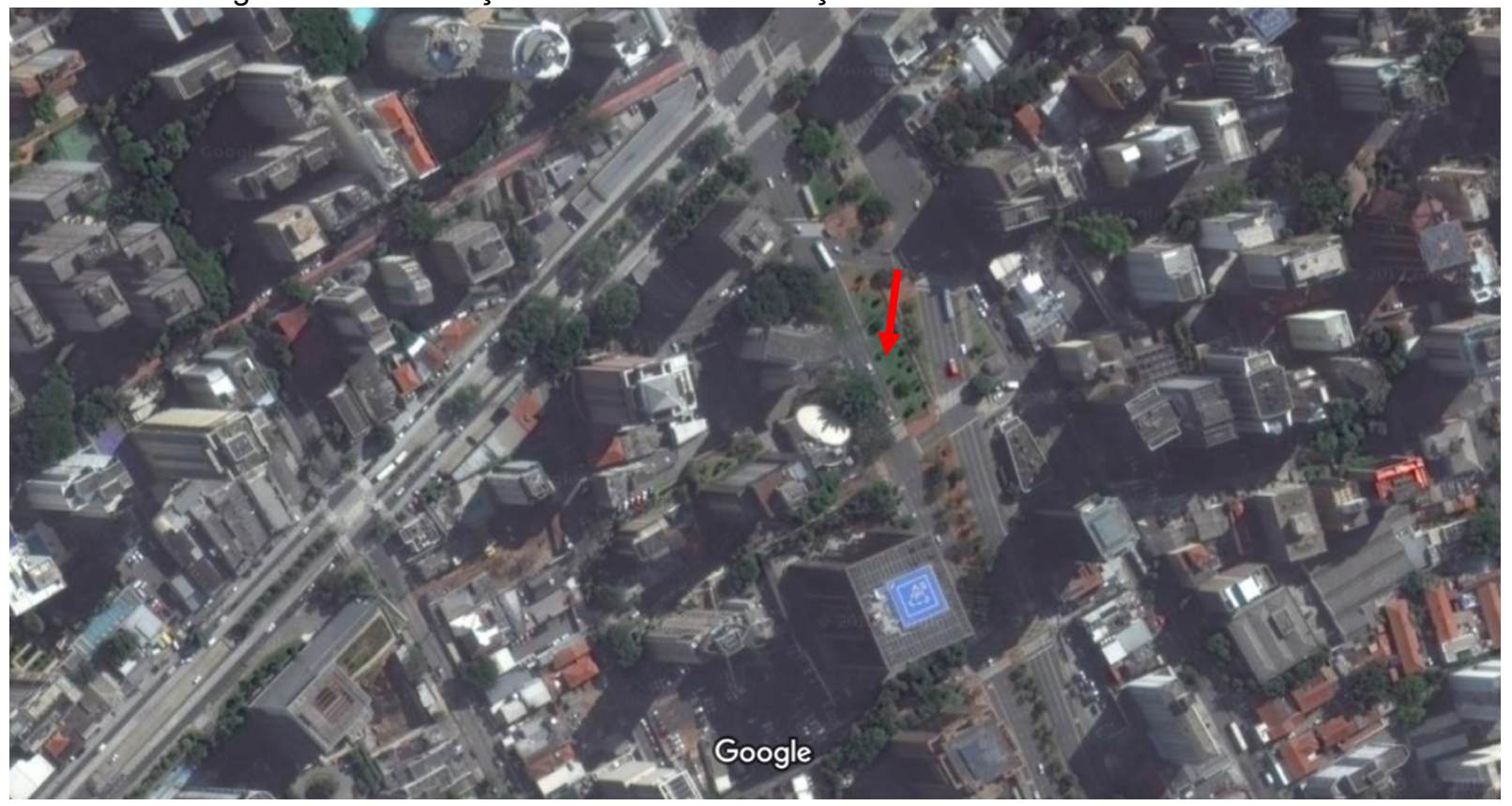

Fonte: Google Earth, 2017.

Figura 4 - Localização ampliada da estação de medição na ciclovia da Av. Faria Lima

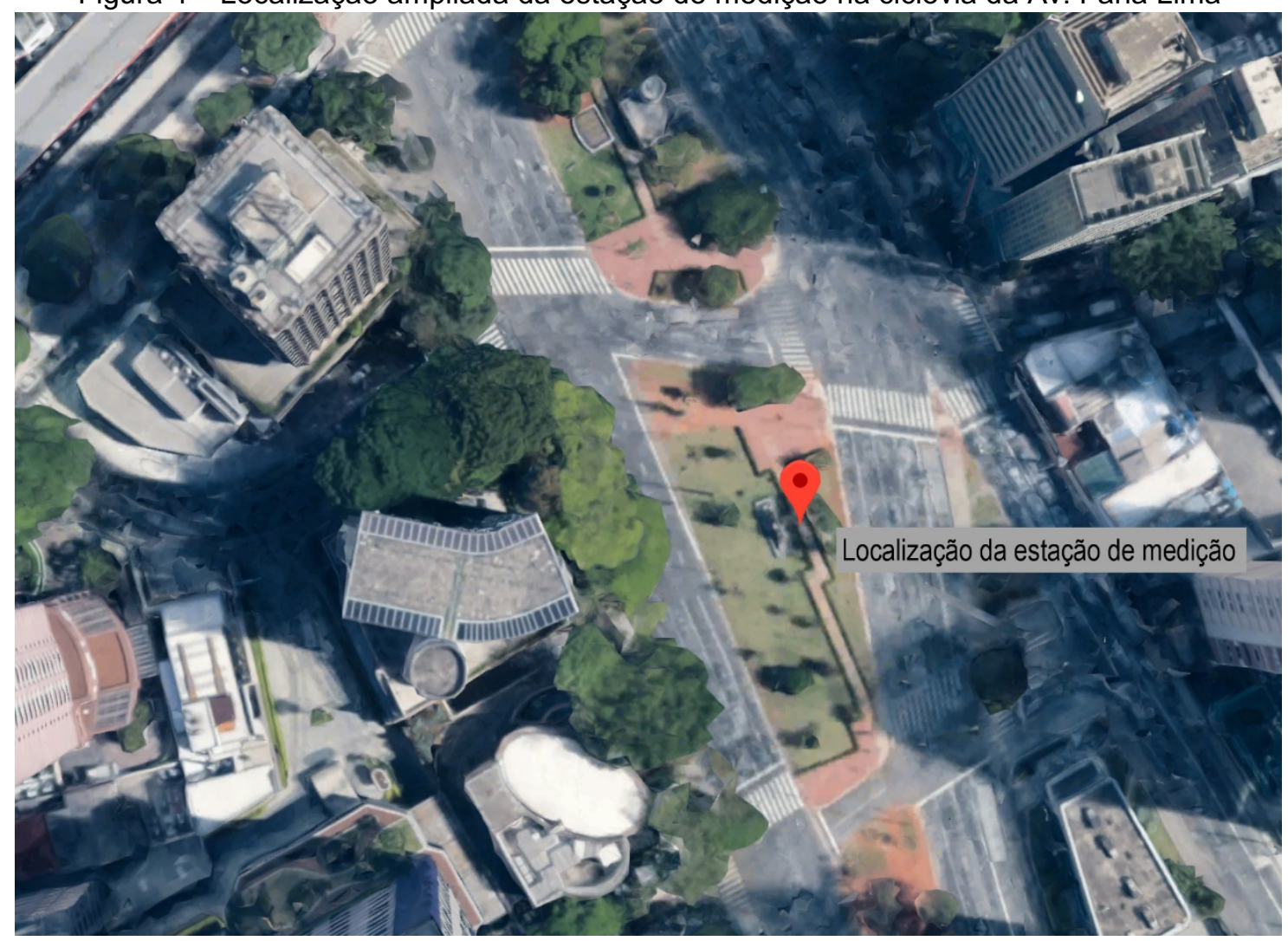

Fonte: Google Earth, 2018. 


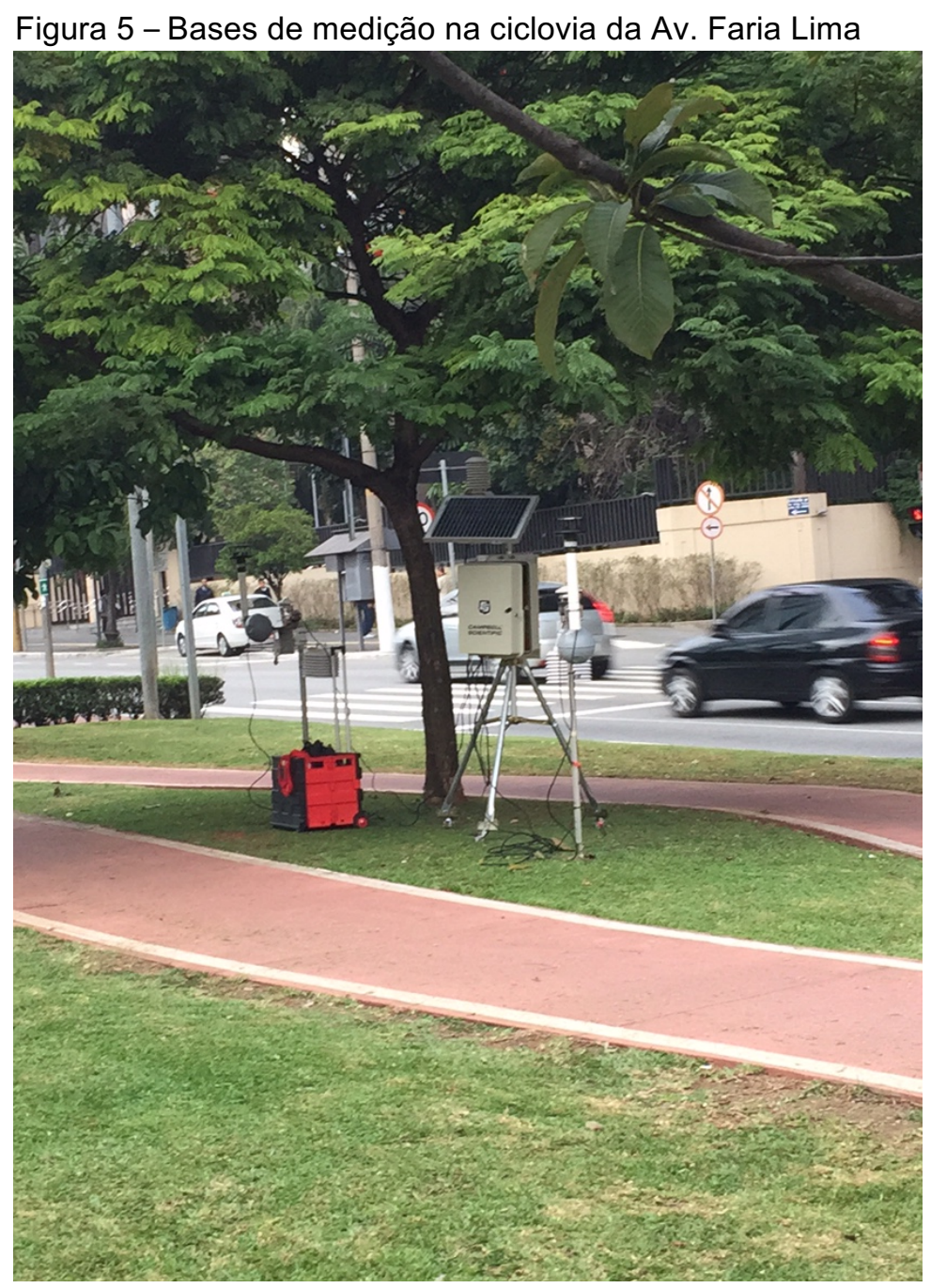

Fonte: a autora, 2017.

\subsubsection{Procedimento do levantamento de dados primários}

Os equipamentos foram posicionados nas bases de medição às 5:30am para que os termômetros de globo estivessem estabilizados antes do início da medição. Segundo a norma ISO 7726 (1998), o tempo de resposta de um termômetro de globo é de aproximadamente 20 a 30 min, dependendo das características do globo e do ambiente onde acontece a medição, por esta razão a montagem dos equipamentos foi feita 30 minutos antes do inicio das medições, que foram feitas entre 6:00am e 10:00am, como colocado anteriormente. As duas bases de medição estavam próximas possibilitando que o monitoramento fosse feito por um pesquisador. Para aumentar a segurança e possibilitar a aplicação do questionário aos ciclistas com maior tranquilidade, havia no mínimo duas pessoas no local durante os períodos de medição. 
As medições foram feitas à $1,4 \mathrm{~m}$ de altura, altura média do tronco dos ciclistas e com distância de aproximadamente $30 \mathrm{~cm}$ da ciclovia. Após os períodos de medição, a tabulação dos dados foi feita no programa Excel. Foram aplicados questionários a ciclistas que passaram no local durante o levantamento e os dados obtidos foram usados para calcular o índice de Temperatura Equivalente Percebida (TEP) objetivando interpretar a percepção e preferência térmica dos ciclistas.

Para a quantificação física das variáveis ambientais foi considerada a Norma ISO 7726 (1998), que determina a precisão exigida dos instrumentos de acordo com a homogeneidade e heterogeneidade das variáveis medidas (MONTEIRO, 2008). O ambiente foi classificado como tipo C (conforto) pelas variações moderadas, visto que não foram apresentadas situações de stress térmico, tipo $S$ (Stress). As características são apresentadas na Tabela 6:

Tabela 6 - ISO 7726 (1998): Características requeridas e desejáveis dos instrumentos

\begin{tabular}{|c|c|c|c|c|}
\hline Variáveis & $\begin{array}{l}\text { Faixa para } \\
\text { conforto }\end{array}$ & Precisão para conforto & $\begin{array}{l}\text { Faixa para } \\
\text { estresse }\end{array}$ & Precisão para estresse \\
\hline \multirow[t]{2}{*}{ Temperatura do ar ( $\left.\mathrm{t}_{\mathrm{ar}}\right)$} & $10-40^{\circ} \mathrm{C}$ & Requerida: $\pm 0,5^{\circ} \mathrm{C}$ & $-40-120^{\circ} \mathrm{C}$ & Requerida: $\pm 0,5^{\circ} \mathrm{C}\left(0-50^{\circ} \mathrm{C}\right)$ \\
\hline & & Desejada: $\pm 0,2{ }^{\circ} \mathrm{C}$ & & Desejada: $\pm 0,25{ }^{\circ} \mathrm{C}\left(0-50^{\circ} \mathrm{C}\right)$ \\
\hline \multirow[t]{2}{*}{ Temperatura radiante $\left(t_{r m}\right)$} & $10-40^{\circ} \mathrm{C}$ & Requerida: $\pm 2{ }^{\circ} \mathrm{C}$ & $-40-150{ }^{\circ} \mathrm{C}$ & Requerida: $\pm 5^{\circ} \mathrm{C}\left(0-50^{\circ} \mathrm{C}\right)$ \\
\hline & & Desejada: $\pm 0,2{ }^{\circ} \mathrm{C}$ & & Desejada: $\pm 5^{\circ} \mathrm{C}\left(0-50^{\circ} \mathrm{C}\right)$ \\
\hline \multirow[t]{2}{*}{ Velocidade do ar ( } & $0,05-1 \mathrm{~m} / \mathrm{s}$ & Requerida: $\pm[0,05+0,05 \mathrm{~V}]$ & $0,2-20 \mathrm{~m} / \mathrm{s}$ & Requerida: $\pm[0,1+0,05 \mathrm{~V}]$ \\
\hline & & Desejada: $\pm[0,02+0,07 \mathrm{~V}]$ & & Desejada: $\pm[0,05+0,05 \mathrm{~V}]$ \\
\hline Umidade absoluta $\left(\mathrm{p}_{\mathrm{ar}}\right)$ & $0,5-3,0 \mathrm{kPa}$ & $\pm 0,15 \mathrm{kPa}\left(\left|\mathrm{t}_{\mathrm{ar}}-\mathrm{t}_{\mathrm{rm}}\right|<10^{\circ} \mathrm{C}\right)$ & $0,5-6,0 \mathrm{kPa}$ & $\pm 0,15 \mathrm{kPa}\left(\left|\mathrm{t}_{\mathrm{ar}}-\mathrm{t}_{\mathrm{rm}}\right|<20^{\circ} \mathrm{C}\right)$ \\
\hline
\end{tabular}

Fonte: ISO (1998).

\subsubsection{Variáveis ambientais}

As variáveis ambientais levantadas foram temperatura média e umidade relativa do ar, velocidade e direção do vento, temperatura de globo, radiação solar, fator de cobertura do céu e presença de precipitação. Os equipamentos utilizados nas medições de campo para levantamento dos dados primários pertencem ao Laboratório de Conforto e Eficiência Energética LABAUT-FAUUSP. Nas bases de 
medição 01, localizado sob densa copa de árvore, e 02, localizado em área predominantemente ensolarada, foram coletadas as variáveis ambientais descritas abaixo com os seguintes equipamentos:

a) A temperatura média e umidade relativa do ar foram medidos com sensor HOBO U23 001 com proteção Solar Shield RS1. Para a umidade relativa a faixa de medição é de 0 à $100 \%$, para temperaturas entre $-40^{\circ}$ e $70^{\circ} \mathrm{C}$, a resolução é de $0.03 \%$.

b) A temperatura de globo foi medida pelo sensor $\mathrm{HOBO} \cup 23-004$, a faixa de medição está entre $-40^{\circ}$ e $100^{\circ} \mathrm{C}$, a resolução é de $0.02^{\circ}$ à $25^{\circ} \mathrm{C}$, tendo sido utilizados globos cinza médio fosco, de $17 \mathrm{~cm}$ de diâmetro, com emissividade de aproximadamente 0,41 . Foram escolhidos globos na cor cinza tendo em vista que sua absorção de radiação térmica de onde curta (radiação direta) é mais parecida com a de pessoas vestidas, se comparada à dos globos de cor preta. A temperatura radiante média foi estimada a partir da medição da temperatura de globo;

c) A medição da radiação solar foi feita com piranômetro CMP3, fabricado pela Kipp and Zonen com faixa de medição entre $-40^{\circ}$ e $80^{\circ} \mathrm{C}$, com Light Spectrum Wave band entre 310 e 2800 nm, irradiação máxima de 2000 $\mathrm{W} / \mathrm{m} 2$ e sensibilidade entre 5 e $20 \mu \mathrm{V} / \mathrm{W} / \mathrm{m} 2$;

d) A velocidade e direção do vento foram medidas com anemômetro Wind Sonic 01 fabricado pela Campbell Scientific, com faixa de medição entre $35^{\circ}$ e $70^{\circ} \mathrm{C}$ e umidade relativa entre $<5 \%$ e $100 \%$. A direção do vento é medida entre $0^{\circ}$ e $359^{\circ}$ e tem resolução de $1^{\circ}$. A velocidade do vento é medida entre 0 e $60 \mathrm{~m} \mathrm{~s}-1$, e resolução de $0.01 \mathrm{~m} / \mathrm{s}-1$. Ambos foram ligados ao datalogger $\mathrm{CR} 800$,

Entre as bases de medição 01 e 02 , foi posicionado uma base de medição complementar. Nesta base, a temperatura média e umidade relativa do ar foram medidos com sensor HMP45C, com faixa de medição entre $-39,2^{\circ}$ e $60^{\circ} \mathrm{C}$, ligados ao datalogger $\mathrm{CR} 800$, que funciona em temperaturas entre $-25^{\circ}$ e $50^{\circ} \mathrm{C}$ e ambientes sem condensação. Ambos são fabricados pela Campbell Scientific. Foram tiradas fotos para identificar o fator de cobertura do céu nos pontos de medição 01 e 02, com câmera fotográfica Nikon COOLPIX 4500 e lente grande angular (olho de peixe) Nikon Fisheye converter FC-E8 0.21x Japan. 
Figura 6 - Foto grande angular nas bases de medição 01 - à sombra

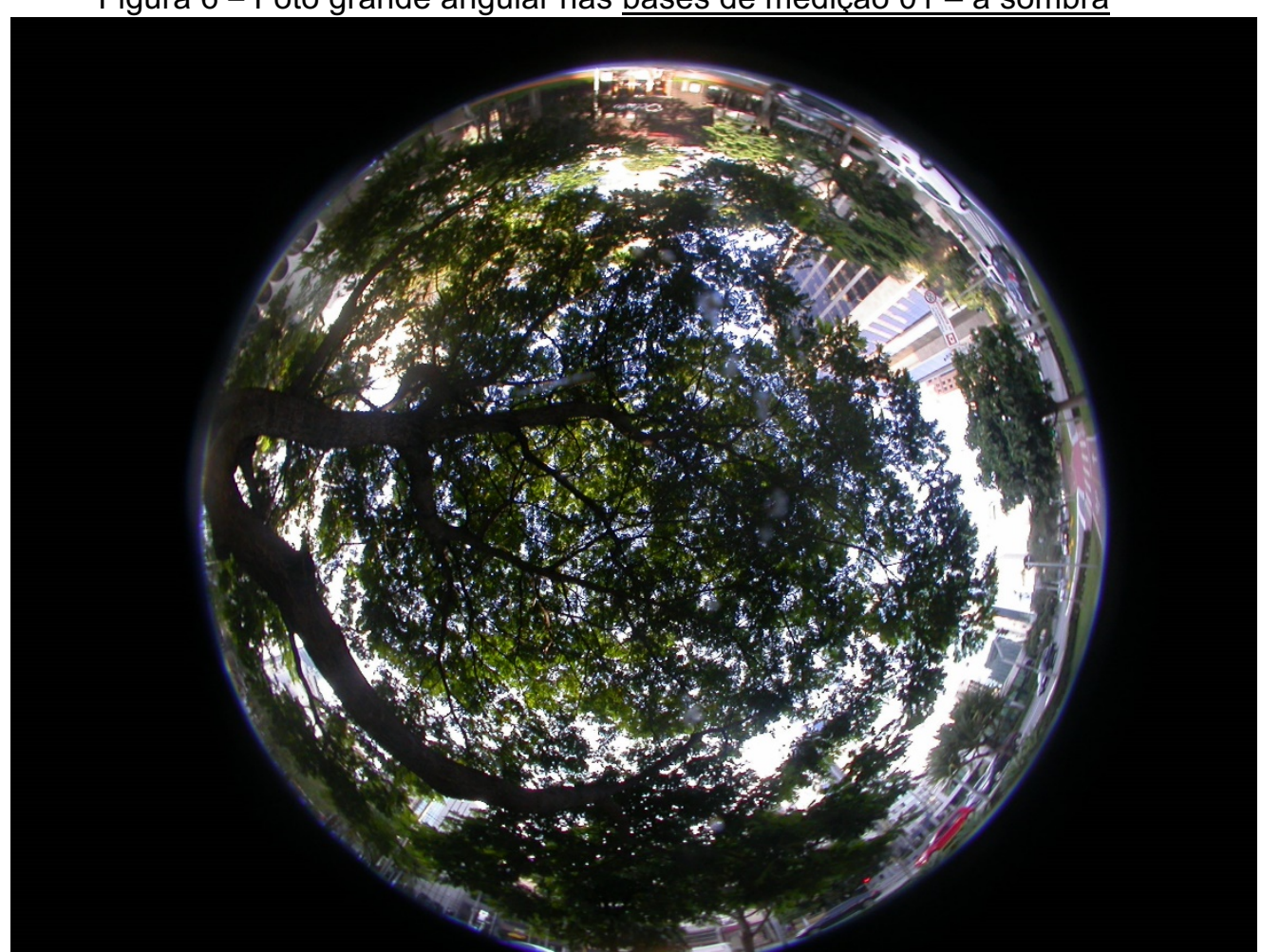

Fonte: a autora, 2017.

Figura 7 - Foto grande angular no ponto de medição 02 - ao sol

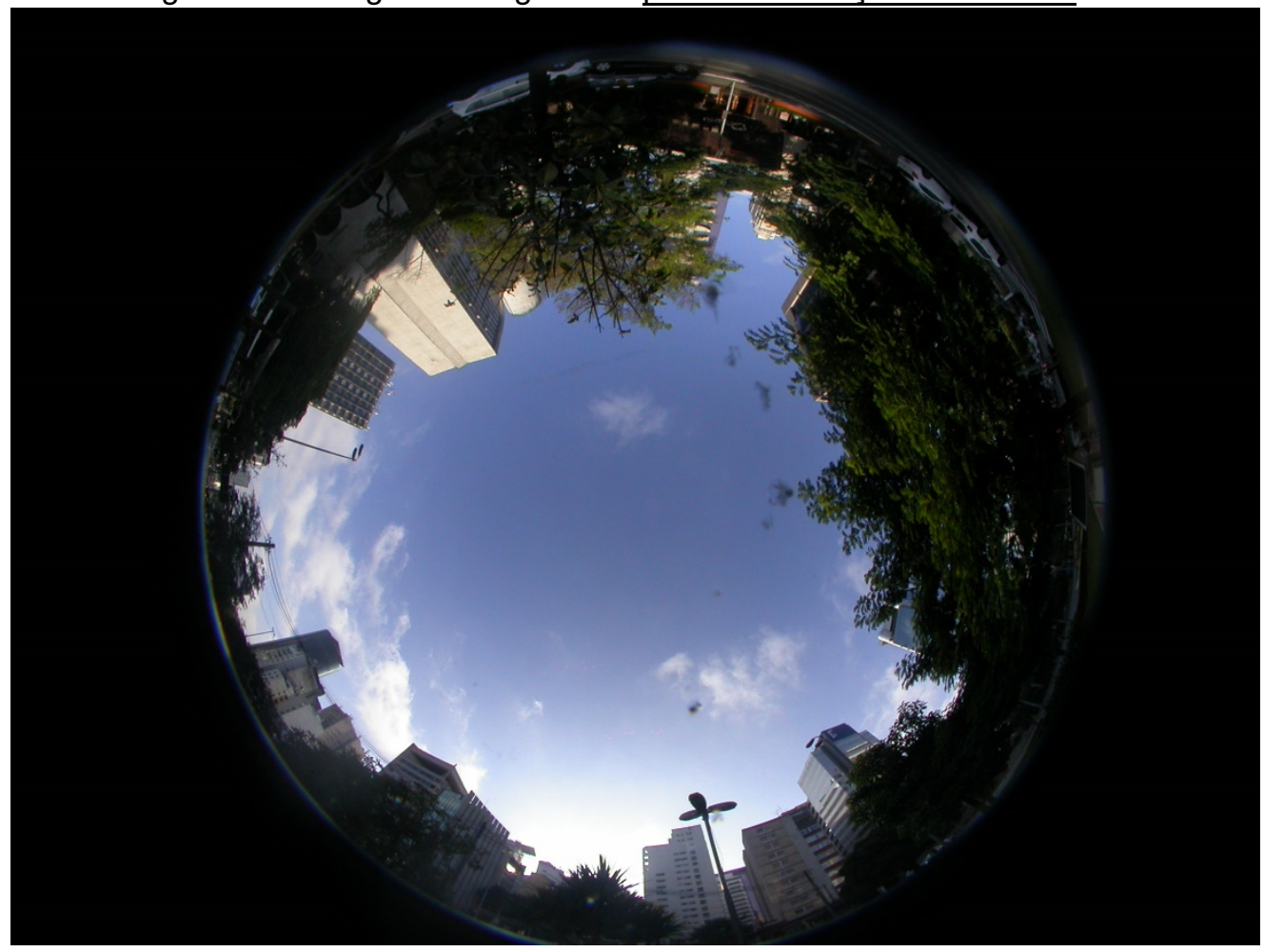

Fonte: a autora, 2017. 
As variáveis individuais levantadas na pesquisa foram:

a. Taxa metabólica, considerando os valores de taxa metabólica e resistência térmica da roupa, identificadas por meio da observação e registradas em relatórios fotográficos. De acordo com a norma ISO 8996 (2004) são considerados três níveis de precisão na determinação das taxas metabólicas. Foi definido o nível 2, que define o valor a ser utilizado a partir do nível de intensidade da atividade dos ciclistas. A definição da taxa metabólica para o uso de bicicleta não está descrita na norma. Considerando que a amostra foi de ciclistas em atividade lenta ou moderada, foram adotados os valores descritos abaixo:

Tabela 7 - Gasto energético estimado para atividades de ciclismo de diferentes intensidades

\begin{tabular}{lllrc} 
Atividade & \multicolumn{1}{c}{ Descrição } & Velocidade & MET $^{9}$ \\
\hline \multirow{4}{*}{ Ciclismo } & \multirow{2}{*}{ Lazer } & Ida para o trabalho ou por prazer & $<16 \mathrm{~km} / \mathrm{h}$ & 4,0 \\
\cline { 3 - 5 } & & Esforço leve, lento & 16 à $19 \mathrm{~km} / \mathrm{h}$ & 6,0 \\
\cline { 3 - 5 } & & Esforço moderado & 19,3 à $22,3 \mathrm{~km} / \mathrm{h}$ & 8,0 \\
\cline { 2 - 5 } & \multirow{3}{*}{ Corrida } & Rápido, vigoroso & 22,5 à $25,5 \mathrm{~km} / \mathrm{h}$ & 10,0 \\
\cline { 3 - 5 } & & Muito rápido, corrida em geral & 25,7 à $30,5 \mathrm{~km} / \mathrm{h}$ & 12,0 \\
\cline { 3 - 5 } & & Corrida sem arrasto & $>32 \mathrm{~km} / \mathrm{h}$ & 16,0 \\
\hline
\end{tabular}

Fonte: Dados compilados de Ainsworth et al. (2011).

b. Resistência térmica da vestimenta, medida pela capacidade de isolamento térmico da roupa e representada pelo índice $\mathrm{CLO}\left(\mathrm{clo}=0,155 \mathrm{~m}^{2} \mathrm{C} / \mathrm{W}\right)$. São considerados a resistência evaporativa da roupa e o fator de roupa calculados conforme a norma ISO 9920 (1995) e a norma ISO 7730 (2005).

\subsubsection{Variáveis subjetivas}

As variáveis subjetivas consideradas nesta pesquisa foram a percepção e preferência térmica dos ciclistas, identificadas através de questionários aplicados pessoalmente durante os períodos de medição. O levantamento baseou-se nos princípios estabelecidos pela norma ISO 10551 (1995), utilizando critérios de ponto central e escalas de intensidades positivas e/ou negativas.

\footnotetext{
${ }^{9} \mathrm{MET}$ - Taxa metabólica (W/m2), que resulta da conversão de energia química em mecânica e térmica.
} 
Os questionários aplicados foram baseados nos questionários utilizados por Monteiro (2008). A adaptação dos questionários feita pela autora, que objetivou um preenchimento rápido e uma linguagem de fácil compreensão, buscado minimizar o período de interação entre o pesquisador e o ciclista.

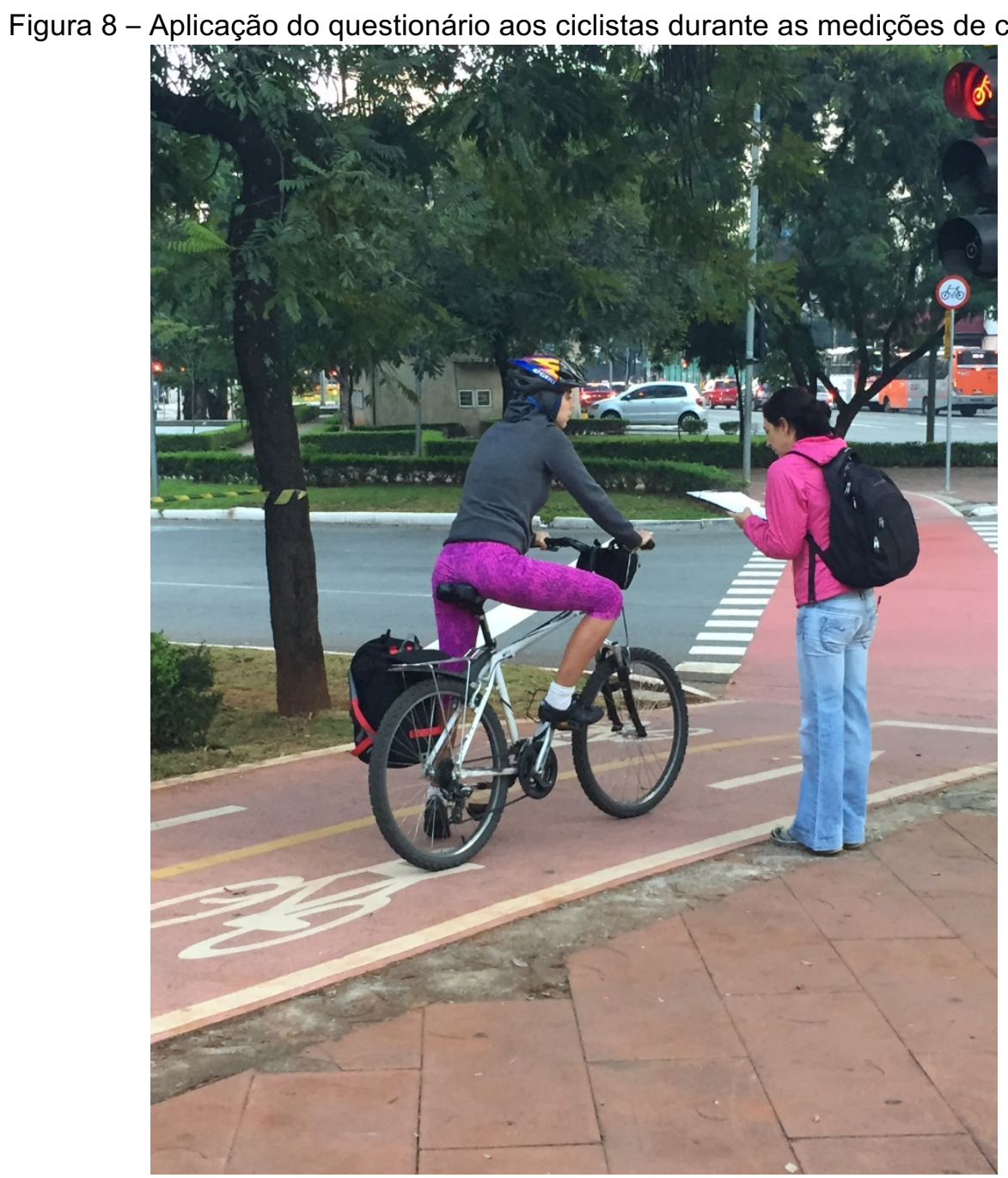

Fonte: a autora, 2017 
Figura 9 - Questionário aplicado aos ciclistas durante as medições de campo

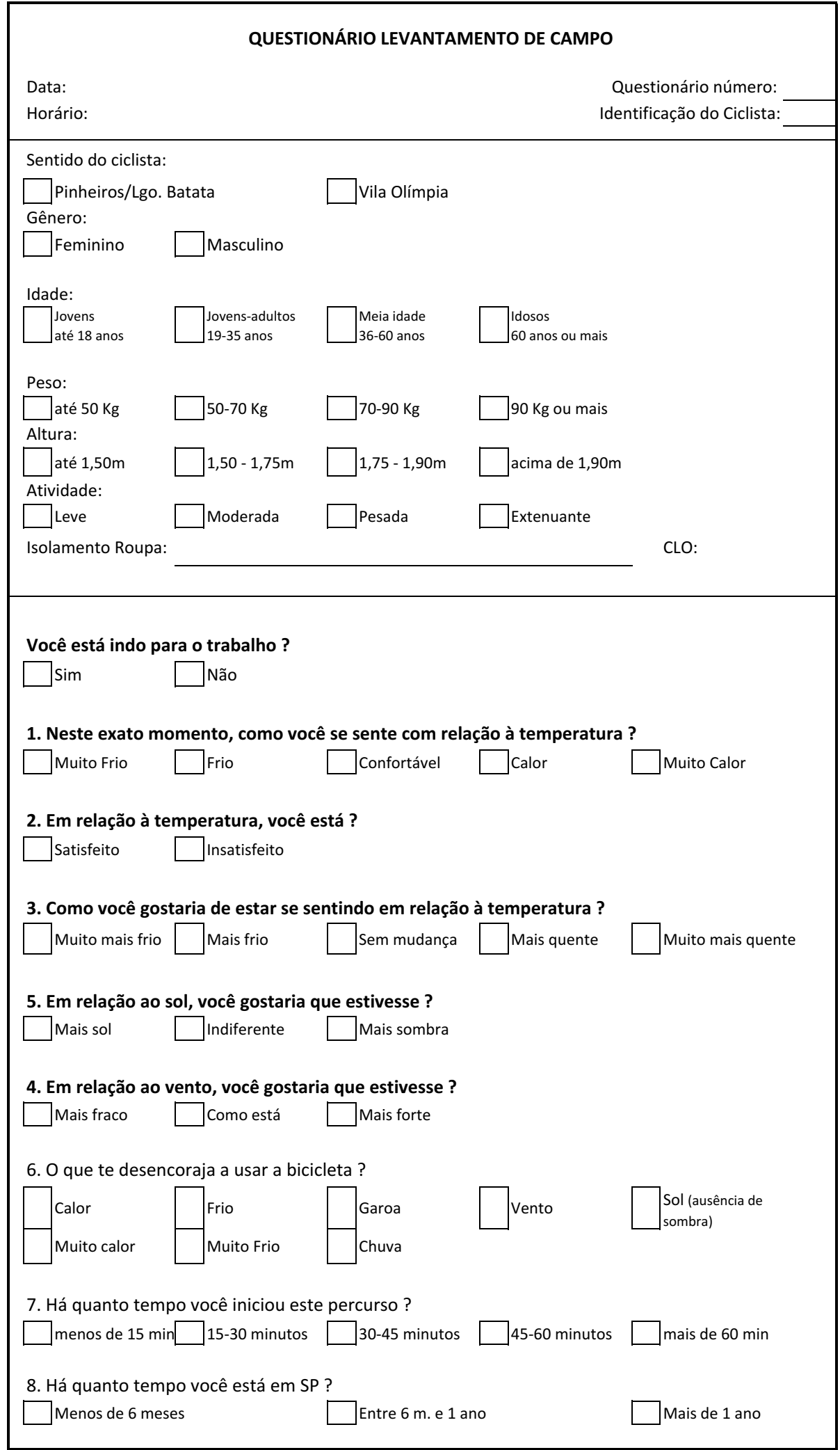

Fonte: a autora. 


\section{TRATAMENTO DOS DADOS SECUNDÁRIOS E PRIMÁRIOS DA PESQUISA}

O tratamento dos dados levantados buscou estabelecer a correlação entre os aspectos ambientais e o fluxo de bicicletas em duas escalas, possibilitando uma análise mais abrangente. As escalas consideradas foram:

a. Centro expandido da cidade de São Paulo, por meio dos dados climáticos de uma Estação Meteorológica e da área de abrangência do sistema de bikesharing ${ }^{10}$;

b. Ciclovia ao longo da Av. Faria Lima, por meio de dados do fluxo de bicicletas contabilizados localmente, assim como pela medição de campo dos aspectos ambientais, realizada pela autora.

\subsection{Dados secundários}

\subsubsection{Considerações iniciais}

A decisão diária pelo uso da bicicleta para ir ao trabalho acontece predominantemente pela manhã, visto que o modo de transporte utilizado na ida ao trabalho tende a ser o mesmo na volta para casa. A análise de dados secundários, e o levantamento de dados primários, foram direcionados para o período de maior fluxo de bicicletas nas manhãs dos dias úteis, entre 6:00 e 10:00.

\subsubsection{Dados climáticos da Estação Meteorológica do IAG ${ }^{11}$}

Os dados de temperatura e umidade relativa do ar foram coletados entre 01 de janeiro de 2016 e 31 de dezembro de 2016, com periodicidade horária. As tabelas com os dados mensais de temperatura e as tabelas com os dados mensais de umidade relativa do ar encontram-se no Anexo $A$.

\footnotetext{
10 Sistema de compartilhamento de bicicletas.

11 Estação Meteorológica do Instituto de Astronomia, Geofísica e Ciências Atmosféricas-IAG da USP, sediada no Parque CIENTEC.
} 
Foram considerados os dados entre as $6: 00$ e as 10:00 horas da manhã, coincidindo com os períodos de coleta dos dados de fluxo de bicicletas. Os dados foram consolidados de forma a obter as seguintes informações:

a. Temperatura do ar às 6:00, 7:00, 8:00, 9:00 e 10:00 horas da manhã;

b. Temperatura média do ar, entre 6:00 e 10:00 horas da manhã;

c. Temperatura do ar, máxima diária;

d. Temperatura do ar, mínima diária;

e. Umidade relativa do ar às 6:00, 7:00, 8:00, 9:00 e 10:00 horas da manhã;

f. Umidade relativa do ar, média diária;

g. Umidade relativa do ar, máxima diária;

h. Umidade relativa do ar, mínima diária;

\subsubsection{Dados sobre o fluxo de bicicletas}

As informações coletadas por meio do sistema de compartilhamento de bicicletas, chamado sistema de bikesharing, BIKE SAMPA foram consolidadas da seguinte forma:

a. Número de viagens feitas ao longo do dia;

b. Número de viagens feitas entre 6:00 e 10:00 horas da manhã.

A coleta de dados com o horário de retirada das bicicletas e o número de percursos realizados por meio do sistema de compartilhamento de bicicletas BIKE SAMPA, que abrange parte do centro expandido de São Paulo, foi feita entre o dia 01 de janeiro e o dia 31 de dezembro do ano de 2016. Os dados entre 7 de maio e 2 de junho estavam indisponíveis por questões técnicas do sistema. As outras informações disponibilizadas, como código do percurso, número, nome e endereço da estação de retirada e da estação de devolução, horário de devolução e duração do percurso foram desconsideradas. As informações sobre o total diário de viagens e sobre o número de viagens feitas entre 6:00 e 10:00 da manhã foram organizadas identificando os sábados, domingos e feriados, permitindo a segregação e consolidação dos dados coletados em dias úteis, objeto principal da pesquisa. A tabela com as referidas informações encontra-se no Apêndice A. 
As informações coletadas por meio do contador de bicicletas da CET SP, instalado na ciclovia da Av. Faria Lima, seguiu o mesmo critério e foi consolidado da seguinte forma:

a. Número de viagens feitas ao longo do dia;

b. Número de viagens feitas entre 6:00 e 10:00 horas da manhã.

Foram considerados os dados entre 01 de janeiro de 2016 e 31 de dezembro de 2016, mas os dados entre 1 e 19 de janeiro estavam indisponíveis, assim como os dados do dia 11 de março.

\subsubsection{Identificação de padrões no fluxo de bicicletas no centro expandido de São Paulo}

Com o objetivo de investigar se os padrões identificados na revisão bibliográfica se repetem no centro expandido da cidade de São Paulo, foram analisados separadamente o fluxo total de bicicletas ao longo do ano, os fluxos predominantemente recreativos e os fluxos funcionais, todos consolidados mensalmente. A análise foi feita considerando os fluxos diários de bicicletas e os fluxos entre as 6:00 e as 10:00 horas da manhã. Os gráficos com estes dados encontram-se no Apêndice B.

Também foram analisados os ciclos diários por meio de amostragem, ao longo do mês de março de 2016. A escolha pela análise dos dados do mês de março se deu por este período não apresentar grande diferença entre o fluxo de ciclistas funcionais e o fluxo de ciclistas recreativos. A análise e discussão destes dados encontram-se no capítulo 5.

\subsubsection{Identificação de padrões no fluxo de bicicletas na ciclovia da Av. Faria Lima}

O levantamento dos dados secundários também foi utilizado para validar a escolha da ciclovia ao longo da Av. Faria Lima para o levantamento dos dados primários. Os gráficos abaixo ilustram o fluxo de bicicletas na ciclovia da Av. Faria Lima, onde foi feito o levantamento de dados primários, com dados do contador 
eletrônico de bicicletas ${ }^{12}$, próximo ao cruzamento da Av. Faria Lima com a rua dos Pinheiros. A ciclovia apresenta caráter misto: Nos dias úteis apresenta maior fluxo de ciclistas entre as 7:00 e 9:30 da manhã e no final da tarde, sugerindo uma concentração de ciclistas em percursos funcionais; Nos finais de semana e feriados, o fluxo é menos concentrado, repetindo os padrões identificados na revisão da literatura para percursos recreativos.

O gráfico com o fluxo de bicicletas nos dias úteis e o gráfico com o fluxo de bicicleta aos sábados, domingos e feriados, ambos com dados de março de 2016, encontram-se no Apêndice $C$.

\subsubsection{Correlações entre dados climáticos e os dados sobre contagem de bicicletas}

A temperatura do ar na cidade de São Paulo entre 6:00 e 10:00 da manhã ao longo do ano de 2016 variou entre $7,5^{\circ} \mathrm{C}$, registrado em junho, e $27^{\circ} \mathrm{C}$, registrado em dezembro. Os dados recebidos da estação meteorológica sobre a temperatura média e a umidade relativa do ar, entre 6:00 e 10:00 da manhã, foram consolidados por hora e pela média do período, assim como pela média diária. Estas informações foram consolidadas mensalmente com as informações referente ao fluxo de bicicletas. As tabelas com os dados consolidados encontram-se no Apêndice $D$.

A correlação entre as variações de temperatura e de fluxo de bicicletas foi investigada por meio de gráficos onde estas informações foram sobrepostas, permitindo uma análise comparativa mensal. A análise destes dados será feita a seguir, no capítulo 5 .

\subsection{Dados primários}

\subsubsection{Considerações iniciais}

Para aprofundar a investigação sobre a correlação entre as variáveis climáticas e o fluxo de bicicletas no centro expandido de São Paulo foi estudada a correlação entre as variáveis microclimáticas em um ponto da ciclovia ao longo da Av. Faria Lima

\footnotetext{
${ }^{12} \mathrm{O}$ contador eletrônico de bicicletas foi instalado pela Companhia de Engenharia de Tráfego de São Paulo
} 
e o fluxo de bicicletas ao longo desta ciclovia. Nesta escala foi possível identificar o impacto das variáveis ambientais e individuais nos ciclistas. Também foi possível avançar no entendimento da percepção e preferência térmica dos ciclistas, fatores que influenciam a decisão diária dos potenciais ciclistas em fazer uso da bicicleta para ir ao trabalho.

O levantamento dos dados primários foi feito nos dias 19, 20, 22 e 23 de junho de 2016 na Av. Faria Lima, no centro expandido de São Paulo, e são divididos em três grupos:

a) Variáveis ambientais: Temperatura média e umidade relativa do ar, velocidade e direção do vento, temperatura radiante média, radiação solar, fator de cobertura do céu e presença de precipitação.

b) Variáveis individuais: Taxa metabólica e resistência térmica da vestimenta.

c) Variáveis subjetivas: Percepção e a preferência térmica dos ciclistas, por meio da aplicação do Índice de Temperatura Equivalente Percebida - TEP.

\subsubsection{Variáveis ambientais}

Os dados obtidos no levantamento primário foram coletados a cada 5 minutos, entre 6:00 e 10:00 da manhã, e passados dos dataloggers para planilhas de excel pelo técnico responsável pelos equipamentos do LabAut. As planilhas com os dados brutos foram tratadas pela autora ajustando unidades, "casas decimais" e periodicidade de coleta entre os dados coletados pelos três dataloggers, objetivando maior uniformidade na leitura das informações. As informações relativas à temperatura e umidade relativa do ar foram utilizadas a partir das planilhas.

As primeiras horas da manhã registraram as temperaturas mais baixas, em torno de 15 graus $C$, e as medições feitas às 10:00 horas da manhã registraram as temperaturas mais altas, entre 17 e $21^{\circ} \mathrm{C}$. A maior variação térmica registrada chegou a $6{ }^{\circ} \mathrm{C}$. no dia 19 de Junho. Não foi registrada presença de precipitação.

A temperatura radiante média, foi obtida por meio da equação descrita abaixo:

$$
\operatorname{Trm}=\{(\operatorname{Tg}+273) 4-[(1,1 \cdot 108 \cdot \operatorname{Var} 0,6) /(\mathrm{g} \cdot \mathrm{D} 0,4)] \cdot(\mathrm{Tg}-\mathrm{Tar})\} 1 / 4-273
$$


Para a equação de Temperatura Radiante Média, considera-se:

Trm: Temperatura radiante média $\left({ }^{\circ} \mathrm{C}\right)$

Tg: Temperatura de globo $\left({ }^{\circ} \mathrm{C}\right)$

Var: Velocidade do ar $(\mathrm{m} / \mathrm{s})$

$\mathrm{g}$ : Emissividade do globo (adimensional)

D: Diâmetro do globo (m)

Tar: Temperatura do $\operatorname{ar}\left({ }^{\circ} \mathrm{C}\right)$

A velocidade do vento não ultrapassou $2,50 \mathrm{~m} / \mathrm{s}$ e em $57 \%$ das medições esteve abaixo de $1 \mathrm{~m} / \mathrm{s}$. Em $30 \%$ das medições, esteve entre 1 e 1,5m/s e apenas em $13 \%$ ficou acima de 1,5m/s. A direção do vento registrada foi variável e inconstante, não foi possível identificar um padrão. A velocidade dos ciclistas varia bastante mas, de forma geral, em áreas planas a maioria da população circula de bicicleta entre os 15 e os 20 $\mathrm{km} / \mathrm{h}$, e uma percentagem mais reduzida circula acima desta velocidade. Para este estudo o padrão de velocidade considerado para o deslocamento dos ciclistas é de $18 \mathrm{~km} / \mathrm{h}$, que é igual a $5,0 \mathrm{~m} / \mathrm{s}$. A velocidade do vento que está sendo considerada é a velocidade média de deslocamento em meio urbano dos ciclistas, por ser significantemente maior do que a velocidade do vento registrada nas medições.

Para o tratamento de dados dos aspectos ambientais, o ideal seria considerar individualmente a velocidade de cada ciclista, possibilitando o cálculo da velocidade que incide individualmente sobre cada bicicleta. Porém, pela impossibilidade de levantamento destes dados, estão sendo consideradas simplificações. A contribuição da velocidade do vento é pequena se comparada à velocidade do vento percebida pelo ciclista, considerada como padrão nos cálculos para o Índice de Temperatura Equivalente Percebida-TEP.

A ciclovia possui trechos sombreados e não sombreados, e o percurso percorrido pelos ciclistas recebe radiação solar de forma inconstante. Neste sentido, não foi possível identificar a diferença entre ciclistas que estão em área sombreada ou ensolarada e a influência da cobertura do céu e da radiação solar sobre os ciclistas não pode ser verificada. A totalidade dos dados brutos levantados em campo encontram-se no apêndice $E$. 


\subsubsection{Variáveis individuais}

A ciclovia ao longo da Av. Faria Lima possui características de uso misto, sendo rota de ciclistas funcionais e de ciclistas recreativos. Como descrito acima, é possível identificar a predominância de usos da ciclovia relacionando os padrões de fluxo de bicicletas e com a revisão da literatura. Durante o período matutino em dias úteis, objeto de estudo desta pesquisa e quando foi feito o levantamento dos dados primários, a ciclovia é predominantemente funcional.

As características identificadas na mostra de usuários da ciclovia nestes períodos, e as entrevistas realizadas no levantamento de campo, nos permitem traçar um perfil para estes ciclistas. Os ciclistas que circularam nos períodos definidos para o levantamento de campo são predominantemente funcionais, visto que mais de $90 \%$ afirmaram que o percurso era para o trabalho, e são predominantemente do sexo masculino, com presença 2,5 vezes maior que a presença de ciclistas mulheres. A grande maioria dos ciclistas é composta por pessoas de meia idade (36 a 60 anos) e por jovens-adultos (19 a 35 anos). Considerando a localização da Avenida Faria Lima, que liga bairros de médio e alto poder aquisitivo, o perfil dos ciclistas tende a ser formado por pessoas que fazem uso da bicicleta como opção aos outros meios de transporte, não pela impossibilidade de arcar com os custos dos mesmos, característica predominante dos ciclistas da cidade de São Paulo, que concentram-se nas áreas periféricas e de baixo poder aquisitivo.

Em relação à vestimenta, $65 \%$ dos ciclistas estavam com roupas casuais, $25 \%$ estavam com roupas esportivas e $10 \%$ com roupas sociais. A resistência térmica da vestimenta, medida pela capacidade de isolamento térmico da roupa e representada pelo índice CLO (clo $=0,155 \mathrm{~m} 2 \mathrm{C} / \mathrm{W}$ ) considera a resistência evaporativa da roupa e o fator de roupa calculados conforme a norma ISO 9920 (1995) e a norma ISO 7730 (2005). A partir da observação das roupas utilizadas pelos ciclistas que passaram pelo local de medição, foram mapeadas as vestimentas utilizadas pelos ciclistas, descritas no Apêndice F. Os dados identificados foram a base para a identificação de padrões de valores CLO a serem utilizados nesta investigação, apresentados na Tabela 8. 
Tabela 8 - Índice de resistência térmica dos ciclistas, consolidado com vestimentas identificadas no levantamento experimental de campo

Índice de resistência térmica consolidado

\begin{tabular}{cl}
\hline Clo 0,4 & $\begin{array}{l}\text { Calcinha e sutiã ou cueca; saia ou bermuda; camiseta; } \\
\text { meia e sapato ou tênis; capacete }\end{array}$ \\
\hline Clo 0,7 & $\begin{array}{l}\text { Calcinha e sutiã ou cueca; saia, bermuda, calça legging, } \\
\text { jeans ou social; camiseta; blusa leve de frio (manga } \\
\text { comprida); meia e sapato ou tênis; capacete e/ou gorro }\end{array}$ \\
\hline Clo 0,9 & $\begin{array}{l}\text { Calcinha e sutiã ou cueca; calça jeans ou social; camiseta; } \\
\text { casaco de frio (manga comprida); meia e sapato ou tênis; } \\
\text { capacete e/ou gorro }\end{array}$ \\
\hline
\end{tabular}

Fonte: a autora

Os valores de taxa metabólica e resistência térmica da roupa, foram definidos por meio da observação e registradas em relatórios fotográficos. De acordo com a norma ISO 8996 (2004) são considerados três níveis de precisão na determinação das taxas metabólicas. Para este estudo, foi definido o nível 2, que define o valor a ser utilizado a partir do nível de intensidade da atividade dos ciclistas. A definição da taxa metabólica para o uso de bicicleta não está descrita na norma e foram adotados os valores de acordo com Ainsworth et al. (2011), como descrito na Tabela 9.

Tabela 9 - Gasto energético estimado para atividades de ciclismo de diferentes intensidades

\begin{tabular}{|c|c|c|c|c|}
\hline Atividade & & Descrição & Velocidade & MET \\
\hline \multirow{6}{*}{ Ciclismo } & \multirow{3}{*}{ Lazer } & $\begin{array}{l}\text { Ida para o trabalho ou por } \\
\text { prazer }\end{array}$ & $<16 \mathrm{~km} / \mathrm{h}$ & 4,0 \\
\hline & & Esforço leve, lento & 16 à 19 km/h & 6,0 \\
\hline & & Esforço moderado & $\begin{array}{c}19,3 \text { à } 22,3 \\
\mathrm{~km} / \mathrm{h}\end{array}$ & 8,0 \\
\hline & \multirow{3}{*}{ Corrida } & Rápido, vigoroso & $\begin{array}{l}22,5 \text { à } 25,5 \\
\mathrm{~km} / \mathrm{h}\end{array}$ & 10,0 \\
\hline & & Muito rápido, corrida em geral & $\begin{array}{l}25,7 \text { à } 30,5 \\
\mathrm{~km} / \mathrm{h}\end{array}$ & 12,0 \\
\hline & & Corrida sem arrasto & $>32 \mathrm{~km} / \mathrm{h}$ & 16,0 \\
\hline
\end{tabular}

Fonte: Ainsworth et al. (2011).

Para o cálculo da taxa metabólica-MET foi considerado o esforço de ciclistas "de lazer" com esforço moderado, e velocidade entre 16 e 19 km/h. Para estes casos, a taxa metabólica resultante é 6,0. 


\subsubsection{Variáveis subjetivas}

Para quantificar as relações entre variáveis microclimáticas e de sensação térmica na área de estudo, foi aplicado o índice de Temperatura Equivalente Percebida-TEP para identificar os valores de temperatura percebidos pelos ciclistas. O índice Temperatura Equivalente Percebida-TEP pode ser entendido como uma escala de sensação térmica que apresenta valores numericamente iguais aos da temperatura do ar de um ambiente de referência (tar=trm, ur=50\% e var $=0$ ), em que se verifica o mesmo valor médio de percepção de sensação térmica que no ambiente em questão (Monteiro, 2008). A preferência térmica dos ciclistas foi identificada por meio de questionários aplicados durante o levantamento de dados primários. $\mathrm{Na}$ equação do índice TEP foram considerados os valores de taxa metabólica, isolamento da roupa, de acordo com a equação descrita abaixo:

$$
\begin{gathered}
\text { TEP }=-29,877+0,4828 \cdot \operatorname{tar}+0,5172 \cdot \operatorname{trm}+0,0802 \cdot \operatorname{ur}-2,322 \cdot \operatorname{var}-\quad-0,1742 \cdot \\
\operatorname{tm}+5,118 \cdot M+38,023 \cdot I c I
\end{gathered}
$$

Para a equação de Temperatura Equivalente Percebida, assumiu-se as seguintes condições para o ambiente de referência:

- Temperatura radiante média: igual à temperatura do ar: $\operatorname{trm}=\operatorname{tar}$

- Velocidade do ar: movimento do ar resultante do deslocamento dos ciclistas, aproximadamente igual a zero: $\operatorname{var}=5,55 \mathrm{~m} / \mathrm{s}$

- Umidade relativa igual a cinquenta por cento: ur $=50 \%$

- Temperatura radiante média foi obtida a partir dos dados de temperatura de globo, temperatura e velocidade do ar, obtidos no levantamento.

O tratamento iconográfico, a análise e discussão dos resultados serão feitos no capítulo seguinte. 


\section{ANÁLISE E DISCUSSÃO DOS RESULTADOS}

\subsection{Considerações iniciais}

Sistemas de mobilidade urbana mais sustentáveis são essenciais na busca por cidades e economias de baixo carbono. A bicicleta possui um papel estratégico neste cenário e as iniciativas de fomento a esta forma de transporte estão cada vez mais presentes. Porém, é importante entendermos quais os aspectos que influenciam a tomada de decisão pelo uso da bicicleta como meio de transporte. As variáveis microclimáticas influenciam, em maior ou menor escala, os usuários de transportes ativos, em especial os ciclistas. As variações na temperatura média do ar e a presença de precipitação são os aspectos mais relevantes e ambos apresentam uma correlação não linear com o fluxo de bicicletas.

A revisão da literatura, com estudos concentrados na Europa, América do Norte e Austrália, apresentou a correlação entre variações climáticas e a frequência no uso da bicicleta. Houve consenso entre os autores sobre um padrão anual no uso da bicicleta, com maior fluxo no verão, menor fluxo no inverno e fluxos crescentes e decrescentes na primavera e outono, respectivamente. Também estava muito presente a diferença entre os padrões de fluxo diário em rotas predominantemente recreativas e em rotas predominantemente funcionais. Nas rotas mistas os dois padrões estavam presentes, o predominantemente recreativo aos finais de semana e feriados e o predominantemente funcional nos dias úteis. Estas hipóteses foram levantadas e investigadas no centro expandido de São Paulo e na ciclovia da Av. Faria Lima.

Na revisão da literatura, os autores mostraram consenso sobre o impacto das variações na temperatura do ar e níveis de precipitação, sendo ambos os aspectos de maior influência no fluxo de bicicletas. Foram identificados efeitos não lineares em ambos os casos, com temperaturas baixas ou altas influenciando negativamente $o$ número de ciclistas. No caso dos índices pluviométricos, a intensidade da chuva apresentou efeitos diferentes sobre os ciclistas. Estas duas hipóteses também foram investigadas em São Paulo, permitindo avaliar a contribuição das diferenças culturais e climáticas de um estudo feito no Brasil, América do Sul.

No centro expandido de São Paulo, objeto desta investigação, é possível observar que o fluxo diário de bicicletas, tanto nos dias úteis como nos finais de 
semana e feriados (chamados dias "não úteis" ou predominantemente recreativos), é mais alto no outono, entre março e maio. As temperaturas mais baixas, registradas em junho, e as temperaturas mais altas, registradas entre dezembro e fevereiro, são acompanhadas de uma redução no número de percursos feitos de bicicleta pelo sistema de compartilhamento de bicicletas que atende a esta região. Também é possível observar uma redução no fluxo de bicicletas ao longo da Av. Faria Lima, porém não é possível afirmar que o volume de bicicletas nas ruas é menor nos períodos de inverno e de verão, porque os meses de janeiro e fevereiro apresentam uma quantidade maior de ciclistas.

Os gráficos que ilustram os fluxos mensais médios, entre 06:00 e 24:00 e entre 06:00 e 10:00, apresentam tendência semelhante. Porém o fluxo entre 06:00 e 10:00 mostra um descolamento entre o fluxo de bicicletas nos dias úteis e o fluxo nos dias não úteis.

Figura 10 - Fluxo mensal médio de bicicletas, entre 06:00 e 24:00.

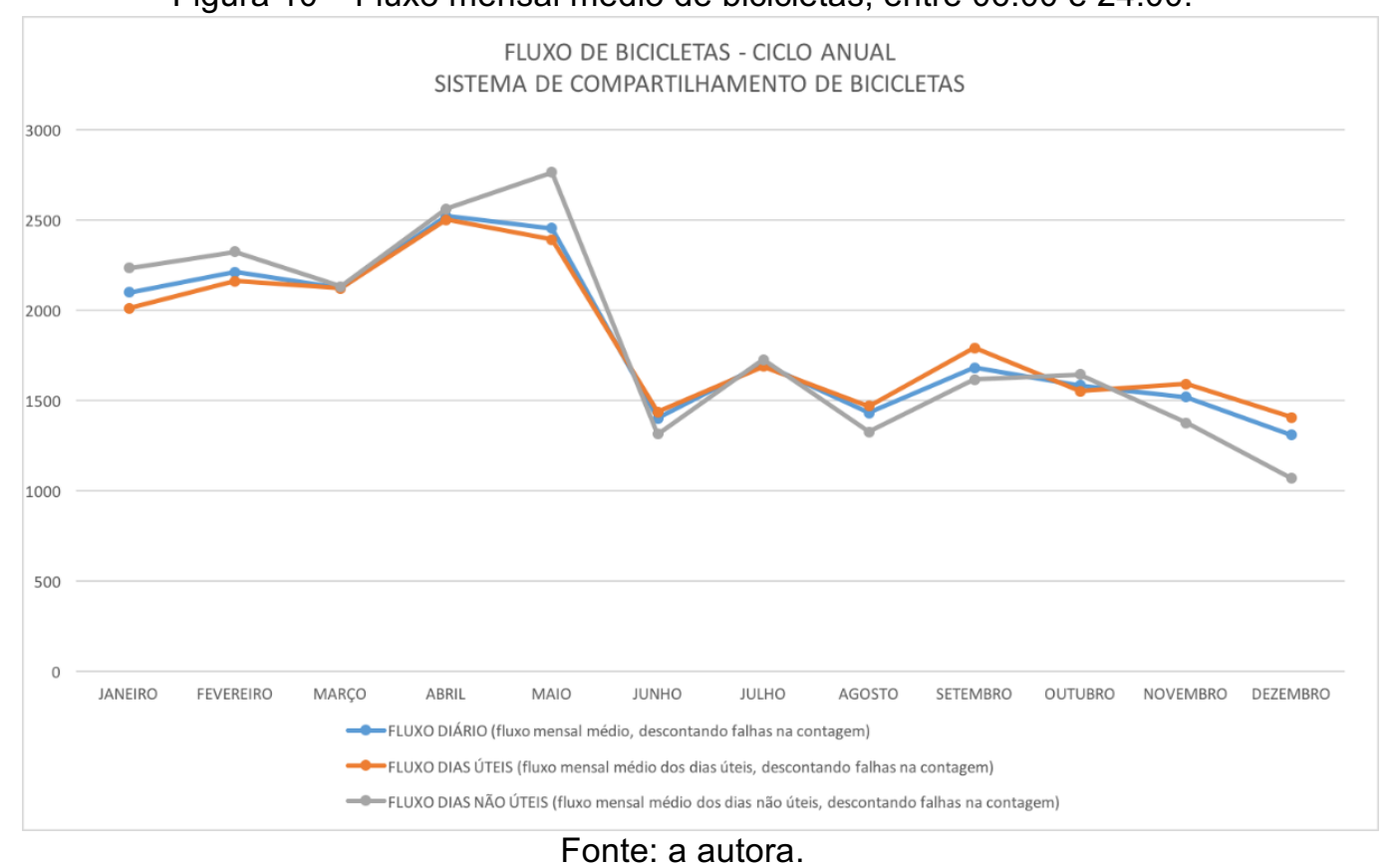

Fonte: a autora.

Os levantamentos secundários mostram que o clima da cidade de São Paulo, entre 6:00hs e 10:00hs, apresenta variabilidade ente as estações do ano, mas não possui períodos proibitivos ao uso da bicicleta em percursos para o trabalho, como mostra a Figura 11. A não ocorrência de temperaturas e sensações térmicas extremas, como neve em períodos mais frios e temperaturas acima de 40 graus nos 
meses mais quentes, mostra que é possível fazer uso da bicicleta para ir ao trabalho ao longo de todo o ano.

Figura 11 - Fluxo mensal médio de bicicletas, entre 6:00 e 10:00am

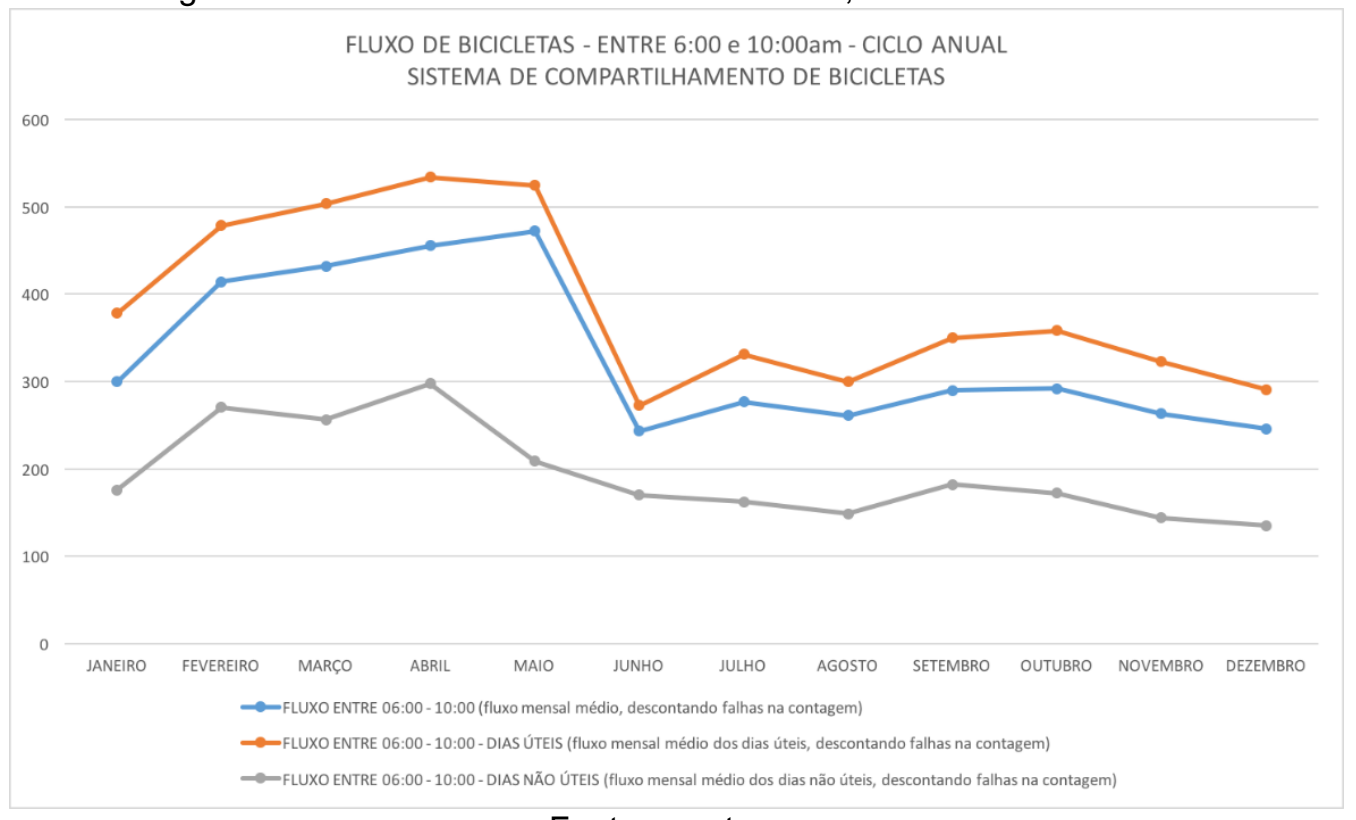

Fonte: a autora.

Ao apresentar índices maiores de fluxo de ciclistas ao longo dos meses com temperatura mais amena, o estudo sugere que o conforto do ciclista é uma das variáveis que influenciam a tomada de decisão pelo uso deste meio de transporte. No verão, o clima pode ser considerado convidativo para percursos ao ar livre, mas parece contribuir negativamente para percursos mais longos, por gerar maior desgaste físico.

Na cidade de São Paulo, durante o verão é mais comum a precipitação ocorrer no período da tarde, reduzindo sua influência na decisão pelo uso da bicicleta nas primeiras horas do dia. Já no inverno, o clima contribui para o menor desgaste físico nos percursos mais longos, mas pode não ser muito convidativo para percursos mais curtos, inclusive pelas condições de vestimenta. As roupas usadas nos dias mais frios em geral não são adequadas para pedalar, e em percursos mais curtos, esta variável pode desencorajar os usuários.

A Pesquisa Perfil de Quem usa bicicleta na cidade de São Paulo (CICLOCIDADE, 2016) aponta que a maioria dos ciclistas entrevistados utiliza a bicicleta como meio de transporte mais de 5 vezes na semana, caracterizando-se como ciclistas urbanos quotidianos, também chamados de ciclistas funcionais. A pesquisa identifica que os deslocamentos são feitos principalmente por pessoas entre 
15 e 44 anos (mais de $80 \%$ ), sendo que metade dos usuários possui entre 25 e 34 anos. A maior parte deles tem baixo poder aquisitivo, ganhando entre 1 e 2 salários mínimos, e tem ensino médio completo. Este quadro está mudando com o aumento de ciclistas na área central da cidade, em sua maioria com ensino superior e ganhando de 3 a 10 salários. Estes dados puderam ser observados no levantamento de campo, cujas características dos ciclistas indicam os pontos salientados pela pesquisa.

\subsection{Análise e discussão}

Na revisão da literatura, foram identificados padrões de variação diária no volume de ciclistas utilitários, com períodos de pico comuns aos outros meios de transporte (AHMED; ROSE; JAKOB, 2010; MIRANDA-MORENO et al., 2014; SMITH; KAUERMANN, 2000; TIN TIN et al., 2012), podendo ser correlacionados com os horários em que uma grande quantidade de pessoas está a caminho ou voltando do trabalho. Ahmed, Rose e Jakob (2010) verificaram que o pico ocorre entre 7:00 e 9:00 e entre 16:00 e 18:00, sendo o primeiro deles mais expressivo. Smith (2000) identificou picos de ciclistas utilitários entre 06:00 e 09:00 e entre 16:00 e 19:00. Tin Tin et al. (2012) identificaram picos entre 7:00 e 8:00 e entre 17:00 e 18:00. A análise de características morfológicas e de uso e ocupação do solo podem indicar quais são as rotas onde predominam os percursos recreativos ou funcionais, ou rotas mistas que concentram os dois tipos de percurso.

Para entender a correlação entre as variações climáticas e o comportamento dos ciclistas que usam a bicicleta na ida ao trabalho, objeto do presente estudo, foram avaliados os fluxos de deslocamentos de bicicleta no período matutino, entre 6:00 e 10:00. Considerando os períodos matutinos de maior fluxo identificados na revisão da literatura, entre 7:30 e 9:30am, a escolha por um período mais abrangente foi feita no intuito de incluir os períodos anteriores e posteriores ao maior volume de ciclistas para, inclusive, confirmar se em São Paulo o período de maior fluxo coincide com os períodos levantados por outras pesquisas.

Foi possível identificar que no centro expandido da cidade de São Paulo, nos dias úteis, os percursos de bicicleta concentram-se no início da manhã, entre 7:30 e 9:30 e no final da tarde, entre 17:00 e 20:00, seguindo a tendência de maior fluxo de veículos. Esta evidência ilustra o possível uso da bicicleta para traslados para o trabalho, com predominância nos horários citados. Aos sábados, domingos e feriados, 
os percursos feitos de bicicleta são distribuídos ao longo do dia, entre 9:00 e 18:00hs, padrão semelhante ao apresentado nos estudos da revisão bibliográfica. A variabilidade do fluxo de ciclistas nos períodos predominantemente recreativos é ligeiramente acentuada, mas não difere do fluxo nos períodos predominantemente funcionais. Sendo possível validar a percepção inicial.

No caso do estudo feito em São Paulo, os ciclos diários foram avaliados ao longo do mês de março de 2016. O consolidado de todas as viagens apresenta uma tendência onde predomina o uso funcional, concentrando o maior número de ciclistas nos horários que concentram o maior número de percursos para e a partir do trabalho, conhecidos como horários de "rush". Quando as viagens nos períodos predominantemente recreativos e predominantemente funcionais são avaliadas separadamente, os padrões das concentrações das viagens ficam mais claros, como ilustrado pelos gráficos a seguir.

As três variações de fluxos estão representadas na Figura 12 abaixo. Foram considerados predominantemente recreativos os percursos de bicicleta feitos aos sábados, domingos e feriados, representados pelas cores alaranjadas, e predominantemente funcionais os percursos feitos nos dias úteis, representados pelas cores azuladas. É possível observar dois padrões diferentes de fluxo de bicicletas ao longo do dia, sendo o fluxo nos dias úteis mais concentrado em horários que concentram traslados para o trabalho, e o fluxo nos dias não úteis mais distribuído.

Figura 12 - Fluxo de bicicletas ao longo de março de 2016

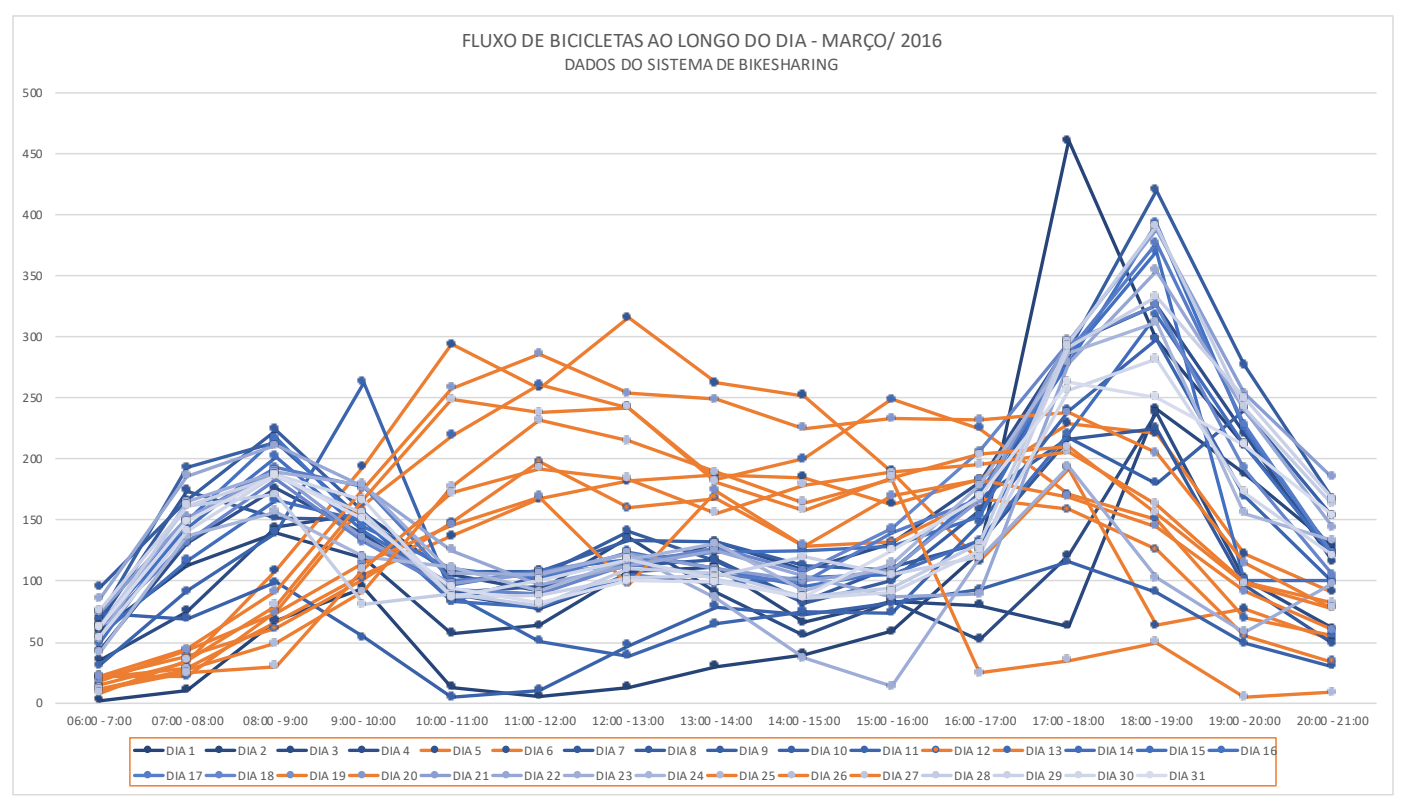


Fonte: a autora.

O gráfico abaixo ilustra como o fluxo de bicicletas está distribuído ao longo do dia aos sábados, domingos e feriados.

Figura 13 - Fluxo de bicicletas aos sábados, domingos e feriados em março de 2016

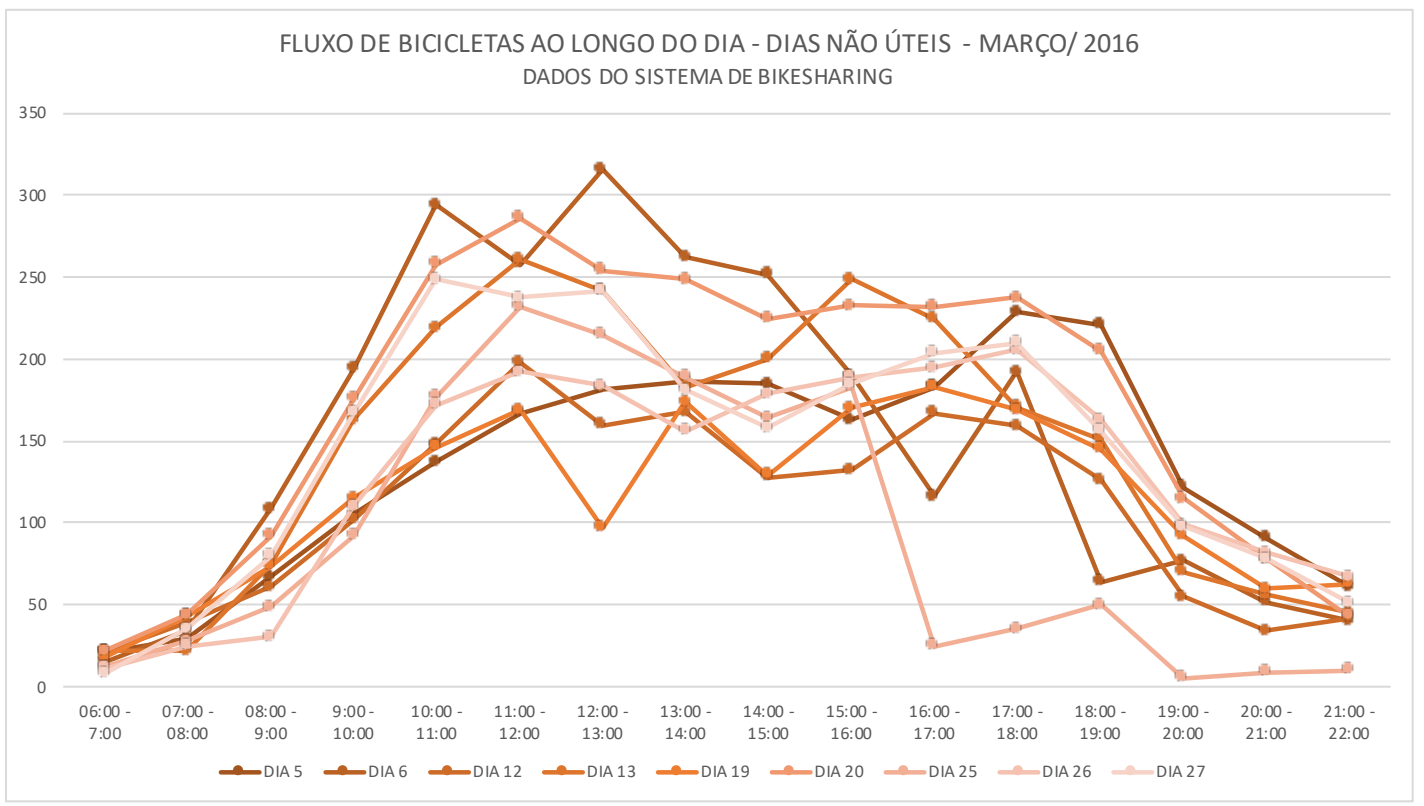

Fonte: a autora.

O gráfico abaixo ilustra como o fluxo de bicicletas está distribuído ao longo dos dias úteis, entre segunda e sexta-feira.

Figura 14 - Fluxo de bicicletas nos dias úteis em março de 2016

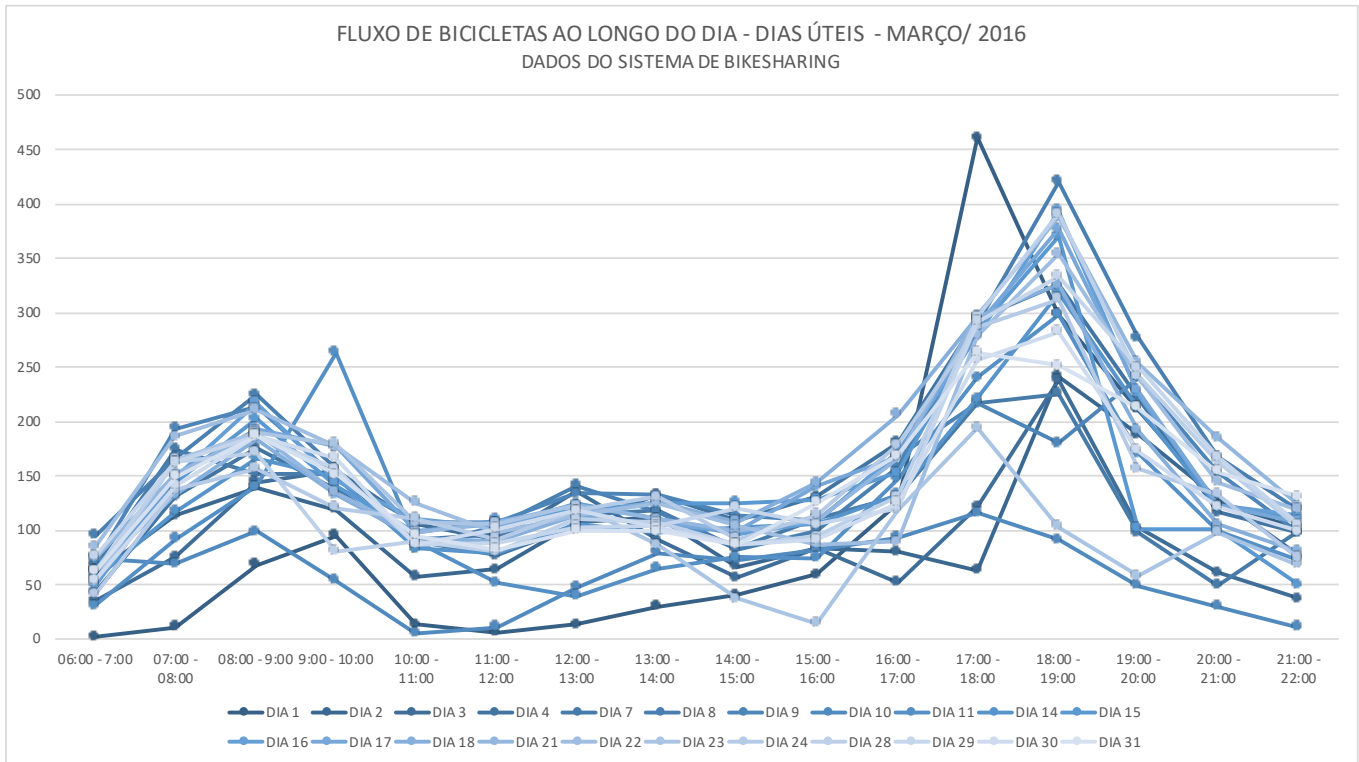

Fonte: a autora. 
A temperatura média na cidade de São Paulo entre 6:00 e 10:00 da manhã ao longo do ano de 2016 variou entre $7,5^{\circ} \mathrm{C}$, registrado em junho, e $27^{\circ} \mathrm{C}$, registrado em dezembro. O gráfico abaixo ilustra a variação da temperatura média entre 6:00 e 10:00 da manhã e sua correlação com o fluxo de bicicletas, ambos consolidados mensalmente.

Figura 15 - Correlação entre fluxo de bicicletas e temperatura média, entre 6:00 e 10:00 em 2016

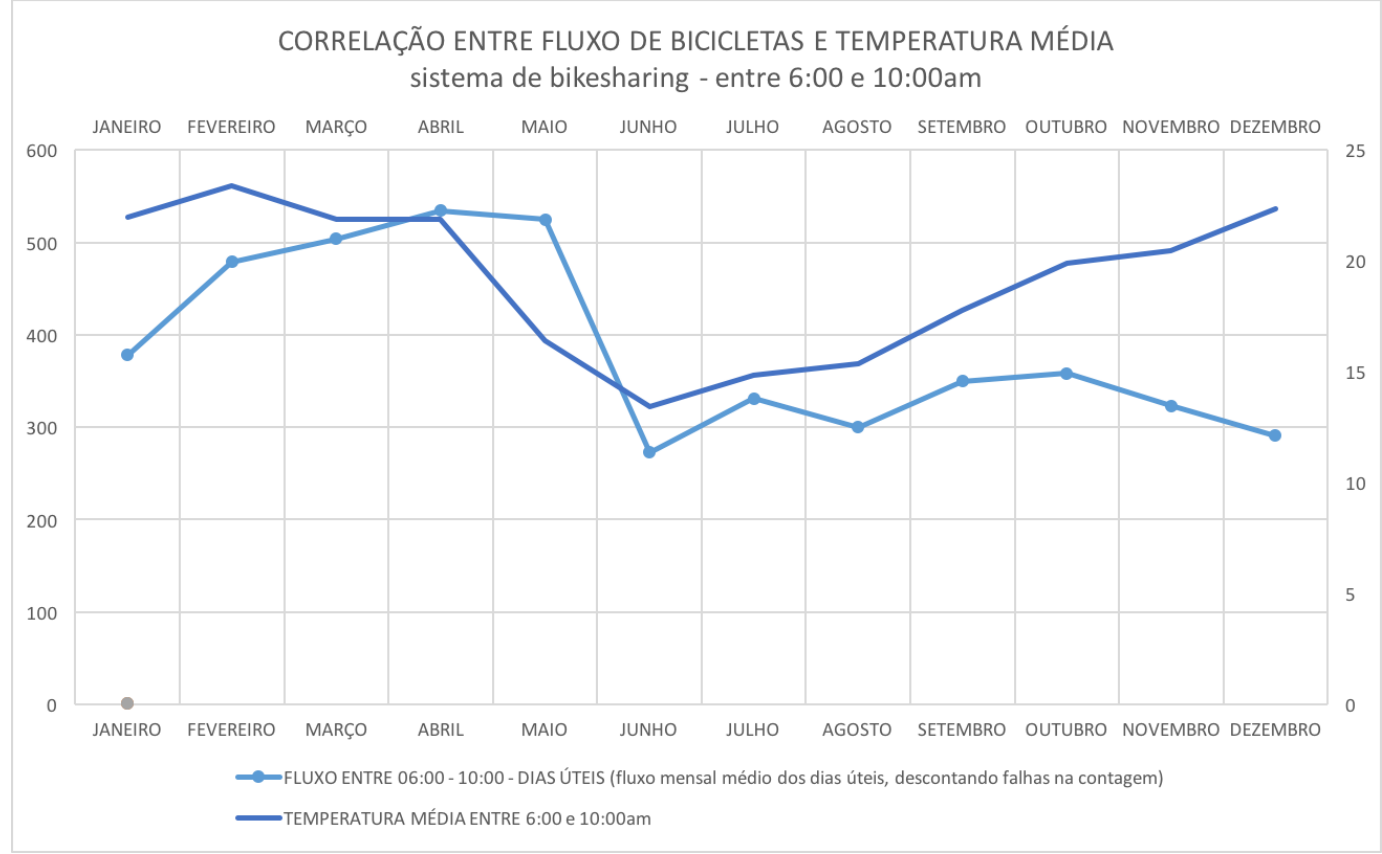

Fonte: a autora.

A queda de temperatura no outono e início do inverno é acompanhada por uma redução no fluxo de bicicletas e o aumento da temperatura na primavera é acompanhada por um aumento no fluxo de bicicletas. O verão, que apresenta temperaturas mais altas, indica que a correlação não é linear e o gráfico mostra um descolamento das curvas que indicam a temperatura e o fluxo de bicicletas. Os dados levantados na presente pesquisa vão de encontro com as informações pesquisadas na revisão bibliográfica e indicam que aspectos culturais e de infraestrutura podem influenciar o percentual total do número de ciclistas, quando comparado a outros modais de transporte, mas os aspectos ambientais e de conforto térmico parecem influenciar os ciclistas de forma semelhante ao redor do mundo.

Considerando as variáveis subjetivas de percepção e preferência térmica dos ciclistas na tomada de decisão pelo uso da bicicleta, foi aplicado o índice de Temperatura Equivalente Percebida-TEP para identificar os valores de temperatura percebidos pelos ciclistas e investigar a influência dos mesmos na tomada de decisão 
pelo uso da bicicleta como meio de transporte. Durante o levantamento de campo, a temperatura média do ar ficou entre 16,0 e $19,1^{\circ} \mathrm{C}$ e a Temperatura Equivalente Percebida ficou entre 24,2 e $43,3^{\circ} \mathrm{C}$, mostrando a influência das variáveis individuais, como a taxa metabólica e a resistência térmica da roupa, na sensação de conforto térmico dos ciclistas. Os cálculos estão descritos no Apêndice G.

Durante o levantamento de campo, feito na ciclovia ao longo da Av. Faria Lima, os questionários aplicados aos ciclistas incluíram questões sobre sensação térmica e preferência térmica. As informações levantadas foram confrontadas com os valores das faixas interpretativas da Temperatura Equivalente Percebida-TEP, descritos abaixo:

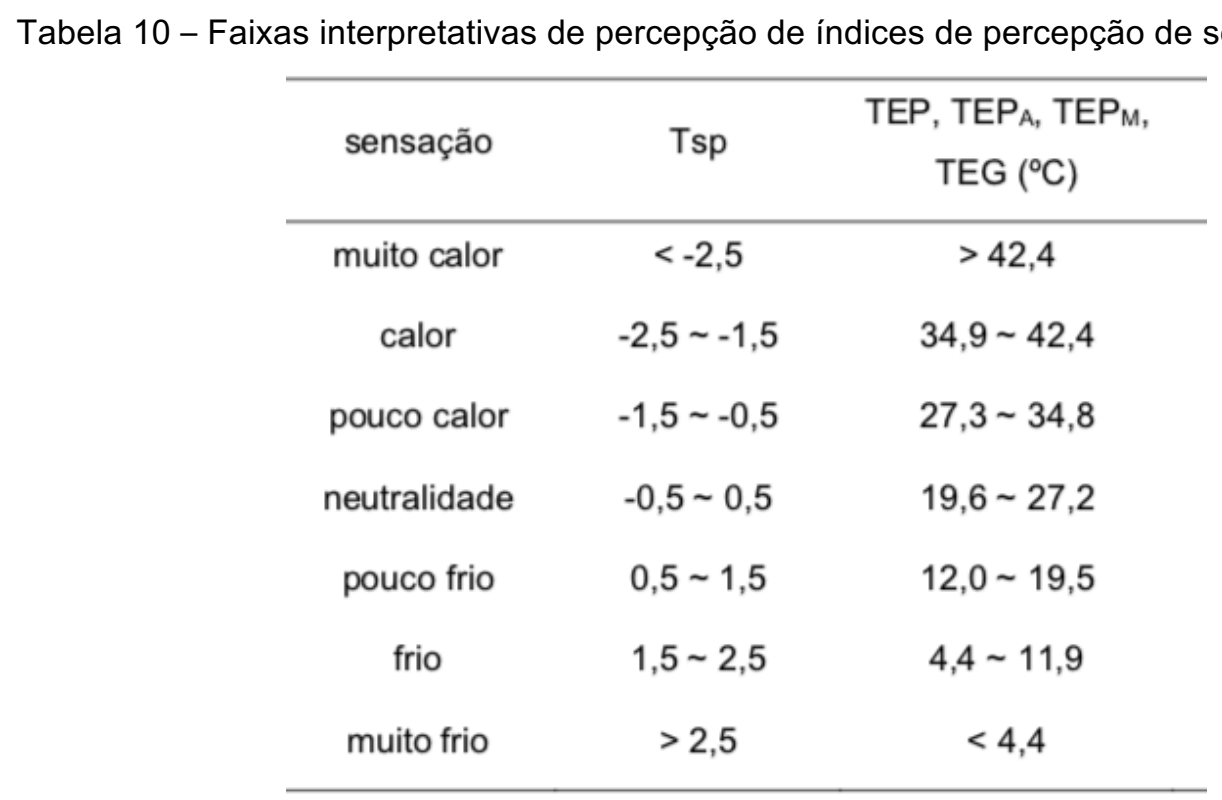

Fonte: adaptado de Monteiro (2018).

O cálculo da Temperatura Equivalente Percebida - TEP, quando relacionado com a faixa interpretativa deste índice não mostra uma correlação clara com as respostas concedidas pelos ciclistas sobre a percepção térmica e nível de satisfação em relação a ela. O número de questionários aplicados nesta pesquisa não é suficiente para uma conclusão acerca do tema, mas pode ser considerado uma primeira aproximação. A correlação entre as informações citadas encontra-se na tabela abaixo e os questionários aplicados aos ciclistas encontram-se no Apêndice $\mathrm{H}$. 
Tabela 11 - Temperatura Equivalente Percebida, faixas interpretativas e respostas dos questionários aplicados aos ciclistas no levantamento de campo

\begin{tabular}{|c|c|c|c|c|c|}
\hline & & TEP & $\begin{array}{c}\text { Faixas interpretativas do índice de } \\
\text { Temperatura Equivalente Percebida - TEP }\end{array}$ & $\begin{array}{l}\text { Questionário aplicado aos cic } \\
\text { Como se sente em relação a } \\
\text { temperatura? }\end{array}$ & $\begin{array}{c}\text { stas no levantamento de campo: } \\
\text { Em relação à temperatura, você } \\
\text { está? }\end{array}$ \\
\hline \multirow{13}{*}{ 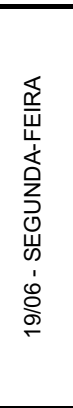 } & Ciclista 01 & 43,11 & muito calor & neutralidade & satisfeito \\
\hline & Ciclista 02 & 35,50 & calor & neutralidade & satisfeito \\
\hline & Ciclista 03 & 24,20 & neutralidade & neutralidade & satisfeito \\
\hline & Ciclista 04 & 35,85 & calor & neutralidade & satisfeito \\
\hline & Ciclista 05 & 35,85 & calor & neutralidade & satisfeito \\
\hline & Ciclista 06 & 35,72 & calor & frio & insatisfeito \\
\hline & Ciclista 07 & 24,31 & neutralidade & frio & satisfeito \\
\hline & Ciclista 08 & 36,25 & calor & neutralidade & satisfeito \\
\hline & Ciclista 09 & 24,85 & neutralidade & neutralidade & satisfeito \\
\hline & Ciclista 10 & 25,05 & neutralidade & neutralidade & satisfeito \\
\hline & Ciclista 11 & 36,46 & calor & neutralidade & satisfeito \\
\hline & Ciclista 12 & 25,20 & neutralidade & frio & insatisfeito \\
\hline & Ciclista 13 & 25,38 & neutralidade & neutralidade & satisfeito \\
\hline \multirow{6}{*}{ 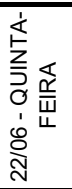 } & Ciclista 14 & 35,08 & calor & frio & satisfeito \\
\hline & Ciclista 15 & 35,08 & calor & frio & satisfeito \\
\hline & Ciclista 16 & 35,08 & calor & neutralidade & satisfeito \\
\hline & Ciclista 17 & 35,32 & calor & frio & satisfeito \\
\hline & Ciclista 18 & 35,32 & calor & neutralidade & satisfeito \\
\hline & Ciclista 19 & 39,37 & calor & frio & insatisfeito \\
\hline \multirow{6}{*}{ 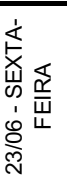 } & Ciclista 20 & 35,73 & calor & neutralidade & satisfeito \\
\hline & Ciclista 21 & 43,33 & muito calor & frio & satisfeito \\
\hline & Ciclista 22 & 35,96 & calor & neutralidade & satisfeito \\
\hline & Ciclista 23 & 35,44 & calor & muito frio & insatisfeito \\
\hline & Ciclista 24 & 43,04 & muito calor & neutralidade & satisfeito \\
\hline & Ciclista 25 & 43,33 & muito calor & frio & satisfeito \\
\hline
\end{tabular}

Fonte: a autora.

O conforto e a sensação térmica das pessoas não são temas muito presentes nas discussões cotidianas e os ciclistas apresentaram certa dificuldade em responder às questões relativas ao tema. Apesar dos aspectos relacionados ao conforto térmico influenciarem as atitudes e estarem presentes no cotidiano de todos, não raro passam despercebidos como fatores relevantes na decisão das pessoas sobre sua permanência em locais abertos ou na forma de se locomover pela cidade. A dificuldade dos ciclistas entrevistados nesta pesquisa em interpretar a própria sensação de conforto/desconforto térmico, em outras palavras sua aceitabilidade ao microclima onde está inserido, pode ter contribuído com um desvio nos dados apresentados.

Outro fator a ser considerado é a taxa metabólica dos ciclistas. Os valoreslimite da taxa metabólica levantados empiricamente para o estabelecimento do índice TEP foram entre 1,3 e 2,5 e os valores da taxa metabólica dos ciclistas entrevistados nesta pesquisa estão em torno de 6 . O uso do índice TEP para ciclistas é uma extrapolação e o alto valor da taxa metabólica pode ser uma das razões para a aplicação do índice TEP não apresentar uma correlação significativa com as respostas dos questionários aplicados aos ciclistas, levando ao entendimento de que a aplicação deste índice a ciclistas não é adequada. 
Tabela 12 - Valores-limite de taxa metabólica para o índice TEP

\begin{tabular}{ccccc}
\hline $\mathbf{M}$ [met] & $\begin{array}{c}\text { valor mínimo } \\
\text { observado }\end{array}$ & $\begin{array}{c}\text { valor médio } \\
\text { mínimo }\end{array}$ & $\begin{array}{c}\text { valor médio } \\
\text { máximo }\end{array}$ & $\begin{array}{c}\text { valor máximo } \\
\text { observado }\end{array}$ \\
\hline Cidade Universitária & 1,3 & 1,3 & 1,3 & 1,3 \\
Bairro da Luz & 1,0 & 1,2 & 2,5 & 5,8 \\
Avenida Paulista & 1,0 & 1,2 & 2,3 & 5,8 \\
\hline
\end{tabular}

Fonte: Monteiro, 2018.

\subsection{Análise qualitativa do levantamento de campo}

Durante o levantamento de campo, feito em dias úteis e durante o período com maior fluxo de ciclistas funcionais (entre 6:00 e 10:00 da manhã), os ciclistas que estavam parados, dando passagem aos carros foram questionados sobre a influência das variáveis ambientais como fator de decisão para o uso da bicicleta em seus traslados. Para a maioria dos ciclistas entrevistados, a variável ambiental não foi considerada um fator significativo. A revisão bibliográfica aponta para o mesmo sentido, considerando que os ciclistas recreativos sofrem maior influência das variáveis ambientais.

Os ciclistas entrevistados citaram como maiores impeditivos para pedalar a chuva forte e temperaturas muito quentes, sendo a primeira delas a mais citada. Mas alguns ciclistas afirmaram pedalar "em qualquer condição climática", inclusive sob chuva. As temperaturas mais baixas se mostraram um fator que reduz o fluxo de bicicletas. Apesar deste aspecto não ter sido muito citado, é importante salientar que os ciclistas entrevistados estavam sob esta condição, ou seja eram pessoas prédispostas a pedalar sob temperaturas mais baixas.

De acordo com os ciclistas entrevistados, o metabolismo do exercício físico ajuda no conforto térmico durante os dias de frio. As variáveis ambientais que incomodam mais os ciclistas são muito calor e chuva, que são "menos administráveis" com roupas. Considerando que em São Paulo as situações de frio intenso correspondem a um frio ameno, esta variável aparece com menor relevância.

Interessante notar que em condições mais frias, houve uma mudança no comportamento dos ciclistas, que não paravam no sinal vermelho e se mostravam menos acessíveis para responder ao questionário. Ciclistas em atividade "pesada" ou 
"extenuante" não param no sinal vermelho, impossibilitando a entrevista (nenhum deles respondeu ao questionário).

Nas entrevistas a predominância de pessoas em traslado para o trabalho foi confirmada. Esta informação reforça uma impressão visual dos entrevistadores, que identificaram inúmeros ciclistas com bicicletas equipadas para as atividades diárias, com cadeiras para levar crianças, porta-bagagens, malas acopladas à bicicleta, entre outros.

\subsection{Considerações finais}

A revisão da literatura aponta que as variáveis microclimáticas influenciam, em maior ou menor escala, os ciclistas. Em cidades de clima temperado úmido ou temperado frio, as variações na temperatura média do ar e a presença de precipitação foram identificadas como os aspectos ambientais mais relevantes, apresentando uma correlação não linear com o fluxo de bicicletas. Este foi o ponto de partida para a presente pesquisa, cuja contribuição faz reflexões sobre estas correlações considerando o clima brasileiro e a cultura e os hábitos de habitantes de São Paulo.

Considerando o impacto ambiental dos meios de transporte nos centros urbanos, em especial pelo uso dos automóveis, é evidente a necessidade de uma mudança disruptiva na forma como os habitantes dos grandes centros urbanos se locomovem. Impactos ambientais, como a geração de poluição do ar e a emissão de gases de efeito estufa, possuem forte correlação com questões de saúde pública, visto que a má qualidade do ar nos centros urbanos, e as doenças decorrentes dela, respondem por uma em cada 8 mortes no mundo. $O$ impacto econômico na saúde pública e decorrente do tempo gasto em congestionamentos também é relevante e reforçam a necessidade da busca por sistemas de mobilidade urbana mais sustentáveis.

Pesquisas evidenciam o potencial da cidade de São Paulo em promover mudanças em seu sistema de mobilidade urbana. Do total de viagens realizadas de ônibus, $9 \%$ são pedaláveis ${ }^{13}$ e $22 \%$ são facilmente pedaláveis ${ }^{14}$. Entre as viagens de automóvel, $10 \%$ são pedaláveis e $33 \%$ são facilmente pedaláveis. Neste cenário, fica

\footnotetext{
${ }^{13}$ Viagens pedaláveis: são aquelas de até $8 \mathrm{~km}$, realizadas entre $6 \mathrm{~h}$ e $20 \mathrm{~h}$, por pessoas com até 50 anos.

${ }^{14}$ Viagens facilmente pedaláveis: são aquelas de até $5 \mathrm{~km}$, realizadas entre $6 \mathrm{~h}$ e $20 \mathrm{~h}$, por pessoas com até 50 anos.
} 
evidente a contribuição da bicicleta na transição para um sistema de transporte urbano mais sustentável. O uso da bicicleta como meio de transporte pode ser usado para traslados mais curtos ou estar aliado a outros meios de transporte para vencer distâncias maiores, aumentando a área de abrangência de estações modais de grande fluxo, como estações de metrô, trem ou terminais de ônibus.

O incentivo ao transporte ativo para vencer deslocamentos nos centros urbanos está cada vez mais presente nas políticas públicas e legislações. Porém, as cidades brasileiras, e em especial São Paulo, ainda não possuem a infraestrutura necessária para garantir a segurança dos ciclistas. Além da segurança, aspectos relacionados à cultura e hábitos devem ser considerados. A presente pesquisa conclui que os aspectos ambientais e de conforto térmico dos ciclistas aparecem com um dos fatores a serem considerados no incentivo ao uso deste meio de transporte para percursos regulares, como traslados para e a partir do trabalho. A pesquisa contribui com o entendimento da influência destes aspectos na tomada de decisão dos potenciais ciclistas, considerando este tema ainda é pouco explorado.

Durante o período de levantamento dos dados climáticos da cidade de São Paulo, ao longo do ano de 2016, não foram registradas temperaturas extremas, as variações de temperatura média registradas durante o período desta pesquisa foram de $7,5^{\circ} \mathrm{C}$ em junho à $27^{\circ} \mathrm{C}$ em dezembro. Também não foram registradas ocorrências com alto impacto sobre ciclistas, como neve ou intensas rajadas de vento, consequentemente o microclima urbano não foi identificado como um dos principais fatores na decisão por este meio de transporte. A análise permitiu a identificação de uma correlação entre as variáveis climáticas e microclimáticas, o conforto térmico dos ciclistas e o impacto na decisão do ciclista pelo uso da bicicleta, por meio do cruzamento dos dados ambientais e do fluxo de bicicletas.

Os meses de março, abril e maio apresentaram a maior concentração de ciclistas, indicando o outono como o período do ano que concentra o maior fluxo de ciclistas, porém não é possível afirmar que existe um padrão de ciclo anual, visto que a análise foi feita apenas ao longo do ano de 2016. A variação no fluxo entre os ciclistas recreativos apresentou maior variação, se comparado ao fluxo dos ciclistas funcionais, de acordo com o que foi levantado na revisão da literatura. Os períodos que apresentaram o menor fluxo de ciclistas foram os meses de junho, agosto e dezembro. 
O fluxo de ciclistas funcionais em dias úteis apresentou um padrão, concentrando-se no início da manhã, entre 7:30 e 9:30 e no final da tarde, entre 17:00 e 20:00, seguindo a tendência de maior fluxo de veículos automotores. Aos finais de semana e feriados os percursos feitos de bicicleta são distribuídos ao longo do dia, entre 9:00 e 18:00hs, mas apresentam uma tendência de concentrarem-se no período da manhã, entre 8:00am e 13:00pm.

Analisando separadamente os períodos entre 6:00am e 10:00am dos dias úteis, foi identificada a tendência apresentada anteriormente, onde os meses de junho, julho, agosto, dezembro e janeiro apresentam os menores fluxos de bicicletas. Estes períodos também apresentaram as maiores variações de temperatura média ao longo do ano de 2016 , chegando a $7,5^{\circ} \mathrm{C}$ em junho e $27^{\circ} \mathrm{C}$ em dezembro.

Os ciclistas entrevistados afirmaram de forma geral que as condições climáticas não são um dos aspectos mais relevantes para a tomada de decisão para fazer uso da bicicleta em seus traslados. O levantamento de dados secundários e primários indica que é possível identificar uma correlação não linear entre as variações de temperatura média do ar, e consequentemente o conforto dos ciclistas, e o fluxo de bicicletas entre 7:30am e 9:30am, horário em que predominam os ciclistas funcionais, reforçando a hipótese de que existe uma correlação entre as variáveis climáticas e o fluxo de bicicletas no centro expandido da Cidade de São Paulo. 


\section{CONCLUSÕES}

A presente pesquisa investigou a influência das condições climáticas e o conforto térmico dos ciclistas na tomada de decisão pelo uso da bicicleta como meio de transporte no percurso para o trabalho. Foi possível identificar uma correlação entre variáveis climáticas e microclimáticas e a tomada de decisão pelo uso da bicicleta como meio de transporte no percurso para o trabalho, tanto na revisão da literatura, como no levantamento dos dados secundários, na escala do centro expandido da cidade, e dos dados primários, com as medições de campo realizadas na ciclovia ao longo da Avenida Faria Lima, na cidade de São Paulo. Porém, o impacto do microclima urbano, e do consequente conforto/desconforto térmico do ciclista, não podem ser considerados um dos principais fatores decisórios pelo uso da bicicleta como meio de transporte no percurso para o trabalho no centro expandido da cidade de São Paulo.

Em cidades de clima temperado úmido ou temperado frio, as variações na temperatura média do ar e a presença de precipitação foram identificadas como os aspectos ambientais mais relevantes, apresentando uma correlação não linear com o fluxo de bicicletas. A presente pesquisa, desenvolvida na cidade de São Paulo não identificaou o registro de temperaturas extremas ao longo do ano de 2016, período de levantamento da pesquisa. As variações de temperatura média registradas foram de $7,5^{\circ} \mathrm{C}$ em junho à $27^{\circ} \mathrm{C}$ em dezembro. Também não foram identificadas ocorrências com alto impacto sobre ciclistas, como neve ou intensas rajadas de vento.

As condições de conforto térmico da cidade de São Paulo são enfrentadas pelos ciclistas com a adequação das roupas, o que diminui a influência do microclima sobre o fluxo de bicicletas em rotas predominantemente funcionais. As temperaturas menos severas, presentes na primavera e outono tendem a influenciar positivamente o uso da bicicleta para ir ao trabalho, os períodos que apresentaram o menor fluxo de ciclistas foram os meses de junho, agosto e dezembro.

O Índice de Temperatura Equivalente Percebida - TEP desenvolvido e aplicado para pontos fixos (pedestres) com alta capacidade preditiva, foi aplicado aos ciclistas, mas neste caso não foi identificada uma correlação significativa entre sua faixa interpretativa e as respostas concedidas pelos ciclistas sobre a percepção térmica. A extrapolação proposta, de fazer uso do índice TEP para ciclistas, não apresentou boa capacidade preditiva. A presente pesquisa sugere que o uso do índice TEP não é 
indicado para ciclistas, uma provável razão é o alto valor da taxa metabólica dos ciclistas e o fato do índice TEP ter sido desenvolvido para pedestres realizando atividades com baixa taxa metabólica. Considerando o presente estudo como uma aproximação ao tema no contexto brasileiro, são levantadas algumas possibilidades para pesquisas futuras. O levantamento de campo da presente pesquisa foi feito no inverno, e futuras pesquisas podem fazer um levantamento de campo mais abrangente na cidade de São Paulo, em diferentes estações do ano, incluindo medições no verão, primavera e outono e aumentando o número de questionários aplicados aos ciclistas. Outra possibilidade é a verificação da correlação proposta em outros centros urbanos brasileiros com diferentes climas. Pesquisas futuras podem propor investigações por períodos mais longos, buscando identificar padrões anuais de fluxo de ciclistas, e eventuais diferenças de fluxo ao longo dos anos.

Para aplicar o índice de Temperatura Equivalente Percebida - TEP a ciclistas, seria necessário adaptar a equação ou avaliar a possibilidade de montar um índice específico para ciclistas, com melhor capacidade preditiva. 


\section{REFERÊNCIAS}

AAHEIM, H.; HAUGE, K. Impacts of Climate Change on Travel Habits: A National Assessment Based on Individual Choices. Cicero Report, n. 7, Aug. 2005.

AHMED, F. et al. Commuter cyclist travel behavior. Transportation Research Record: Journal of the Transportation Research Board, n. 2387, p. 76-82, 2013.

AHMED, F. et al. Commuter cyclists sensitivity to changes in weather: Insights from two cities with different climatic conditions. In: ANNUAL MEETING OF THE TRANSPORTATION RESEARCH BOARD, 91., 2012, Washington. Proceedings... Washington: TRB, 2012.

AHMED, F.; ROSE, G.; JAKOB, C. Examining the impact of changes in weather on commuter cyclist's travel behavior. In: ANNUAL MEETING OF THE TRANSPORTATION RESEARCH BOARD, 92., 2013, Washington. Proceedings... Washington: TRB, 2012.

AHMED, F.; ROSE, G.; JAKOB, C. Impact of weather on commuter cyclist behaviour and implications for climate change adaptation. In: AUSTRALASIAN TRANSPORT RESEARCH FORUM, 33., 2010, Camberra. Proceedings... Camberra: ATRF, 2010.

AINSWORTH, B. E. et al. Compendium of Physical Activities: A Second Update of Codes and MET Values. Medical Science Sports Exerc., v. 43, n. 8, p. 1575-1581, 2011.

AMIRI, M., SADEGHPOUR, F. Factors affecting cycling patterns in cold weather. In: INTERNATIONAL CONFERENCE ON SUSTAINABLE DESIGN AND CONSTRUCTION, 2012, Fort Worth. Proceedings... Fort Worth: ASCE, 2013, p. 222229.

AMIRI, M.; SADEGHPOUR, F. Cycling characteristics in cities with cold weather. Sustainable Cities and Society, v. 14, n. 1, p. 397-403, 2015.

BERGSTROM, A., MAGNUSSON, R. Potential of transferring car trips to bicycle during winter. Transportation Research, Part A: Policy and Practice, v. 37, p. 649666, 2003.

BOCKER, L.; DIJST M.; PRILLWITZ, J. Impact of everyday weather on individual daily travel behaviours in perspective: A literature review. Transport Reviews, v. 33, n. 1, p. 71-91, 2013.

BOCKER, L.; PRILLWITZ, J.; DIJST, M. Climate change impacts on mode choices and travelled distances: a comparison of present with 2050 weather conditions for the Randstad Holland. Journal of Transport Geography, v. 28, p. 176-185, 2013.

BOCKER, L.; DIJST, M. FABER, J. Weather, transport mode choices and emotional travel experiences. Transportation Research, Part A: Policy and Practice, v. 94, p. 360-373, 2016. 
BOCKER, L. et al. Em-route weather and place valuations for different transport mode users. Holanda: Faculty of Geosciences, Utrecht University, 2014b.

BOCKER, L.; THORSSON, S. Integrated weather effects on cycling shares, frequencies, and durations in Rotterdam, the Netherlands. Weather, Climate and Society, 6 (4). American Meteorological Society, 2014a.

BOTMA, H.; PAPENDRECHT, H. Trafic Operation of Bicycle Trafic. Transportation Research Record, v. 1320, p. 65-72, 1991.

BRANDENBURG, C.; MATZARAKIS, A.; ARNBERGER, A. The effects of weather on frequencies of use by commuting and recreation bicyclists. In: Matzarakis, $A$., de Freitas, C.R., Scott, D. (Eds.), Advances in Tourism Climatology. Berichte des Meteorologischen Instituts der Universität Freiburg, Freiburg, pp. 189-197, 2004

BRANDENBURG, C.; MATZARAKIS, A.; ARNBERGER, A. Weather and cycling: a first approach to the effects of weather conditions on cycling. Meteorological Applications, v. 14, p. 61-67, 2007.

BRASIL. Ministério das Cidades. Política nacional de mobilidade urbana sustentável. Cadernos MCidades Mobilidade. Brasília: MCID, 2004.

BRASIL. Ministério das Cidades. Secretaria Nacional de Transporte e da Mobilidade Urbana. PlanMob Construindo a Cidade Sustentável: Caderno de Referencia para elaboração de Plano de Mobilidade Urbana. Brasília: MCID, 2007.

BRASIL. Ministério das Cidades. Secretaria Nacional de Transporte e da Mobilidade Urbana. Programa Brasileiro de Mobilidade por Bicicleta - Bicicleta Brasil. Caderno de referência para elaboração de Plano de Mobilidade por Bicicleta nas Cidades. Brasília: MCID, 2007.

BRASIL. Decreto-Lei N ${ }^{\circ}$ 12.587, de 3 de janeiro de 2012. Lex: Política Nacional de Mobilidade Urbana - PNMU. Ed. federal. Brasília: Planalto, 2012.

BROWN, R. D.; GILLESPIE, T. J. Microclimatic Landscape Design: creating thermal comfort and energy efficiency. New York: John Wiley \& Sons, 1995.

COMPANHIA DE TECNOLOGIA DE SANEAMENTO AMBIENTAL (CETESB).

Relatório de qualidade do ar no Estado de São Paulo. São Paulo: CETESB, 2008.

CICLOCIDADE. Pesquisa Perfil de Quem usa bicicleta na cidade de São Paulo. 2016. Disponível em: <https://www.ciclocidade.org.br/noticias/809-pesquisa-perfil-dequem-usa-bicicleta-na-cidade-de-sao-paulo-relatorio-completo>. Acesso em: 01 mar. 2017.

CLIFTON, K., CHEN, R. Representing weather in travel behaviour models: A case study from Sydney, AUS. In: AUSTRALASIAN TRANSPORT RESEARCH FORUM, 2011, 34., Adelaide. Proceedings... Adelaide: ATRF, 2011. 
COMISSÃO EUROPEIA. Cidades para Bicicletas, Cidades de Futuro. Luxemburgo: Serviço das Publicações Oficiais das Comunidades Europeias, 2000.

CORCORAN, J. et al. Spatio-temporal patterns of a Public Bicycle Sharing Program: the effect of weather and calendar events. Jornal of Transport Geography, 41, pp.292-305, 2014.

EL-ASSI, W.; MAHMOUD, M. S.; HABIB, K. N. Effects of built environment and weather on bike sharing demand: a station level analysis of commercial bike sharing in Toronto. Transportation, v. 44, n. 3, p. 589-613, 2017.

EMMERSON, P.; RYLEY, T. J.; DAVIES, D. G. The impact of weather on cycle flows. Traffic Engineering and Control, v. 39, n. 4, p. 238-243, Apr. 1998.

ENGBERS, L. H.; HENDRIKSEN, I. J. M. Characteristics of a population of commuter cyclists in the Netherlands: perceived barriers and facilitators in the personal, social and physical environment. International Journal of Behavioral Nutrition and Physical Activity, v. 7, n. 89, 2010.

FLYNN, B. S. et al. Weather factor impacts on commuting to work by bicycle.

Preventive Medicine, v. 54, p. 122-124, 2012.

GAETE, C. M. Ranking Copenhagenize2013: As 20 cidades mais bem preparadas para o ciclismo urbano. Arch Daily. 27 maio 2013. Disponível em:

<https://www.archdaily.com.br/br/01-116484/ranking-copenhagenize2013-as-20-

cidades-mais-bem-preparadas-para-o-ciclismo-urbano>. Acesso em: 01 mar. 2019.

GALLOP, C.; TSE, C. A seasonal autoregressive model of Vancouver bicycle traffic using weather variables. In: TRANSPORTATION RESEARCH BOARD CONFERENCE, 91., 2012, Washington. Proceedings... Washington: TRB, 2012.

GEBHART, K.; NOLAND, R. B. The impact of weather conditions on capital bikeshare trips. In: TRANSPORTATION RESEARCH BOARD CONFERENCE, 93., 2013, Washington. Proceedings... Washington: TRB, 2013.

HANSON, S.; HANSON, P. Evaluating the impact of weather on bicycle use. Transportation Research Record, v. 629, p. 43-48, 1977.

HEINEN, E.; MATT, K.; VAN WEE, B. Day-to-day choice to commute or not by bicycle. Transportation Research Record, v. 2230, p. 9-18, 2011.

HEINEN, E.; VAN WEE, B.; MAAT, K. Commuting by bicycle: an overview of the literature. Transport Reviews 30 (1), 59-96, 2010 não é citado, por isso não deve constar nas referências.

HELBICH, M.; BOCKER, L.; DJIST, M. Geographic heterogeneity in cycling under various weather conditions: Evidence from Greater Rotterdam. Journal of Transport Geography, v. 38, p. 38-47, 2014. 
INSTITUTO DE ENERGIA E MEIO AMBIENTE. A bicicleta e as cidades: como inserir a bicicleta na política de mobilidade urbana. São Paulo: Instituto de Energia e Meio Ambiente, 2010.

INTERNATIONAL ORGANIZATION FOR STANDARDIZATION. ISO 10551. Ergonomics of the thermal environment: assessment of the influence of the thermal environment using subjective judgement scales. Genève: ISO, 1995.

INTERNATIONAL ORGANIZATION FOR STANDARDIZATION. ISO 7726. Ergonomics of the thermal environment: Instruments for measuring physical quantities. Genève: ISO, 1998.

INTERNATIONAL ORGANIZATION FOR STANDARDIZATION. ISO $\mathbf{7 7 3 0 .}$ Ergonomics of the thermal environment: Analytical determination and interpretation of termal comfort using calculation of the PMV and PPD índices and local termal comfort criteria. Genève: ISO, 2005.

INTERNATIONAL ORGANIZATION FOR STANDARDIZATION. ISO 7933. Ergonomics of the thermal environment: Analytical determination and interpretation of heat stress using calculation of the predicted heat strain. Genève: ISO, 1995.

INTERNATIONAL ORGANIZATION FOR STANDARDIZATION. ISO 8996. Ergonomics of the thermal environment: Determination of metabolic rate. Genève: ISO, 2004.

INTERNATIONAL ORGANIZATION FOR STANDARDIZATION. ISO $\mathbf{9 9 2 0 .}$ Ergonomics of the thermal environment: Estimation of the thermal insulation and evaporative resistance of a clothing ensemble. Genève: ISO, 2007.

LIU, C.; SUSILO, Y. O.; KARLSTRÖM, A. The influence of weather characteristics variability on individual's travel mode choice in different seasons and regions in Sweden. Transport Policy, v. 41, p. 147-158, July 2015.

LOPES, B. C. M. et al. Adaptação de métodos para análise de conforto térmico em ciclovias: estudo exploratório em Campinas/SP/Brasil. In: CONGRESSO LUSOBRASILEIRO DE PLANEAMENTO URBANO, REGIONAL E INTEGRAÇÃO SUSTENTÁVEL,6., 2014, Lisboa. Anais... Lisboa: Pluris, 2014.

MATHISEN, T.; ANNEMA, J.; KROESEN, M. The effects of weather and climate change on cycling in Northern Norway. European Journal of Transport and Infrastructure Research, v. 15, n. 2, 2015.

MENG, M. et al. Effect of weather conditions and weather forecast on cycling travel behavior in Singapore. International Journal of Sustainable Transportation, v. 10, n. 9, p. 773-780, 2016.

MIRANDA-MORENO, L. F.; NOSAL, T. Weather or not to cycle: Temporal trends and impact of weather on cycling in an urban environment. Transportation Research Record: Journal of the Transportation Research Record, v. 2247, p. 42-52, 2011. 
MIRANDA-MORENO, L. F. et al. Classification of bicycle traffic patterns in five North American Cities. Transp. Research Record, v. 2339, n. 1, 2014.

MONTEIRO, L. M. Conforto térmico em espaços urbanos abertos: verificações modelares como aportes à exploração de abordagens. 2018. Tese (Livre Docência em Tecnologia da Arquitetura) - Faculdade de Arquitetura e Urbanismo, Universidade de São Paulo, São Paulo, 2018.

MONTEIRO, L. M. Modelos Preditivos de conforto térmico: Quantificação de relações entre variáveis microclimáticas e de sensação térmica para avaliação e projeto de espaços abertos. 2008. Tese (Doutorado em Tecnologia da Arquitetura) Faculdade de Arquitetura e Urbanismo, Universidade de São Paulo, São Paulo, 2008.

MONTEIRO, L. M., ALUCCI, M. P. Modelo Adaptativo de conforto para avaliação in loco de espaços urbanos abertos. Ambiente Construído, Porto Alegre, v. 12, n. 1, p. 61-79, jan./mar. 2012.

MONTEIRO, L. M., ALUCCI, M. P. Procedimentos de quantificação de variáveis para análise termo-fisiológica em espaços abertos. In: ENCONTRO LATINO-AMERICANO SOBRE CONFORTO NO AMBIENTE CONSTRUÍDO, 8., 2005, Maceió. Anais... Maceió: ENCAC, 2005.

MOTOAKI, Y.; DAZIANO, R. A. A hybrid-choice latent-class model for the analysis of the effects of weather on cycling demand. Transportation Research, Part A: Policy and Practice, v. 75, p. 217-230, 2015.

NANKERVIS, M. The effect of weather and climate on bicycle commuting. Transportation Research, Part A: Policy and Practice, v. 33, n. 6, p. 417-431, 1999.

NOSAL, T.; MIRANDA-MORENO, L. F. The effect of weather on the use of North American bicycle facilities: A multi-city analysis using automatic counts. Transportation Research, Part A: Policy and Practice, v. 66, n. 1, p. 213-225, 2014.

PARKIN, J.; WARDMAN, M.; PAGE, M. Estimation of the determinants of bicycle mode share for the journey to work using census data. Transportation, v. 35, n. 1, p. 93109, 2008.

PHUNG, J.; ROSE, G. Temporal variations in usage of Melbourne"s bike paths. In: AUSTRALASIAN TRANSPORT RESEARCH FORUM, 30., 2007, Melbourne. Proceedings... Melbourne: ATRF, 2007. p. 25-27 [CD ROM].

PUCHER, J.; BUEHLER, R. Cycling for Everyone: Lessons from Europe. Transportation Research Record: Journal of the Transportation Research Board, Washington, v. 2074, p. 58-65, $2008 \mathrm{~b}$.

PUCHER, J.; BUEHLER, R. Making cycling irresistible: lessons from the Netherlands, Denmark and Germany, Transport Reviews, 28(4), pp. 495-528, 2008a. 
PUCHER, J.; BUEHLER, R. Why Canadians cycle more than Americans: a comparative analysis of bicycling trends and policies, Transport Policy, 13(3), pp. 265-279, 2006

RICHARDSON, A. J. Seasonal and weather impacts on urban cycling trips. TUTI Report, Victoria, v. 1, 2000.

ROGERS, R.; GUMUCHDJIAN, P. Cities for a small planet. Londres: Westview Press, 2001.

SABIR, M. Weather and travel behaviour. Amsterdam: Research Series, Vrije Universiteit, 2011.

SAELENS, B. E.; SALLIS, J. F.; FRANK, L. D. Environmental correlates of walking and cycling: findings from the transportation, urban design and planning literatures. Ann Behav Med, v. 25, p. 80-91, 2003.

SALLES, J. ONU elegeu a bicicleta como o transporte ecologicamente mais sustentável do planeta. Jornal Oeste, 26 out. 2010. Disponível em:

http://www.jornaloeste.com.br/noticias/exibir.asp?id=12877\&noticia=onu_elegeu_a_b icicleta_como_o_transporte_ecologicamente_mais_sustentavel_do_planeta

SANEINEJAD, S.; KENNEDY, C.; ROORDA, M. Modeling the Impact of Weather on Active Transportation. Lisboa: paper Presented at the 12th WCTR, 2010 não foi citado, por isso não deve constar nas referências.

SANEINEJAD, S.; ROORDA, M. J.; KENNEDY, C. Modelling the impact of weather conditions on active transportation travel behaviour. Transportation Research, Part D: Transport and Environment, v. 17, n. 2, p. 129-137, 2012.

SEARS, J. et al. To bike or not to bike: seasonal factors for bicycle commuting. Transportation Research Record, v. 2314, p. 105-111, 2012.

SÃO PAULO (Município). Secretaria Municipal de Transportes. PlanMob/SP 2015: Plano de Mobilidade de São Paulo. São Paulo: SMT, 2015.

SILVEIRA, M.; MAIA, M. Variáveis que influenciam no uso da bicicleta e as crenças da teoria do comportamento planejado. Transportes, v. 23, n. 1, p. 24-36, 2015.

SMITH, M. S.; KAUERMANN, G. Bicycle commuting in Melbourne during the 2000s energy crisis: A semiparametric analysis of intraday volumes. Transportation Research, Part B, v. 45, p.1846-1862, 2011.

SPENSER, P.; WATTS, R.; VIVANCO, L.; FLYNN, B. The effect of environmental factors on bicycle commuters in Vermont: Influences of a northern climate. Journal of Transport Geography 31, pp.11-1, 2013.

THOMAS, T.; JAARSMA, R.; TUTERT, B. Exploring temporal fluctuations of daily cycling demand on Dutch cycle paths: the influence of weather on cycling. Transportation, v. 40, n. 1, p. 1-22, 2013. 
THOMAS, T.; JAARSMA, R.; TUTERT, B. Temporal Variations of Bicycle Demand in the Netherlands: Influence of Weather on Cycling. In: TRANSPORTATION RESEARCH BOARD ANNUAL MEETING, 88., 2009, Washington. Proceedings... Washington: TRB, 2009.

TIN TIN, S. et al. Temporal, seasonal and weather effects on cycle volume: an ecological study. Environmental Health: A Global Access Science Source, v. 11, n. 12, 2012.

TORRES-FREIRE, C.; CALLIL, V.; CASTELLO, G. Impacto social do uso da bicicleta em São Paulo. São Paulo: Cebrap, 2018.

VALE, D. S. A cidade e a bicicleta: uma leitura analítica. Finisterra, n. 103, Lisboa, dez. 2016.

WADUD, Z. Cycling in a changed climate. Journal of Transport Geography, v. 35, p. 12-20, 2013.

WARDMAN, M.; TIGHT, M.; PAGE, M. Factors influencing the propensity to cycle to work. Transportation Research, Part A, v. 41, n. 4, p. 339-350, 2007.

WINTERS, M. et al. Motivators and deterrents of bicycling: Comparing influences on decisions to ride. Transportation, v. 38, n. 1, p. 153-168, 2011.

WINTERS, M. et al. Utilitarian bicycling a multilevel analysis of climate and personal influences. American Journal of Preventive Medicine, v. 32, n. 1, p. 52-58, 2007.

WITTINK, R. Cycling and the climate agenda. Netherlands: Interface for Cycling Expertise, 2010.

Sites:

GOOGLE. São Paulo. Google Earth. [Imagens extraídas do software]. 2017

GOOGLE. São Paulo. Google Earth. [Imagens extraídas do software]. 2019 
ANEXOS

Anexo A - Tabelas com os dados mensais de temperatura e umidade relativa do ar 


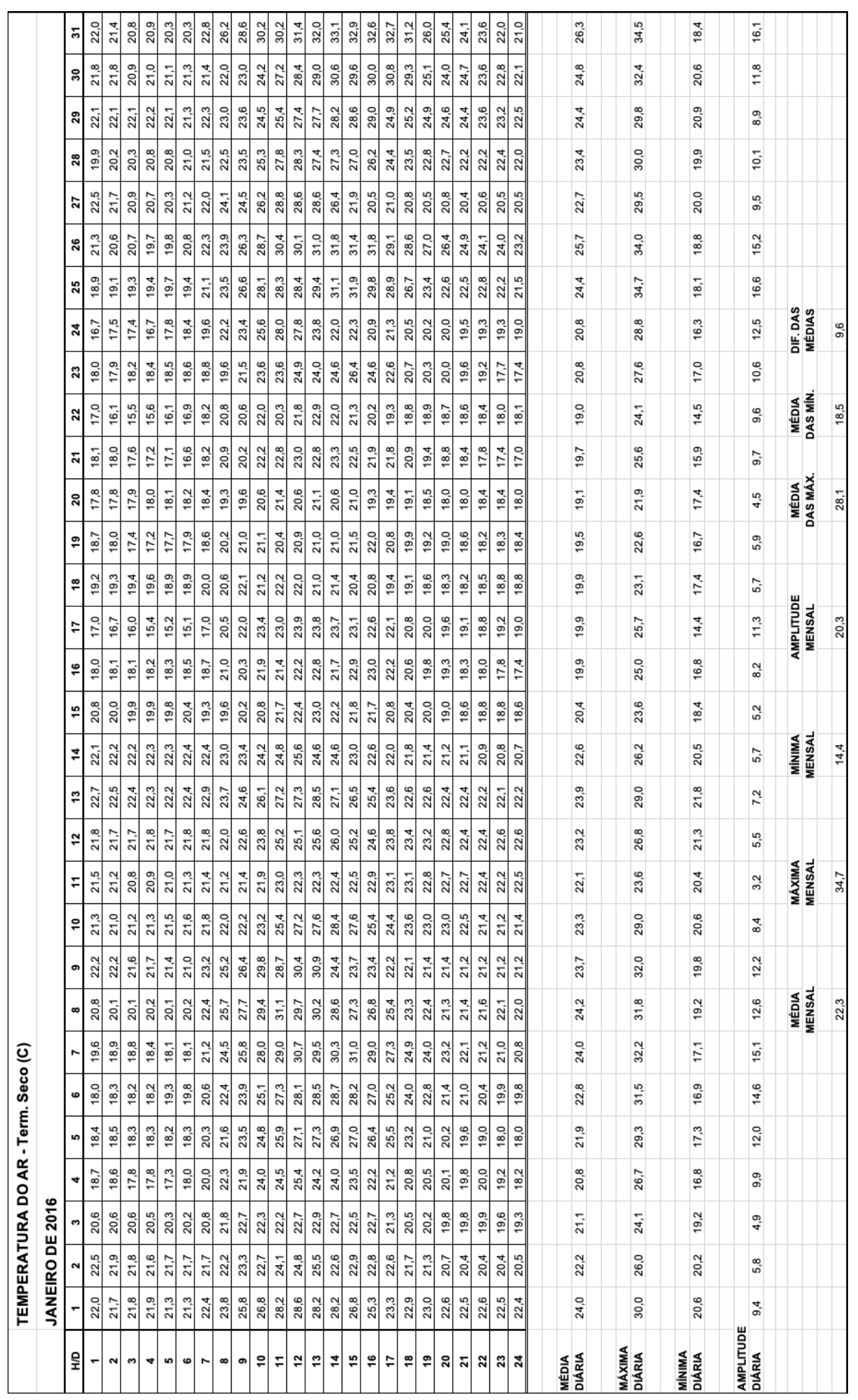




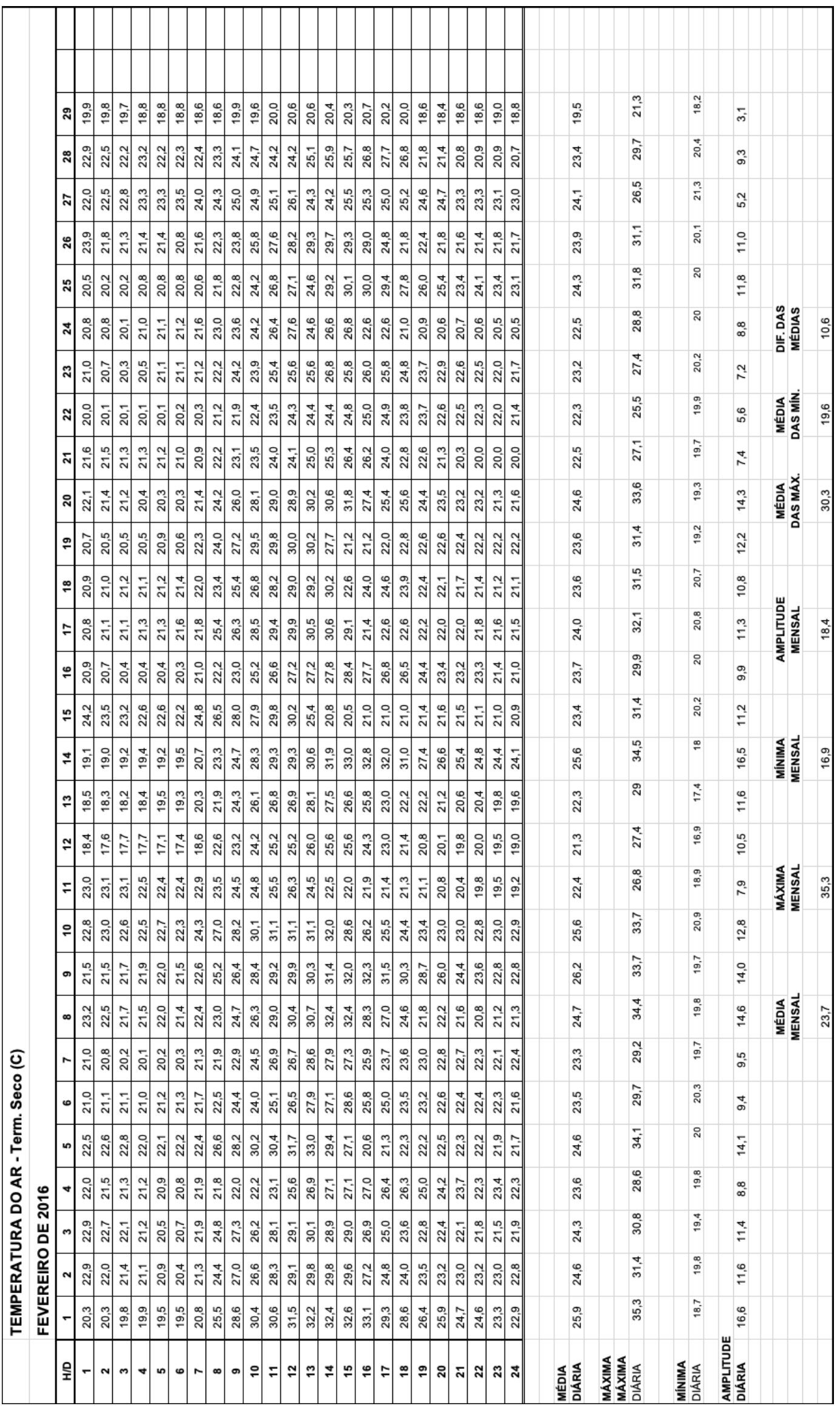




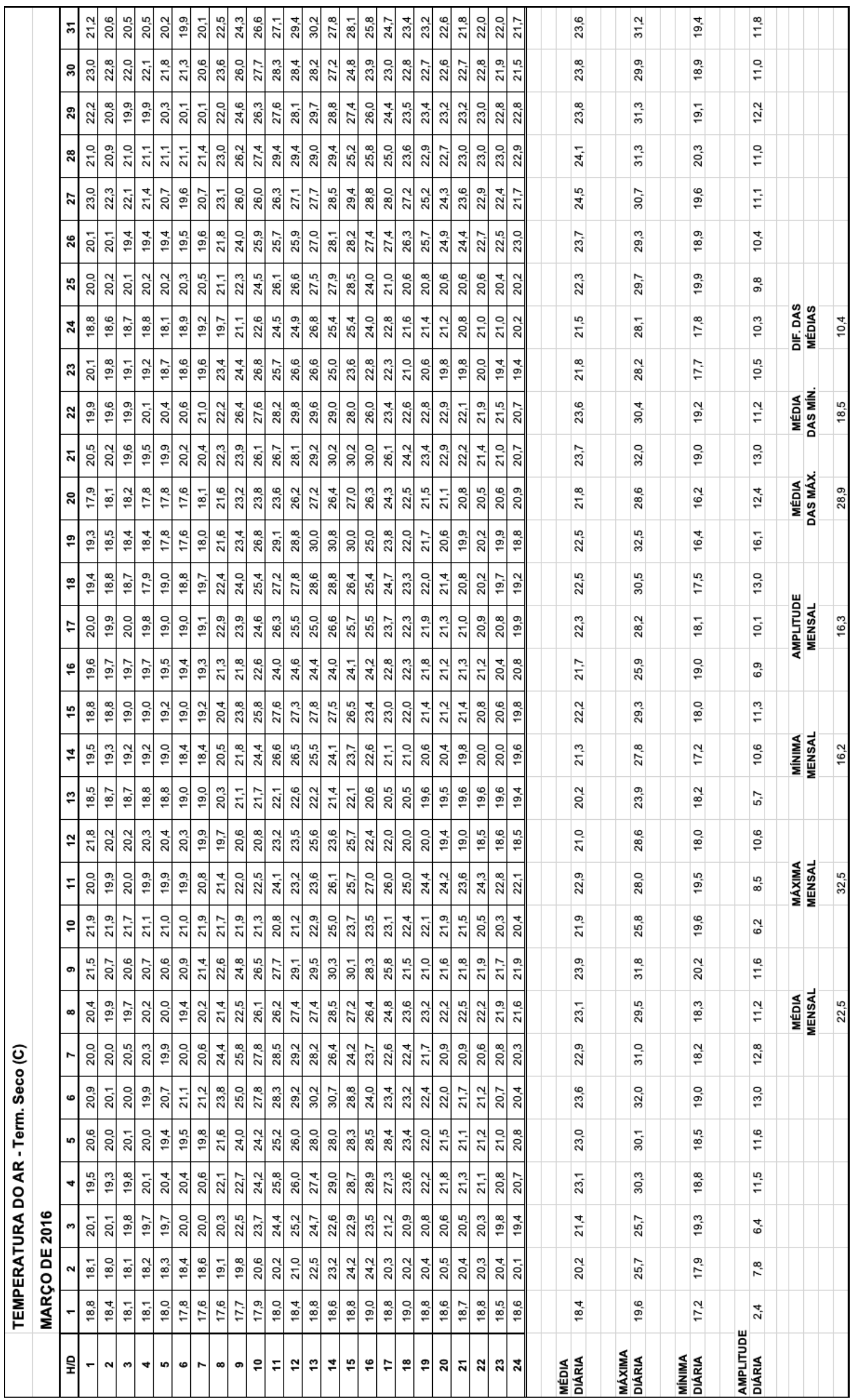




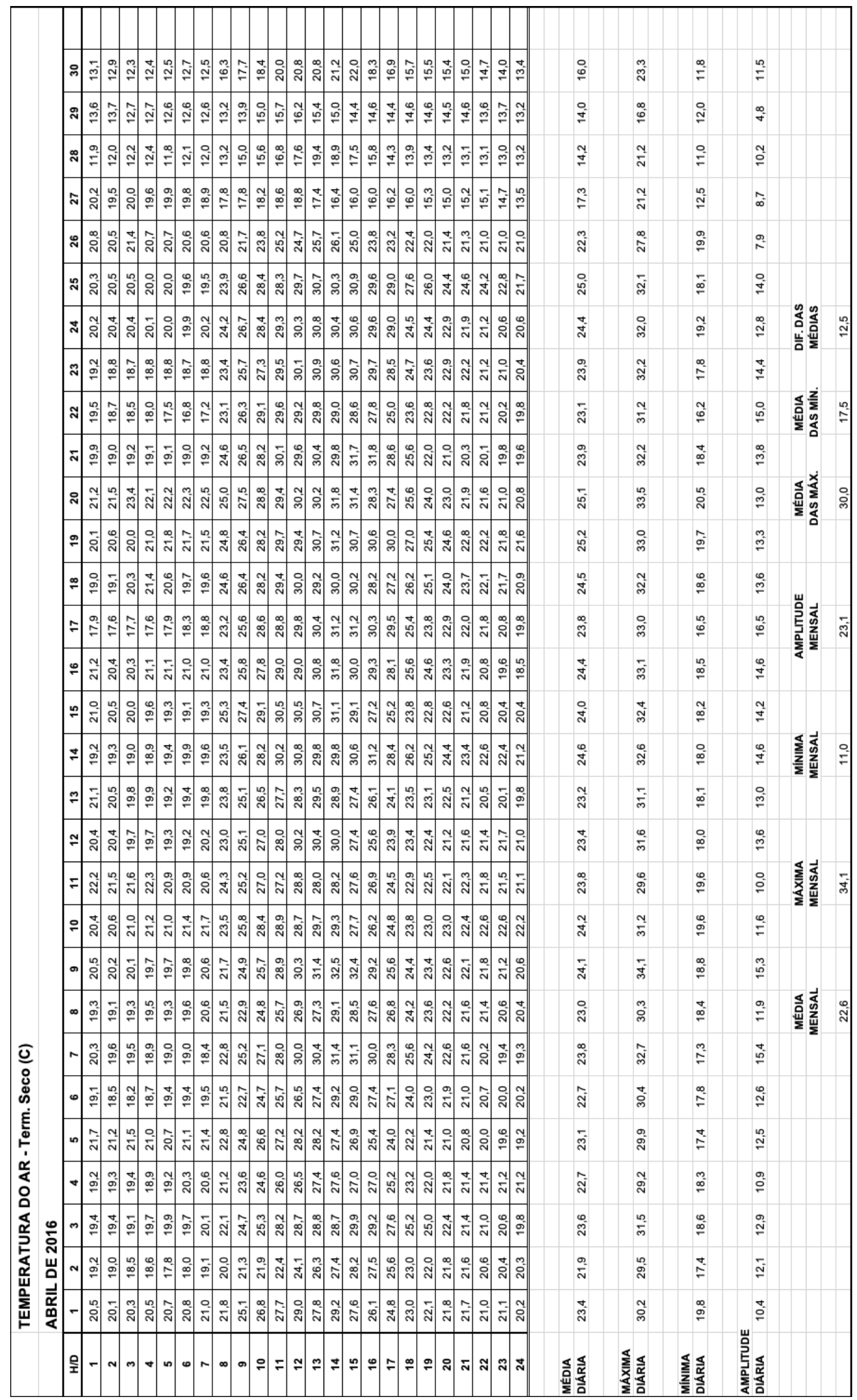




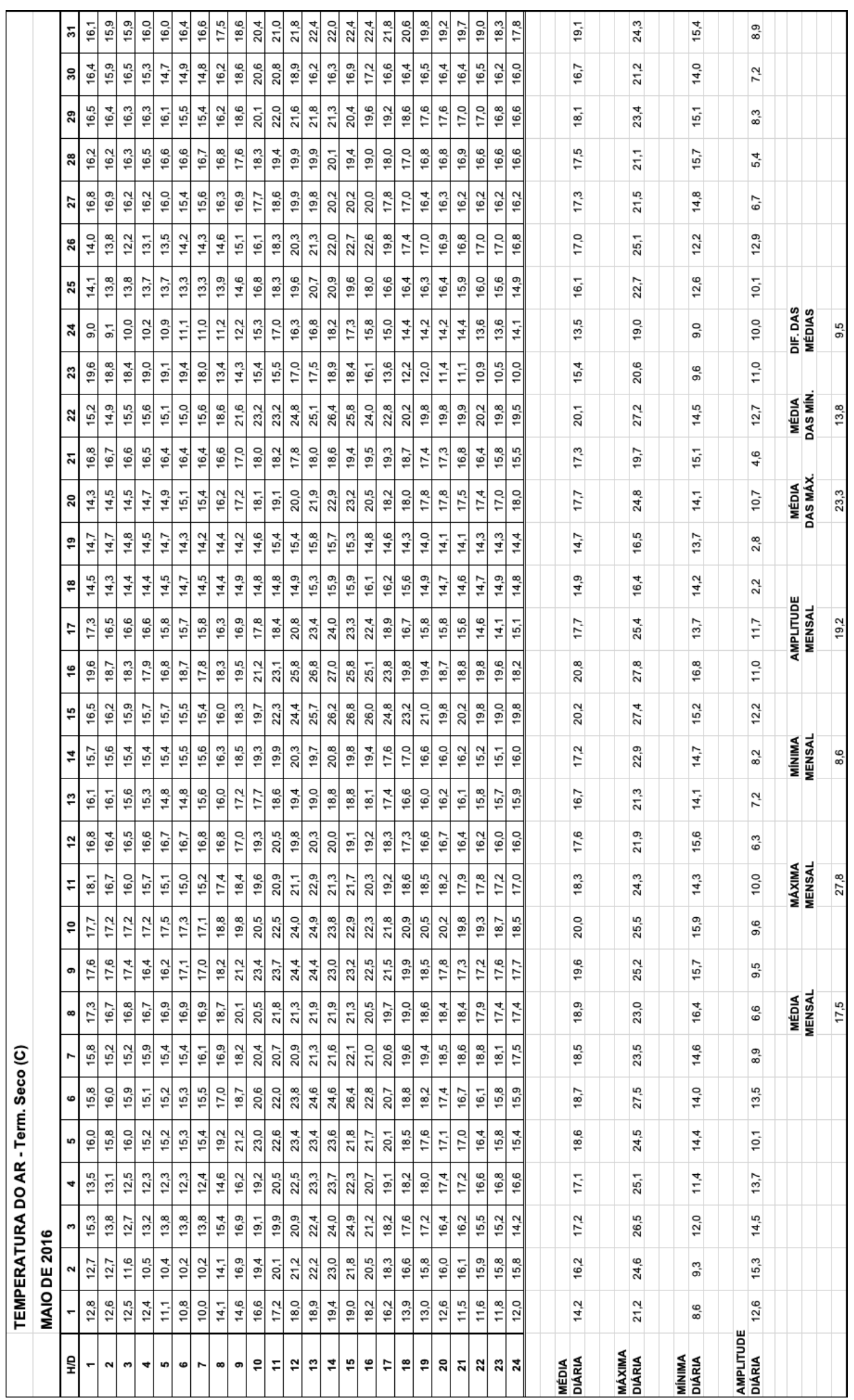




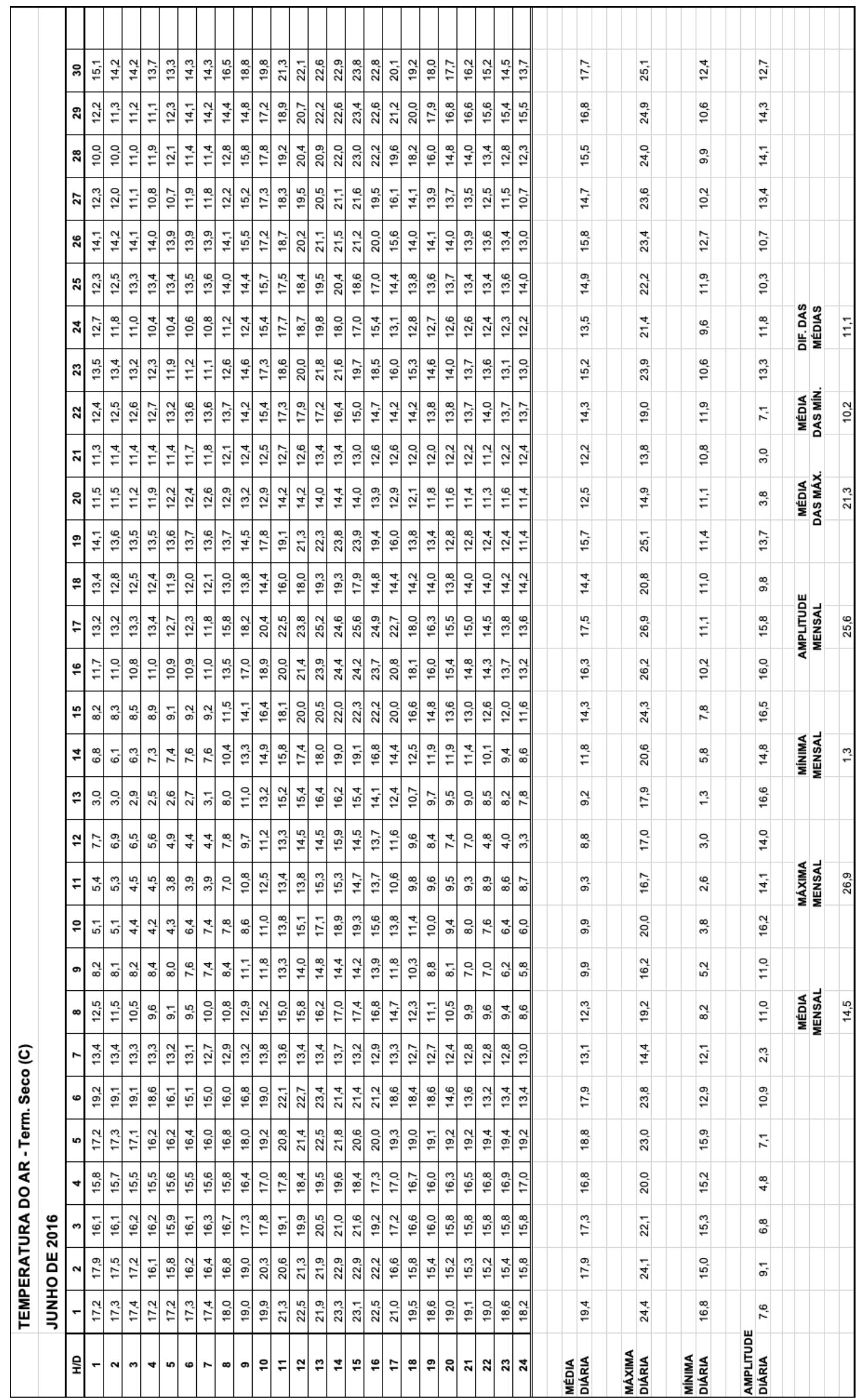




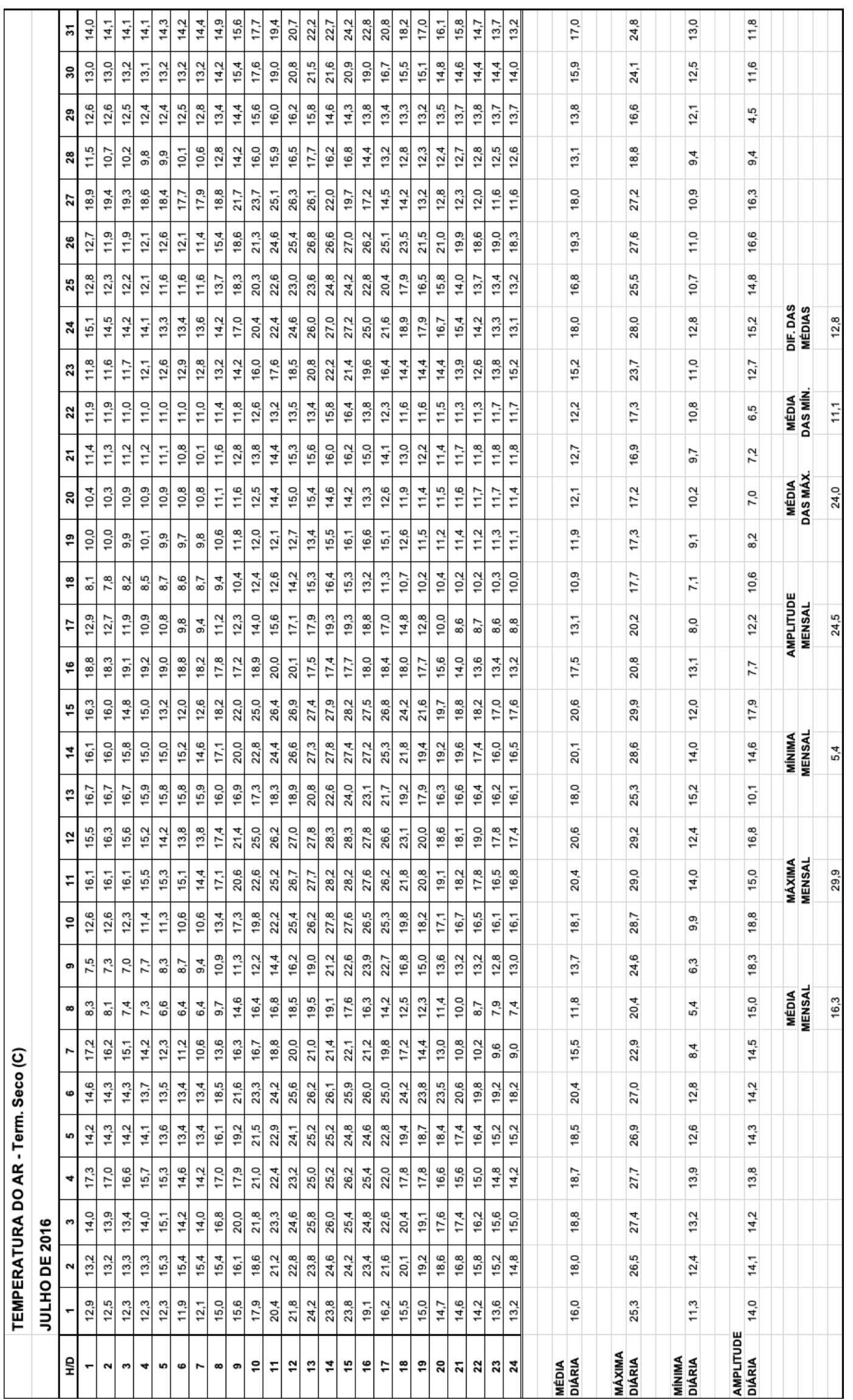




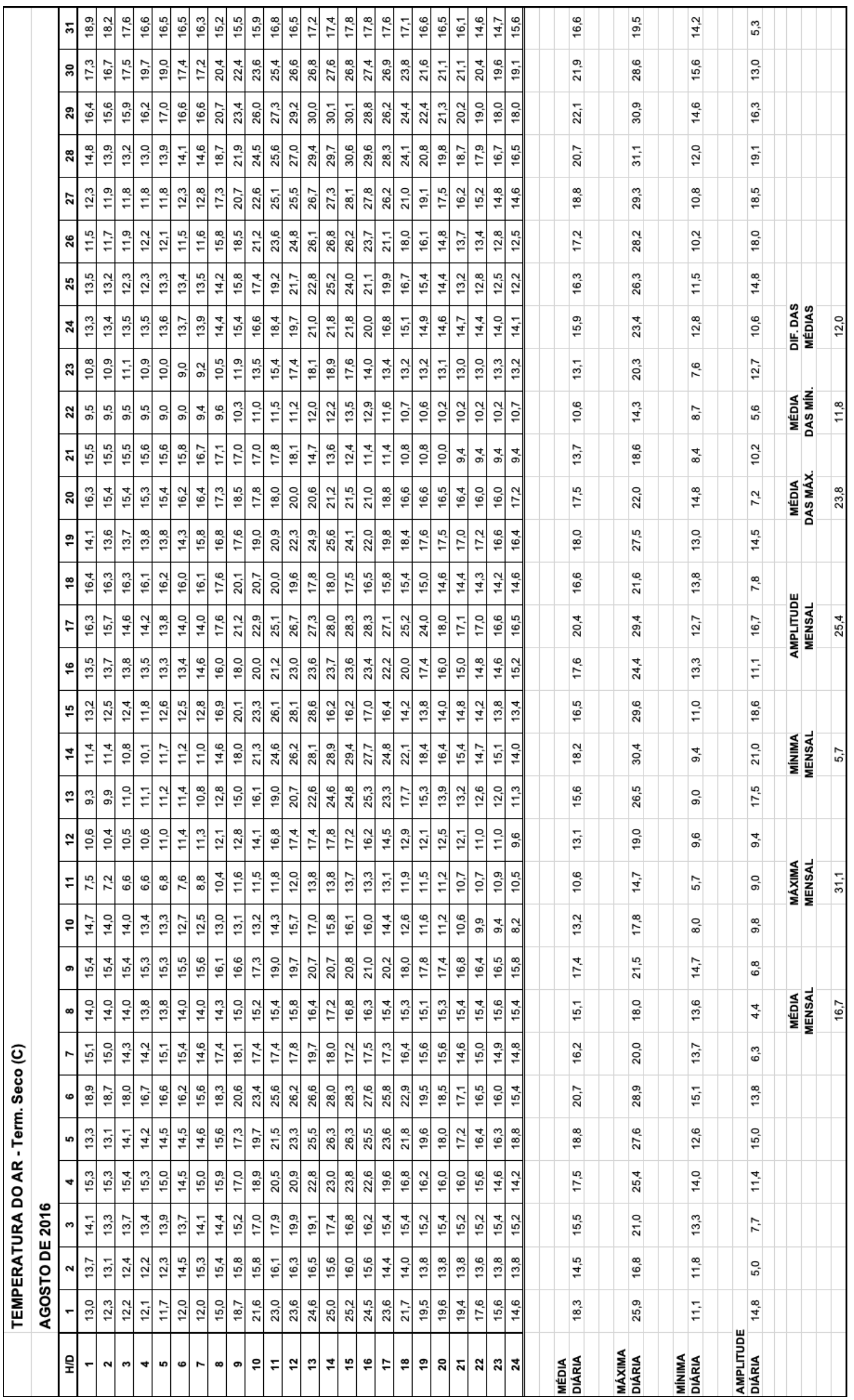




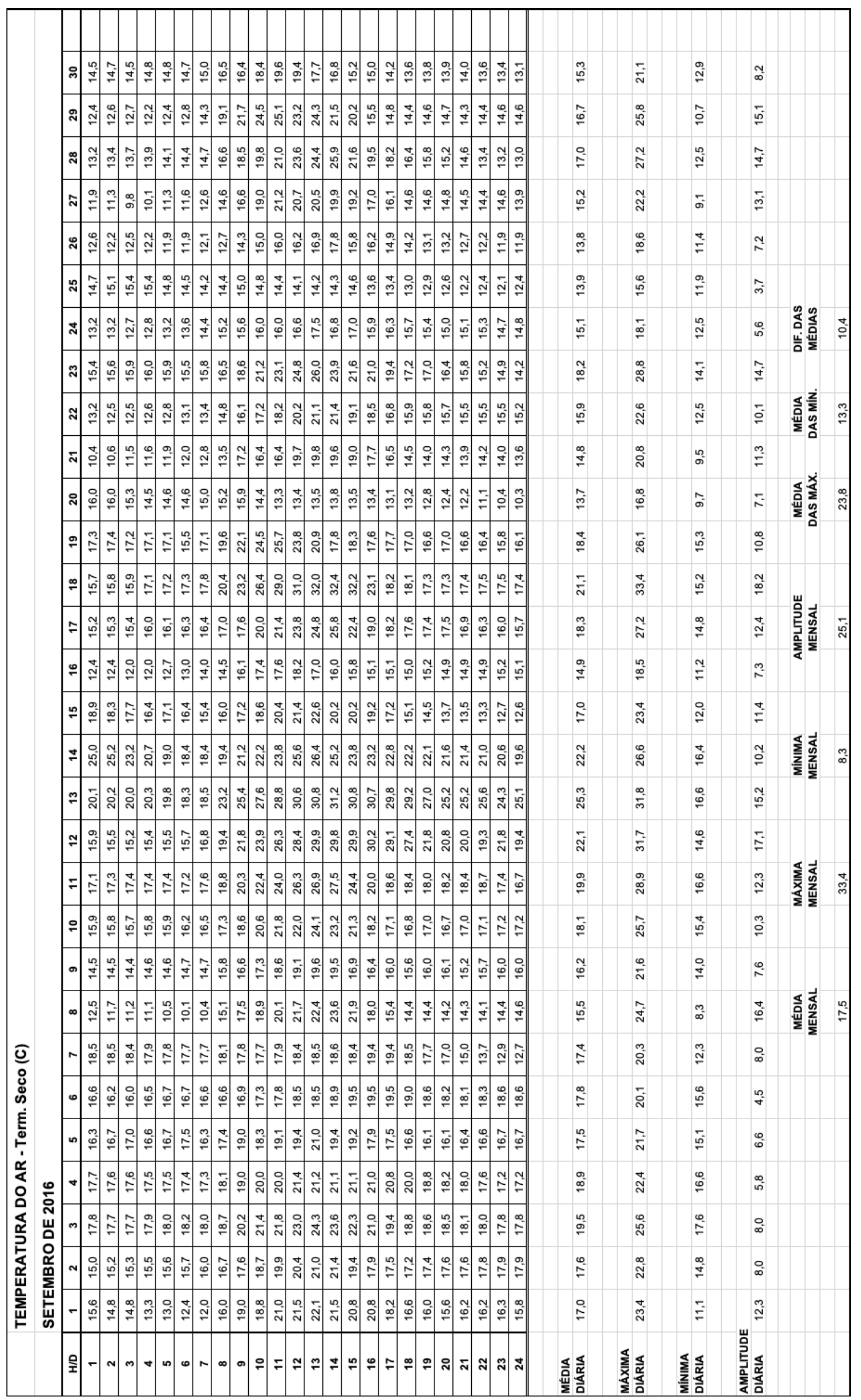




\begin{tabular}{|c|c|c|c|c|c|c|c|c|c|c|c|c|c|c|c|}
\hline & $\bar{m}$ & $\begin{array}{lll}0 & 0 \\
0 & 0 & 0 \\
0 & 0 & 0\end{array}$ & & 00 & 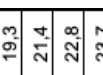 & ๙ึ: & 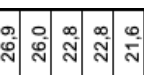 & 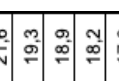 & 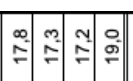 & $\stackrel{\%}{\circ}$ & $\stackrel{\infty}{\infty}$ & $\bar{\oplus}$ & $\hat{N}$ & & \\
\hline & 0 & & : & $\stackrel{8}{0}$ & $\stackrel{\circ}{=} 2$ & 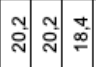 & 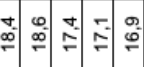 & $\stackrel{\square}{\circ}=0$ & 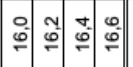 & $\hat{\oplus}$ & $\stackrel{\infty}{i}$ & 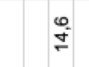 & $\approx$ & & \\
\hline & 2 & 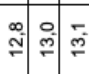 & & 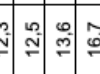 & & 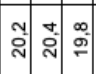 & 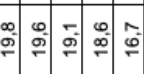 & 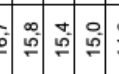 & 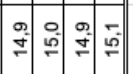 & के & 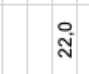 & $\stackrel{\ddagger}{=}$ & $\stackrel{\circ}{\circ}$ & & \\
\hline & \begin{tabular}{|l|l}
$\infty$ & $\vdots$
\end{tabular} & $\therefore$ & & 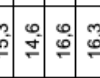 & 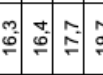 & ติ & 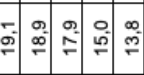 & $\stackrel{0}{\circ}$ & 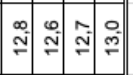 & के & $\hat{\bar{i}}$ & $\cong$ & $\stackrel{\circ}{\sigma}$ & & \\
\hline & $\approx:$ & 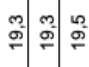 & & 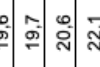 & 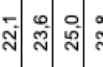 & 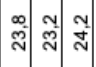 & సี : : : & 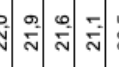 & 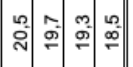 & $\stackrel{\varphi}{i}$ & $\stackrel{n}{i}$ & $\stackrel{\sim}{\infty}$ & $\stackrel{m}{\%}$ & & \\
\hline & $\approx:$ & ๙े बें & : & 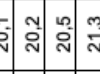 & $\frac{0}{2}=$ & 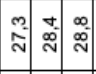 & 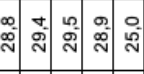 & 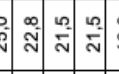 & 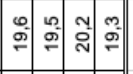 & ๙ లి & $\stackrel{\infty}{\infty}$ & $\stackrel{\text { ڤ }}{\rho}$ & $\stackrel{\bullet}{=}$ & & \\
\hline & 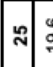 & 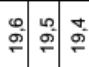 & : & 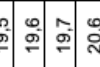 & 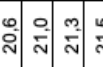 & $\stackrel{n}{\sim} \underset{\sim}{\pi}$ & 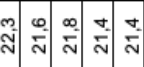 & 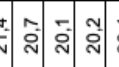 & 高㲞言 & : & $\overline{\text { ī }}$ & $\stackrel{\circ}{\circ}$ & $\bar{f}$ & & \\
\hline & 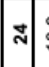 & 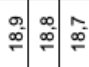 & 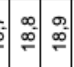 & $\stackrel{9}{\circ}$ & 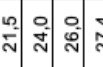 & స: & : & 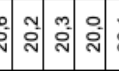 & 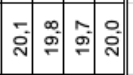 & $\hat{\bar{i}}$ & $\stackrel{\circ}{\circ}$ & $\stackrel{\Phi}{\stackrel{\infty}{\infty}}$ & $\stackrel{\circ}{=}$ & 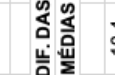 & : \\
\hline & $\approx$ & 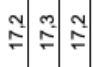 & $=2$ & 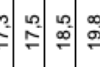 & 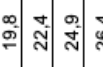 & 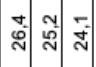 & $\overline{\mathrm{A}}$ & $\stackrel{\infty}{\infty}: \stackrel{\infty}{\oplus}$ & $\stackrel{\infty}{\infty} \underset{\infty}{\infty} \infty$ & $\bar{i}$ & $\approx$ & 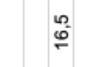 & $\hat{\circ}$ & & \\
\hline & $\approx$ & $=: \stackrel{0}{\circ}:$ & $: 0$ & 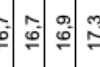 & $=0$ & 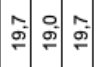 & 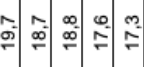 & 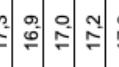 & 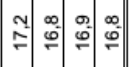 & $\stackrel{\Re}{=}$ & à & $\dddot{q}$ & F & 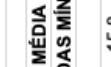 & $\stackrel{\infty}{\stackrel{\infty}{g}}$ \\
\hline & $\approx$ & $\stackrel{0}{\circ}: 0=$ & $=\infty$ & 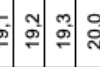 & 원 $=\frac{0}{\pi}=$ & 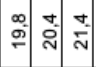 & 車 & $\stackrel{\infty}{\infty}$ & 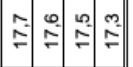 & $\stackrel{\infty}{\%}$ & 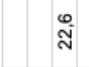 & $\stackrel{乛}{\check{I}}$ & $\stackrel{\circ}{\circ}$ & & \\
\hline & 2 & $\overline{\bar{n}}=\stackrel{2}{\circ}$ & 资 & 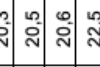 & 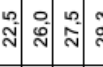 & ஸें 일 & 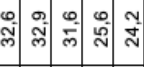 & 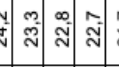 & 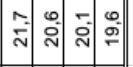 & $\overline{\mathrm{i}}$ & 哭 & 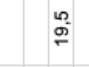 & ڤ & 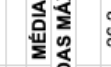 & 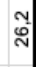 \\
\hline & $\approx \vdots$ & 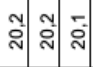 & 就 & 蚝部 & 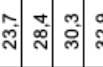 & 今ે & 象同 & 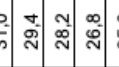 & : & i̊ & $\hat{\phi}$ & $\stackrel{\circ}{\%}$ & $\hat{\AA}$ & & \\
\hline & $\approx$ & ڤ̊̀ & 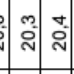 & 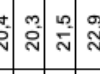 & ปู) & 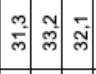 & 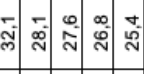 & 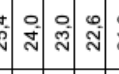 & $\stackrel{0}{\pi}:$\begin{tabular}{c}
0 \\
\hdashline
\end{tabular} & $\overline{\mathrm{d}}$ & 䗆 & $\stackrel{\infty}{\infty}$ & $\Phi$ & & \\
\hline & $\approx$ & ஃ̊: & $\stackrel{0}{\circ} \stackrel{0}{\circ} \stackrel{\circ}{\circ}$ & $=2 \overbrace{}^{2}$ & 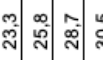 & 品 & స్ల్లి نి & $\dot{0}$ & $\stackrel{m}{2}=$ & 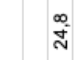 & $\bar{s}$ & ฆิ & ฆे & & $\stackrel{\mathscr{N}}{\sim}$ \\
\hline & $\div$ & 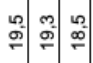 & $=$ & 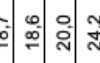 & సै: & 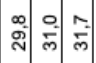 & స్̄ & 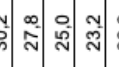 & 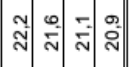 & f & 密 & $\stackrel{n}{\sim}$ & के & & \\
\hline & 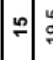 & $\stackrel{2}{\circ}: \frac{\infty}{\circ}: 0$ & {$\left[\begin{array}{ccc}0 & 0 \\
\hdashline & 0 & 0 \\
\hdashline & 0\end{array}\right.$} & $: \stackrel{\circ}{\circ}: \stackrel{\infty}{\circ}$ & : & 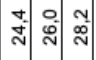 & 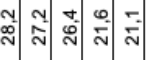 & 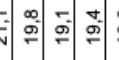 & 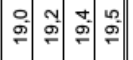 & $\stackrel{m}{i}$ & 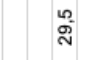 & $\stackrel{\infty}{\infty}$ & $\stackrel{N}{=}$ & & \\
\hline & \pm & 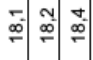 & 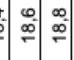 & 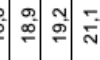 & 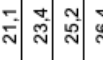 & 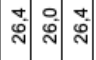 & 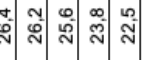 & 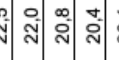 & 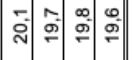 & $\stackrel{0}{i}$ & $\stackrel{i}{i}$ & 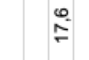 & $\stackrel{5}{\circ}$ & 站童 & $\overline{7}$ \\
\hline & $=\vdots$ & $\stackrel{0}{\circ}=0$ & $=\infty$ & $\stackrel{2}{\circ}$ & 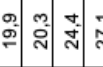 & $\therefore \approx$ & 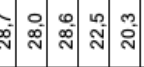 & $\stackrel{2}{\circ}$ & 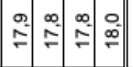 & $\stackrel{m}{i}$ & 今ं & 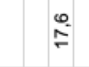 & $\stackrel{\mathscr{N}}{\sim}$ & & \\
\hline & $\approx$ & 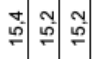 & 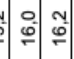 & 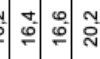 & ลี สุ: & : & 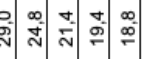 & 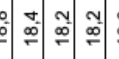 & 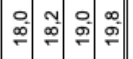 & $\stackrel{\infty}{\stackrel{\infty}{\infty}}$ & 总 & $\stackrel{0}{\ddagger}$ & $\stackrel{\infty}{\infty}$ & & \\
\hline & $=5$ & 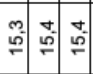 & 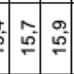 & 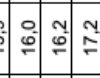 & 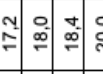 & 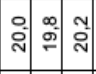 & 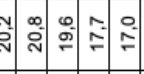 & 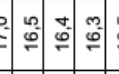 & 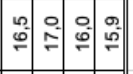 & $\tilde{\simeq}$ & $\overline{\text { i }}$ & $\stackrel{\infty}{ \pm}$ & $\stackrel{2}{\sim}$ & 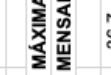 & ळ \\
\hline & $0=$ & 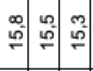 & 2 & 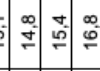 & 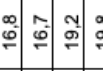 & 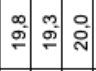 & 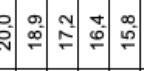 & 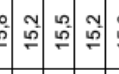 & 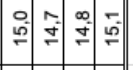 & $\stackrel{\ddagger}{\oplus}$ & $\stackrel{\bullet}{i}$ & 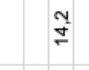 & $\stackrel{5}{*}$ & & \\
\hline & $\circ:$ & 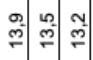 & & $=0$ & $\hat{=}=0$ & & 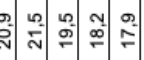 & 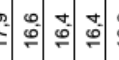 & 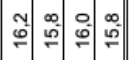 & $\stackrel{\circ}{\circ}$ & สి & $\stackrel{\infty}{=}$ & $\overline{=}$ & & \\
\hline & $\infty ?$ & 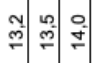 & & 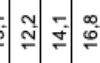 & 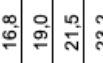 & 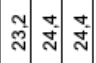 & 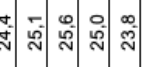 & $\circ: \stackrel{\circ}{\circ}$ & 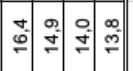 & $\stackrel{\infty}{\infty}$ & $\bar{i}$ & $\bar{F}$ & $\stackrel{\circ}{\circ}$ & 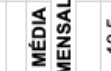 & 。ำ \\
\hline ত্ & $\wedge \%$ & :ำ: & 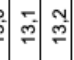 & 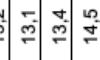 & 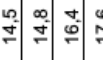 & $\stackrel{0}{\circ} \stackrel{0}{\circ}=0$ & 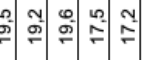 & 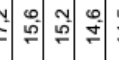 & 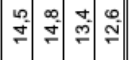 & $\overbrace{\infty}^{\infty}$ & $\stackrel{n}{i}$ & $\cong$ & $\stackrel{\infty}{\infty}$ & & \\
\hline 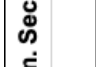 & 0 & 员 & {$\left[\begin{array}{c}\infty \\
0 \\
0\end{array}\right.$} & {$\left[\begin{array}{ll}0 \\
0\end{array}\right.$} & $\stackrel{0}{=}: \pm 0$ & จุ & 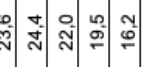 & 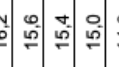 & 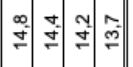 & $\hat{\digamma}$ & $\bar{s}$ & $\stackrel{\infty}{\sim}$ & $\stackrel{\varphi}{=}$ & & \\
\hline 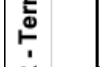 & $\infty$ & $\stackrel{0}{0}$ & $\underbrace{\infty}_{ \pm=1}$ & {$\left[\begin{array}{l}0 \\
0\end{array}\right.$} & 毒: & $\because: \frac{\infty}{\infty}$ & $\stackrel{0}{0}: 0 \%$ & : & $\begin{array}{lll} \pm \\
0\end{array}$ & $\hat{\oplus}$ & $\stackrel{ \pm}{i}$ & 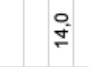 & $\stackrel{5}{\sim}$ & & \\
\hline & + & $\stackrel{\oplus}{\oplus} \oplus$ & 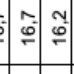 & $\stackrel{2}{\mathscr{0}}$ & $\cong$ & $\therefore \stackrel{0}{=} \stackrel{0}{=}$ & : & $=\left[\begin{array}{lll}\infty & 0 \\
\oplus & \oplus & \oplus \\
\oplus\end{array}\right.$ & 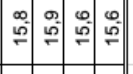 & $\cong$ & $\stackrel{\infty}{\pi}$ & : & $\stackrel{2}{\sim}$ & & \\
\hline & $m:$ & 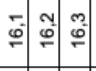 & 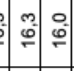 & {$\left[\begin{array}{c}0 \\
0\end{array}\right.$} & $\because 0$ & $\stackrel{0}{\because} \cong$ & $=000$ & 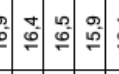 & $0: 0$ & $\hat{\varphi}$ & $\stackrel{\infty}{\infty}$ & $\stackrel{\ddagger}{\circ}$ & $\stackrel{\infty}{m}$ & & \\
\hline & $\sim$ & 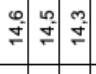 & $4=$ & 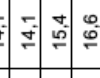 & 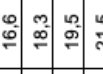 & $\stackrel{n}{\sim}=\frac{0}{\sim}$ & 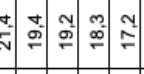 & 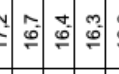 & 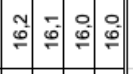 & $\stackrel{\circ}{\check{1}}$ & $\stackrel{\infty}{\pi}$ & $\Phi$ & $\hat{\infty}$ & & \\
\hline & - & 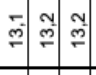 & $\stackrel{n}{2}$ & $=0$ & 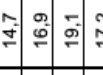 & $\stackrel{2}{\cong} \stackrel{0}{\cong}:$ & 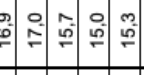 & 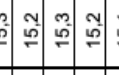 & 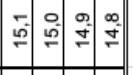 & $\bar{s}$ & $\stackrel{\infty}{\circ}$ & $\stackrel{\infty}{\sim}$ & i & & \\
\hline & & & & 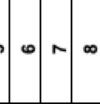 & $\infty$ & $=\cong \cong$ & 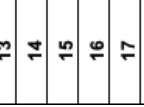 & 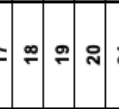 & $\approx \approx \approx \pi$ & 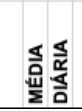 & 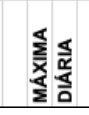 & 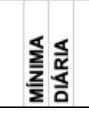 & 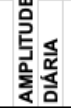 & & \\
\hline
\end{tabular}




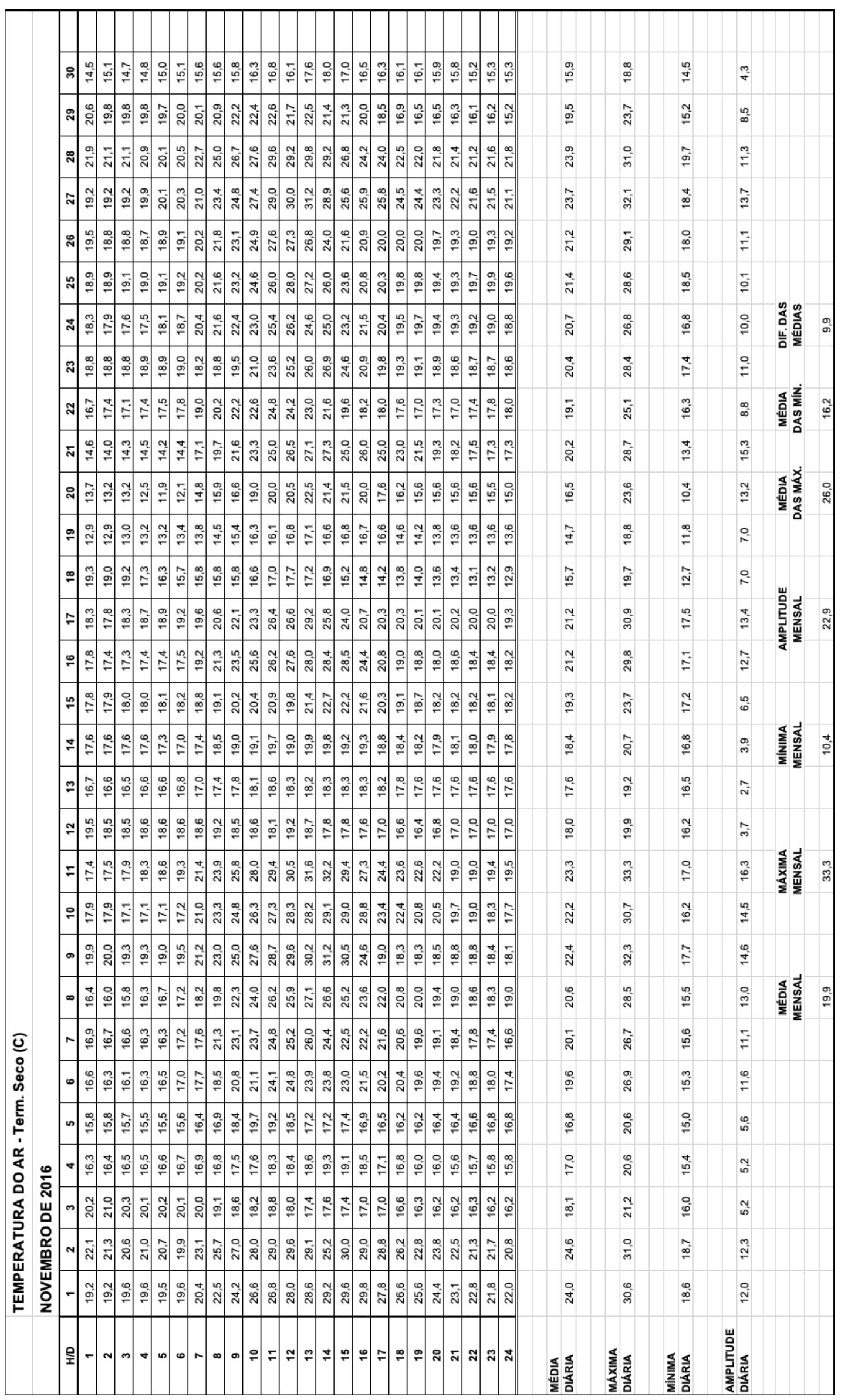




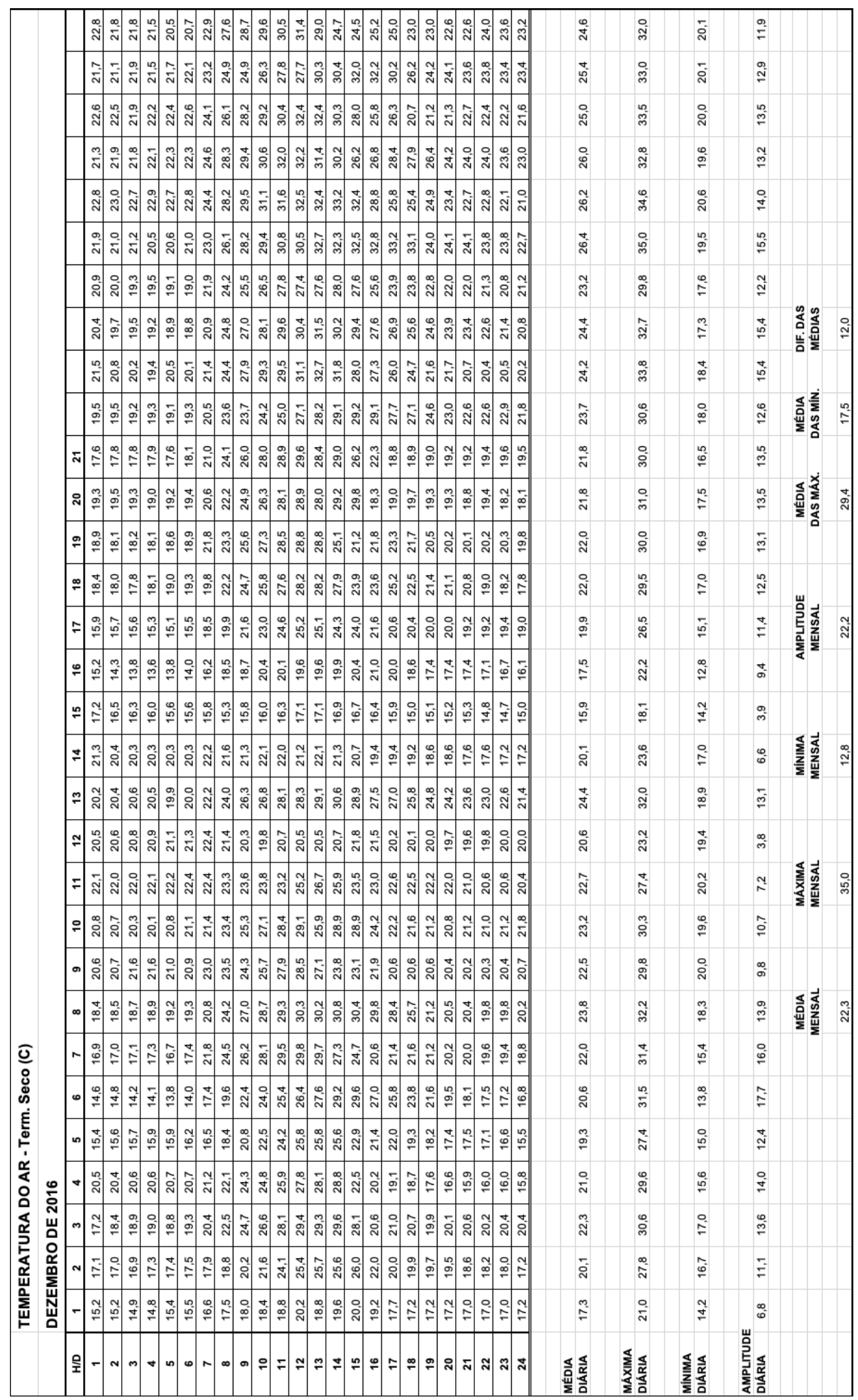




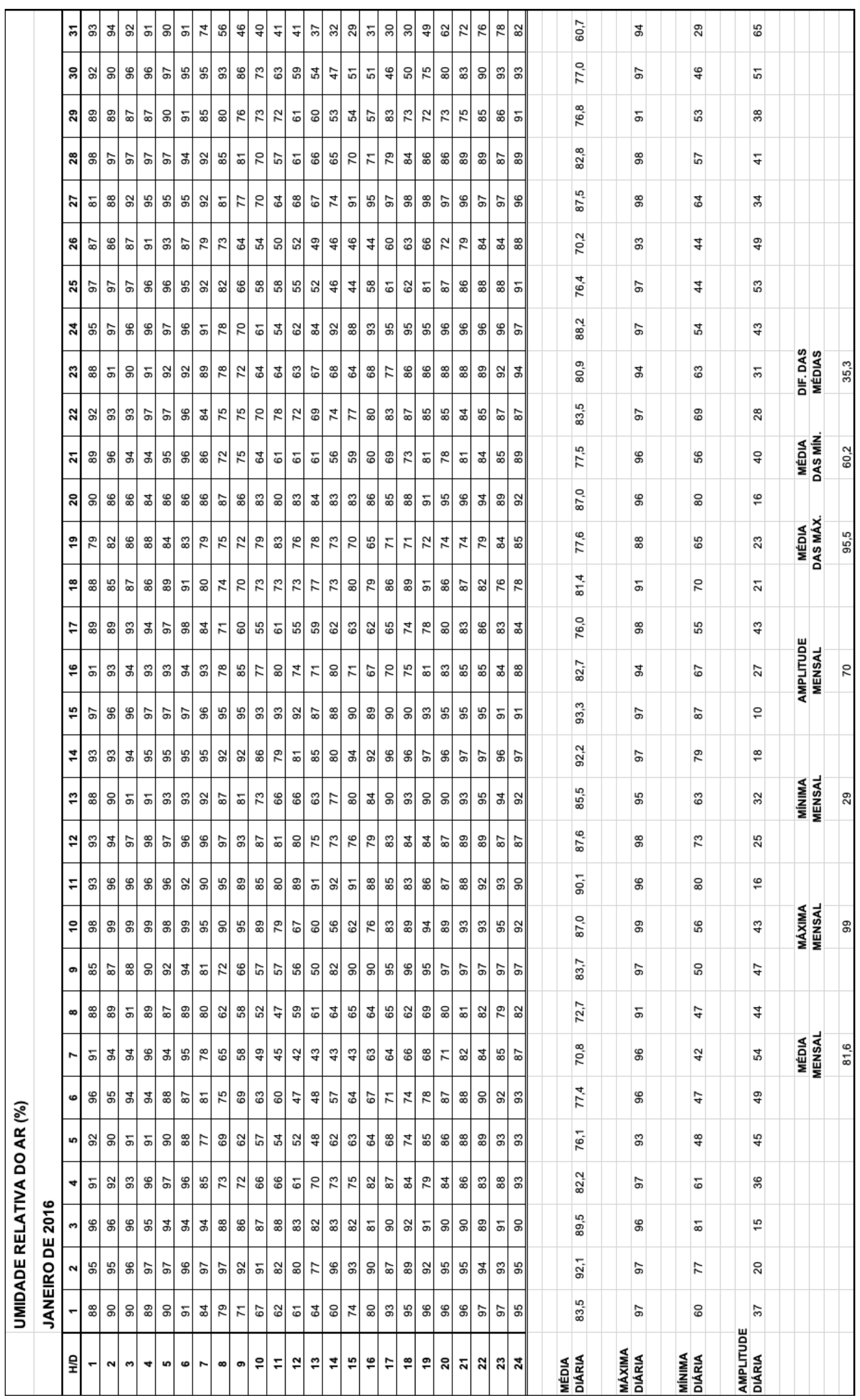




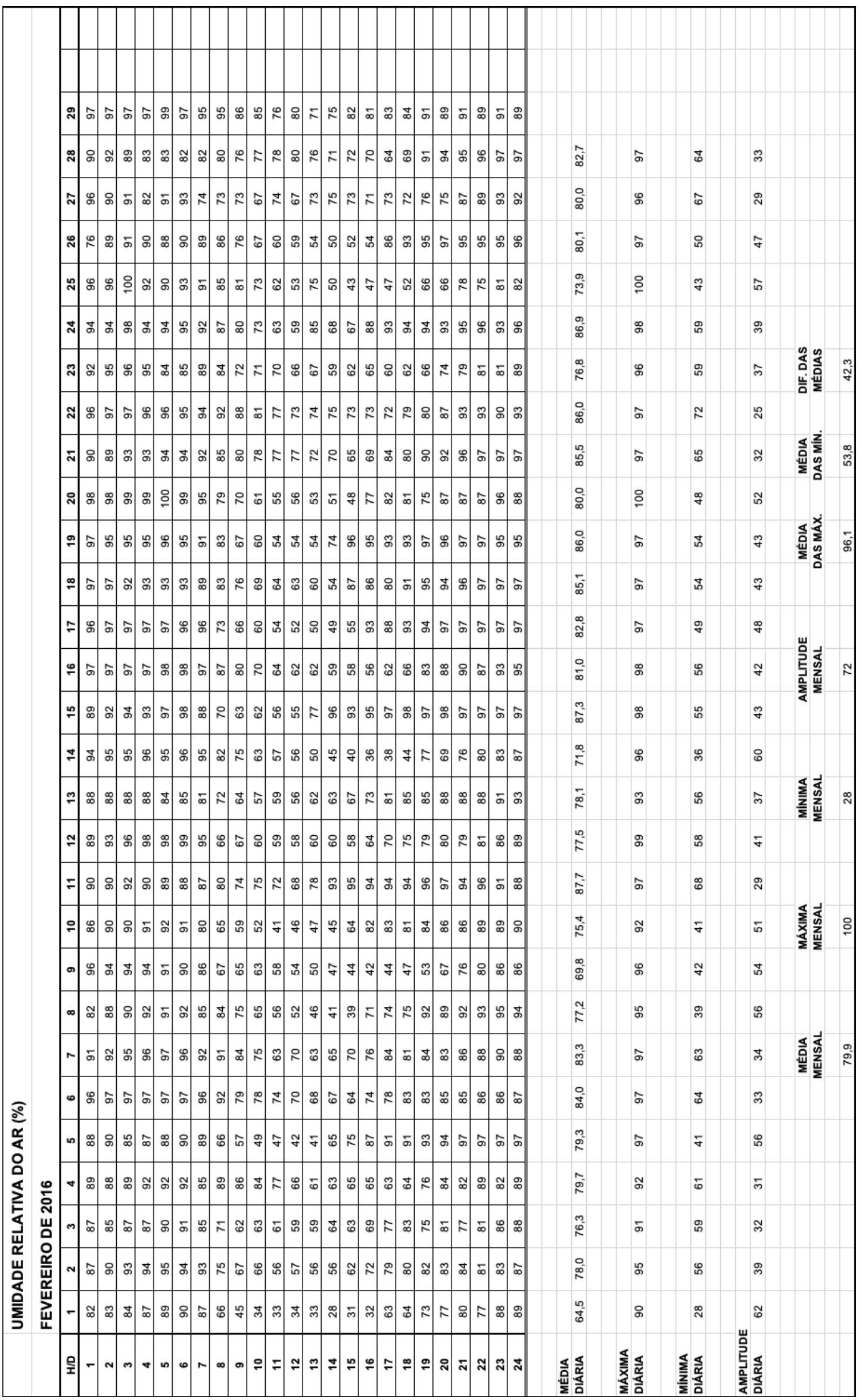




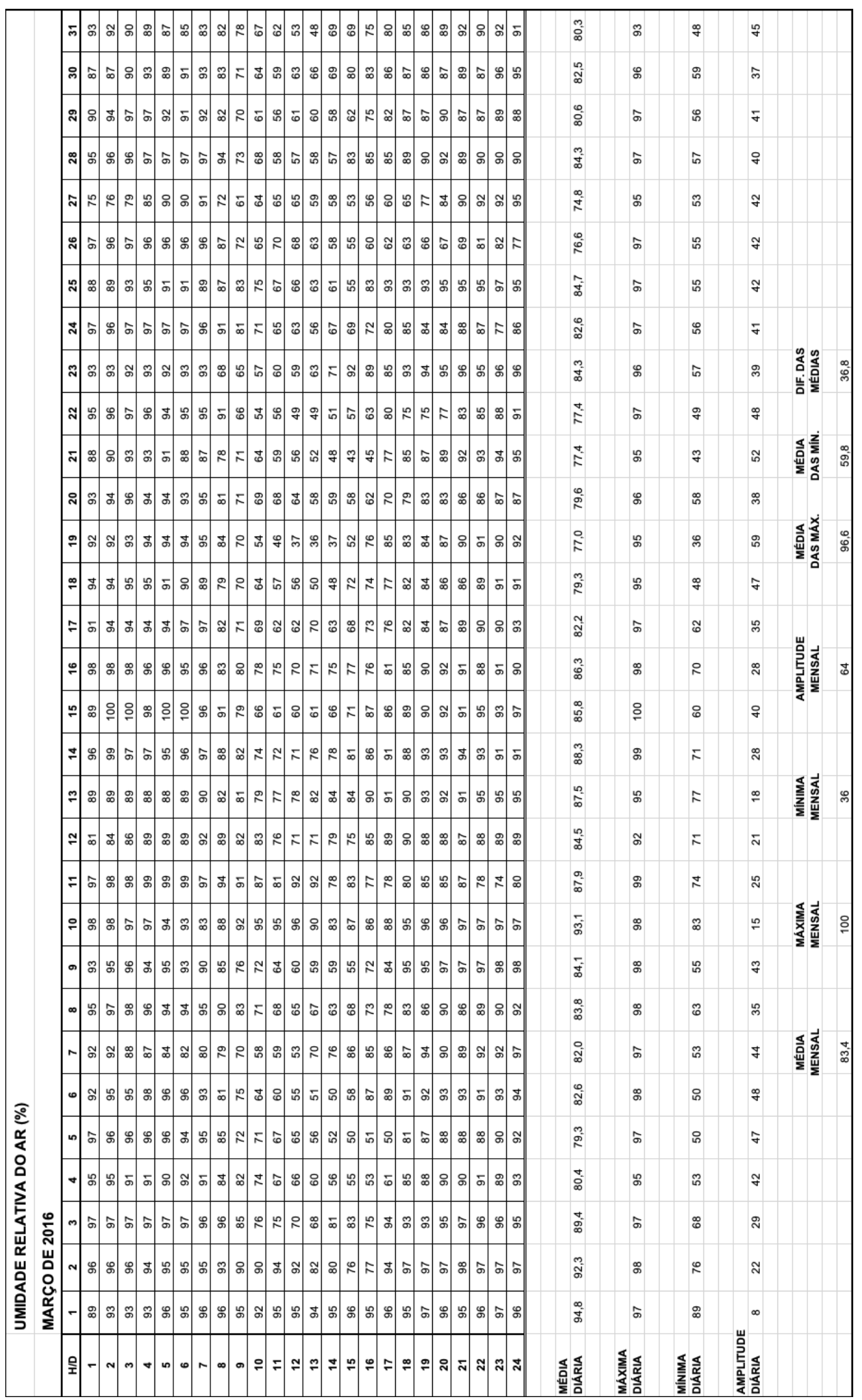




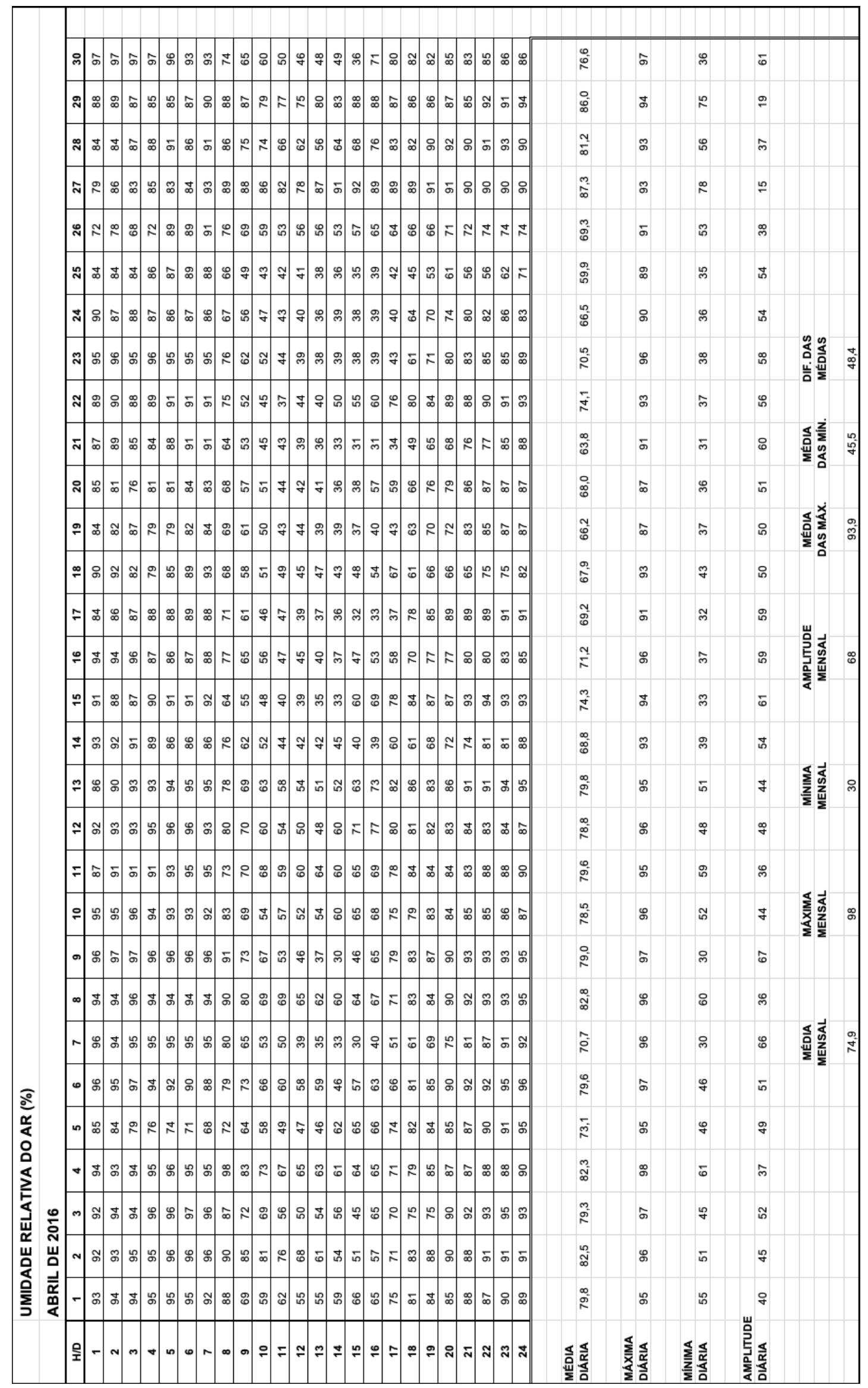




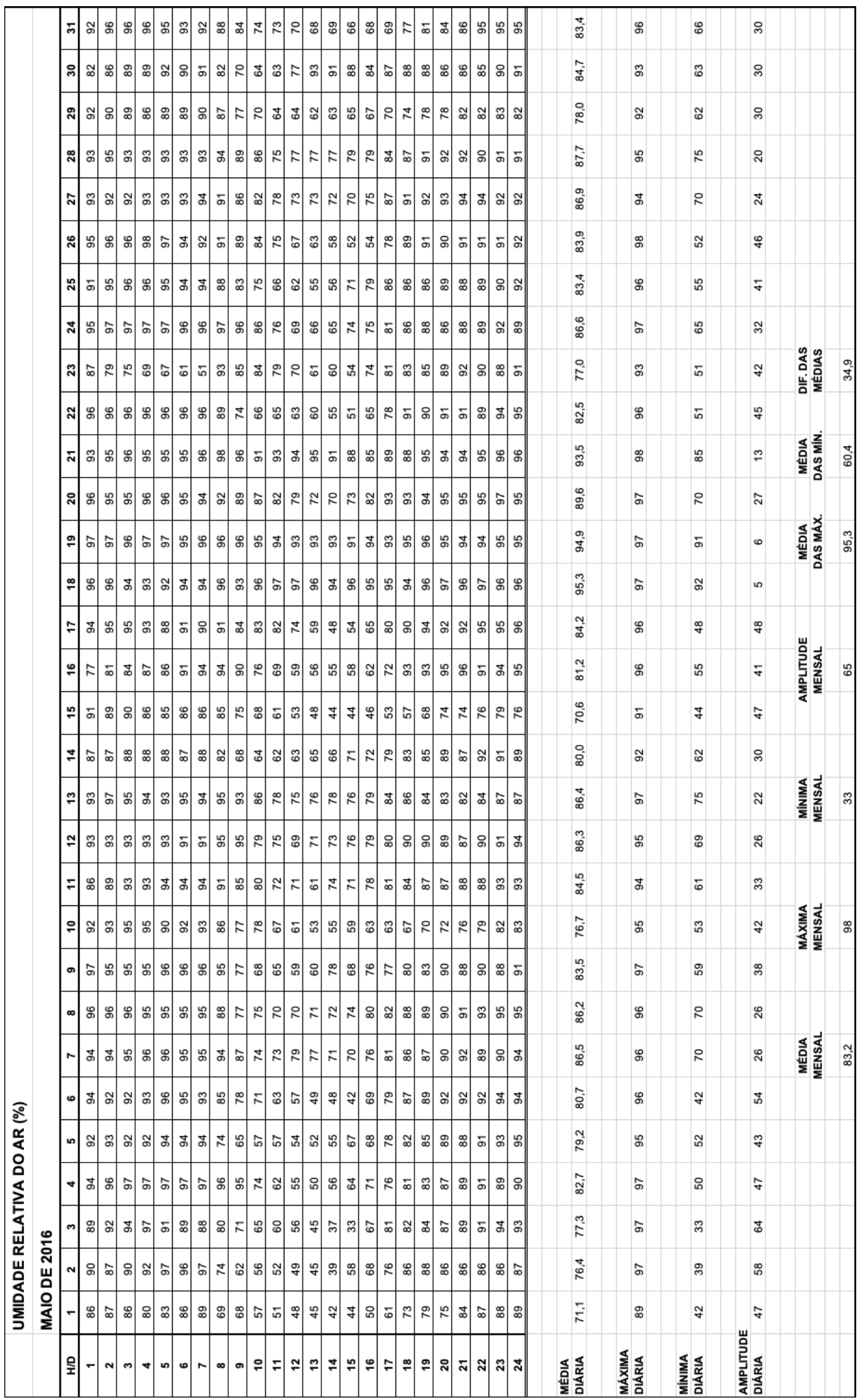




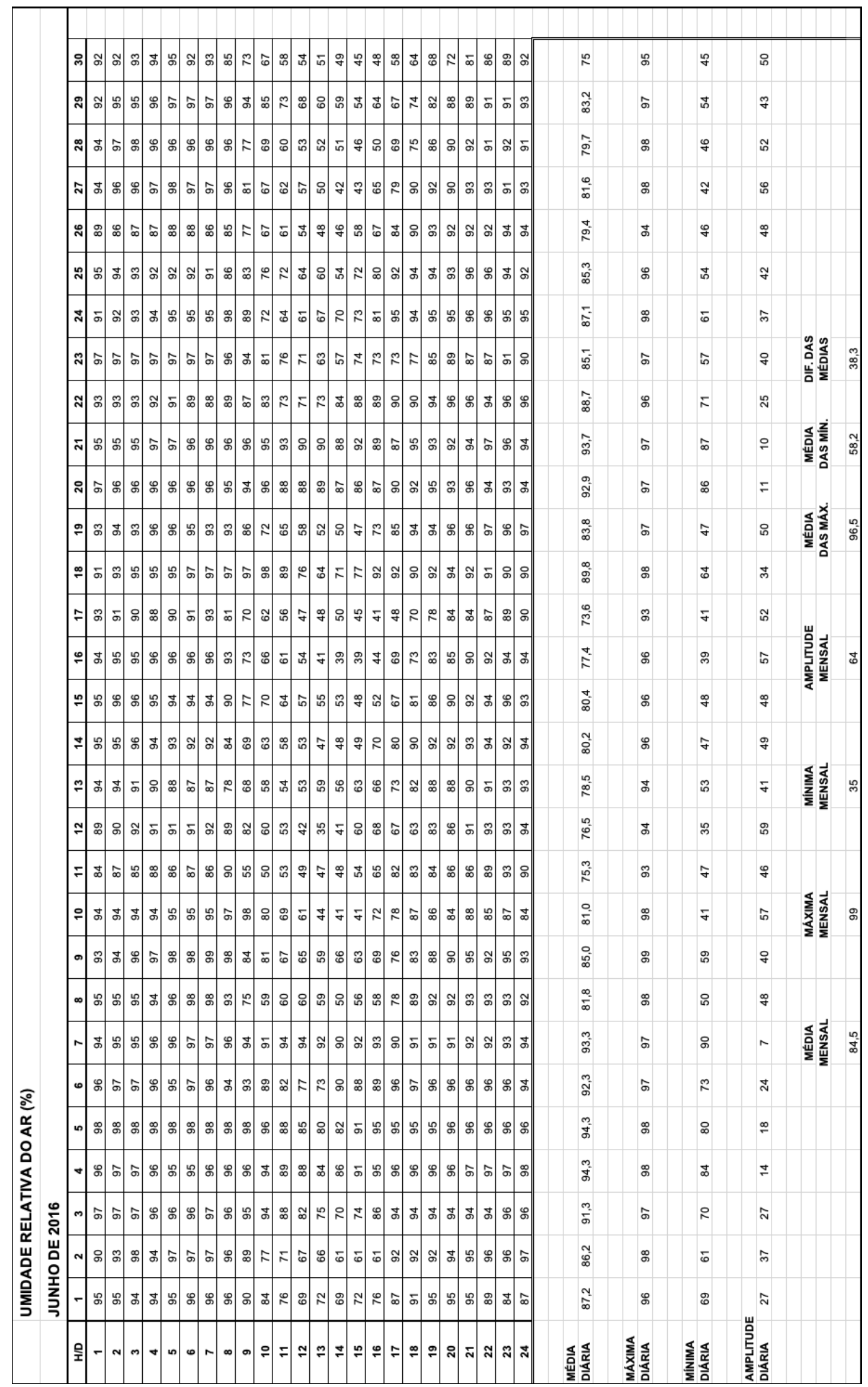




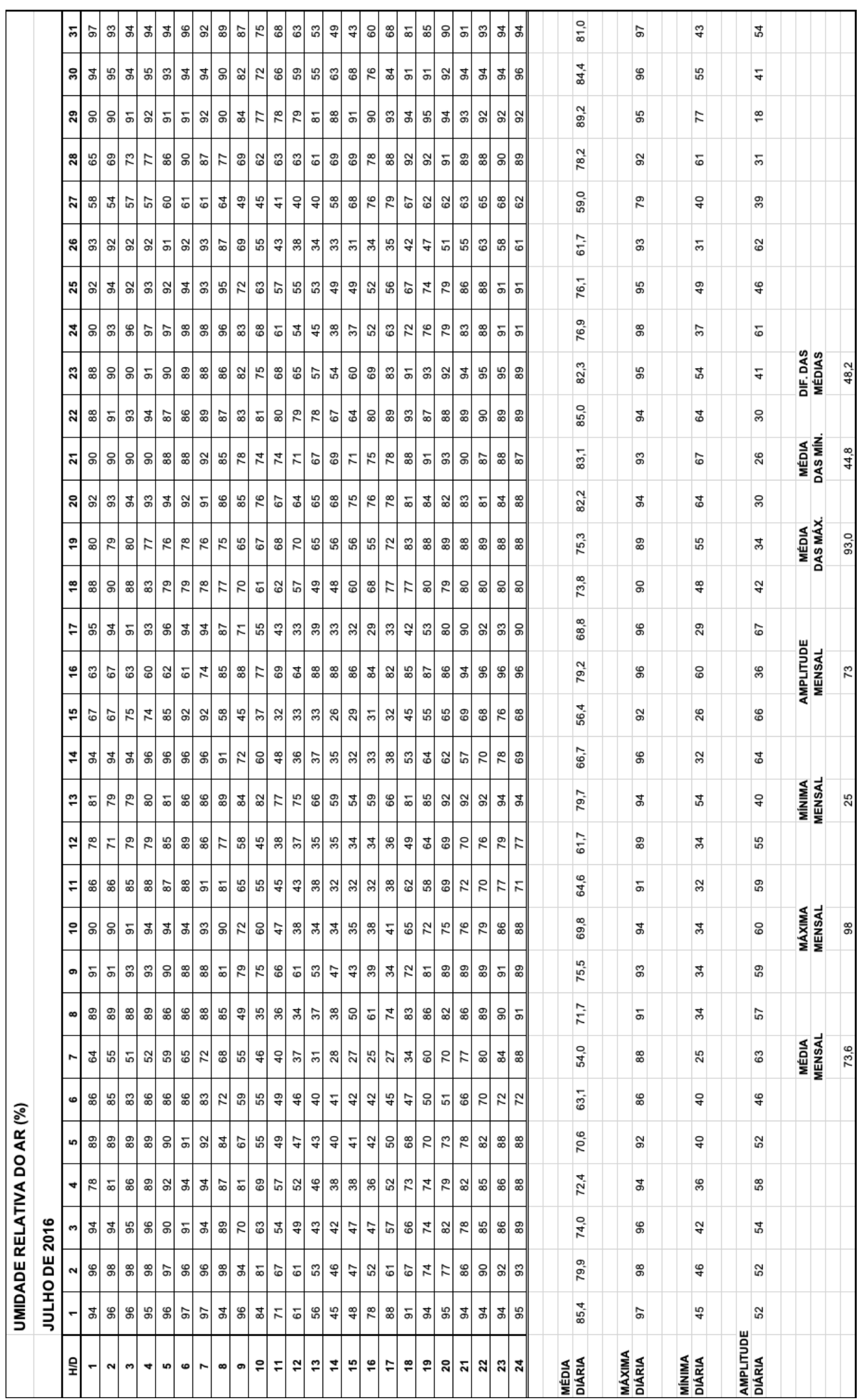




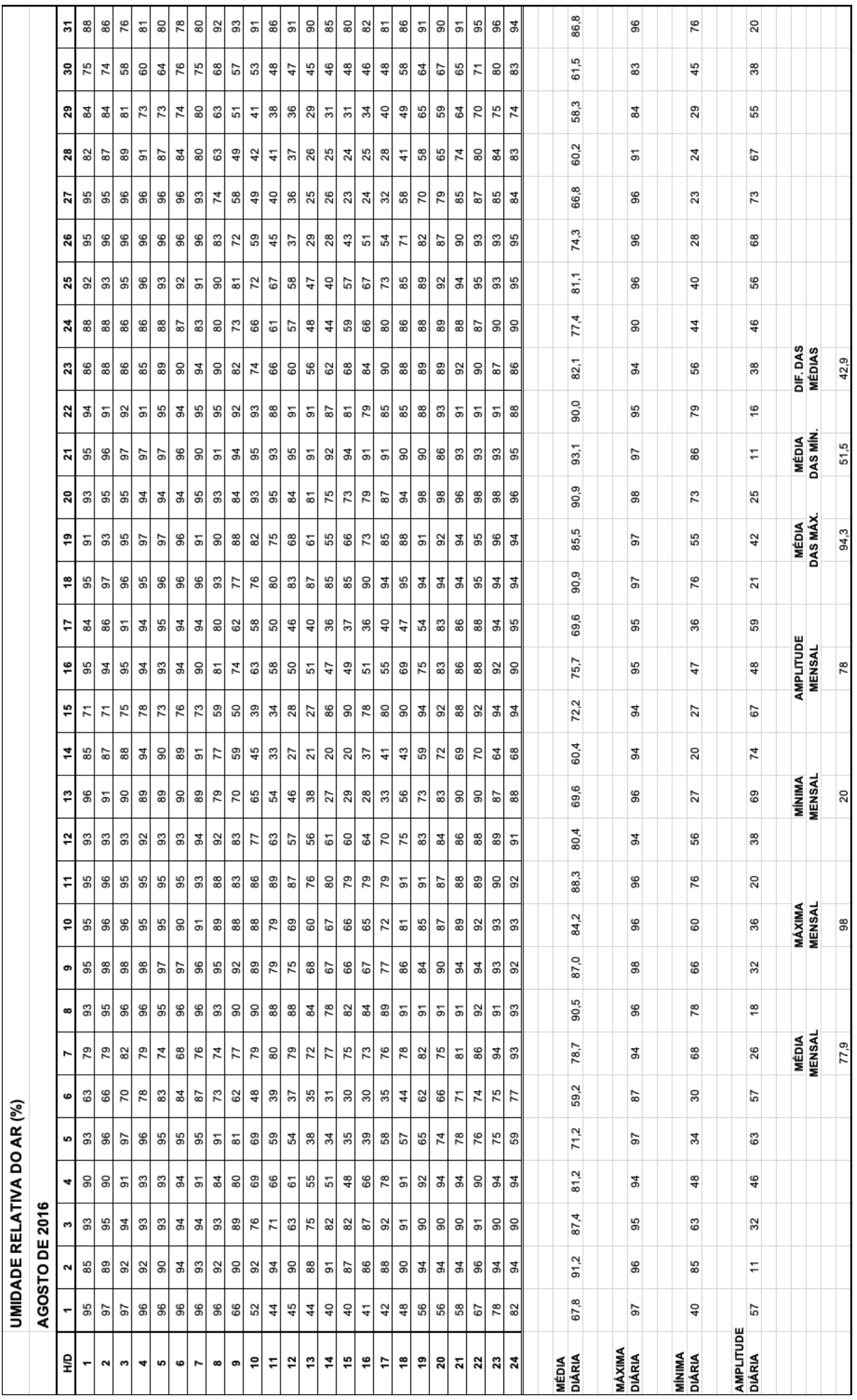




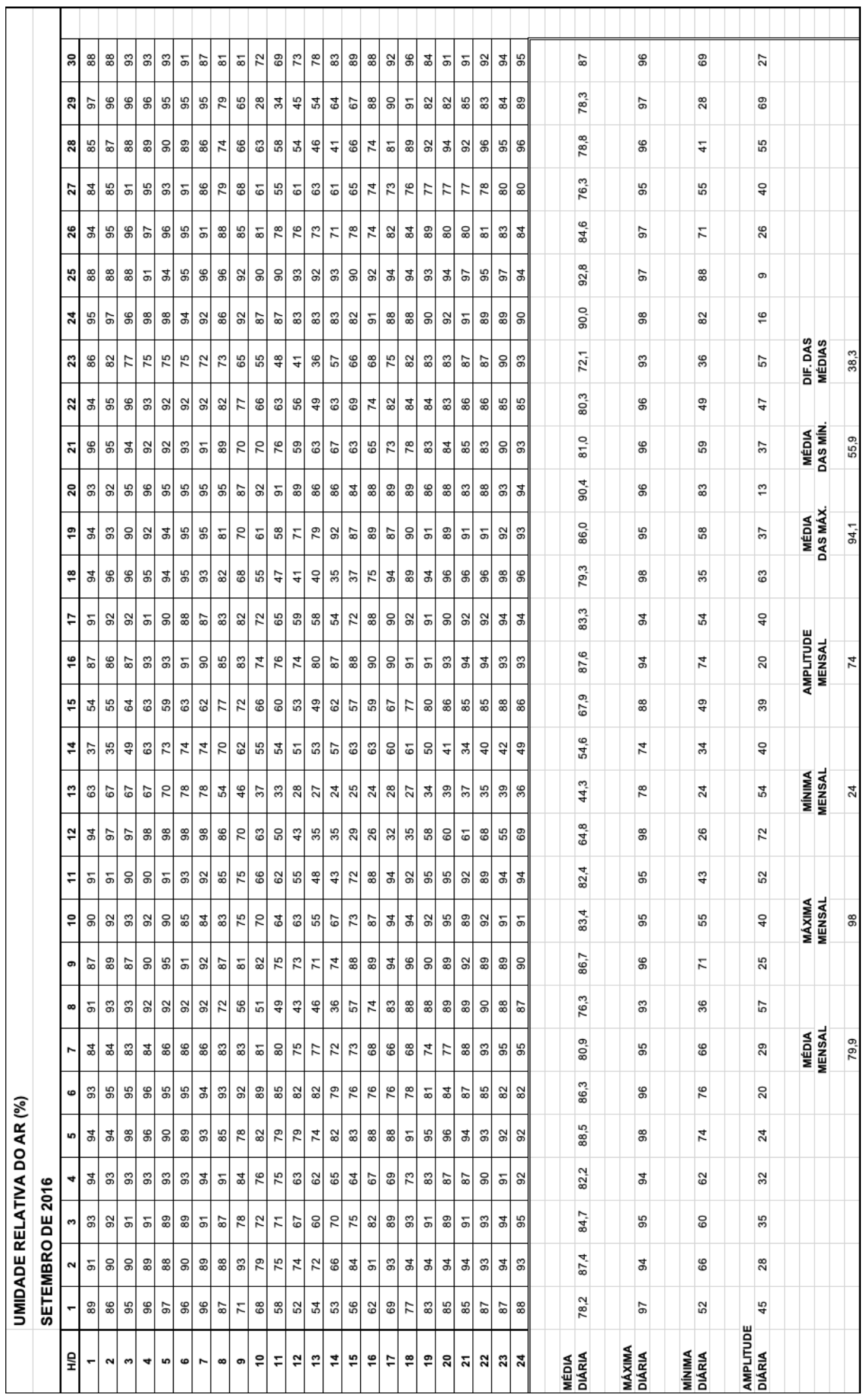




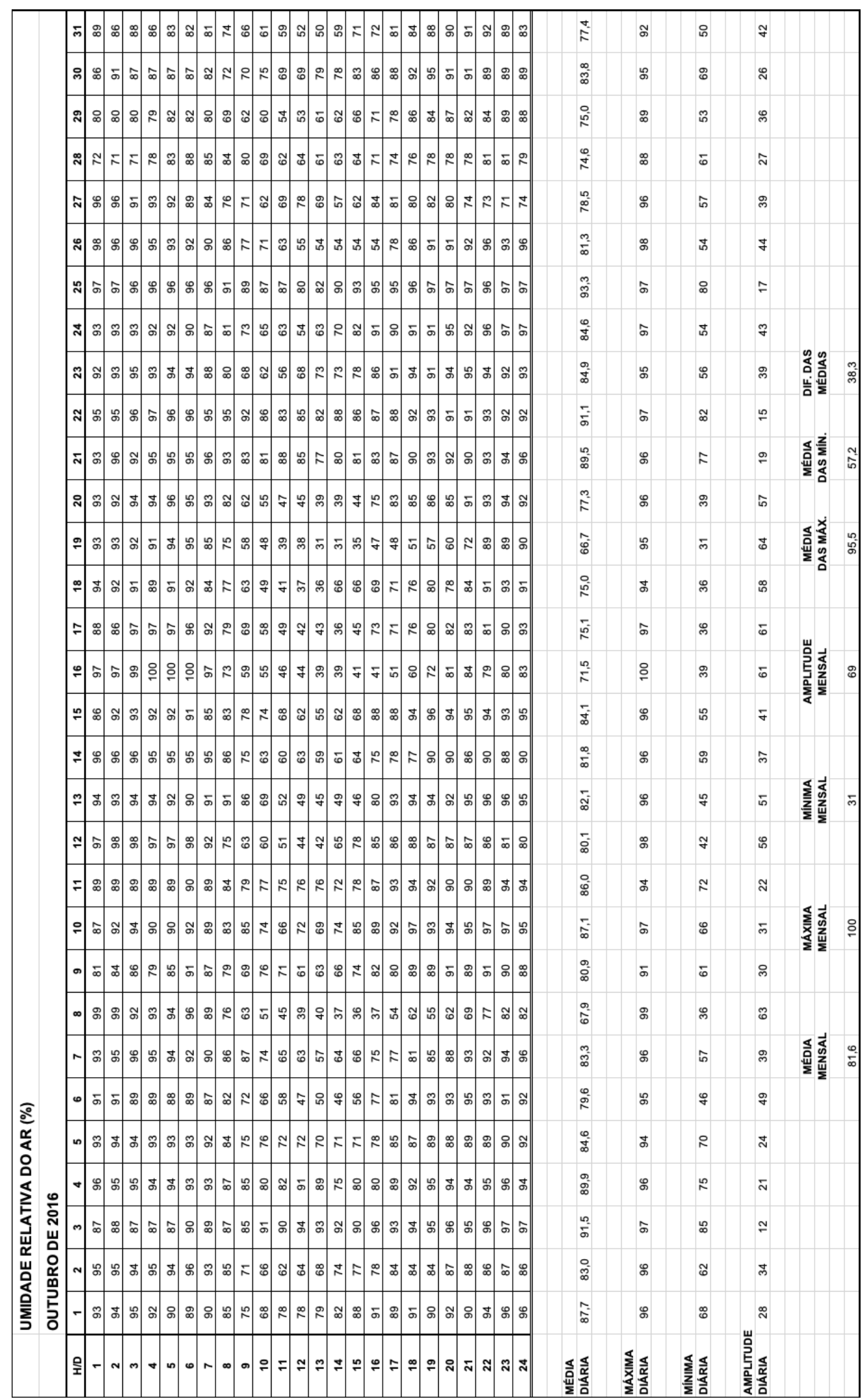




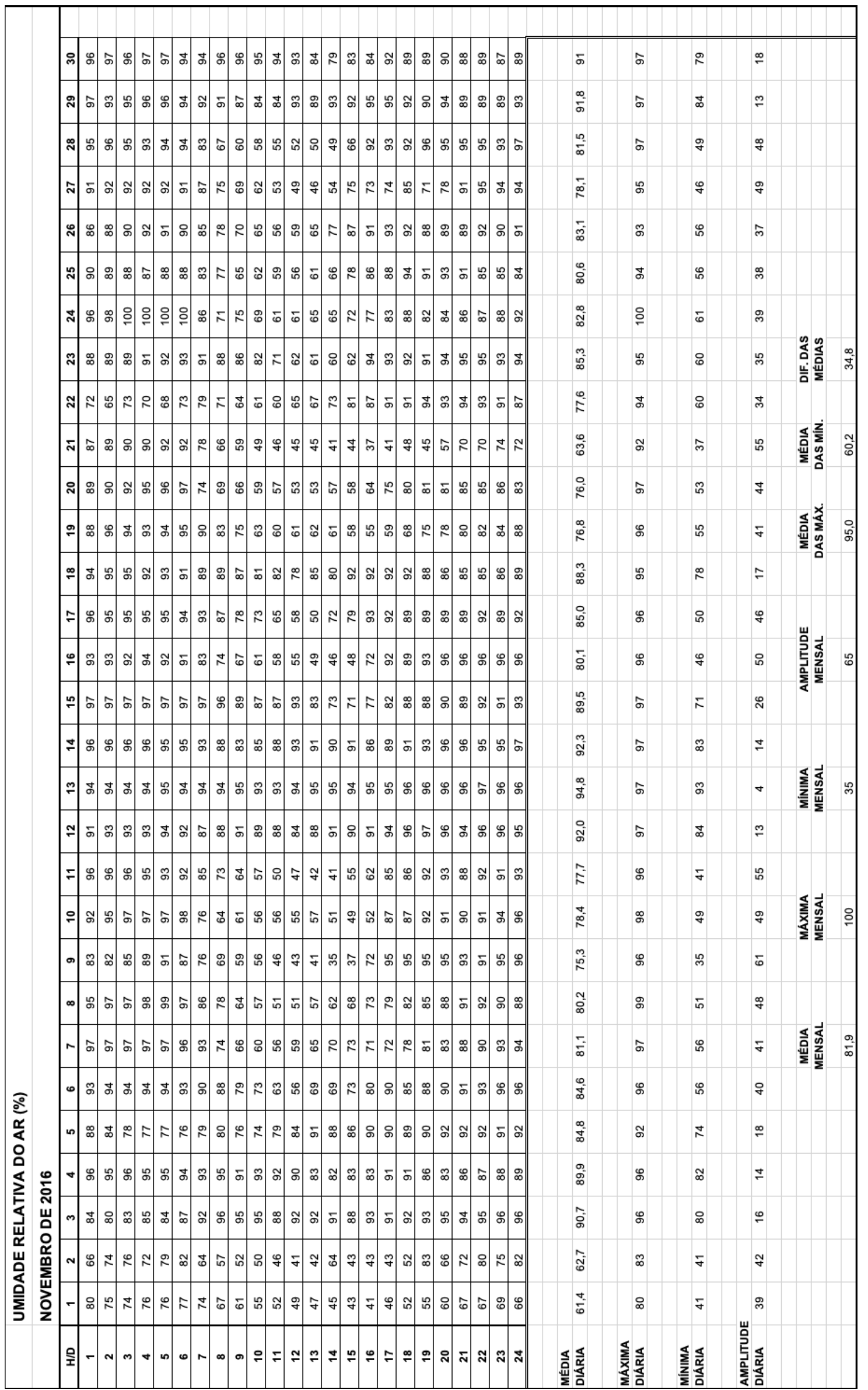




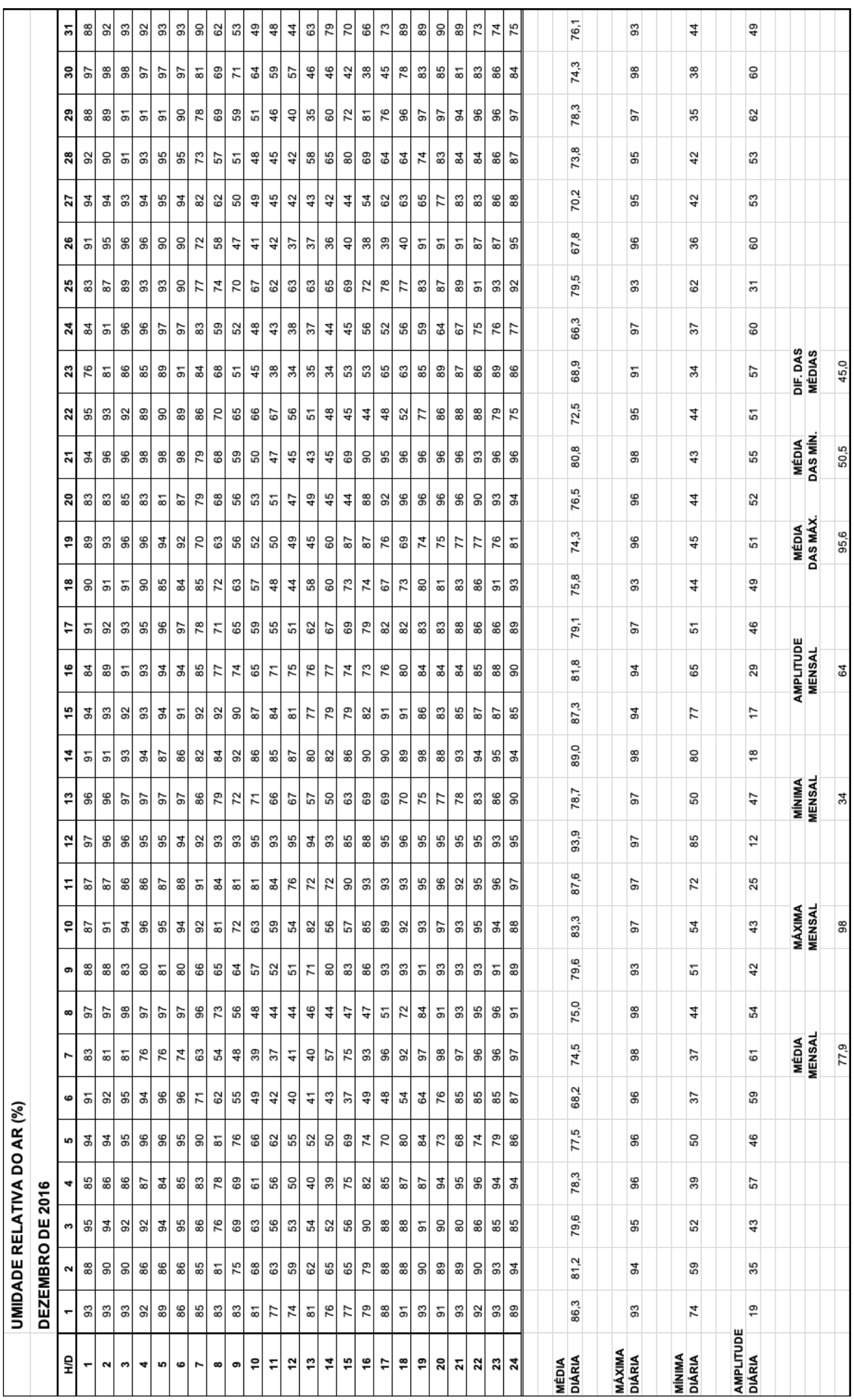




\section{APÊNDICES}

Apêndice A - Consolidação das informações coletadas por meio do sistema de compartilhamento de bicicletas BIKE SAMPA

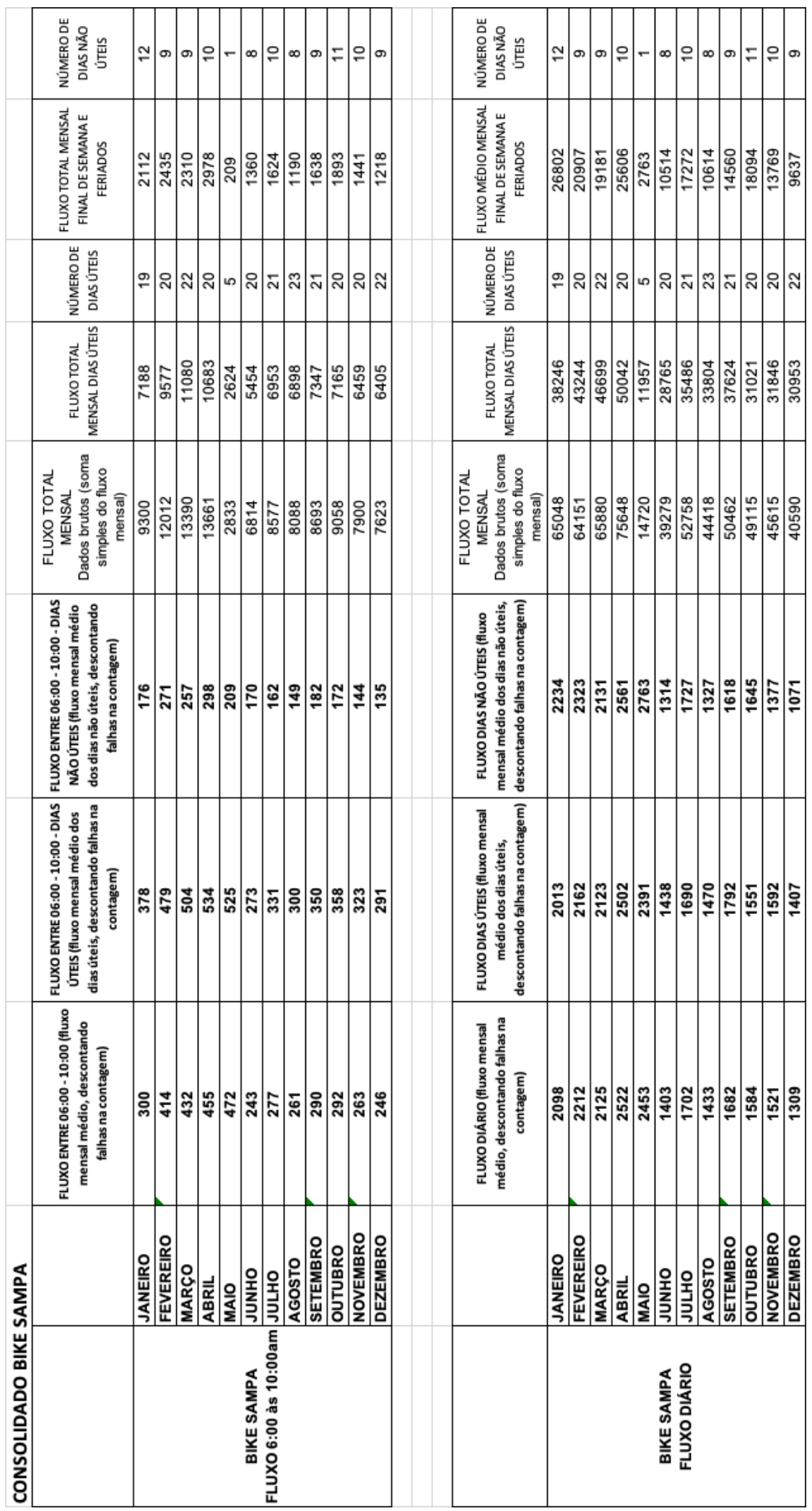


Apêndice B - Gráficos do fluxo anual de bicicletas do sistema de bikesharing

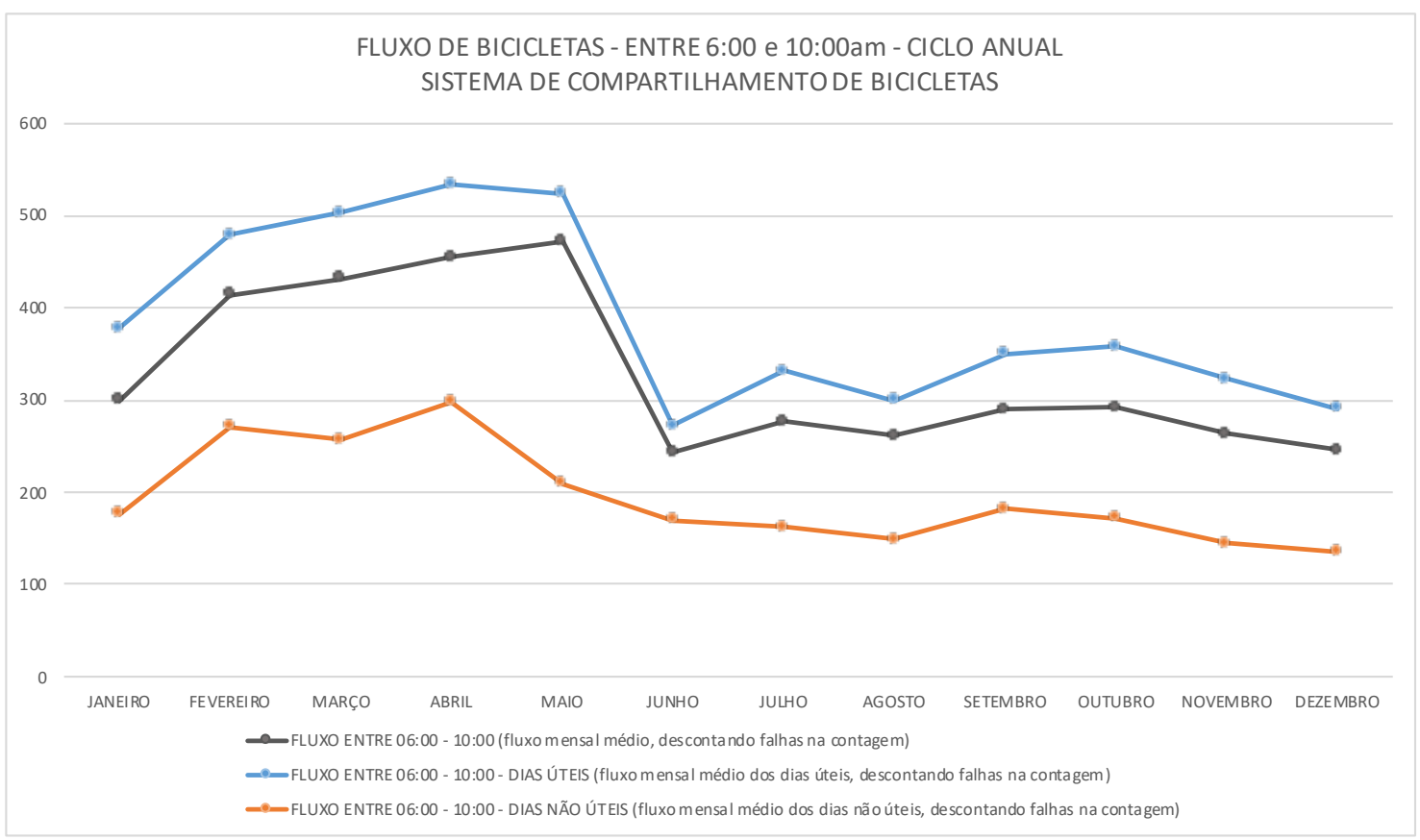

FLUXO DE BICICLETAS DIÁRIO - CICLO ANUAL SISTEMA DE COMPARTILHAMENTO DE BICICLETAS

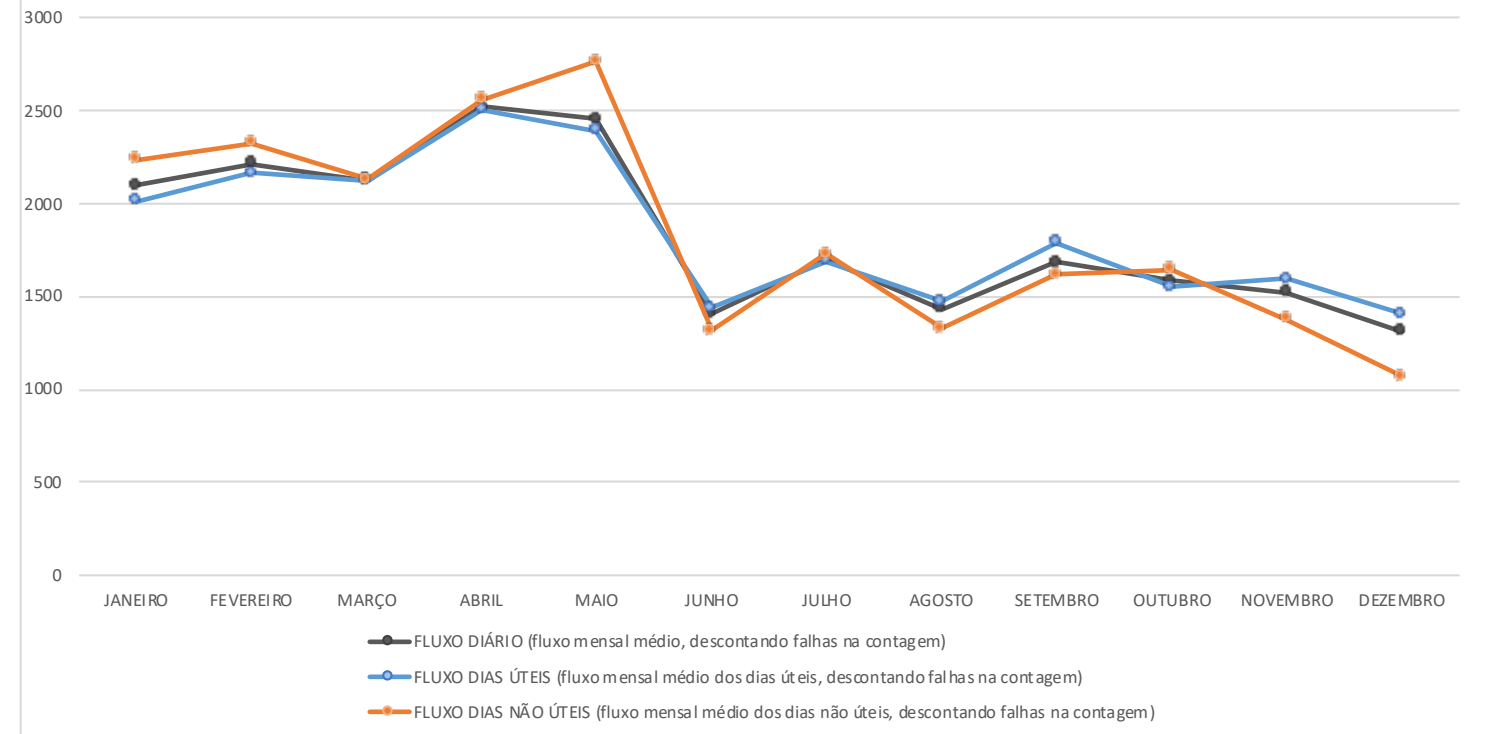


Apêndice C - Fluxo de bicicletas na ciclovia ao longo da Av. Faria Lima em Março de 2016

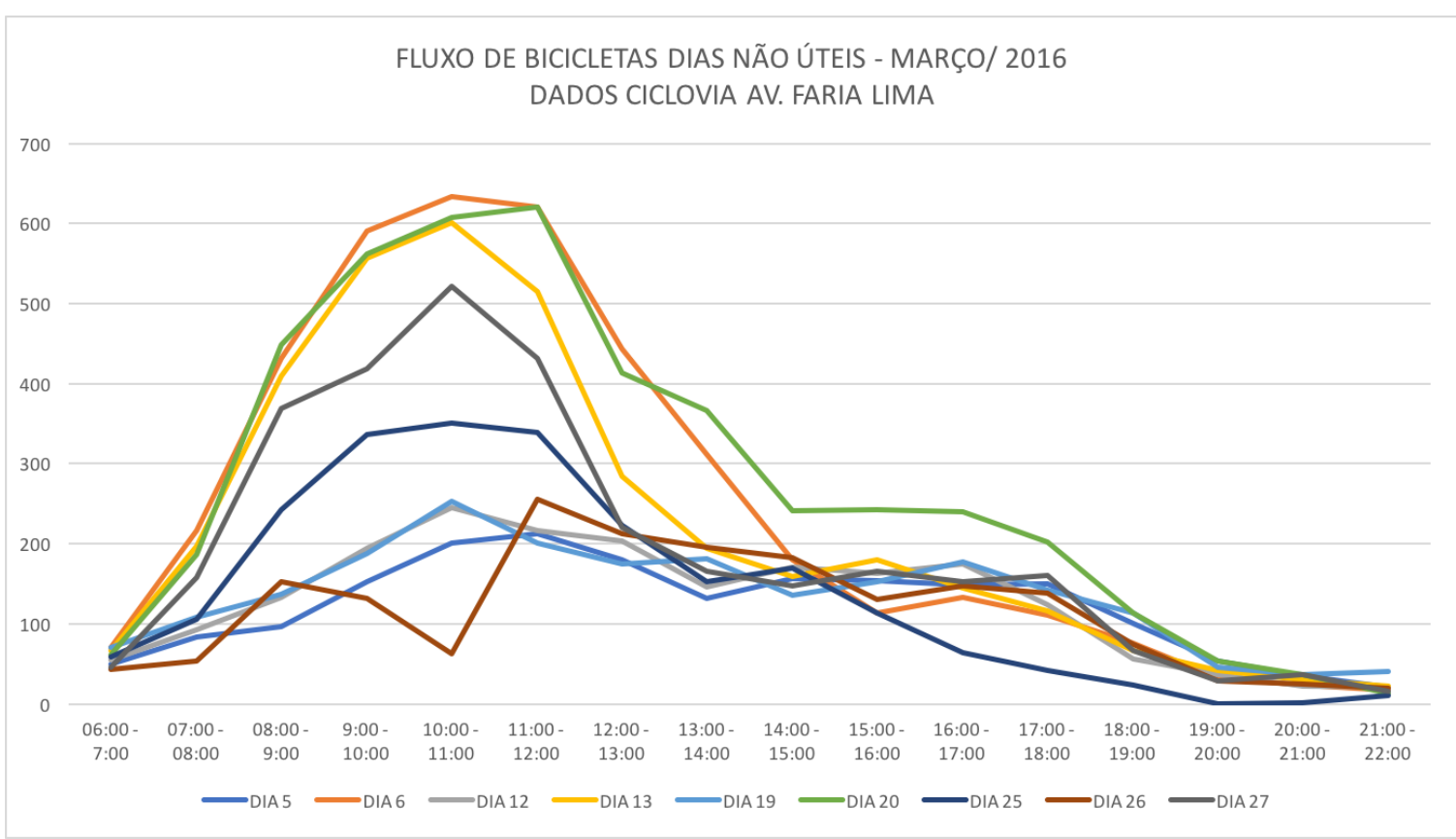

FLUXO DE BICICLETAS DIAS ÚTEIS - MARÇO/ 2016 DADOS CICLOVIA AV. FARIA LIMA

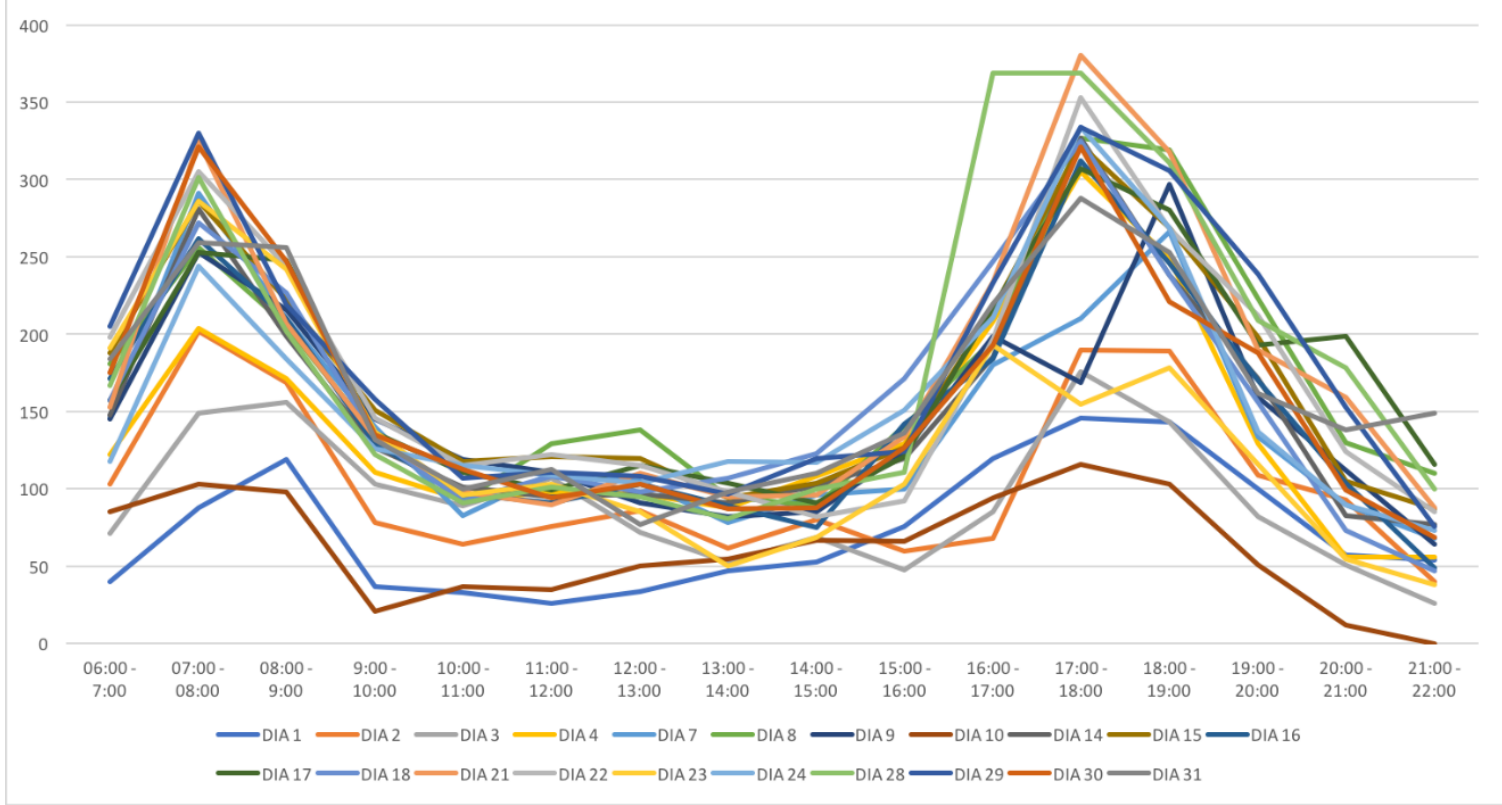


Apêndice D - Tabela com dados consolidados mensalmente de temperatura e umidade relativa do ar, da Estação Meteorológica do IAG, e com dados do fluxo de bicicletas em duas escalas 


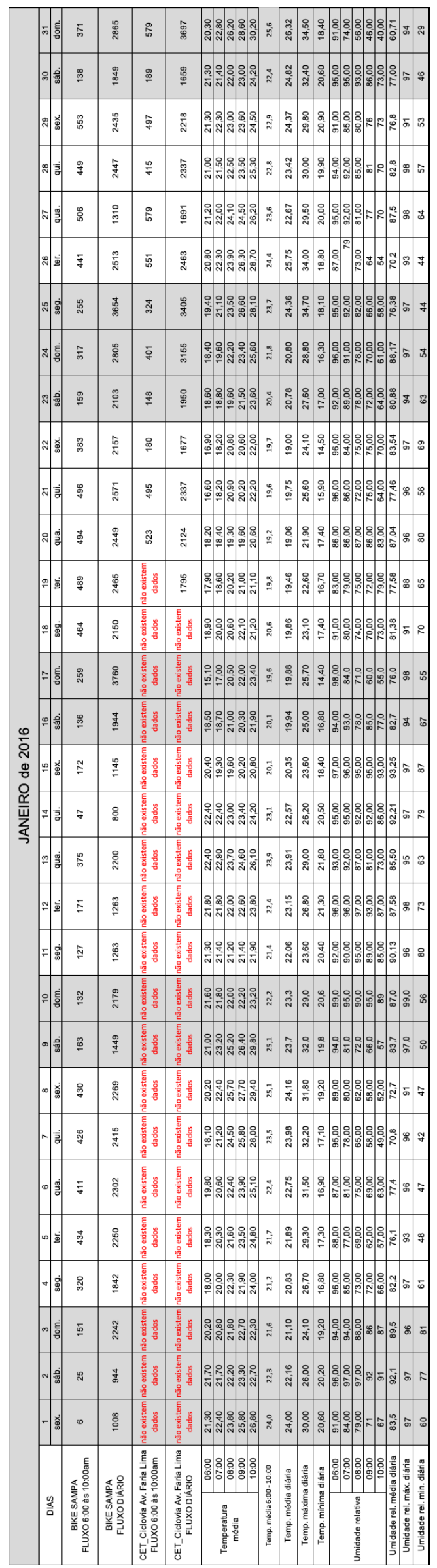




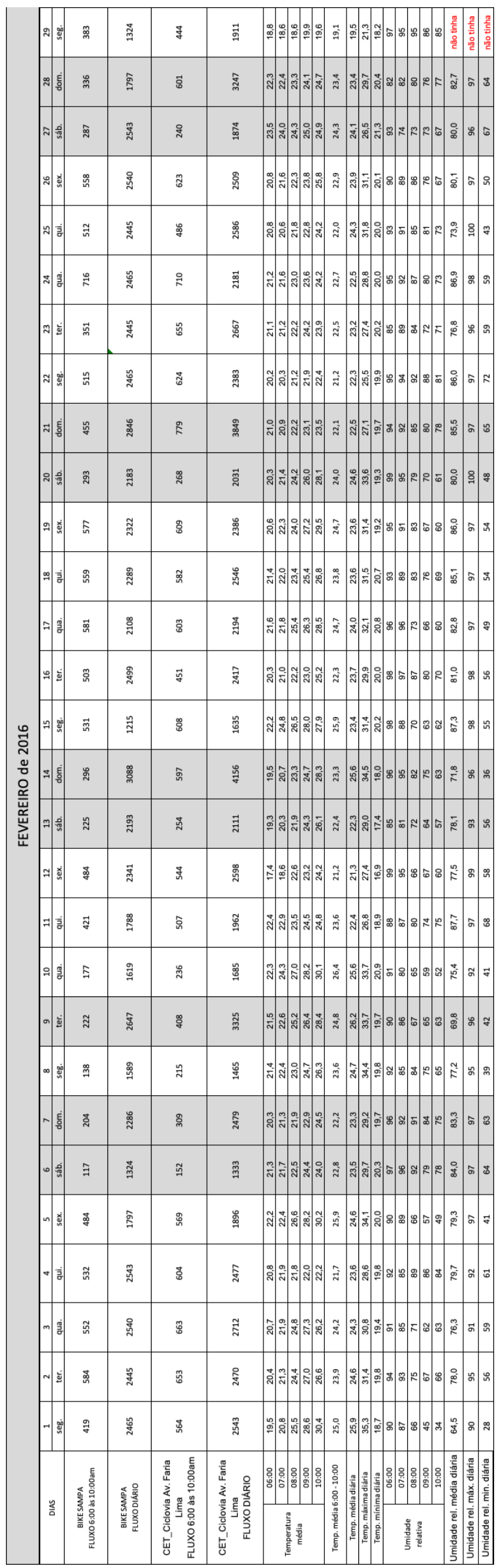




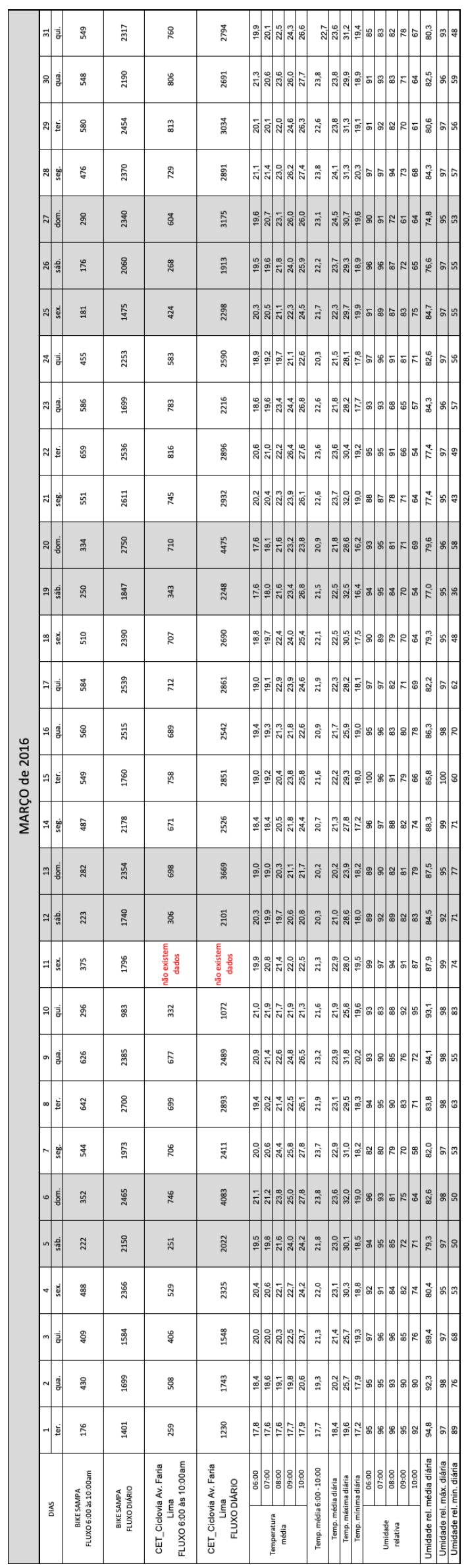




\begin{tabular}{|c|c|c|c|c|c|c|c|c|c|}
\hline & 要 & $\nsubseteq$ & స్ & ळ & ‡ & $\sqrt{1 / 0}$ & 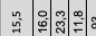 & & $\vdots 2$ \\
\hline & वी & D & 䍖 & $\approx$ & $\frac{E}{\pi}$ & & $\dddot{2} \cong$ & & 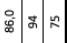 \\
\hline & $\approx$ क & 亏ั) & 思 & : & $\vec{\Phi}$ & & $\dddot{m}: \cong$ & & $\cong \mathscr{\varpi}$ \\
\hline & $\approx \approx$ & 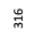 & ॐ్ ొ & $\nexists$ & ప్ & & $\mid$ & & 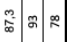 \\
\hline & $\approx$ & $\approx$ & 男 & g & 解 & & $\stackrel{n}{\pi}: \frac{\infty}{2}$ & 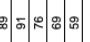 & ஃே \\
\hline & 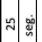 & $g$ & 涸 & 。 & $\vdots$ & & 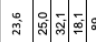 & & $\begin{array}{l}\text { : } \\
0\end{array}$ \\
\hline & $\approx$ हो & ळ్లి & పే & ‡ & 等 & & 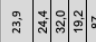 & & $\because \approx$ \\
\hline & $\approx=0$ & స్ & $\exists$ & \& & 志 & & $\underset{\sim}{\infty}$ & & $\stackrel{2}{:}:$ \\
\hline & $\approx \approx$ & 荧 & 第 & F & 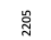 & & $\tilde{\pi}$ & & $\bar{\equiv} \mathrm{m}$ \\
\hline & $\overrightarrow{\mathrm{a}} \overline{\mathrm{z}}$ & $\vec{~}$ & 签 & $\%$ & ğ & 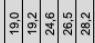 & $\stackrel{m}{\pi}$ & & : \\
\hline & $\therefore$ : & $\tilde{\sigma}$ & 单 & 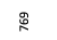 & 里 & & $\tilde{\Xi}$ & & 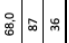 \\
\hline & 9 & \% & हे & $\approx$ & $\vec{g}$ & & $\frac{n}{i}$ & & $\tilde{\Phi} \approx \approx$ \\
\hline & $=0$ & कู & ฆิ & 贺 & 芦 & & 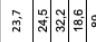 & & $\stackrel{8}{8}: 7$ \\
\hline & $=\frac{\mathrm{g}}{8}$ & $\stackrel{\circ}{\circ}$ & 䍠 & $\stackrel{m}{\varpi}$ & สู & & $\underset{\tilde{\sim}}{\infty} \infty$ & & ฐี \\
\hline & $=\frac{0}{0}$ & 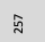 & 亏్ & 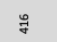 & $\overrightarrow{5}$ & & 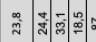 & & $\cong \approx$ \\
\hline בี & $=0$ & 8 & ปิ & 员 & 营 & & $\stackrel{8}{i}$ & & $\frac{2}{2}: m$ \\
\hline 롱 & $\Rightarrow$ & 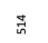 & సి & $\approx$ & $\approx$ & & $\stackrel{n}{\pi}=\frac{q}{2}$ & & $\stackrel{\infty}{\infty}: \infty$ \\
\hline & $m$ & ळ్ & 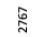 & 听 & $\stackrel{n}{n}$ & & $\approx$ & & 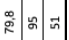 \\
\hline & $\approx \approx$ & ₹ & 賈 & 艿 & $\approx$ & & สิ & & \begin{tabular}{l}
$\infty$ \\
\hdashline
\end{tabular} \\
\hline & $\Rightarrow$ & $\stackrel{\mathscr{B}}{\mathrm{G}}$ & ลี & శొ & 怘 & 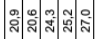 & 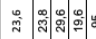 & & $\stackrel{0}{:}$ \\
\hline & 의 & z & 。్ల & 贺 & 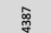 & 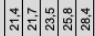 & $\stackrel{\approx}{\Sigma}$ & & $: \%$ \\
\hline & 嗐 & 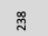 & $\stackrel{\sharp}{\sharp}$ & ల్ల & జ్లొ & 10 & 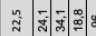 & & : \\
\hline & 我苟 & $\tilde{\tilde{n}}$ & 惫 & 管 & \& & 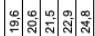 & 굴 & ますのの & ๕๐ะ \\
\hline & - & $\stackrel{\circ}{\circ}$ & ఫ్ & 员 & 尺्ల్లి & 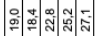 & $\approx=\infty$ & & : \\
\hline & $0 \frac{3}{3}$ & J & : & 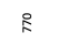 & ธี & & 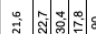 & 8 & ๕๐: \\
\hline & $n$ & 天 & జ్హె & $\tilde{\alpha}$ & 管 & & $m$ & & 包的 \\
\hline & 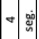 & $\approx$ & 鴣 & 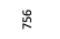 & 表 & & $\overrightarrow{\mathrm{z}} \hat{\mathrm{z}}$ & & ฐ® \\
\hline & m & ల్ల & 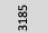 & $\approx$ & ఫั & 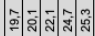 & $\ddot{\sim}:$ & & ま \\
\hline & $\sim$ & ๙ึ & $\stackrel{m}{\sim}$ & $\stackrel{\infty}{\infty}$ & $\stackrel{m}{z}$ & 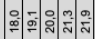 & $\overrightarrow{\mathrm{d}}$ & & ะ๊ : \\
\hline & $-\mid$ & : & 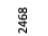 & 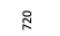 & ஓ్ స్ & $\infty$ & $\overrightarrow{\mathrm{n}}$ & 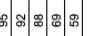 & 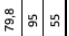 \\
\hline & $\frac{\underline{y}}{\partial}$ & 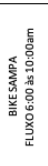 & 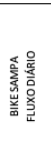 & 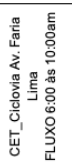 & 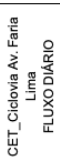 & 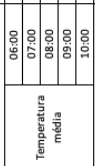 & 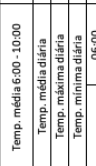 & 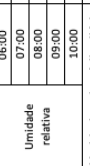 & 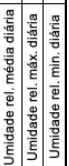 \\
\hline
\end{tabular}




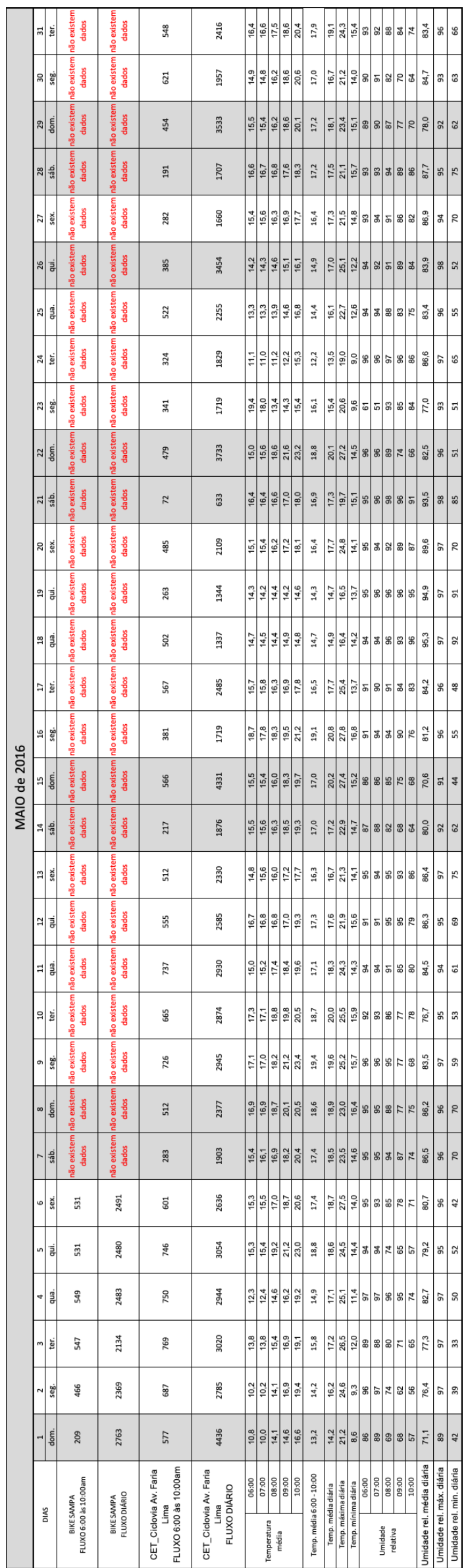




\begin{tabular}{|c|c|c|c|c|c|c|c|c|c|c|}
\hline & 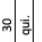 & $\overrightarrow{0}$ & 兽 & : & ฐ్సి & 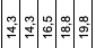 & $\Phi$ & & 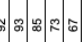 & $\begin{array}{lll}0 \\
\vdots\end{array}$ \\
\hline & 2) & g్ & 魚 & $\stackrel{\infty}{*}$ & हूँ & & $g$ & & 580 & 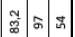 \\
\hline & $\approx$ & 兽 & 毒 & $\ddot{\sigma}$ & 晜 & & $\stackrel{\infty}{m}$ & & $D=8$ & $\widehat{c}$ \\
\hline & $\approx$ 约 & 畾 & gू & $\vec{G}$ & ฐ & & $\stackrel{m}{a}$ & & & 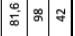 \\
\hline & $\approx$ 部 & $\Xi$ & $\Xi$ & $\AA$ & :్లి & & $\frac{9}{\exists}$ & & & $\dot{2}: \div$ \\
\hline & a & $\approx$ & $\exists$ & $\cong$ & $\Xi$ & & $\cong$ & & & \%ั: \\
\hline & 2 & 8 & 总 & $\approx$ & ฐิ & 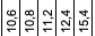 & $\vec{z}$ & & 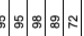 & 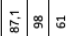 \\
\hline & च & 兽 & \%్ & 㽞 & 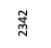 & 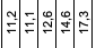 & $\ddot{m}$ & & & $5 \approx$ \\
\hline & $\approx \approx$ & $\stackrel{\tilde{m}}{ }$ & 苫 & \& & 鸮 & & $\overrightarrow{3}$ & & 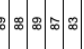 & $\stackrel{\tilde{\Phi}}{\mathscr{\Phi}}:=$ \\
\hline & 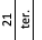 & ఖ & ‡్ & $\approx$ & 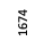 & & $\vec{\Xi}$ & & 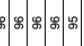 & के \\
\hline & 2 $\approx$ : & $\approx$ & 品 & 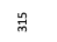 & $\Xi$ & 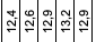 & $\approx$ & 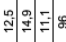 & 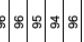 & 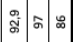 \\
\hline & 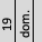 & $\approx$ & ఫ్ & 斁 & 浿 & & 3 & & $\Phi$ & ळ \\
\hline & 9 & $\dddot{\varpi}$ & $\stackrel{\Xi}{\exists}$ & ฮี & छ & & $\vec{m}$ & & & 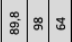 \\
\hline & $\Rightarrow=$ 总 & 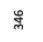 & $\overrightarrow{\underline{m}}$ & $\mathscr{m}$ & $\stackrel{్}{\pi}$ & & 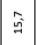 & & & $\begin{array}{llll}0 & 07\end{array}$ \\
\hline & $=\frac{5}{5}$ & శ్లి & 㟔 & $\hbar$ & 蒡 & & $\frac{m}{z}$ & 유: & 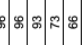 & \begin{tabular}{l|l}
$*$ & $:$
\end{tabular} \\
\hline ڤี & $=5$ & $\stackrel{\infty}{m}$ & 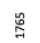 & जี & สి & 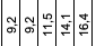 & $\exists$ & & & 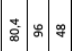 \\
\hline 울 & $=$ & స్ల & శ్రొ & 㫄 & ఫ్స & & 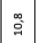 & & $\$ 8$ & $\approx$ \\
\hline & 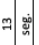 & $\Xi$ & 鸪 & \% & $\stackrel{\mathscr{g}}{9}$ & & $\stackrel{\circ}{:}$ & & & 悉 \\
\hline & $\approx$ : & 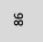 & 兽 & $\nexists$ & $\stackrel{m}{\pi}$ & & 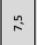 & & & $\stackrel{2}{2}$ \\
\hline & $=0$ & $\exists$ & $\nexists$ & $\nsubseteq$ & 国 & & 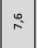 & & $8 \mid \sin$ & $\frac{m}{2}=$ \\
\hline & 의 & $\stackrel{m}{\sim}$ & 吕 & $\overrightarrow{5}$ & 吾 & & $\approx$ & & 至 & $\stackrel{\circ}{\circ}: 7$ \\
\hline & o. & శ్ & 洄 & 怠 & สँ & & $\sigma_{\sigma}^{m}$ & & $\$$ & 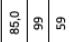 \\
\hline & $\infty$ & $\nsubseteq$ & $\stackrel{2}{\infty}$ & 号 & 奠 & & $\exists$ & & 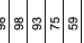 & 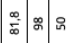 \\
\hline & $\therefore$ & ๘ & : & 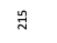 & 曾 & & $\vec{m}$ & & & 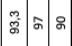 \\
\hline & 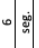 & 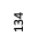 & \% & 第 & 䎖 & & 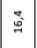 & & 8 & 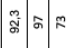 \\
\hline & m & 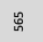 & 윰 & 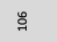 & $\dddot{\Xi}$ & 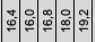 & $\cong$ & & $\mathbb{\infty}: \infty$ & 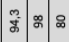 \\
\hline & $+\frac{6}{2}$ & ప & ๙ి & 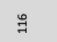 & इ & & $\vec{s}$ & & $\$ \%$ & $\%$ \\
\hline & m) & $\approx$ & 岁 & 유 & $\nexists$ & & 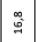 & & 50 & $\frac{m}{\bar{\omega}} \approx 2$ \\
\hline & $\sim . \overline{\text { | }}$ & 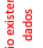 & 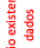 & $\dddot{q}$ & : & & $\Xi$ & & $\Leftrightarrow \% \mathbb{F}$ & $\tilde{\Phi}: \approx$ \\
\hline & $-\frac{5}{5}$ & 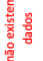 & 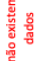 & $\%$ & $\stackrel{m}{\tilde{N}}$ & $=0$ & 䍠 & & & $\approx$ \\
\hline & 言 & 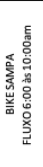 & 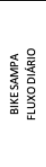 & 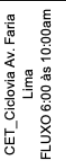 & 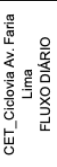 & 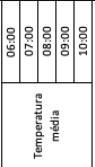 & 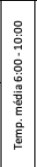 & 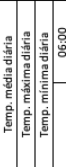 & 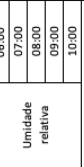 & 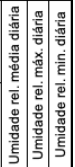 \\
\hline
\end{tabular}




\begin{tabular}{|c|c|c|c|c|c|c|c|c|c|}
\hline & लm & 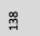 & ‡్ & $\approx$ & 岛 & $\frac{7}{y}=0$ & $\dot{\Xi}:$ & $\approx \approx \infty 10$ & $\approx$ \\
\hline & $\therefore:$ & ‡ & च్g & $\cong$ & 嵒 & & 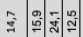 & & 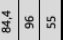 \\
\hline & aी & ప & 畣 & 夈 & 吕 & & $\stackrel{\infty}{m}$ & ๑ま & 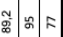 \\
\hline & 呟 & 总 & 等 & 蛋 & 暴 & $\because$ & $\hat{\approx} \bar{g}$ & $A: \mathbb{:}: 0$ & : \\
\hline & $\approx \approx$ & $\approx$ & 曽 & 8 & 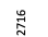 & 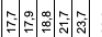 & $\stackrel{\square}{:}$ & 898 & $\begin{array}{llll}8 & 0 & 0\end{array}$ \\
\hline & $\div$ & 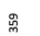 & 禺 & : & 等 & $\Phi$ & $: 0$ & 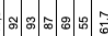 & $\begin{array}{r}5 \\
\overline{0}\end{array}$ \\
\hline & 跑 & $\tilde{n}$ & 尊 & $\approx$ & 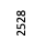 & & 可 & 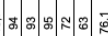 & : \\
\hline & $\approx$ : & $\vec{d}$ & है & 号 & $\stackrel{\text { ğ }}{7}$ & 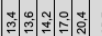 & $\Xi \pm$ & $8: 8:$ & : $: \mathrm{m}$ \\
\hline & 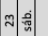 & 。్ల & ‡ & ప्व & 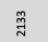 & $\approx$ & 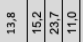 & 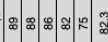 & $\approx$ \\
\hline & $\approx$ a & 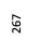 & 嘿 & $\approx$ & बี & & $: \approx$ & 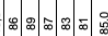 & 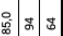 \\
\hline & $\vec{\approx}$ & $\underset{\mathrm{g}}{\mathrm{m}}$ & $\stackrel{\underline{g}}{g}$ & 号 & ह & . & $\dddot{\approx}$ & 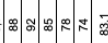 & 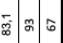 \\
\hline & $2 \mid \frac{j}{z}$ & శ్లి & ఏొ & $\frac{8}{4}$ & హ్ స్ & & $\exists \overline{:}$ & 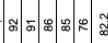 & 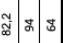 \\
\hline & g) & $\stackrel{n}{N}$ & 高 & $\stackrel{m}{\xi}$ & ఫ్సి & & 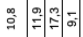 & 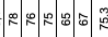 & ڤே \\
\hline & 象 & 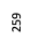 & 兽 & 羿 & छे & & $\stackrel{2}{\circ}$ & $R=\underbrace{\infty}_{\pi}$ & ז๊: : \\
\hline & $=\mathrm{a}$ & 8 & 岁 & ষ্ণ & $\approx$ & t & 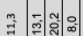 & 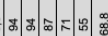 & : $: 2$ \\
\hline & $=\mid$ & $\sqsubseteq$ & $\Sigma$ & gి & ๓ू & @ & $\Xi$ & 2 & : $: 8$ \\
\hline ष्๊ & $=0$ & ₹ & 㴓 & 急 & $\approx \approx \pi$ & 30 & : & 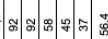 & 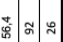 \\
\hline & $=$ & 芦 & 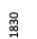 & 范 & జ్ & 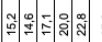 & $g \bar{a}$ & 8 & $\tilde{8}: \approx$ \\
\hline & $m$ & $\nexists$ & 曽 & 范 & 苞 & 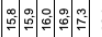 & $\dot{\Xi}$ & $\approx \tilde{\Sigma}$ & 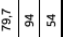 \\
\hline & $\approx$ & $\exists$ & 兽 & $\overrightarrow{\mathrm{g}}$ & 参 & & 心 & & $\stackrel{\circ}{\circ}$ \\
\hline & $=$ & $g$ & ఏ & ซ & झㄱ & 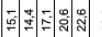 & 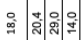 & 8 & $\because \approx$ \\
\hline & 9 晏 & ฐ & ચ & 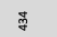 & 奇 & 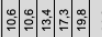 & $\frac{m}{3}$ & ه & : : \\
\hline & $\circ:$ & $\ddot{g}$ & 品 & $\vec{a}$ & 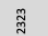 & & 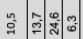 & 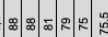 & 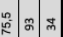 \\
\hline & $\infty$ 苟 & 总 & हे & ᄒ & สี & & 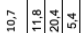 & $A$ & 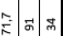 \\
\hline & 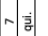 & m & 崽 & हn & 劳 & & 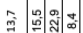 & 89 & 妾: \\
\hline & . & $\dddot{q}$ & 量 & జ & $\underset{\tilde{N}}{\tilde{N}}$ & & : & $\overline{8}$ & : \\
\hline & $m$ & 兽 & జี้ & 号 & 管 & & 5 & 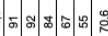 & : \\
\hline & + & m & E & m & 㚃 & & $\Phi$ & $\Phi$ & \pm \\
\hline & $\mathrm{m}$ & ‡ & 椫 & ๓ & 商 & 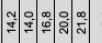 & $\Xi \pm$ & $=80$ & 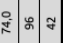 \\
\hline & $\sim$ 열 & $\Xi$ & 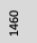 & $\approx$ & సั & 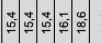 & $\tilde{0}$ & $\mathscr{g} \mathscr{\infty}$ & : $:$ \\
\hline & 同 & $\approx$ & 喟 & जे & สี & 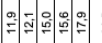 & $\because$ & & 9 \\
\hline & $\frac{\underline{2}}{\bar{a}}$ & 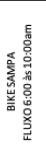 & 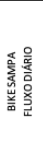 & 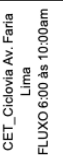 & 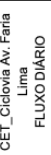 & 年 & 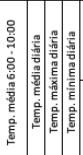 & 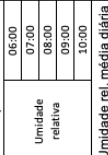 & 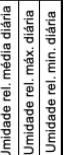 \\
\hline
\end{tabular}




\begin{tabular}{|c|c|c|c|c|c|c|c|c|c|}
\hline & 髚 & 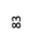 & สू & ส & 苟 & 党: & 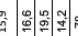 & $\Phi$ & $: 2$ \\
\hline & 影 & $\frac{8}{7}$ & 多 & 邑 & $\underset{m}{\stackrel{m}{m}}$ & & a: & & \% \\
\hline & वा & \% & ‡ & 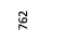 & इे & $\stackrel{000}{0}$ & 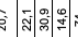 & & $\$$ ฉ \\
\hline & จ & $\Xi$ & ఫ్సి & 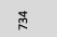 & ఫ్ & & : & & $\overrightarrow{2} \approx$ \\
\hline & $\approx \approx$ & ळ & 吕 & ळ & 芶 & 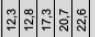 & & $\mathbb{D}|g|$ & $\approx$ \\
\hline & 象 & $\stackrel{\infty}{m}$ & ฐి & 8 & ฟี & 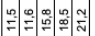 & 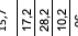 & $\frac{\pi}{2}$ & $\because$ \\
\hline & $\approx$ & 范 & 罵 & 吕 & 峾 & & 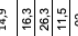 & & $\%$ \\
\hline & 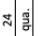 & : & $\Xi$ & 思 & $\nexists$ & 苞: & : & $\left.8\right|_{\tilde{E}} ^{*}$ & $: \neq 1$ \\
\hline & $\approx$ & 芩 & 惢 & $\approx$ & 亗 & 象: & 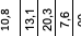 & $\overline{\tilde{\alpha}}$ & $\approx:$ \\
\hline & $\approx$ च & $\cong$ & इ & జ & $\nexists$ & : & \% & 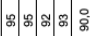 & $\because 2$ \\
\hline & $\approx$ च & 8 & ఏે & 8 & ๓ & 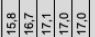 & 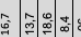 & & $\approx \approx$ \\
\hline & 䄜 & 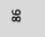 & 器 & g & छ & & $\approx$ & & $\approx:$ \\
\hline & of & జ & 䓓 & $\approx$ & ळ & 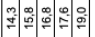 & 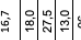 & & $\approx$ \\
\hline & $\approx$ a & $\vec{~}$ & 号 & 品 & 囟 & $\tilde{a}$ & $\vec{\Phi}$ & & $\approx: 1$ \\
\hline & $\Rightarrow \frac{j}{3}$ & 일 & g & 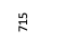 & 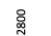 & 뙤죠 & 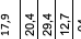 & & $\because \div$ \\
\hline & $=0$ & 羔 & క్రి & E & ఫ్ & 8 & $:$ & & $\because 7$ \\
\hline 응 & A & ฉี & $\dddot{m}$ & 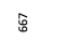 & 兑 & $\overbrace{}^{\infty}$ & $\Xi$ & & $\approx \approx$ \\
\hline प्र & 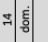 & $\ddot{a}$ & g & 霖 & 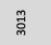 & $\frac{m}{i}$ & $\tilde{\Xi}$ & & $\approx \approx$ \\
\hline & $m \frac{1}{2}$ & ळ & 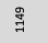 & ळ & ఏ్ & & $\cong$ & & $\approx \approx$ \\
\hline & $\approx \approx$ & ‡ & ‡ & 争 & 鹃 & & 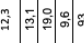 & & $: \because$ \\
\hline & $=\frac{\dot{a}}{2}$ & 擘 & $\dddot{\sharp}$ & 总 & : & & 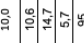 & & $\because 2$ \\
\hline & of & $\stackrel{2}{\pi}$ & ฐ్ & : & శ్శి & & $\approx$ & & $\because 8$ \\
\hline & $\sigma$ & 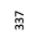 & 高 & त्ठㅇ & 兽 & & $\Xi$ & & $::$ \\
\hline & $\infty$ & $\approx$ & 青 & \% & ఫั & & 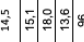 & & $\because:$ \\
\hline & $\wedge$ & ন & ฐี & $\overrightarrow{\mathrm{g}}$ & 丞 & & 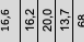 & & $: \%$ \\
\hline & $6 \frac{1}{2}$ & $\dddot{\varpi}$ & $\Xi$ & $\approx$ & สี & & ฐ & ฉ & $\approx \approx$ \\
\hline & 嗦 & $\stackrel{\infty}{\sim}$ & 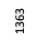 & E & 兽 & & $\vdots$ & & $\approx \equiv$ \\
\hline & $+\frac{\dot{3}}{3}$ & ఫ్ల & 鴣 & $\frac{\vec{b}}{\sigma}$ & 品 & & 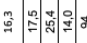 & $08 \frac{\pi}{\infty}$ & 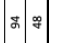 \\
\hline & $\mathrm{m} \frac{\mathrm{g}}{\mathrm{g}}$ & 品 & ঐ & $\approx$ & 荬 & & 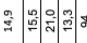 & 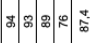 & $\approx$ \\
\hline & $\sim$ & 尔 & $\stackrel{m}{m}$ & 鬲 & $\approx$ & 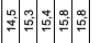 & 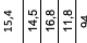 & $\approx \approx$ & $\approx$ \\
\hline & - & . & ‡̊ & : & 兽 & & 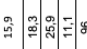 & $\mathscr{E} \mathscr{\mathscr { E }} \mathbb{\infty}$ & $\approx 9$ \\
\hline & $\frac{\underline{y}}{\bar{a}}$ & 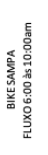 & 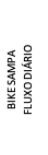 & 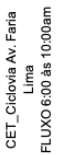 & 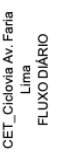 & 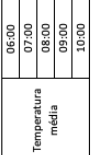 & 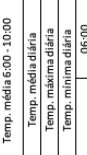 & 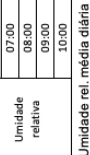 & 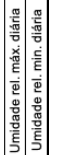 \\
\hline
\end{tabular}




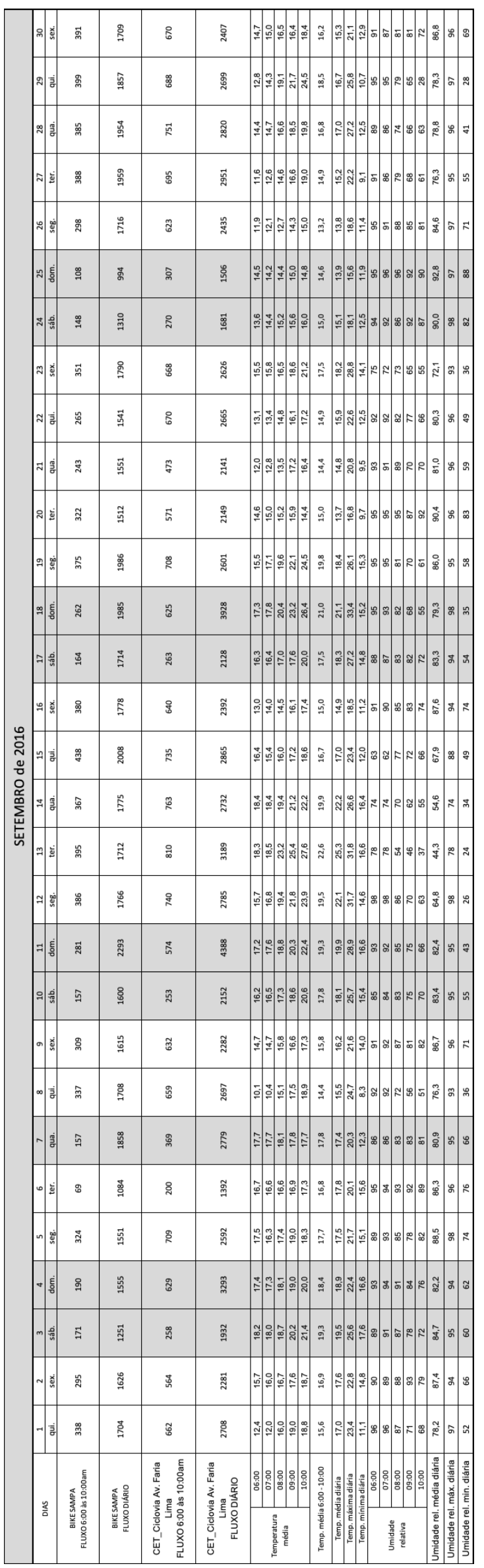




\begin{tabular}{|c|c|c|c|c|c|c|c|c|c|}
\hline & 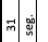 & $\vec{\Phi}$ & 嚍 & & & 80 & $\stackrel{\square}{\Xi}:$ & $8:=$ & $\approx \approx$ \\
\hline & 9. & 8 & 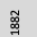 & s & శ్శి & & 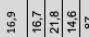 & $\approx 2: 10$ & $: 8$ \\
\hline & 2) & $\cong$ & ప్g & $\nexists$ & $\stackrel{\tilde{a}}{a}$ & & $\dot{g}:$ & $: 8$ & : \\
\hline & $\approx$ & g & 욤 & 영 & శ్ & & $: 0$ & $8 \mid 8$ & $\begin{array}{l}0 \\
:\end{array}$ \\
\hline & $\approx=$ & 足 & 象 & $\overline{6}$ & $\nexists$ & & $\approx$ & $\approx \approx \approx$ & $8:$ in \\
\hline & 2 & 荤 & $\nexists$ & \% & 籴 & & $\approx \tilde{\tilde{z}}$ & $A=\approx$ & $:$ \\
\hline & $\approx$ & $\vec{\Phi}$ & \$ & 岁 & ప్రి & & 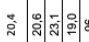 & $=$ & 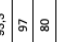 \\
\hline & $\approx$ & $\approx$ & 䒱 & : & 苟 & : & $\approx$ & & $\approx$ \\
\hline & $\approx$ & ‡ & $\$$ & $\stackrel{\infty}{\xi}$ & 商 & 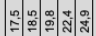 & $\stackrel{\square}{\square}$ & 88 & 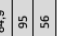 \\
\hline & $\approx \approx \frac{1}{2}$ & 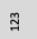 & క్ర & $\Xi$ & 寖 & & $\cong:$ & & $\approx \approx$ \\
\hline & त周 & $\stackrel{0}{\pi}$ & 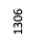 & 果 & $\$$ & & $\tilde{z}:$ & & $:=$ \\
\hline & $\therefore$ 한 & กิ & $\Xi$ & q & g & & $\vec{i}$ & & $\approx \%$ \\
\hline & $\Rightarrow 2$ & 学 & 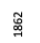 & 蛋 & 照 & & 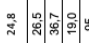 & 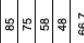 & 50 \\
\hline & $\rightarrow$ & 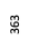 & 嘼 & $\approx$ & 蒡 & & 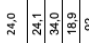 & 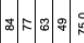 & $\approx$ \\
\hline & $\Rightarrow \approx$ & ‡ & 䍖 & $\$$ & 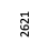 & 困䒽| & 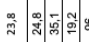 & & $\therefore \approx$ \\
\hline$\stackrel{0}{\circ}$ & $=\mid \frac{1}{8}$ & $\approx$ & ‡్ & 骂 & ‡ & & $\stackrel{n}{n}$ & & $8 \%$ \\
\hline 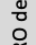 & $=0$. & $\Xi$ & 幽 & ప్ల & ี & & $\stackrel{2}{\frac{\pi}{2}}$ & 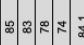 & $\approx$ \\
\hline है & $\Rightarrow$ & $\approx$ & ఏ & कू & 菅 & 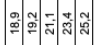 & $\stackrel{\leftrightarrow}{\mathrm{i}}$ & $\frac{1}{2}$ & $: \%$ \\
\hline & $m=\frac{1}{2}$ & 曽 & 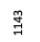 & 莴 & 兽 & 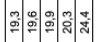 & $\hat{a}$ & $\dot{2}$ & $5: \%$ \\
\hline & $\approx \approx$ & จี & 尊 & है & క్య & ๕: : : : : & 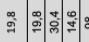 & & $\approx$ \\
\hline & $\Rightarrow$ & $\stackrel{\circ}{\circ}$ & $\frac{9}{9}$ & 웅 & ప్స & & $\cong \approx$ & 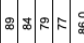 & $\approx \approx$ \\
\hline & $=$ & $\vec{\Phi}$ & 害 & g & 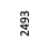 & 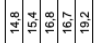 & $\stackrel{:}{:}:$ & & $\approx:$ \\
\hline & o & ఫి & ‡ & $\$$ & ‡ู & 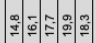 & $\Xi:$ & & मี \\
\hline & $\infty)$ & g & 营 & a & $\frac{\mathrm{m}}{\mathrm{z}}$ & 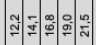 & 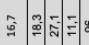 & & \% \\
\hline & $\sim:$ & मे & 照 & 箩 & 泀 & & 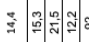 & \& & $: 5$ \\
\hline & 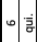 & 总 & శ్g & : & ‡్శ & $\stackrel{0}{0}=0$ & 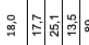 & 08 & 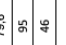 \\
\hline & $\operatorname{mos}$ & 兽 & 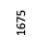 & 兽 & 萦 & 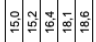 & 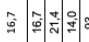 & 202 & $: 2$ \\
\hline & + & 岁 & ন্ন & 9 & 芩 & 90 & 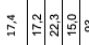 & ๓ & $=2$ \\
\hline & $m$ & 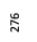 & $\vec{b}$ & g & ‡ & 6 & $\stackrel{0}{0}$ & 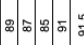 & $\approx \infty$ \\
\hline & $\sim$ & 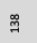 & 兽 & ळ్ & ন & $\Xi \dot{0}=0$ & 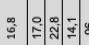 & 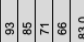 & \% \\
\hline & $-\frac{1}{4}$ & 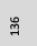 & $\underline{\Xi}$ & $\exists$ & 帝 & 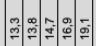 & 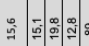 & & $: \%$ \\
\hline & 气̀ & 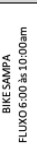 & 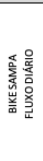 & 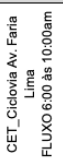 & 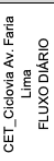 & 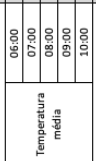 & 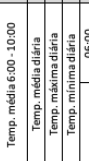 & $\frac{0}{8}$ & 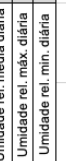 \\
\hline
\end{tabular}




\begin{tabular}{|c|c|c|c|c|c|c|c|c|c|}
\hline & 0 & 号 & 西 & 䄅 & 晜 & & 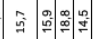 & 3 & $\frac{N}{\bar{\alpha}} \mid \approx=$ \\
\hline & a & ळ్లి & $\stackrel{n}{g}$ & $\approx$ & $\stackrel{\circ}{\text { g }}$ & & $\overrightarrow{\mathrm{J}}$ & $\frac{8}{2}$ & $\stackrel{\infty}{\infty} \approx$ \\
\hline & ح & 윰 & 曾 & ฐ & 兽 & & $\stackrel{n}{n}$ & 680 & $\stackrel{\circ}{\circ} \approx$ \\
\hline & $\approx$ ㅎํㅇ & $\approx$ & 䠢 & § & ğ & & $\ddot{i}$ & & $\bar{x}: \approx$ \\
\hline & * * & $\Phi$ & 重 & $\ddot{d}$ & 己्च & & $\stackrel{\pi}{\pi}$ & & $\bar{m}$ \\
\hline & 용 & 莀 & $\Xi$ & 8 & $\vec{g}$ & an: & 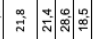 & 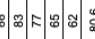 & $\stackrel{\square}{\square}:$ \\
\hline & $z=$ & $\stackrel{\infty}{m}$ & $\tilde{z}$ & g & $\frac{2}{2}$ & & $\tilde{\mathrm{J}} \hat{\mathrm{i}}$ & 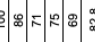 & $\underset{\varpi}{\infty}: \vec{f}$ \\
\hline & $\approx \frac{5}{2}$ & $\Phi$ & శ్ & के & $\stackrel{\text { m }}{\text { ᄀి }}$ & & $\stackrel{m}{g}: \stackrel{*}{2}$ & $\mathbb{\Phi} \mid \mathbb{\infty}$ & 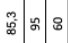 \\
\hline & $\approx$ & 面 & $\dddot{\Xi}$ & 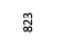 & 율 & & $:$ & 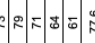 & $\stackrel{2}{\approx}: 8$ \\
\hline & تः & $\vec{j}$ & $\stackrel{8}{8}$ & 吾 & 兽 & & $\Xi$ & 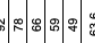 & $\%$ \% \\
\hline & ㅇㅎㅎ & $\Phi$ & 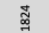 & స్ & ल/ & & $\hat{n}$ & 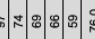 & 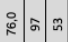 \\
\hline & 9: & み & $\Xi$ & : & 泪 & & 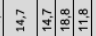 & & 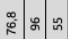 \\
\hline & 의 & 帝 & : & 윱 & 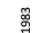 & & 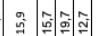 & & 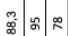 \\
\hline & $\Rightarrow$ & 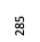 & 莺 & 逭 & 윢 & & 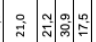 & & 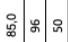 \\
\hline & $=\frac{3}{3}$ & $\approx$ & $\vec{\sigma}$ & gి & శ్లి & & $\ddot{i}$ & & $\overline{8}: \%$ \\
\hline ฮิ & $=$ & \$ & $\Xi$ & ळ & :ึّ & & $m$ & & \\
\hline 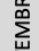 & 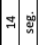 & $\mathscr{\infty}$ & 嚍 & $\cong$ & $\approx$ & & $\tilde{\Phi}: \hat{\Phi}: \hat{a}$ & $\Phi)$ & హ్ \\
\hline $\bar{z}$ & $\Rightarrow \mathrm{g}$ & $\Rightarrow$ & $\stackrel{\square}{2}$ & $\&$ & 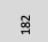 & & $\vdots: 00$ & 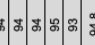 & $\approx$ \\
\hline & $\approx \approx$ & 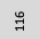 & ğ & @ & ‡ & $\infty$ & $\underline{\mathrm{g}}$ & & ๙ँे \\
\hline & $\Rightarrow=$ 总 & 家 & 害 & 哭 & $\vec{g}$ & & $i$ & & $\hat{E}: F$ \\
\hline & ㅇㅎㅎ & 总 & $\approx$ & $\tilde{\sigma}$ & 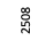 & & $\tilde{\sim}$ & 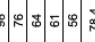 & : \\
\hline & $\rightarrow \frac{3}{3}$ & g & $\stackrel{m}{g}$ & $\$$ & ॥् & & $\stackrel{m}{i}$ & & 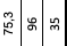 \\
\hline & $\infty$ & g & ğ & $\$$ & 第 & & \begin{tabular}{|l|}
$m$ \\
$\substack{n \\
i}$
\end{tabular} & & 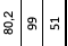 \\
\hline & - & $\stackrel{\circ}{\circ}$ & $\widetilde{\Xi}$ & $E$ & 兽 & & 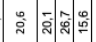 & $\frac{7}{2}$ & $\overline{\bar{\omega}} \approx$ \\
\hline & $-\frac{5}{8}$ & ๓ & 骂 & ๓ీ & 兽 & & 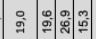 & 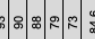 & 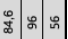 \\
\hline & $m$ & ఇ & 㐁 & $\stackrel{2}{\pi}$ & $\vec{g}$ & & $\mathscr{\Xi}: \mathscr{:}$ & ळ & $\approx \equiv$ \\
\hline & - & 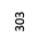 & $\nexists$ & F & 怘 & & $\vec{\Xi}$ & 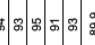 & 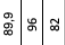 \\
\hline & $\mathrm{m}$ & $\AA$ & ‡ & 确 & 昜 & & \begin{tabular}{l|l}
$\tilde{g}$ & $\overline{\bar{\theta}}$
\end{tabular} & 8 & ธิ) \\
\hline & $\sim$ & 兽 & 梁 & $g$ & $\approx$ & & 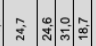 & $5 \%$ & กิณ \\
\hline & -1 & : & $\cong$ & $\stackrel{\square}{\Phi}$ & 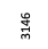 & 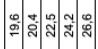 & 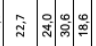 & & 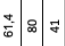 \\
\hline & $\frac{\underline{y}}{a}$ & 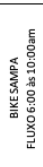 & 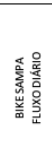 & 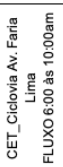 & 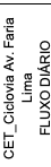 & 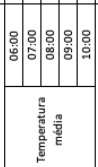 & 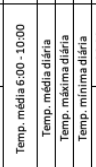 & $\frac{10}{30}$ & 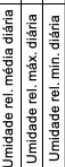 \\
\hline
\end{tabular}




\begin{tabular}{|c|c|c|c|c|c|c|c|c|}
\hline & 部富 & 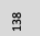 & 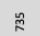 & ఫू & ळ్g & $:$ & 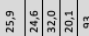 & 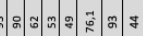 \\
\hline & 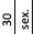 & $\Phi$ & E & สี & ఫ్ & & 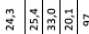 & 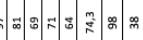 \\
\hline & 2: & \& & Бू & 屃 & స్త్ & & 每: & $\Rightarrow=\frac{m}{0}=2$ \\
\hline & $\approx$ & ळ & ‡ & $\Phi_{\infty}$ & $\sqsubseteq$ & : & ¿ & \% \\
\hline & $\approx$ & $\approx$ & ‡్ & 号 & 茑 & & $\approx$ & 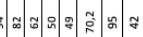 \\
\hline & $\approx$ & $\cong$ & 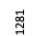 & D్ల & 嵒 & & 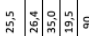 & $\Rightarrow \%: \%$ \\
\hline & a & $=$ & इू & ă & 梁 & ? & $\ddot{i}$ & $6 \%$ \\
\hline & $\approx=\frac{5}{2}$ & 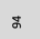 & ğ & ఫి & ఏ్ & & $\stackrel{9}{2}$ & $9 \%$ \\
\hline & $\approx$ & $\approx$ & ‡ & 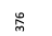 & 黑 & 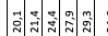 & $\stackrel{0}{i}$ & 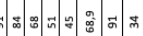 \\
\hline & $\approx$ 訔 & 8 & 兽 & 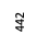 & 赵 & t & $\stackrel{m}{*}$ & $\Leftrightarrow \div \frac{\pi}{\pi} \approx 7$ \\
\hline & त客 & ๙ิ & 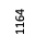 & 苟 & 究 & 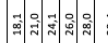 & $\vec{i}$ & 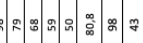 \\
\hline & a $:$ & $\approx$ & 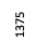 & 苟 & 瓷 & 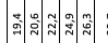 & $\hat{\tilde{n}}$ & 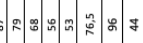 \\
\hline & $\Rightarrow$ & పี & ఇ్ి & 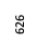 & పี & 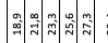 & $\ddot{m}$ & $\frac{m}{2}: \frac{2}{7}$ \\
\hline & 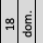 & $\rightrightarrows$ & 曽 & 惫 & 䔍 & ? & $\ddot{\tilde{z}}$ & $\frac{m}{2} \approx$ \\
\hline & $=\Rightarrow$ & $\Xi$ & $\nexists$ & $\approx$ & 岁 & 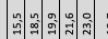 & $g$ & $\vec{g} \approx \vec{a}$ \\
\hline ्ְت & $=0$ & $\Xi$ & 䠢 & $\approx$ & 帝 & 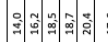 & $\stackrel{\circ}{:}$ & $=$ \\
\hline $\begin{array}{l}8 \\
0 \\
0\end{array}$ & $\Rightarrow=\frac{1}{1}$ & 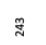 & $\dddot{m}$ & $\frac{8}{8}$ & ఫ్స & $\infty$ & $\hat{g}$ & 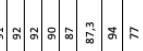 \\
\hline 岧 & $=\frac{1}{2}$ & व & 萝 & శ్ & $\vdots$ & $=$ & $\stackrel{n}{i}$ & $\mathscr{\infty}$ \\
\hline & $m$ & $\approx$ & 首 & 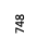 & \$ & 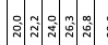 & $\stackrel{\circ}{\approx}$ & 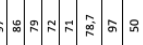 \\
\hline & $\approx \approx$ ڤั & 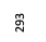 & g̊g & 总 & gू & $m n^{\infty}$ & $\stackrel{i}{i}$ & 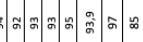 \\
\hline & $\Rightarrow=\frac{\mathrm{g}}{\mathrm{g}}$ & $\Xi$ & $\approx$ & $\frac{8}{7}$ & $\nexists$ & $m$ & 7 & $\because \approx$ \\
\hline & $=0$ & 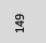 & 莺 & ఏ & $\nsubseteq$ & 6 & ๗ิ & $\frac{m}{m} \approx$ \\
\hline & ه & \$ & $\Xi$ & $\approx$ & 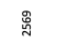 & 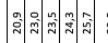 & $\stackrel{n}{m}$ & 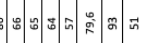 \\
\hline & $\infty$ 言 & 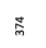 & 黑 & $\approx$ & 善 & $\approx=0$ & $\stackrel{i}{i}$ & $\%$ \\
\hline & $-\frac{9}{g}$ & $\stackrel{\circ}{\circ}$ & 兽 & $\vec{g}$ & ลิ & 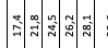 & 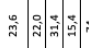 & $\frac{n}{2} \%$ \\
\hline & 田 & $\nexists$ & 兽 & $\stackrel{9}{\varpi}$ & 疋 & $\because 2$ & $\stackrel{n}{g}$ & 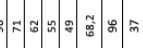 \\
\hline & $m$ & $\Rightarrow$ & 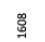 & 6 & 总 & $6=0$ & $\Phi$ & 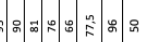 \\
\hline & $+\frac{\mathrm{g}}{\mathrm{g}}$ & $E$ & 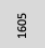 & $g$ & 율 & $m$ & $\underset{\approx}{*}$ & 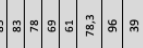 \\
\hline & $m=\frac{6}{2}$ & $\dddot{g}$ & zू & ‡ & శ్ & & $\tilde{z} \mathfrak{z}:$ & 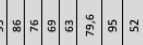 \\
\hline & $\sim$ & g & g & m & 总 & & $\approx 0$ & 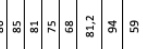 \\
\hline & -1 & $\Phi$ & g & 总 & \$్స & 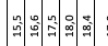 & $\cong=0$ & 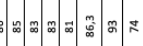 \\
\hline & 气े & 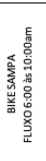 & 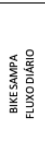 & 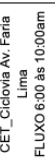 & 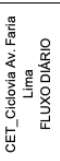 & 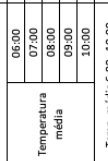 & 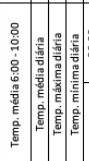 & \begin{tabular}{ll|l}
0 \\
0
\end{tabular} \\
\hline
\end{tabular}




\section{Apêndice E - Dados brutos do levantamento de campo}

\begin{tabular}{|c|c|c|c|c|c|c|c|c|c|c|c|c|c|c|c|c|c|}
\hline \multirow[t]{2}{*}{ TOAS } & \multirow[t]{2}{*}{$\begin{array}{l}\text { CRBooseries } \\
\text { medmariana }\end{array}$} & CR800 & 19444 & $\begin{array}{c}\text { CR800.Std.2 } \\
8.02\end{array}$ & $\begin{array}{c}\text { CPU:mediçŏes } \\
\text { mariana.CR8 }\end{array}$ & 8959 & Table1 & & & & & & & & & & \\
\hline & & & & & & & & & DMBRA & & & & & & SOL & & \\
\hline TIMESTAMP & RECORD & BATERIA $(\mathrm{N})$ & $\begin{array}{c}\text { TEMP.AR } \\
\text { ('C) }\end{array}$ & \begin{tabular}{|c|} 
TEMP. AR \\
('C)
\end{tabular} & UR(x) & \begin{tabular}{|l|} 
DIREÇĀO \\
VENTO(")
\end{tabular} & \begin{tabular}{|c|} 
VELOC. \\
VENTO $(\mathrm{m} / \mathrm{s})$
\end{tabular} & \begin{tabular}{|c|} 
VELOC. \\
VENTO( $\mathrm{m} / \mathrm{s})$
\end{tabular} & $\begin{array}{l}\text { RADIAÇ̄̄o } \\
\left(\mathrm{W} / \mathrm{m}^{2}\right)\end{array}$ & $\begin{array}{l}\text { RADIAÇ̄̄o } \\
\left(\mathrm{W} / \mathrm{m}^{2}\right)\end{array}$ & Slrkd_sombra_Tot & \begin{tabular}{l|} 
DIREÇÃO \\
VENTO(")
\end{tabular} & \begin{tabular}{|c|} 
VELOC. VENTO \\
$(\mathrm{m} / \mathrm{s})$
\end{tabular} & \begin{tabular}{|c|} 
VELOC. \\
VENTO $(\mathrm{m} / \mathrm{s})$
\end{tabular} & $\begin{array}{l}\text { RADIACĀAo } \\
\left(\mathrm{W} / \mathrm{m}^{2}\right)\end{array}$ & $\begin{array}{l}\text { RADIAÇ̄̃o } \\
\left(\mathrm{W} / \mathrm{m}^{2}\right)\end{array}$ & $\frac{\text { Slrkl_sombra_Tot }}{\mathrm{k} / \mathrm{m}^{\wedge}{ }^{2}}$ \\
\hline is & RN & Instantâneo & Média & Instantâneo & Instantâneo & Instantâneo & Média & \begin{tabular}{|l|} 
Instantâneo \\
\end{tabular} & Média & Instantâneo & Total & Instantâneo & Média & \begin{tabular}{|c|} 
Instantâneo \\
\end{tabular} & $\left(\mathrm{W} / \mathrm{m}^{2}\right)^{-}$ & & $\begin{array}{l}\mathrm{k} / \mathrm{m} / 2 \\
\text { Total }\end{array}$ \\
\hline 19/06/201705:45 & 2 & \begin{tabular}{|l|}
12.85 \\
\end{tabular} & 15,81 & 15.81 & 78.58 & 23 & 0.46 & 0.46 & NAN & NAN & NAN & 188 & 0.06 & 0.06 & NAN & NAN & NAal \\
\hline 19/06/2017 06:00 & 3 & 12.82 & 15,93 & 15.93 & 79.86 & 261 & 0.85 & 0,85 & NAN & NAN & NAN & 63 & 0.55 & 0,55 & NAN & NAN & NAN \\
\hline 19/06/2017 06:15 & 4 & 12.81 & 16,08 & 16.08 & 78.72 & 343 & 0.71 & 0,71 & 0 & 0 & 0 & 341 & 0.28 & 0,28 & 0 & 0 & 0 \\
\hline 19/06/2017 06:30 & 5 & 12.79 & 16,21 & 16.21 & 78.48 & 5 & 0.97 & 0,97 & 0 & 0 & 0 & 346 & 0.94 & 0,94 & 0 & 0 & 0 \\
\hline $19 / 06 / 201706: 45$ & 6 & 12.78 & 16,25 & 16.25 & 78.46 & 357 & 1.07 & 1,07 & 0 & 0 & 0 & 358 & 0.83 & 0,83 & 0 & 0 & 0 \\
\hline $19 / 06 / 201707: 00$ & 7 & 12.77 & 16,22 & 16.22 & 77.57 & 4 & 1.18 & 1,18 & 2.383 & 2.383 & 2.144 .711 & 317 & 0.82 & 0,82 & 3.315 & 3.315 & 2.983 .059 \\
\hline $19 / 06 / 201707: 15$ & 8 & 12.77 & 16,36 & 16.36 & 76.93 & 16 & 0.99 & 0,99 & 4.528 & 4.528 & 4.074 .978 & 351 & 0.94 & 0,94 & 9.06 & 9.06 & 8.153 .751 \\
\hline $\begin{array}{l}19 / 06 / 201707: 30 \\
\end{array}$ & 9 & 12.78 & 16,63 & 16.63 & 75.36 & 18 & 0.7 & 0,7 & 7.388 & 7.388 & 664.875 & 13 & 1.15 & $\frac{1,15}{1,15}$ & 15.69 & 15.69 & 1.412 .013 \\
\hline $19 / 06 / 201707: 45$ & 10 & 12.79 & 16,7 & 16.7 & 75.6 & 348 & 0.62 & 0,62 & 10.25 & 10.25 & 9.221 .837 & 2 & 1.06 & 1,06 & 21.65 & 21.65 & 1.948 .843 \\
\hline $19 / 06 / 201708: 00$ & 11 & $\begin{array}{ll}12.8 \\
\end{array}$ & 17,14 & 17.14 & 73.89 & 13 & 0.77 & 0,77 & 13.1 & 13.1 & 1.179 .446 & 327 & 0.57 & 0,57 & 26.73 & 26.73 & 2.406 .039 \\
\hline 19/06/2017 08:15 & 12 & 12.81 & 17,75 & 17.75 & 70.45 & 353 & 1.07 & 1,07 & 15.49 & 15.49 & 1.393.731 & 340 & 1.02 & 1,02 & 31.15 & 31.15 & 280.341 \\
\hline 19/06/2017 08:30 & 13 & 12.81 & 18,26 & 18.26 & 66.02 & 273 & 0.12 & 0,12 & 16.91 & 16.91 & 1.522.281 & 115 & 0.16 & 0,16 & 34.24 & 34.24 & 3.081 .556 \\
\hline 19/06/2017 08:45 & 14 & 12.82 & 18,6 & 18.6 & 63.91 & 31 & 0.63 & 0,63 & 18.34 & 18.34 & 1.650 .922 & 343 & 1.12 & 1,12 & 37.99 & 37.99 & 3.419 .528 \\
\hline 19/06/2017 09:00 & 15 & 12.82 & 18,97 & 18.97 & 62 & 347 & 1.08 & 1,08 & 19.77 & 19.77 & 177.955 & 5 & 1.06 & 1,06 & 41.97 & 41.97 & 3.777 .353 \\
\hline 19/06/2017 09:15 & 16 & 12.83 & 19,37 & 19.37 & 59.17 & 40 & 0.97 & 0,97 & 20.73 & 20.73 & 1.865.309 & 15 & 1.43 & 1,43 & 43.96 & 43.96 & 3.956 .276 \\
\hline 19/06/2017 09:30 & 17 & 12.83 & 20,36 & 20.36 & 56.89 & 163 & 0.6 & 0,6 & 23.11 & 23.11 & $\begin{array}{l}2.079 .712 \\
\end{array}$ & 150 & 0.61 & 0,61 & 46.61 & 46.61 & 4.194 .845 \\
\hline $19 / 06 / 201709: 45$ & 18 & 12.84 & 21,04 & 21.04 & 53.07 & 21 & 0.51 & 0,51 & 23.82 & 23.82 & 2.143 .917 & 106 & 0.28 & 0,28 & 49.26 & 49.26 & 4.433 .174 \\
\hline 19/06/2017 10:00 & 19 & 12.85 & 21,67 & 21.67 & 51.32 & 342 & 1.58 & 1,58 & 26.2 & 26.2 & 2.358 .095 & 41 & 0.78 & 0,78 & 51.68 & 51.68 & 4.651 .429 \\
\hline & & & 17,86 & & & & & 0,85 & & & & & & 0,80 & & & \\
\hline $20 / 006 / 201706: 00 \mid$ & 22 & 12.81 & 15,93 & 15.93 & 83.3 & 211 & $\begin{array}{ll}1.97 \\
\end{array}$ & 1,97 & 0 & 0 & 0 & 198 & 2.28 & 2,28 & 0 & 0 & 0 \\
\hline 20/06/2017 06:15 & 23 & 12.81 & 16,07 & 16.07 & 81.3 & 259 & 0.27 & 0,27 & 0 & 0 & 0 & 196 & $\frac{2.26}{0.5}$ & $\frac{2,26}{0,5}$ & 0 & 0 & 0 \\
\hline $20 / 06 / 201706: 30$ & 24 & 12.79 & 15,97 & 15.97 & 80.9 & 176 & 0.87 & 0,87 & 0 & 0 & 0 & 157 & 1.07 & 1,07 & 0 & 0 & 0 \\
\hline 20/06/2017 06:45 & 25 & 12.8 & 16,11 & 16.11 & 80.6 & 135 & 1.66 & 1,66 & 0 & 0 & 0 & 149 & 1.36 & 1,36 & 0.221 & 0.221 & 0.1987921 \\
\hline $20 / 06 / 201707: 00$ & 26 & 12.79 & 16,15 & 16.15 & 80.1 & 193 & 1.26 & 1,26 & 0.238 & 0.238 & 0.2143875 & 151 & 1.14 & 1,14 & 3.534 & 3.534 & 318.069 \\
\hline $20 / 06 / 201707: 15$ & 27 & 12.79 & 15,91 & 15.91 & 81.9 & 278 & 0.35 & 0,35 & 0.715 & 0.715 & 0.6431537 & 318 & 0.66 & 0,66 & 7.731 & 7.731 & 6.957 .664 \\
\hline $20 / 06 / 201707: 30$ & 28 & 12.79 & 15,94 & 15.94 & 81.8 & 234 & 0.88 & 0,88 & 2.144 & 2.144 & 1.929 .458 & 185 & 1.18 & 1,18 & 20.98 & 20.98 & 1.888 .506 \\
\hline $20 / 06 / 201707: 45$ & 29 & 12.78 & 16,04 & 16.04 & 81.4 & 141 & 0.87 & 0,87 & 2.62 & 2.62 & 2.358 .227 & 165 & 0.69 & 0,69 & 21.43 & 21.43 & 1.928 .264 \\
\hline 20/06/2017 08:00 & 30 & 12.78 & 16,25 & 16.25 & 79.67 & 149 & 1.12 & 1,12 & 2.382 & 2.382 & 2.143 .842 & 202 & 1.08 & 1,08 & 20.1 & 20.1 & 180.899 \\
\hline $20 / 06 / 201708: 15$ & 31 & 12.79 & 15,91 & 15.91 & 82.5 & 146 & 1.6 & 1,6 & 2.144 & 2.144 & 1.929 .458 & 162 & 0.98 & 0,98 & 25.18 & 25.18 & 2.266 .207 \\
\hline $20 / 06 / 201708: 30$ & 32 & 12.8 & 16,01 & 16.01 & 83 & 119 & 0.86 & 0,86 & 8.81 & 8.81 & 7.932 .327 & 346 & 0.29 & 0,29 & 77.53 & 77.53 & 6.977 .629 \\
\hline $20 / 06 / 201708: 45$ & 33 & 12.8 & 16,21 & 16.21 & 81.9 & 208 & 0.6 & 0,6 & 7.384 & 7.384 & 6.646 .024 & 242 & 0.89 & 0,89 & 66.93 & 66.93 & 6.023 .442 \\
\hline 20/06/2017 09:00 & 34 & 12.8 & 16,45 & 16.45 & 81.1 & 244 & 0.81 & 0,81 & 9.05 & 9.05 & 8.146 .633 & 237 & 1.29 & 1,29 & 68.69 & 68.69 & 6.182 .396 \\
\hline 20/06/2017 09:15 & 35 & 12.81 & 16,79 & 16.79 & 78 & 281 & 0.63 & 0,63 & 12.15 & 12.15 & 109.336 & 179 & 0.74 & 0,74 & 107.3 & 107.3 & 9.661 .201 \\
\hline 20/06/2017 09:30 & & 12.83 & 16,83 & 16.83 & 75.59 & 144 & 2.32 & 2,32 & 10.48 & 10.48 & 9.432 .972 & 163 & 1.83 & 1,83 & 91.2 & 91.2 & 8.210 .088 \\
\hline $20 / 06 / 201709: 45$ & 37 & 12.86 & 17,1 & 17.1 & 74.77 & 130 & 1.3 & 1,3 & 18.58 & 18.58 & 1.672 .222 & 176 & 0.77 & 0,77 & 157 & 157 & 1.413 .419 \\
\hline $20 / 06 / 201710: 00$ & 38 & 12.92 & 17,24 & 17.24 & 73.51 & 223 & 1.73 & 1,73 & 26.92 & 26.92 & 2.422 .547 & 185 & 0.99 & 0,99 & 170.7 & 170.7 & 153.665 \\
\hline & & & 16,29 & & & & & 1,12 & & & & & & 1,04 & & & \\
\hline $22 / 06 / 201706: 00$ & 39 & 12.82 & 16,32 & 16.32 & 77.59 & 345 & 0.79 & 0,79 & 0 & 0 & 0 & 325 & 0.85 & 0,85 & 0 & 0 & 0 \\
\hline $22 / 06 / 201706: 15$ & 40 & 12.81 & 16,34 & 16.34 & 77.31 & 178 & 0.65 & 0,65 & 0 & 0 & 0 & 196 & 0.55 & 0,55 & 0 & 0 & 0 \\
\hline $22 / 06 / 201706: 30$ & 41 & 12.8 & 16,34 & 16.34 & 77.14 & 27 & 0.67 & 0,67 & 0 & 0 & 0 & 26 & 0.12 & 0,12 & 0 & 0 & 0 \\
\hline $22 / 06 / 201706: 45$ & 42 & $\begin{array}{ll}12.8 \\
\end{array}$ & 16,21 & 16.21 & 77.29 & 302 & 0.31 & 0,31 & 0 & 0 & 0 & 262 & 0.1 & 0,1 & 0 & 0 & 0 \\
\hline $22 / 06 / 201707: 00$ & 43 & 12.79 & 16,32 & 16.32 & 76.71 & 113 & 0.16 & 0,16 & 0.715 & 0.715 & 0.6431975 & 219 & 0.48 & 0,48 & 3.093 & 3.093 & 2.783 .255 \\
\hline $22 / 06 / 201707: 15$ & 44 & 12.79 & 16,25 & 16.25 & 76.78 & 313 & 1.27 & 1,27 & 1.906 & 1.906 & $\begin{array}{l}1.715 .245 \\
\end{array}$ & 325 & 1.44 & 1,44 & 10.16 & 10.16 & 9.145 .254 \\
\hline $22 / 06 / 201707: 30$ & 45 & 12.79 & 16,28 & 16.28 & 75.89 & 251 & 0.32 & 0,32 & 3.335 & 3.335 & 3.001 .611 & 143 & 1.06 & 1,06 & 18.56 & 18.56 & 1.669 .965 \\
\hline $22 / 06 / 201707: 45$ & 46 & 12.79 & 16,42 & 16.42 & 76.13 & 309 & 1.31 & 1,31 & 5.956 & 5.956 & 5.359 .986 & 275 & 0.88 & 0,88 & 42.41 & 42.41 & 3.817 .041 \\
\hline $22 / 06 / 201708: 00$ & 47 & 12.8 & 16,49 & 16.49 & 75.76 & 325 & 1.13 & 1,13 & 11.67 & 11.67 & 1.050 .557 & 321 & 1.13 & 1,13 & 59.86 & 59.86 & 5.387 .592 \\
\hline $22 / 06 / 201708: 15$ & 48 & 12.99 & 16,52 & 16.52 & 75.49 & 300 & 1.07 & 1,07 & 19.3 & 19.3 & 1.736 .647 & 20 & 1.08 & 1,08 & 57.21 & 57.21 & 5.149 .062 \\
\hline $22 / 06 / 201708: 30$ & 49 & 13.01 & 16,79 & .79 & 73.61 & 221 & 1.51 & 1,51 & 26.44 & 26.44 & 2.379 .872 & 223 & 1.19 & 1,19 & 234.4 & 234.4 & 2.109 .346 \\
\hline $22 / 06 / 201708: 45$ & 50 & 13.2 & 16,89 & & 72.14 & 119 & 0.77 & 0,77 & 29.06 & 29.06 & 2.615 .678 & 76 & 1.12 & 1,12 & 301.3 & 301.3 & 2.711 .694 \\
\hline $22 / 06 / 201709: 00$ & 51 & 13. & 17,55 & 17. & 69.7 & 299 & 1.25 & 1,25 & 34.06 & 34.06 & 3.065 .477 & 309 & 0.55 & 0,55 & 385.4 & 385.4 & 3.468 .641 \\
\hline $22 / 06 / 201709: 15$ & 52 & 13.12 & 17,88 & 17.88 & 68.12 & 265 & 1.68 & 1,68 & 33.1 & 33.1 & 2.979 .123 & 262 & 1.67 & 1,67 & 433 & 433 & 3.897 .205 \\
\hline $22 / 06 / 201709: 30$ & 53 & 13.12 & 18,28 & 18.28 & 68.07 & 327 & 0.33 & 0,33 & 34.28 & 34.28 & 3.085 .404 & 9 & 0.59 & 0,59 & 469.1 & 469.1 & 4.221 .924 \\
\hline $22 / 06 / 201709: 45$ & 54 & 13.1 & 18,85 & 18.85 & 64.5 & 236 & 0.36 & 0,36 & 33.57 & 33.57 & 3.020 .985 & 220 & 0.69 & 0,69 & 495.6 & 495.6 & 4.460 .132 \\
\hline $22 / 06 / 201710: 00$ & 55 & 13.12 & 19,23 & 19.23 & 62.26 & 185 & 2.47 & 2,47 & 30.71 & 30.71 & 2.763 .866 & 211 & 2.41 & 2,41 & 365.1 & 365.1 & 3.285 .978 \\
\hline & & & 17,00 & & & & & 0,94 & & & & & & 0,94 & & & \\
\hline $23 / 06 / 201706: 00$ & 57 & 12.86 & & 85 & .04 & 354 & 0.7 & 0 & 0 & 0 & 0 & 318 & 0.52 & 0.52 & 0 & 0 & 0 \\
\hline $23 / 06 / 201706: 15$ & 58 & 12.83 & 15,83 & 15.83 & 78.54 & 329 & 0.92 & 0,9 & 0 & 0 & 0 & 330 & 1.71 & $\frac{0,172}{1,71}$ & 0.221 & 0.221 & $\frac{0}{0.1987925}$ \\
\hline $23 / 06 / 201706: 30$ & 59 & 12.83 & 16,04 & 16.04 & 78.38 & 248 & 0.19 & 0, & 0 & 0 & 0 & 252 & 0.91 & 0,4 & 0.442 & 0.442 & 0.3976092 \\
\hline $23 / 06 / 201706: 45$ & 60 & 12.83 & 15,84 & 15.8 & 78. & 248 & 0.8 & 0, & 0 & 0 & 0 & 30 & 0.8 & & 0.44 & 0.442 & 0.3976178 \\
\hline $23 / 06 / 201707: 00$ & 61 & 12.8 & 16,0 & 16.0 & 77. & 201 & 1.6 & 1 & 1.191 & 1.15 & 1.071.999 & 19 & 1. & 1, & 3.5 & 3.5 & 180.874 \\
\hline $23 / 06 / 201707: 15$ & 62 & 12. & 16 & 16. & 77.2 & 55 & 0. & 0, & 3.8 & 3.8 & & 16 & 0. & 0 & & & \\
\hline $23 / 06 / 201707$ & 63 & 12.8 & 16, & 16. & 77. & 301 & 1. & 1, & & 3.8 & & 29 & 1. & 1, & 10. & 10 & \\
\hline $23 / 06 / 201$ & 64 & 12 & 16, & 16. & & 27 & 1.3 & 1, & & 5.2 & & 24 & 1. & 1, & & 36 & \\
\hline $23 / 06 / 20$ & 65 & 12.7 & 16, & & & 33 & 1. & & & 4.2 & & 31 & 1. & 1,8 & & 9. & \\
\hline $23 / 06 / 20$ & 66 & 12 & $\begin{array}{l}16,8,89 \\
\end{array}$ & 16.89 & & $\frac{37}{14}$ & 0. & & 4.7 & $\frac{4.7}{4.7}$ & & 138 & 1.4 & $\frac{1,6}{1,6}$ & 13 & 13 & \\
\hline $6 / 20170$ & 67 & 12 & 17 & 17 & & 31 & 0. & & & 6.4 & & 312 & 0. & 0,5 & 17.45 & 17. & \\
\hline $5 / 201708$ & 68 & 12. & 16, & 16. & & 210 & & 0, & 8. & 8.5 & & 27 & 0.84 & 0,84 & 22.31 & 22.31 & \\
\hline $23 / 06 / 201709$ & 69 & 12. & 17,1 & 17. & 72. & 296 & 0.8 & 0,86 & 35. & 35.97 & & 303 & 0.84 & 0,84 & 299.3 & 299.3 & 2.693 .869 \\
\hline $23 / 06 / 201709$ & 70 & 12.83 & 17,5 & 17. & 70. & 209 & 2.07 & 2,07 & 23. & 23.35 & & 213 & 2.08 & 2,08 & 87.3 & 87.3 & $\begin{array}{l}7.852 .787 \\
\end{array}$ \\
\hline $23 / 06 / 201709: 3$ & 71 & 12.88 & 18,08 & 18.08 & 68.22 & 351 & 0.5 & 0,5 & 50.98 & 50.98 & 4.588 .141 & 273 & 0.28 & 0,28 & 463.7 & 463.7 & 4.172 .894 \\
\hline \begin{tabular}{|l|}
$23 / 06 / 201709: 45$ \\
\end{tabular} & 72 & 12.93 & 18,59 & 18.59 & 67 & 341 & 1.05 & 1,05 & 47.88 & 47.88 & 4.309 .421 & 330 & 0.95 & 0,95 & 386.1 & 386.1 & 3.475 .091 \\
\hline $23 / 06 / 201710: 00$ & 73 & 12.97 & 18,82 & 18.82 & 64.51 & 269 & 1.09 & 1,09 & 50.5 & 50.5 & 4.544 .822 & 267 & 1.94 & 1,94 & 553.3 & 553.3 & 4.979 .556 \\
\hline & & & 16,82 & & & & & 0,93 & & & & & & 1,12 & & & \\
\hline
\end{tabular}


TRIPÉS - 19/06/2016

\begin{tabular}{|c|c|c|c|c|c|c|c|}
\hline \multirow{2}{*}{ \# } & \multirow{2}{*}{ DATA, HORA } & \multicolumn{3}{|c|}{ SOMBRA } & \multicolumn{3}{|c|}{ SOL } \\
\hline & & TEMP. AR ("C) & UR (\%) & TEMP. GLOBO ("C) & TEMP. AR ( $\left.{ }^{\circ} \mathrm{C}\right)$ & UR (\%) & TEMP. GLOBO $\left({ }^{\circ} \mathrm{C}\right)$ \\
\hline 937 & $06 / 19 / 1705 \mathrm{~h} 0 \mathrm{~min} 0 \mathrm{~s}$ & 21,9 & 58 & 21,9 & 21,9 & 59 & 21,9 \\
\hline 938 & $06 / 19 / 1705 \mathrm{~h} 5 \mathrm{~min} 0 \mathrm{~s}$ & 21,9 & 58 & 21,9 & 21,9 & 59 & 21,9 \\
\hline 939 & $06 / 19 / 1705 \mathrm{~h} 10 \mathrm{~min} 0 \mathrm{~s}$ & 21,9 & 58 & 21,9 & 21,9 & 59 & 21,9 \\
\hline 940 & 06/19/17 05h15min0s & 21,9 & 58 & 21,9 & 21,9 & 59 & 21,9 \\
\hline 941 & $06 / 19 / 1705 \mathrm{~h} 20 \mathrm{~min} 0 \mathrm{~s}$ & 21,9 & 58 & 21,9 & 21,9 & 59 & 21,9 \\
\hline 942 & $06 / 19 / 1705 \mathrm{~h} 25 \mathrm{~min} 0 \mathrm{~s}$ & 21,9 & 58 & 21,9 & 21,9 & 59 & 21,9 \\
\hline 943 & $06 / 19 / 1705 \mathrm{~h} 30 \mathrm{~min} 0 \mathrm{~s}$ & 21,9 & 58 & 21,9 & 21,9 & 59 & 21,9 \\
\hline 944 & $06 / 19 / 1705 \mathrm{~h} 35 \mathrm{~min} 0 \mathrm{~s}$ & 21,9 & 63 & 22,1 & 21,9 & 65 & 22,2 \\
\hline 945 & $06 / 19 / 1705 \mathrm{~h} 40 \mathrm{~min} 0 \mathrm{~s}$ & 21,1 & 64 & 19,5 & 21,3 & 64 & 19,6 \\
\hline 946 & $06 / 19 / 1705 \mathrm{~h} 45 \mathrm{~min} 0 \mathrm{~s}$ & 19,1 & 71 & 16,1 & 19,2 & 72 & 16,3 \\
\hline 947 & $06 / 19 / 1705 \mathrm{~h} 50 \mathrm{~min} 0 \mathrm{~s}$ & 17,8 & 76 & 15,0 & 17,7 & 78 & 15,2 \\
\hline 948 & $06 / 19 / 1705 \mathrm{~h} 55 \mathrm{~min} 0 \mathrm{~s}$ & 17,1 & 80 & 14,8 & 17,0 & 82 & 15,0 \\
\hline 949 & $06 / 19 / 1706 \mathrm{~h} 0 \mathrm{~min} 0 \mathrm{~s}$ & 16,6 & 82 & 14,9 & 16,5 & 83 & 14,9 \\
\hline 950 & $06 / 19 / 1706 \mathrm{~h} 5 \mathrm{~min} 0 \mathrm{~s}$ & 16,3 & 84 & 14,8 & 16,2 & 85 & 14,7 \\
\hline 951 & $06 / 19 / 1706 \mathrm{~h} 10 \mathrm{~min} 0 \mathrm{~s}$ & 16,1 & 85 & 15,2 & 16,1 & 85 & 14,4 \\
\hline 952 & $06 / 19 / 1706 \mathrm{~h} 15 \mathrm{~min} 0 \mathrm{~s}$ & 16,0 & 85 & 15,3 & 16,0 & 86 & 14,9 \\
\hline 953 & $06 / 19 / 1706 \mathrm{~h} 20 \mathrm{~min} 0 \mathrm{~s}$ & 16,0 & 85 & 15,2 & 16,0 & 86 & 15,2 \\
\hline 954 & $06 / 19 / 1706 \mathrm{~h} 25 \mathrm{~min} 0 \mathrm{~s}$ & 16,0 & 86 & 15,4 & 15,9 & 86 & 15,0 \\
\hline 955 & $06 / 19 / 1706 \mathrm{~h} 30 \mathrm{~min} 0 \mathrm{~s}$ & 16,0 & 86 & 15,3 & 15,9 & 87 & 14,8 \\
\hline 956 & $06 / 19 / 1706 \mathrm{~h} 35 \mathrm{~min} 0 \mathrm{~s}$ & 16,0 & 86 & 15,4 & 16,0 & 87 & 14,8 \\
\hline 957 & $06 / 19 / 1706 \mathrm{~h} 40 \mathrm{~min} 0 \mathrm{~s}$ & 16,0 & 86 & 15,3 & 16,0 & 87 & 15,0 \\
\hline 958 & $06 / 19 / 1706 \mathrm{~h} 45 \mathrm{~min} 0 \mathrm{~s}$ & 16,1 & 86 & 15,4 & 16,0 & 87 & 15,0 \\
\hline 959 & $06 / 19 / 1706 \mathrm{~h} 50 \mathrm{~min} 0 \mathrm{~s}$ & 16,1 & 86 & 15,4 & 16,0 & 87 & 14,9 \\
\hline 960 & $06 / 19 / 1706 \mathrm{~h} 55 \mathrm{~min} 0 \mathrm{~s}$ & 16,0 & 86 & 15,4 & 16,0 & 87 & 14,7 \\
\hline 961 & 06/19/17 07h0min0s & 16,0 & 86 & 15,4 & 16,0 & 86 & 14,8 \\
\hline 962 & $06 / 19 / 1707 \mathrm{~h} 5 \mathrm{~min} 0 \mathrm{~s}$ & 16,1 & 86 & 15,5 & 16,0 & 87 & 14,8 \\
\hline 963 & $06 / 19 / 1707 \mathrm{~h} 10 \mathrm{~min} 0 \mathrm{~s}$ & 16,1 & 85 & 15,5 & 16,0 & 87 & 14,8 \\
\hline 964 & $06 / 19 / 1707 \mathrm{~h} 15 \mathrm{~min} 0 \mathrm{~s}$ & 16,2 & 85 & 15,7 & 16,1 & 86 & 15,0 \\
\hline 965 & 06/19/17 07h20min0s & 16,2 & 85 & 15,6 & 16,1 & 86 & 15,0 \\
\hline 966 & $06 / 19 / 1707 \mathrm{~h} 25 \mathrm{~min} 0 \mathrm{~s}$ & 16,2 & 85 & 15,7 & 16,2 & 86 & 15,0 \\
\hline 967 & $06 / 19 / 1707 \mathrm{~h} 30 \mathrm{~min} 0 \mathrm{~s}$ & 16,3 & 85 & 15,7 & 16,2 & 86 & 15,2 \\
\hline 968 & $06 / 19 / 1707 \mathrm{~h} 35 \mathrm{~min} 0 \mathrm{~s}$ & 16,3 & 85 & 15,9 & 16,3 & 86 & 15,3 \\
\hline 969 & $06 / 19 / 1707 \mathrm{~h} 40 \mathrm{~min} 0 \mathrm{~s}$ & 16,4 & 84 & 16,0 & 16,4 & 85 & 15,4 \\
\hline 970 & $06 / 19 / 1707 \mathrm{~h} 45 \mathrm{~min} 0 \mathrm{~s}$ & 16,5 & 83 & 16,1 & 16,4 & 84 & 15,5 \\
\hline 971 & 06/19/17 07h50min0s & 16,5 & 83 & 16,1 & 16,5 & 84 & 15,6 \\
\hline 972 & 06/19/17 07h55min0s & 16,6 & 84 & 16,2 & 16,5 & 85 & 15,6 \\
\hline 973 & 06/19/17 08h0min0s & 16,7 & 83 & 16,5 & 16,7 & 84 & 15,8 \\
\hline 974 & $06 / 19 / 1708 \mathrm{~h} 5 \mathrm{~min} 0 \mathrm{~s}$ & 16,7 & 83 & 16,5 & 16,7 & 83 & 15,9 \\
\hline 975 & $06 / 19 / 1708 \mathrm{~h} 10 \mathrm{~min} 0 \mathrm{~s}$ & 16,8 & 83 & 16,7 & 16,8 & 84 & 16,0 \\
\hline 976 & $06 / 19 / 1708 \mathrm{~h} 15 \mathrm{~min} 0 \mathrm{~s}$ & 16,9 & 82 & 16,9 & 16,9 & 83 & 16,1 \\
\hline 977 & $06 / 19 / 1708 \mathrm{~h} 20 \mathrm{~min} 0 \mathrm{~s}$ & 17,1 & 81 & 17,0 & 17,0 & 82 & 16,2 \\
\hline 978 & $06 / 19 / 1708 \mathrm{~h} 25 \mathrm{~min} 0 \mathrm{~s}$ & 17,3 & 80 & 17,3 & 17,2 & 81 & 16,5 \\
\hline 979 & $06 / 19 / 1708 \mathrm{~h} 30 \mathrm{~min} 0 \mathrm{~s}$ & 17,5 & 80 & 17,5 & 17,4 & 80 & 16,8 \\
\hline 980 & $06 / 19 / 1708 \mathrm{~h} 35 \mathrm{~min} 0 \mathrm{~s}$ & 17,7 & 77 & 17,8 & 17,6 & 78 & 17,1 \\
\hline 981 & $06 / 19 / 1708 \mathrm{~h} 40 \mathrm{~min} 0 \mathrm{~s}$ & 17,8 & 77 & 17,9 & 17,7 & 78 & 17,2 \\
\hline 982 & $06 / 19 / 1708 \mathrm{~h} 45 \mathrm{~min} 0 \mathrm{~s}$ & 17,9 & 76 & 17,9 & 17,8 & 78 & 17,2 \\
\hline 983 & $06 / 19 / 1708 \mathrm{~h} 50 \mathrm{~min} 0 \mathrm{~s}$ & 18,1 & 77 & 18,2 & 18,0 & 78 & 17,5 \\
\hline 984 & $06 / 19 / 1708 \mathrm{~h} 55 \mathrm{~min} 0 \mathrm{~s}$ & 18,3 & 75 & 18,3 & 18,2 & 76 & 17,7 \\
\hline 985 & 06/19/17 09h0min0s & 18,4 & 75 & 18,4 & 18,2 & 76 & 17,7 \\
\hline 986 & $06 / 19 / 1709 \mathrm{~h} 5 \mathrm{~min} 0 \mathrm{~s}$ & 18,5 & 73 & 18,5 & 18,4 & 74 & 17,9 \\
\hline 987 & 06/19/17 09h10min0s & 18,6 & 72 & 18,7 & 18,5 & 74 & 18,0 \\
\hline 988 & 06/19/17 09h15min0s & 18,7 & 72 & 18,8 & 18,6 & 73 & 18,1 \\
\hline 989 & $06 / 19 / 1709 \mathrm{~h} 20 \mathrm{~min} 0 \mathrm{~s}$ & 18,9 & 71 & 19,1 & 18,8 & 72 & 18,4 \\
\hline 990 & $06 / 19 / 1709 \mathrm{~h} 25 \mathrm{~min} 0 \mathrm{~s}$ & 19,1 & 70 & 19,2 & 19,0 & 71 & 18,6 \\
\hline 991 & $06 / 19 / 1709 \mathrm{~h} 30 \mathrm{~min} 0 \mathrm{~s}$ & 19,2 & 70 & 19,3 & 19,1 & 72 & 18,7 \\
\hline 992 & $06 / 19 / 1709 \mathrm{~h} 35 \mathrm{~min} 0 \mathrm{~s}$ & 19,4 & 70 & 19,6 & 19,3 & 71 & 19,0 \\
\hline 993 & $06 / 19 / 1709 \mathrm{~h} 40 \mathrm{~min} 0 \mathrm{~s}$ & 19,7 & 70 & 20,0 & 19,6 & 70 & 19,3 \\
\hline 994 & $06 / 19 / 1709 \mathrm{~h} 45 \mathrm{~min} 0 \mathrm{~s}$ & 19,9 & 69 & 20,3 & 19,8 & 70 & 19,6 \\
\hline 995 & $06 / 19 / 1709 \mathrm{~h} 50 \mathrm{~min} 0 \mathrm{~s}$ & 20,2 & 67 & 20,6 & 20,1 & 68 & 19,9 \\
\hline 996 & $06 / 19 / 1709 \mathrm{~h} 55 \mathrm{~min} 0 \mathrm{~s}$ & 20,5 & 65 & 20,8 & 20,4 & 66 & 20,2 \\
\hline 997 & 06/19/17 10h0min0s & 20,7 & 64 & 20,9 & 20,7 & 65 & 20,5 \\
\hline
\end{tabular}


TRIPÉS - 19/06/2016

\begin{tabular}{|c|c|c|c|c|c|c|c|}
\hline \multirow{2}{*}{$\#$} & \multirow{2}{*}{ DATA, HORA } & \multicolumn{3}{|c|}{ SOMBRA } & \multicolumn{3}{|c|}{ SOL } \\
\hline & & TEMP. AR ( $\left.{ }^{\circ} \mathrm{C}\right)$ & UR (\%) & TEMP. GLOBO ("C) & TEMP. AR ( $\left.{ }^{\circ} \mathrm{C}\right)$ & UR (\%) & TEMP. GLOBO ("C) \\
\hline 937 & $06 / 19 / 1705 \mathrm{h0min0s}$ & 21,9 & 58 & \begin{tabular}{|l|}
21,9 \\
\end{tabular} & 21,9 & 59 & 21,9 \\
\hline 938 & $06 / 19 / 1705 \mathrm{~h} 5 \mathrm{~min} 0 \mathrm{~s}$ & 21,9 & 58 & 21,9 & 21,9 & 59 & 21,9 \\
\hline 939 & 06/19/17 05h10min0s & 21,9 & 58 & 21,9 & 21,9 & 59 & 21,9 \\
\hline 940 & 06/19/17 05h15min0s & 21,9 & 58 & 21,9 & 21,9 & 59 & 21,9 \\
\hline 941 & $06 / 19 / 1705 \mathrm{~h} 20 \mathrm{~min} 0 \mathrm{~s}$ & 21,9 & 58 & 21,9 & 21,9 & 59 & 21,9 \\
\hline 942 & $06 / 19 / 1705 \mathrm{~h} 25 \mathrm{~min} 0 \mathrm{~s}$ & 21,9 & 58 & 21,9 & 21,9 & 59 & 21,9 \\
\hline 943 & $06 / 19 / 1705 \mathrm{~h} 30 \mathrm{~min} 0 \mathrm{~s}$ & 21,9 & 58 & 21,9 & 21,9 & 59 & 21,9 \\
\hline 944 & $06 / 19 / 1705 \mathrm{~h} 35 \mathrm{~min} 0 \mathrm{~s}$ & 21,9 & 63 & 22,1 & 21,9 & 65 & 22,2 \\
\hline 945 & 06/19/17 05h40min0s & 21,1 & 64 & 19,5 & 21,3 & 64 & 19,6 \\
\hline 946 & $06 / 19 / 1705 \mathrm{~h} 45 \mathrm{~min} 0 \mathrm{~s}$ & 19,1 & 71 & 16,1 & 19,2 & 72 & 16,3 \\
\hline 947 & $06 / 19 / 1705 \mathrm{~h} 50 \mathrm{~min} 0 \mathrm{~s}$ & 17,8 & 76 & 15,0 & 17,7 & 78 & 15,2 \\
\hline 948 & $06 / 19 / 1705 \mathrm{~h} 55 \mathrm{~min} 0 \mathrm{~s}$ & 17,1 & 80 & 14,8 & 17,0 & 82 & 15,0 \\
\hline 949 & 06/19/17 06h0min0s & 16,6 & 82 & 14,9 & 16,5 & 83 & 14,9 \\
\hline 950 & $06 / 19 / 1706 \mathrm{~h} 5 \mathrm{~min} 0 \mathrm{~s}$ & 16,3 & 84 & 14,8 & 16,2 & 85 & 14,7 \\
\hline 951 & $06 / 19 / 1706 \mathrm{~h} 10 \mathrm{~min} 0 \mathrm{~s}$ & 16,1 & 85 & 15,2 & 16,1 & 85 & 14,4 \\
\hline 952 & 06/19/17 06h15min0s & 16,0 & 85 & 15,3 & 16,0 & 86 & 14,9 \\
\hline 953 & $06 / 19 / 1706 \mathrm{~h} 20 \mathrm{~min} 0 \mathrm{~s}$ & 16,0 & 85 & 15,2 & 16,0 & 86 & 15,2 \\
\hline 954 & $06 / 19 / 1706 \mathrm{~h} 25 \mathrm{~min} 0 \mathrm{~s}$ & 16,0 & 86 & 15,4 & 15,9 & 86 & 15,0 \\
\hline 955 & $06 / 19 / 1706 \mathrm{~h} 30 \mathrm{~min} 0 \mathrm{~s}$ & 16,0 & 86 & 15,3 & 15,9 & 87 & 14,8 \\
\hline 956 & $06 / 19 / 1706 \mathrm{~h} 35 \mathrm{~min} 0 \mathrm{~s}$ & 16,0 & 86 & 15,4 & 16,0 & 87 & 14,8 \\
\hline 957 & $06 / 19 / 1706 \mathrm{~h} 40 \mathrm{~min} 0 \mathrm{~s}$ & 16,0 & 86 & 15,3 & 16,0 & 87 & 15,0 \\
\hline 958 & $06 / 19 / 1706 \mathrm{~h} 45 \mathrm{~min} 0 \mathrm{~s}$ & 16,1 & 86 & 15,4 & 16,0 & 87 & 15,0 \\
\hline 959 & 06/19/17 06h50min0s & 16,1 & 86 & 15,4 & 16,0 & 87 & 14,9 \\
\hline 960 & $06 / 19 / 1706 \mathrm{~h} 55 \mathrm{~min} 0 \mathrm{~s}$ & 16,0 & 86 & 15,4 & 16,0 & 87 & 14,7 \\
\hline 961 & $06 / 19 / 1707 \mathrm{~h} 0 \mathrm{~min} 0 \mathrm{~s}$ & 16,0 & 86 & 15,4 & 16,0 & 86 & 14,8 \\
\hline 962 & $06 / 19 / 1707 \mathrm{~h} 5 \mathrm{~min} 0 \mathrm{~s}$ & 16,1 & 86 & 15,5 & 16,0 & 87 & 14,8 \\
\hline 963 & 06/19/17 07h10min0s & 16,1 & 85 & 15,5 & 16,0 & 87 & 14,8 \\
\hline 964 & 06/19/17 07h15min0s & 16,2 & 85 & 15,7 & 16,1 & 86 & 15,0 \\
\hline 965 & $06 / 19 / 1707 \mathrm{~h} 20 \mathrm{~min} 0 \mathrm{~s}$ & 16,2 & 85 & 15,6 & 16,1 & 86 & 15,0 \\
\hline 966 & $06 / 19 / 1707 \mathrm{~h} 25 \mathrm{~min} 0 \mathrm{~s}$ & 16,2 & 85 & 15,7 & 16,2 & 86 & 15,0 \\
\hline 967 & 06/19/17 07h30min0s & 16,3 & 85 & 15,7 & 16,2 & 86 & 15,2 \\
\hline 968 & 06/19/17 07h35min0s & 16,3 & 85 & 15,9 & 16,3 & 86 & 15,3 \\
\hline 969 & 06/19/17 07h40min0s & 16,4 & 84 & 16,0 & 16,4 & 85 & 15,4 \\
\hline 970 & 06/19/17 07h45min0s & 16,5 & 83 & 16,1 & 16,4 & 84 & 15,5 \\
\hline 971 & 06/19/17 07h50min0s & 16,5 & 83 & 16,1 & 16,5 & 84 & 15,6 \\
\hline 972 & 06/19/17 07h55min0s & 16,6 & 84 & 16,2 & 16,5 & 85 & 15,6 \\
\hline 973 & $06 / 19 / 1708 \mathrm{~h} 0 \mathrm{~min} 0 \mathrm{~s}$ & 16,7 & 83 & 16,5 & 16,7 & 84 & 15,8 \\
\hline 974 & $06 / 19 / 1708 \mathrm{~h} 5 \mathrm{~min} 0 \mathrm{~s}$ & 16,7 & 83 & 16,5 & 16,7 & 83 & 15,9 \\
\hline 975 & 06/19/17 08h10min0s & 16,8 & 83 & 16,7 & 16,8 & 84 & 16,0 \\
\hline 976 & 06/19/17 08h15min0s & 16,9 & 82 & 16,9 & 16,9 & 83 & 16,1 \\
\hline 977 & $06 / 19 / 1708 \mathrm{~h} 20 \mathrm{~min} 0 \mathrm{~s}$ & 17,1 & 81 & 17,0 & 17,0 & 82 & 16,2 \\
\hline 978 & $06 / 19 / 1708 \mathrm{~h} 25 \mathrm{~min} 0 \mathrm{~s}$ & 17,3 & 80 & 17,3 & 17,2 & 81 & 16,5 \\
\hline 979 & $06 / 19 / 1708 \mathrm{~h} 30 \mathrm{~min} 0 \mathrm{~s}$ & 17,5 & 80 & 17,5 & 17,4 & 80 & 16,8 \\
\hline 980 & 06/19/17 08h35min0s & 17,7 & 77 & 17,8 & 17,6 & 78 & 17,1 \\
\hline 981 & 06/19/17 08h40min0s & 17,8 & 77 & 17,9 & 17,7 & 78 & 17,2 \\
\hline 982 & $06 / 19 / 1708 \mathrm{~h} 45 \mathrm{~min} 0 \mathrm{~s}$ & 17,9 & 76 & 17,9 & 17,8 & 78 & 17,2 \\
\hline 983 & $06 / 19 / 1708 \mathrm{~h} 50 \mathrm{~min} 0 \mathrm{~s}$ & 18,1 & 77 & 18,2 & 18,0 & 78 & 17,5 \\
\hline 984 & $06 / 19 / 1708 \mathrm{~h} 55 \mathrm{~min} 0 \mathrm{~s}$ & 18,3 & 75 & 18,3 & 18,2 & 76 & 17,7 \\
\hline 985 & 06/19/17 09h0min0s & 18,4 & 75 & 18,4 & 18,2 & 76 & 17,7 \\
\hline 986 & $06 / 19 / 1709 \mathrm{~h} 5 \mathrm{~min} 0 \mathrm{~s}$ & 18,5 & 73 & 18,5 & 18,4 & 74 & 17,9 \\
\hline 987 & 06/19/17 09h10min0s & 18,6 & 72 & 18,7 & 18,5 & 74 & 18,0 \\
\hline 988 & 06/19/17 09h15min0s & 18,7 & 72 & 18,8 & 18,6 & 73 & 18,1 \\
\hline 989 & 06/19/17 09h20min0s & 18,9 & 71 & 19,1 & 18,8 & 72 & 18,4 \\
\hline 990 & $06 / 19 / 1709 \mathrm{~h} 25 \mathrm{~min} 0 \mathrm{~s}$ & 19,1 & 70 & 19,2 & 19,0 & 71 & 18,6 \\
\hline 991 & 06/19/17 09h30min0s & 19,2 & 70 & 19,3 & 19,1 & 72 & 18,7 \\
\hline 992 & 06/19/17 09h35min0s & 19,4 & 70 & 19,6 & 19,3 & 71 & 19,0 \\
\hline 993 & 06/19/17 09h40min0s & 19,7 & 70 & 20,0 & 19,6 & 70 & 19,3 \\
\hline 994 & $06 / 19 / 1709 \mathrm{~h} 45 \mathrm{~min} 0 \mathrm{~s}$ & 19,9 & 69 & 20,3 & 19,8 & 70 & 19,6 \\
\hline 995 & $06 / 19 / 1709 \mathrm{~h} 50 \mathrm{~min} 0 \mathrm{~s}$ & 20,2 & 67 & 20,6 & 20,1 & 68 & 19,9 \\
\hline 996 & 06/19/17 09h55min0s & 20,5 & 65 & 20,8 & 20,4 & 66 & 20,2 \\
\hline 997 & $06 / 19 / 1710 \mathrm{h0min0s}$ & 20,7 & 64 & 20,9 & 20,7 & 65 & 20,5 \\
\hline
\end{tabular}


TRIPÉS - 22/06/2016

\begin{tabular}{|c|c|c|c|c|c|c|c|}
\hline \multirow{2}{*}{ \# } & \multirow{2}{*}{ DATA, HORA } & \multicolumn{3}{|c|}{ SOMBRA } & \multicolumn{3}{|c|}{ SOL } \\
\hline & & TEMP. AR ("C) & UR (\%) & TEMP. GLOBO ("C) & TEMP. AR ("C) & UR (\%) & TEMP. GLOBO ("C) \\
\hline 1801 & $06 / 22 / 1705$ homin0s & 22,3 & 68 & 22,4 & 22,3 & 68 & 22,3 \\
\hline 1802 & $06 / 22 / 1705 \mathrm{~h} 5 \mathrm{~min} 0 \mathrm{~s}$ & 22,3 & 68 & 22,4 & 22,3 & 68 & 22,3 \\
\hline 1803 & $06 / 22 / 1705 \mathrm{~h} 10 \mathrm{~min} 0 \mathrm{~s}$ & 22,3 & 68 & 22,4 & 22,3 & 68 & 22,3 \\
\hline 1804 & $06 / 22 / 1705 \mathrm{~h} 15 \mathrm{~min} 0 \mathrm{~s}$ & 22,3 & 68 & 22,4 & 22,3 & 68 & 22,3 \\
\hline 1805 & $06 / 22 / 1705 \mathrm{~h} 20 \mathrm{~min} 0 \mathrm{~s}$ & 22,3 & 68 & 22,4 & 22,3 & 68 & 22,3 \\
\hline 1806 & $06 / 22 / 1705 \mathrm{~h} 25 \mathrm{~min} 0 \mathrm{~s}$ & 22,3 & 68 & 22,4 & 22,3 & 68 & 22,3 \\
\hline 1807 & $06 / 22 / 1705 \mathrm{~h} 30 \mathrm{~min} 0 \mathrm{~s}$ & 22,3 & 68 & 22,4 & 22,3 & 68 & 22,3 \\
\hline 1808 & $06 / 22 / 1705 \mathrm{~h} 35 \mathrm{~min} 0 \mathrm{~s}$ & 22,3 & 69 & 22,4 & 22,3 & 69 & 22,3 \\
\hline 1809 & $06 / 22 / 1705 \mathrm{~h} 40 \mathrm{~min} 0 \mathrm{~s}$ & 22,3 & 73 & 22,6 & 22,3 & 73 & 22,4 \\
\hline 1810 & $06 / 22 / 1705 \mathrm{~h} 45 \mathrm{~min} 0 \mathrm{~s}$ & 22,1 & 64 & 22,1 & 22,1 & 65 & 21,8 \\
\hline 1811 & $06 / 22 / 1705 \mathrm{~h} 50 \mathrm{~min} 0 \mathrm{~s}$ & 20,5 & 68 & 18,6 & 20,5 & 70 & 18,5 \\
\hline 1812 & $06 / 22 / 1705 \mathrm{~h} 55 \mathrm{~min} 0 \mathrm{~s}$ & 19,3 & 73 & 17,0 & 19,2 & 73 & 16,7 \\
\hline 1813 & $06 / 22 / 1706 \mathrm{~h} 0 \mathrm{~min} 0 \mathrm{~s}$ & 18,5 & 76 & 16,4 & 18,2 & 78 & 16,3 \\
\hline 1814 & $06 / 22 / 1706 \mathrm{~h} 5 \mathrm{~min} 0 \mathrm{~s}$ & 17,7 & 78 & 16,5 & 17,5 & 80 & 15,9 \\
\hline 1815 & $06 / 22 / 1706 \mathrm{~h} 10 \mathrm{~min} 0 \mathrm{~s}$ & 17,2 & 81 & 16,4 & 17,1 & 82 & 15,7 \\
\hline 1816 & $06 / 22 / 1706 \mathrm{~h} 15 \mathrm{~min} 0 \mathrm{~s}$ & 16,8 & 82 & 16,3 & 16,7 & 83 & 15,8 \\
\hline 1817 & $06 / 22 / 1706 \mathrm{~h} 20 \mathrm{~min} 0 \mathrm{~s}$ & 16,7 & 83 & 16,2 & 16,6 & 83 & 15,8 \\
\hline 1818 & $06 / 22 / 1706 \mathrm{~h} 25 \mathrm{~min} 0 \mathrm{~s}$ & 16,5 & 83 & 16,2 & 16,4 & 84 & 15,7 \\
\hline 1819 & $06 / 22 / 1706 \mathrm{~h} 30 \mathrm{~min} 0 \mathrm{~s}$ & 16,4 & 84 & 16,2 & 16,4 & 84 & 15,8 \\
\hline 1820 & $06 / 22 / 1706 \mathrm{~h} 35 \mathrm{~min} 0 \mathrm{~s}$ & 16,4 & 84 & 16,2 & 16,3 & 85 & 15,7 \\
\hline 1821 & $06 / 22 / 1706 \mathrm{~h} 40 \mathrm{~min} 0 \mathrm{~s}$ & 16,3 & 84 & 16,1 & 16,3 & 85 & 15,6 \\
\hline 1822 & $06 / 22 / 1706 \mathrm{~h} 45 \mathrm{~min} 0 \mathrm{~s}$ & 16,3 & 84 & 16,1 & 16,2 & 85 & 15,4 \\
\hline 1823 & $06 / 22 / 1706 \mathrm{~h} 50 \mathrm{~min} 0 \mathrm{~s}$ & 16,2 & 84 & 16,0 & 16,2 & 85 & 15,3 \\
\hline 1824 & $06 / 22 / 1706 \mathrm{~h} 55 \mathrm{~min} 0 \mathrm{~s}$ & 16,2 & 84 & 16,0 & 16,1 & 85 & 15,2 \\
\hline 1825 & 06/22/17 07h0min0s & 16,2 & 84 & 16,0 & 16,2 & 85 & 15,2 \\
\hline 1826 & $06 / 22 / 1707 \mathrm{~h} 5 \mathrm{~min} 0 \mathrm{~s}$ & 16,3 & 84 & 16,1 & 16,2 & 85 & 15,2 \\
\hline 1827 & $06 / 22 / 1707 \mathrm{~h} 10 \mathrm{~min} 0 \mathrm{~s}$ & 16,3 & 84 & 16,0 & 16,2 & 85 & 15,1 \\
\hline 1828 & $06 / 22 / 1707 \mathrm{~h} 15 \mathrm{~min} 0 \mathrm{~s}$ & 16,2 & 84 & 16,0 & 16,1 & 85 & 15,1 \\
\hline 1829 & $06 / 22 / 1707 \mathrm{~h} 20 \mathrm{~min} 0 \mathrm{~s}$ & 16,2 & 84 & 16,0 & 16,1 & 85 & 15,2 \\
\hline 1830 & $06 / 22 / 1707 \mathrm{~h} 25 \mathrm{~min} 0 \mathrm{~s}$ & 16,2 & 84 & 16,0 & 16,2 & 85 & 15,3 \\
\hline 1831 & $06 / 22 / 1707 \mathrm{~h} 30 \mathrm{~min} 0 \mathrm{~s}$ & 16,2 & 84 & 16,1 & 16,2 & 85 & 15,4 \\
\hline 1832 & $06 / 22 / 1707 \mathrm{~h} 35 \mathrm{~min} 0 \mathrm{~s}$ & 16,3 & 84 & 16,2 & 16,2 & 85 & 15,5 \\
\hline 1833 & $06 / 22 / 1707 \mathrm{~h} 40 \mathrm{~min} 0 \mathrm{~s}$ & 16,3 & 83 & 16,2 & 16,2 & 84 & 15,6 \\
\hline 1834 & $06 / 22 / 1707 \mathrm{~h} 45 \mathrm{~min} 0 \mathrm{~s}$ & 16,2 & 83 & 16,2 & 16,2 & 84 & 15,8 \\
\hline 1835 & $06 / 22 / 1707 \mathrm{~h} 50 \mathrm{~min} 0 \mathrm{~s}$ & 16,2 & 84 & 16,2 & 16,2 & 84 & 16,0 \\
\hline 1836 & $06 / 22 / 1707 \mathrm{~h} 55 \mathrm{~min} 0 \mathrm{~s}$ & 16,3 & 84 & 16,4 & 16,2 & 84 & 16,3 \\
\hline 1837 & $06 / 22 / 1708 \mathrm{~h} 0 \mathrm{~min} 0 \mathrm{~s}$ & 16,3 & 83 & 16,5 & 16,3 & 84 & 16,5 \\
\hline 1838 & $06 / 22 / 1708 \mathrm{~h} 5 \mathrm{~min} 0 \mathrm{~s}$ & 16,3 & 83 & 16,4 & 16,3 & 84 & 16,6 \\
\hline 1839 & $06 / 22 / 1708 \mathrm{~h} 10 \mathrm{~min} 0 \mathrm{~s}$ & 16,4 & 83 & 16,6 & 16,3 & 84 & 16,7 \\
\hline 1840 & $06 / 22 / 1708 \mathrm{~h} 15 \mathrm{~min} 0 \mathrm{~s}$ & 16,4 & 83 & 16,6 & 16,4 & 84 & 16,7 \\
\hline 1841 & $06 / 22 / 1708 \mathrm{~h} 20 \mathrm{~min} 0 \mathrm{~s}$ & 16,5 & 83 & 16,7 & 16,4 & 84 & 16,6 \\
\hline 1842 & $06 / 22 / 1708 \mathrm{~h} 25 \mathrm{~min} 0 \mathrm{~s}$ & 16,5 & 83 & 16,8 & 16,4 & 83 & 16,7 \\
\hline 1843 & $06 / 22 / 1708 \mathrm{~h} 30 \mathrm{~min} 0 \mathrm{~s}$ & 16,5 & 82 & 17,1 & 16,5 & 83 & 17,1 \\
\hline 1844 & $06 / 22 / 1708 \mathrm{~h} 35 \mathrm{~min} 0 \mathrm{~s}$ & 16,5 & 83 & 17,3 & 16,5 & 83 & 17,4 \\
\hline 1845 & $06 / 22 / 1708 \mathrm{~h} 40 \mathrm{~min} 0 \mathrm{~s}$ & 16,6 & 82 & 17,3 & 16,6 & 82 & 17,9 \\
\hline 1846 & $06 / 22 / 1708 \mathrm{~h} 45 \mathrm{~min} 0 \mathrm{~s}$ & 16,7 & 81 & 17,5 & 16,8 & 82 & 20,1 \\
\hline 1847 & $06 / 22 / 1708 \mathrm{~h} 50 \mathrm{~min} 0 \mathrm{~s}$ & 16,8 & 81 & 18,0 & 17,0 & 81 & 21,5 \\
\hline 1848 & $06 / 22 / 1708 \mathrm{~h} 55 \mathrm{~min} 0 \mathrm{~s}$ & 16,9 & 80 & 18,1 & 17,2 & 80 & 21,2 \\
\hline 1849 & 06/22/17 09h0min0s & 17,0 & 81 & 18,2 & 17,3 & 80 & 23,2 \\
\hline 1850 & $06 / 22 / 1709 \mathrm{~h} 5 \mathrm{~min} 0 \mathrm{~s}$ & 17,2 & 80 & 18,7 & 17,6 & 79 & 25,1 \\
\hline 1851 & 06/22/17 09h10min0s & 17,3 & 79 & 18,7 & 17,7 & 78 & 24,8 \\
\hline 1852 & 06/22/17 09h15min0s & 17,4 & 80 & 18,9 & 17,8 & 78 & 26,3 \\
\hline 1853 & $06 / 22 / 1709 \mathrm{~h} 20 \mathrm{~min} 0 \mathrm{~s}$ & 17,4 & 79 & 18,7 & 17,7 & 77 & 25,8 \\
\hline 1854 & $06 / 22 / 1709 \mathrm{~h} 25 \mathrm{~min} 0 \mathrm{~s}$ & 17,5 & 78 & 18,7 & 17,8 & 77 & 25,2 \\
\hline 1855 & $06 / 22 / 1709 \mathrm{~h} 30 \mathrm{~min} 0 \mathrm{~s}$ & 17,5 & 78 & 18,8 & 17,9 & 77 & 25,0 \\
\hline 1856 & $06 / 22 / 1709 \mathrm{~h} 35 \mathrm{~min} 0 \mathrm{~s}$ & 17,7 & 77 & 19,2 & 18,1 & 76 & 25,6 \\
\hline 1857 & $06 / 22 / 1709 \mathrm{~h} 40 \mathrm{~min} 0 \mathrm{~s}$ & 17,8 & 77 & 19,4 & 18,3 & 76 & 26,2 \\
\hline 1858 & $06 / 22 / 1709 \mathrm{~h} 45 \mathrm{~min} 0 \mathrm{~s}$ & 18,1 & 76 & 19,6 & 18,6 & 75 & 26,7 \\
\hline 1859 & $06 / 22 / 1709 \mathrm{~h} 50 \mathrm{~min} 0 \mathrm{~s}$ & 18,2 & 75 & 19,7 & 18,6 & 75 & 27,2 \\
\hline 1860 & $06 / 22 / 1709 \mathrm{~h} 55 \mathrm{~min} 0 \mathrm{~s}$ & 18,3 & 75 & 20,0 & 18,9 & 74 & 28,9 \\
\hline 1861 & 06/22/17 10h0min0s & 18,5 & 74 & 20,2 & 19,1 & 72 & 28,5 \\
\hline
\end{tabular}


TRIPÉS - 23/06/2016

\begin{tabular}{|c|c|c|c|c|c|c|c|}
\hline \multirow{2}{*}{$\#$} & \multirow{2}{*}{ DATA, HORA } & \multicolumn{3}{|c|}{ SOL } & \multicolumn{3}{|c|}{ SOMBRA } \\
\hline & & Temp. Ar $\left({ }^{\circ} \mathrm{C}\right)$ & UR (\%) & Temp. Globo ("C) & Temp. Ar $\left({ }^{\circ} \mathrm{C}\right)$ & UR (\%) & Temp. Globo $\left({ }^{\circ} \mathrm{C}\right)$ \\
\hline 73 & $06 / 23 / 1705 \mathrm{~h} 0 \mathrm{~min} 0 \mathrm{~s}$ & 22,7 & 59 & 22,7 & 22,8 & 58 & 22,6 \\
\hline 74 & 06/23/17 05h5min0s & 22,7 & 59 & 22,7 & 22,7 & 58 & 22,6 \\
\hline 75 & $06 / 23 / 1705 \mathrm{~h} 10 \mathrm{~min} 0 \mathrm{~s}$ & 22,7 & 59 & 22,7 & 22,7 & 58 & 22,6 \\
\hline 76 & $06 / 23 / 1705 \mathrm{~h} 15 \mathrm{~min} 0 \mathrm{~s}$ & 22,7 & 59 & 22,7 & 22,7 & 58 & 22,6 \\
\hline 77 & $06 / 23 / 1705 \mathrm{~h} 20 \mathrm{~min} 0 \mathrm{~s}$ & 22,7 & 59 & 22,7 & 22,7 & 58 & 22,6 \\
\hline 78 & $06 / 23 / 1705 \mathrm{~h} 25 \mathrm{~min} 0 \mathrm{~s}$ & 22,7 & 59 & 22,6 & 22,7 & 58 & 22,6 \\
\hline 79 & $06 / 23 / 1705 \mathrm{~h} 30 \mathrm{~min} 0 \mathrm{~s}$ & 22,7 & 59 & 22,6 & 22,7 & 58 & 22,6 \\
\hline 80 & $06 / 23 / 1705 \mathrm{~h} 35 \mathrm{~min} 0 \mathrm{~s}$ & 22,7 & 59 & 22,6 & 22,7 & 58 & 22,5 \\
\hline 81 & $06 / 23 / 1705 \mathrm{~h} 40 \mathrm{~min} 0 \mathrm{~s}$ & 22,7 & 61 & 22,6 & 22,7 & 63 & 22,6 \\
\hline 82 & $06 / 23 / 1705 \mathrm{~h} 45 \mathrm{~min} 0 \mathrm{~s}$ & 22,1 & 61 & 22,1 & 22,5 & 60 & 21,6 \\
\hline 83 & $06 / 23 / 1705 \mathrm{~h} 50 \mathrm{~min} 0 \mathrm{~s}$ & 19,9 & 68 & 18,3 & 20,8 & 66 & 18,0 \\
\hline 84 & $06 / 23 / 1705 \mathrm{~h} 55 \mathrm{~min} 0 \mathrm{~s}$ & 18,2 & 76 & 16,6 & 19,2 & 70 & 16,5 \\
\hline 85 & $06 / 23 / 1706 \mathrm{~h} 0 \mathrm{~min} 0 \mathrm{~s}$ & 17,3 & 80 & 16,2 & 18,0 & 75 & 16,2 \\
\hline 86 & $06 / 23 / 1706 \mathrm{~h} 5 \mathrm{~min} 0 \mathrm{~s}$ & 16,6 & 82 & 16,0 & 17,1 & 79 & 16,0 \\
\hline 87 & $06 / 23 / 1706 \mathrm{~h} 10 \mathrm{~min} 0 \mathrm{~s}$ & 16,3 & 83 & 15,8 & 16,6 & 81 & 15,9 \\
\hline 88 & $06 / 23 / 1706 \mathrm{~h} 15 \mathrm{~min} 0 \mathrm{~s}$ & 16,1 & 84 & 15,7 & 16,2 & 83 & 15,8 \\
\hline 89 & $06 / 23 / 1706 \mathrm{~h} 20 \mathrm{~min} 0 \mathrm{~s}$ & 15,9 & 85 & 15,7 & 16,0 & 84 & 15,8 \\
\hline 90 & $06 / 23 / 1706 \mathrm{~h} 25 \mathrm{~min} 0 \mathrm{~s}$ & 15,9 & 86 & 15,7 & 15,9 & 85 & 15,8 \\
\hline 91 & $06 / 23 / 1706 \mathrm{~h} 30 \mathrm{~min} 0 \mathrm{~s}$ & 15,9 & 85 & 15,8 & 15,9 & 84 & 15,8 \\
\hline 92 & $06 / 23 / 1706 \mathrm{~h} 35 \mathrm{~min} 0 \mathrm{~s}$ & 15,9 & 85 & 15,8 & 15,9 & 85 & 15,8 \\
\hline 93 & $06 / 23 / 1706 \mathrm{~h} 40 \mathrm{~min} 0 \mathrm{~s}$ & 15,9 & 86 & 15,9 & 15,9 & 85 & 15,9 \\
\hline 94 & $06 / 23 / 1706 \mathrm{~h} 45 \mathrm{~min} 0 \mathrm{~s}$ & 15,9 & 85 & 15,9 & 15,9 & 85 & 15,9 \\
\hline 95 & $06 / 23 / 1706 \mathrm{~h} 50 \mathrm{~min} 0 \mathrm{~s}$ & 15,9 & 85 & 15,9 & 15,9 & 85 & 15,9 \\
\hline 96 & $06 / 23 / 1706 \mathrm{~h} 55 \mathrm{~min} 0 \mathrm{~s}$ & 15,9 & 85 & 15,8 & 15,9 & 85 & 15,8 \\
\hline 97 & 06/23/17 07h0min0s & 15,9 & 86 & 15,8 & 15,9 & 85 & 15,8 \\
\hline 98 & 06/23/17 07h5min0s & 15,9 & 85 & 15,8 & 15,9 & 85 & 15,8 \\
\hline 99 & $06 / 23 / 1707 \mathrm{~h} 10 \mathrm{~min} 0 \mathrm{~s}$ & 15,9 & 86 & 15,8 & 15,9 & 85 & 15,9 \\
\hline 100 & $06 / 23 / 1707 \mathrm{~h} 15 \mathrm{~min} 0 \mathrm{~s}$ & 16,0 & 85 & 15,9 & 16,0 & 85 & 16,0 \\
\hline 101 & $06 / 23 / 1707 \mathrm{~h} 20 \mathrm{~min} 0 \mathrm{~s}$ & 16,0 & 85 & 16,1 & 16,0 & 85 & 16,1 \\
\hline 102 & $06 / 23 / 1707 \mathrm{~h} 25 \mathrm{~min} 0 \mathrm{~s}$ & 16,0 & 85 & 16,2 & 16,0 & 84 & 16,2 \\
\hline 103 & $06 / 23 / 1707 \mathrm{~h} 30 \mathrm{~min} 0 \mathrm{~s}$ & 16,1 & 85 & 16,2 & 16,1 & 84 & 16,2 \\
\hline 104 & $06 / 23 / 1707 \mathrm{~h} 35 \mathrm{~min} 0 \mathrm{~s}$ & 16,1 & 85 & 16,3 & 16,1 & 85 & 16,2 \\
\hline 105 & $06 / 23 / 1707 \mathrm{~h} 40 \mathrm{~min} 0 \mathrm{~s}$ & 16,1 & 86 & 16,3 & 16,1 & 85 & 16,2 \\
\hline 106 & $06 / 23 / 1707 \mathrm{~h} 45 \mathrm{~min} 0 \mathrm{~s}$ & 16,2 & 85 & 16,5 & 16,2 & 84 & 16,4 \\
\hline 107 & $06 / 23 / 1707 \mathrm{~h} 50 \mathrm{~min} 0 \mathrm{~s}$ & 16,3 & 85 & 16,6 & 16,3 & 84 & 16,5 \\
\hline 108 & $06 / 23 / 1707 \mathrm{~h} 55 \mathrm{~min} 0 \mathrm{~s}$ & 16,3 & 85 & 16,6 & 16,3 & 84 & 16,5 \\
\hline 109 & $06 / 23 / 1708 \mathrm{~h} 0 \mathrm{~min} 0 \mathrm{~s}$ & 16,4 & 84 & 16,7 & 16,4 & 83 & 16,6 \\
\hline 110 & $06 / 23 / 1708 \mathrm{~h} 5 \mathrm{~min} 0 \mathrm{~s}$ & 16,6 & 83 & 16,9 & 16,6 & 83 & 16,8 \\
\hline 111 & $06 / 23 / 1708 \mathrm{~h} 10 \mathrm{~min} 0 \mathrm{~s}$ & 16,6 & 83 & 16,8 & 16,6 & 82 & 16,7 \\
\hline 112 & $06 / 23 / 1708 \mathrm{~h} 15 \mathrm{~min} 0 \mathrm{~s}$ & 16,7 & 83 & 17,0 & 16,7 & 82 & 16,8 \\
\hline 113 & $06 / 23 / 1708 \mathrm{~h} 20 \mathrm{~min} 0 \mathrm{~s}$ & 16,8 & 83 & 17,1 & 16,8 & 82 & 16,9 \\
\hline 114 & $06 / 23 / 1708 \mathrm{~h} 25 \mathrm{~min} 0 \mathrm{~s}$ & 16,8 & 82 & 17,2 & 16,9 & 81 & 17,0 \\
\hline 115 & $06 / 23 / 1708 \mathrm{~h} 30 \mathrm{~min} 0 \mathrm{~s}$ & 17,0 & 81 & 17,3 & 16,9 & 80 & 17,1 \\
\hline 116 & $06 / 23 / 1708 \mathrm{~h} 35 \mathrm{~min} 0 \mathrm{~s}$ & 16,9 & 81 & 17,2 & 16,9 & 80 & 16,9 \\
\hline 117 & $06 / 23 / 1708 \mathrm{~h} 40 \mathrm{~min} 0 \mathrm{~s}$ & 16,9 & 81 & 17,3 & 16,9 & 81 & 17,0 \\
\hline 118 & $06 / 23 / 1708 \mathrm{~h} 45 \mathrm{~min} 0 \mathrm{~s}$ & 17,0 & 81 & 17,4 & 17,0 & 80 & 17,1 \\
\hline 119 & $06 / 23 / 1708 \mathrm{~h} 50 \mathrm{~min} 0 \mathrm{~s}$ & 16,9 & 81 & 17,3 & 16,9 & 80 & 17,1 \\
\hline 120 & $06 / 23 / 1708 \mathrm{~h} 55 \mathrm{~min} 0 \mathrm{~s}$ & 16,9 & 81 & 17,3 & 16,9 & 80 & 17,1 \\
\hline 121 & 06/23/17 09h0min0s & 16,9 & 81 & 17,4 & 16,9 & 80 & 17,2 \\
\hline 122 & 06/23/17 09h5min0s & 17,0 & 81 & 17,6 & 16,9 & 80 & 17,2 \\
\hline 123 & $06 / 23 / 1709 \mathrm{~h} 10 \mathrm{~min} 0 \mathrm{~s}$ & 17,0 & 81 & 18,5 & 17,0 & 81 & 17,4 \\
\hline 124 & $06 / 23 / 1709 \mathrm{~h} 15 \mathrm{~min} 0 \mathrm{~s}$ & 17,1 & 80 & 19,7 & 17,0 & 80 & 17,7 \\
\hline 125 & 06/23/17 09h20min0s & 17,3 & 80 & 21,9 & 17,2 & 80 & 18,3 \\
\hline 126 & $06 / 23 / 1709 \mathrm{~h} 25 \mathrm{~min} 0 \mathrm{~s}$ & 17,4 & 80 & 21,0 & 17,3 & 79 & 18,2 \\
\hline 127 & $06 / 23 / 1709 \mathrm{~h} 30 \mathrm{~min} 0 \mathrm{~s}$ & 17,5 & 79 & 21,4 & 17,4 & 79 & 18,3 \\
\hline 128 & $06 / 23 / 1709 \mathrm{~h} 35 \mathrm{~min} 0 \mathrm{~s}$ & 17,7 & 79 & 22,5 & 17,5 & 79 & 18,7 \\
\hline 129 & $06 / 23 / 1709 \mathrm{~h} 40 \mathrm{~min} 0 \mathrm{~s}$ & 17,9 & 78 & 24,9 & 17,7 & 78 & 19,2 \\
\hline 130 & $06 / 23 / 1709 \mathrm{~h} 45 \mathrm{~min} 0 \mathrm{~s}$ & 18,1 & 77 & 26,0 & 17,8 & 77 & 19,4 \\
\hline 131 & $06 / 23 / 1709 \mathrm{~h} 50 \mathrm{~min} 0 \mathrm{~s}$ & 18,4 & 76 & 25,8 & 18,1 & 77 & 19,6 \\
\hline 132 & $06 / 23 / 1709 \mathrm{~h} 55 \mathrm{~min} 0 \mathrm{~s}$ & 18,5 & 76 & 26,2 & 18,2 & 76 & 19,8 \\
\hline 133 & 06/23/17 10h0min0s & 18,8 & 75 & 27,0 & 18,5 & 76 & 20,3 \\
\hline
\end{tabular}


Apêndice F - Descrição das vestimentas utilizadas pelos ciclistas no levantamento dos dados primários

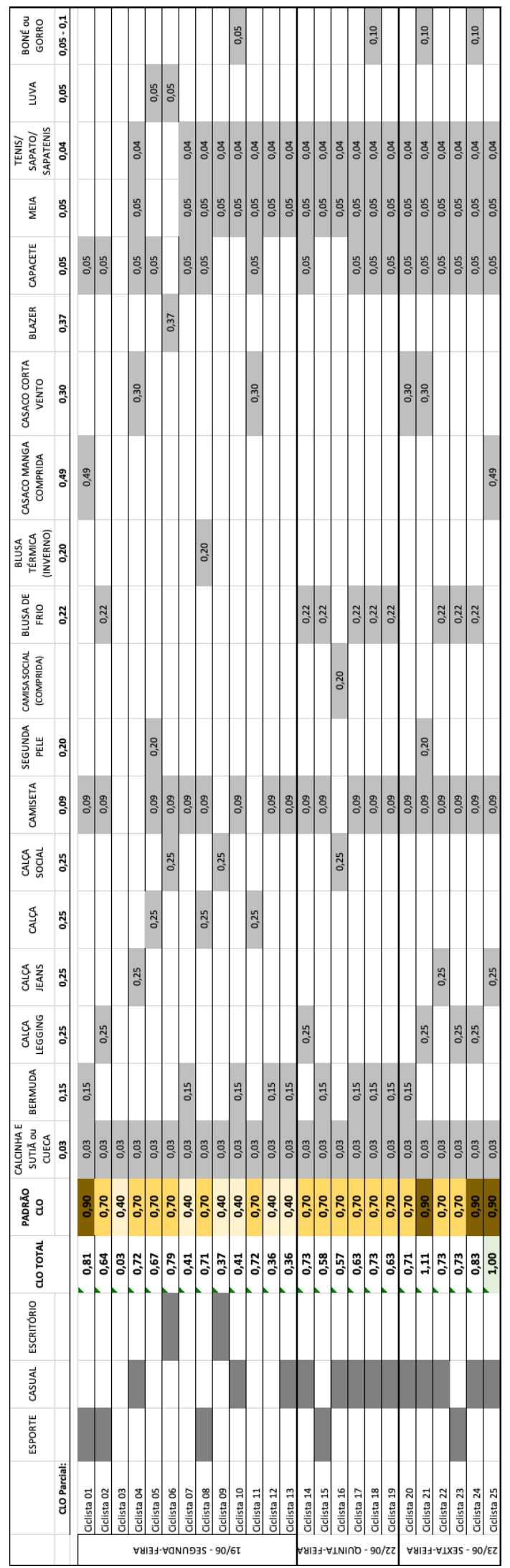


Apêndice G - Cálculos da Temperatura Equivalente Percebida - TEP

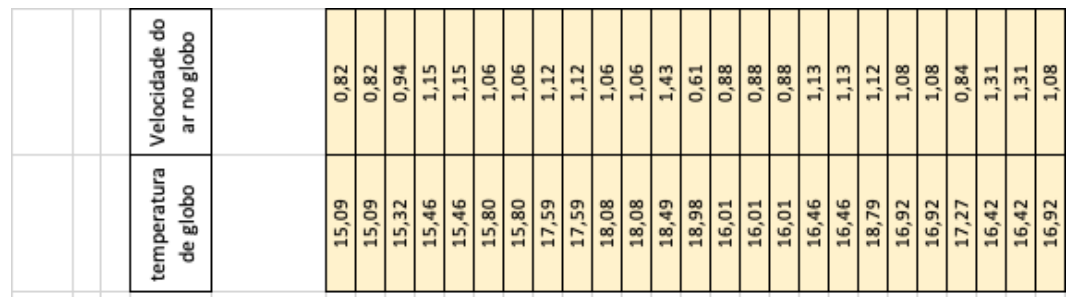

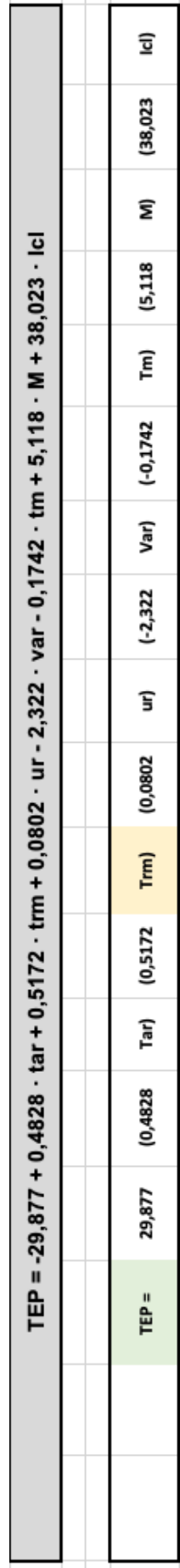

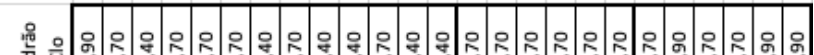

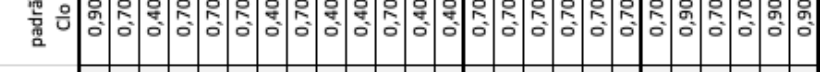
ఇ లెల్ల

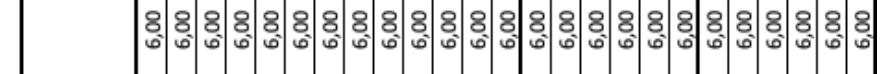

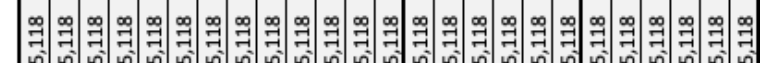
-

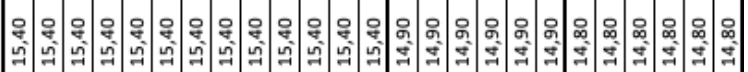

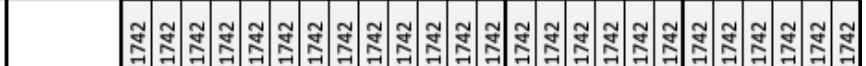

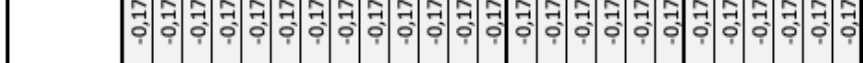

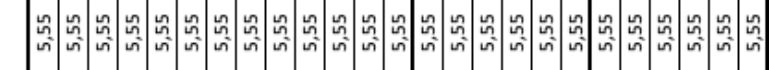

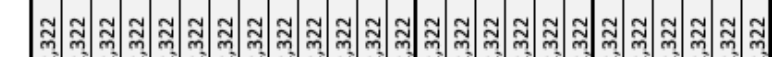

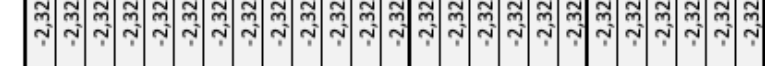

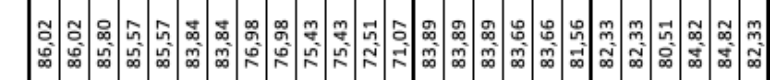

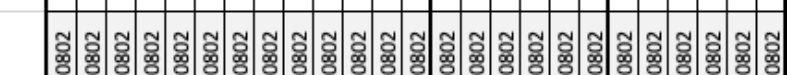

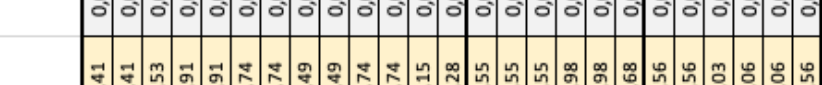

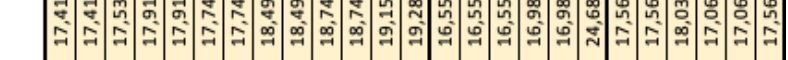

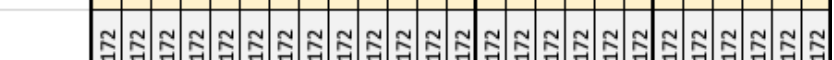

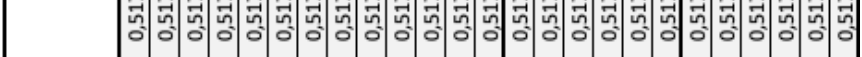

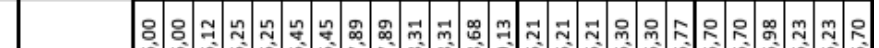

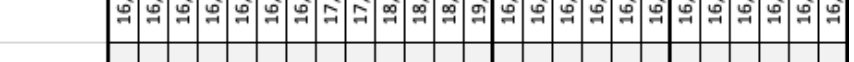

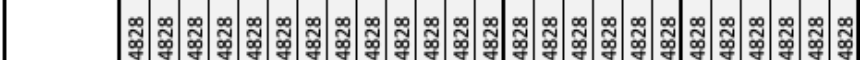

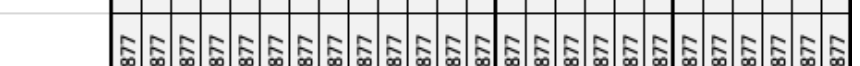

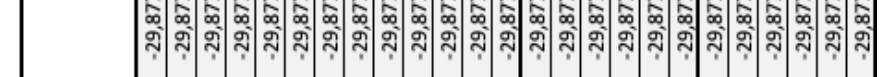

ㅇำผ

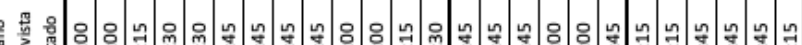

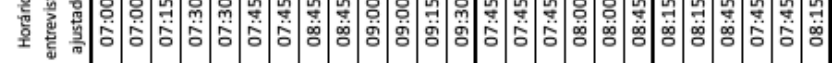

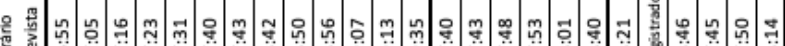

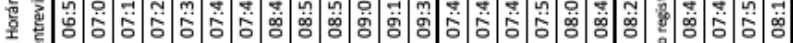

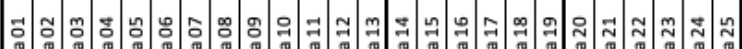

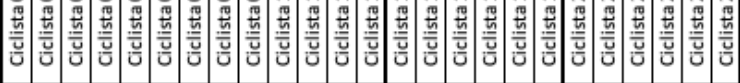


Apêndice H - Questionários aplicados aos ciclistas 


\section{QUESTIONÁRIO LEVANTAMENTO DE CAMPO}

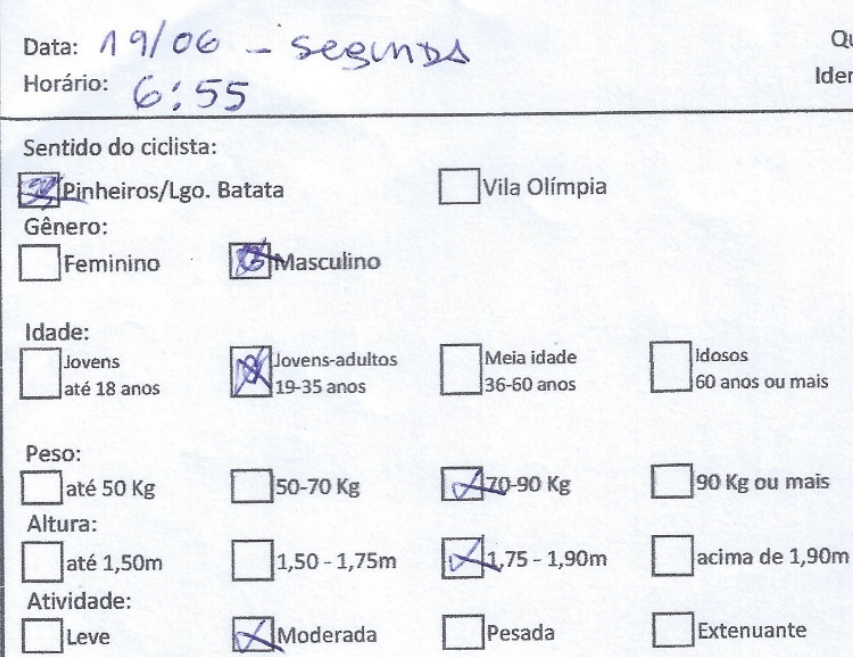

Isolamento Roupa: Becmeds, BLUSA thangs compriss cLo: caitcere (CAsso)

Você está indo para o trabalho ?

QSim $\square$ Não

1. Neste exato momento, como você se sente com relação à temperatura ?

$\square$ Muito Frio $\square$ Frio $\quad \square$ Calor $\quad \square$ Muito Calor

2. Em relação à temperatura, você está ?

(2) sátisfeito $\square$ insatisfeito

3. Como você gostaria de estar se sentindo em relação à temperatura ?

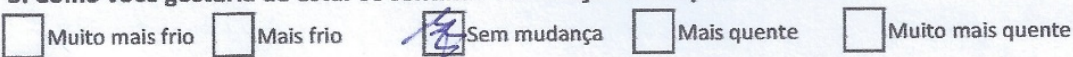

5. Em relação ao sol, você gostaria que estivesse ?

$\square$ Mais sol $\square$ Indiferente $\square$ Mais sombra

4. Em relação ao vento, você gostaria que estivesse ?

$\square$ Mais fraco $\quad \square$ Mais forte

6. O que te desencoraja a usar a bicicleta ?
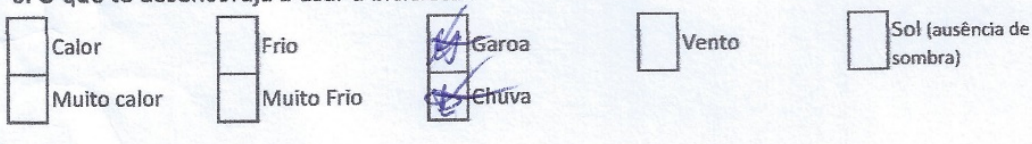

7. Há quanto tempo você iniciou este percurso?

$\square$ menos de 15 min $\square$ 15-30 minutos $\square$ 30-45 minutos $\square$ 45-60 minutos $\square$ mais de 60 min

8. Há quanto tempo você está em SP ?

Menos de 6 meses

Entre $6 \mathrm{~m}$. e 1 ano

Mais de 1 ano 


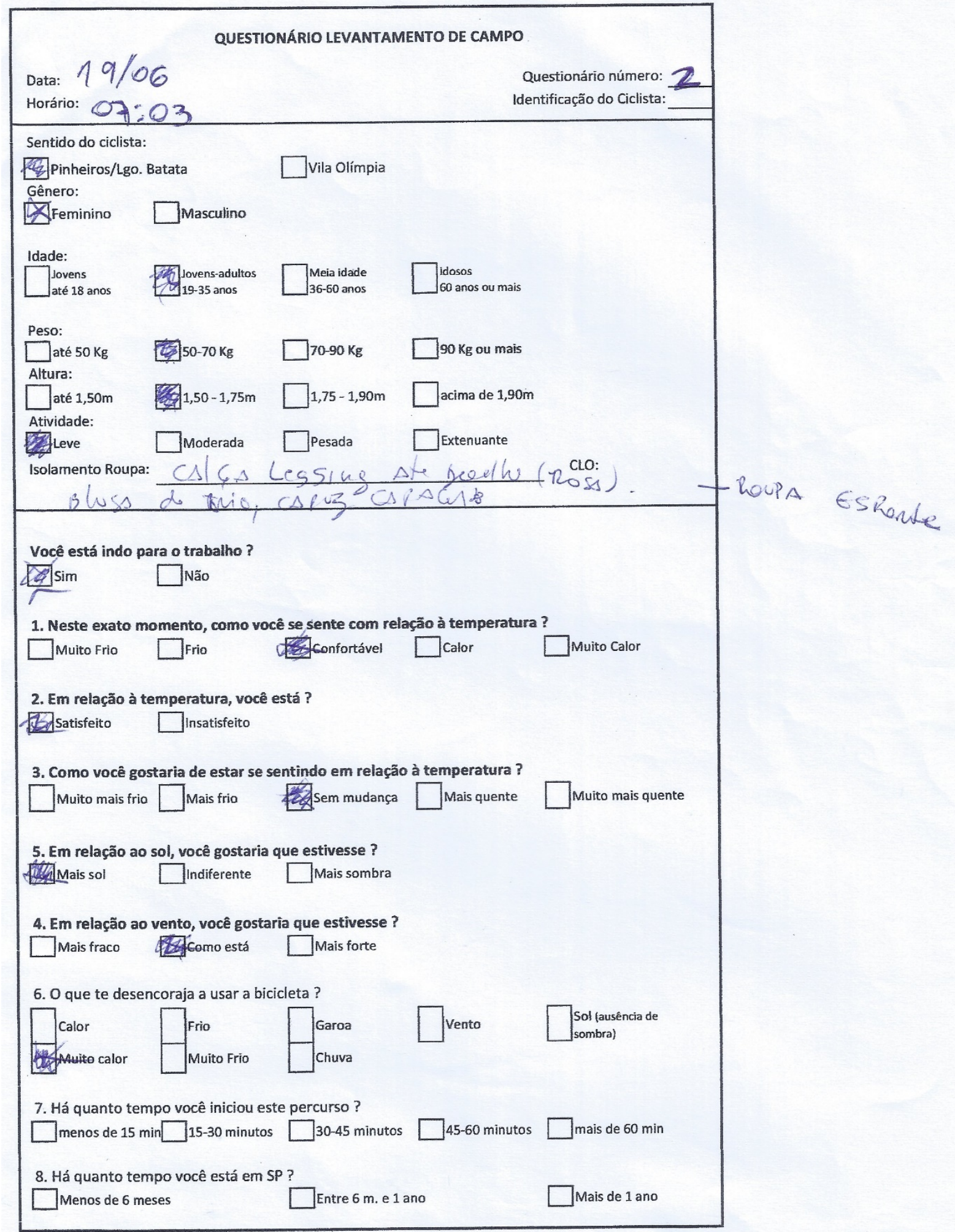




\section{QUESTIONÁRIO LEVANTAMENTO DE CAMPO} Data: $19 / 06-59 \cup 9 D A \quad$ Questionário número:
Horário: 07 Identificação do Ciclista:

Horário: 07.16

Sentido do ciclista:

Lat Pinheiros/Lgo. Batata

Vila Olímpia

Gênero:

Feminino Masculino

Idade:

Jovens Jovens-adultos $\square^{\text {Idosos }}$ Meia idade

até 18 anos $19-35$ anos $\quad 60$ anos ou mais

Peso: $\square$ até $50 \mathrm{Kg} \quad \square 50-70 \mathrm{Kg} \quad \square 70 \mathrm{Kg} \quad \square 90 \mathrm{Kg}$ ou mais

$\square$ até 1,50m $\square$ क्य $1,50-1,75 \mathrm{~m} \square$ 1,75-1,90m $\square$ acima de 1,90m

Atividade:

Leve $\quad \square$ Pesada $\square$ Extenuante

Isolamento Roupa:

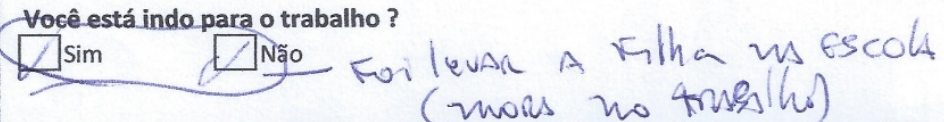

1. Neste exato momento, como você se sente com relação à temperatura ?

$\square$ Muito Frio $\square$ Frio 4 Confortável $\square$ Calor $\square$ Muito Calor

2. Em relação à temperatura, você está ?

Satisfeito $\square$ Insatisfeito

3. Como você gostaria de estar se sentindo em relação à temperatura ?

$\square$ Muito mais frio Mais frio

5. Em relação ao sol, você gostaria que estivesse ?

14. Mais-sol $\square$ Indiferente $\square$ Mais sombra

4. Em relação ao vento, você gostaria que estivesse ?

$\$ 4$ Mais fraco $\square$ Como está $\square$ Mais forte

6. O que te desencoraja a usar a bicicleta ?

$\square$ Calor $\square_{\text {Muito calor }}^{\text {Frio }} \quad \square$ Grio $\quad \square$ Chuva $\quad \square$ Vento

7. Há quanto tempo você iniciou este percurso?

$\square$ menos de 15 min $\square$ 15-30 minutos $\square$ 30-45 minutos

45-60 minutos $\square$ mais de $60 \mathrm{~min}$

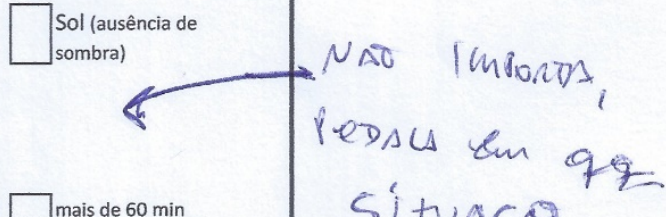

8. Há quanto tempo você está em SP ?

$\square$ Menos de 6 meses

Entre $6 \mathrm{~m} . \mathrm{e} 1$ ano

Mais de 1 ano 


\section{QUESTIONÁRIO LEVANTAMENTO DE CAMPO}

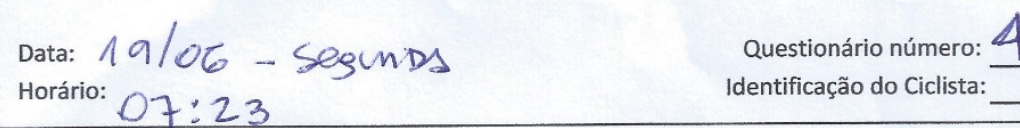

Sentido do ciclista:

49. Pinheiros/Lgo. Batata $\square$ Vila Olímpia

Gênero:

Feminino Masculino

Idade:

$\square_{\text {até } 18 \text { anos }}^{\text {Jovens }} \quad \square \begin{aligned} & \text { Jovens-adultos } \\ & \text { 19-35 anos }\end{aligned} \quad \square$ Meia idade $\quad \square$ Idosos 60 anos ou mais

Peso:

$\square$ até $50 \mathrm{Kg} \square 50-70 \mathrm{Kg} \quad \square 0-90 \mathrm{Kg} \quad \square 90 \mathrm{Kg}$ ou mais

Altura:

$\square$ até $1,50 \mathrm{~m} 1,50-1,75 \mathrm{~m} \square 1,75-1,90 \mathrm{~m} \square$ acima de $1,90 \mathrm{~m}$

Atividade:

$\square$ Leve Moderada $\square$ Pesada $\square$ Extenuante

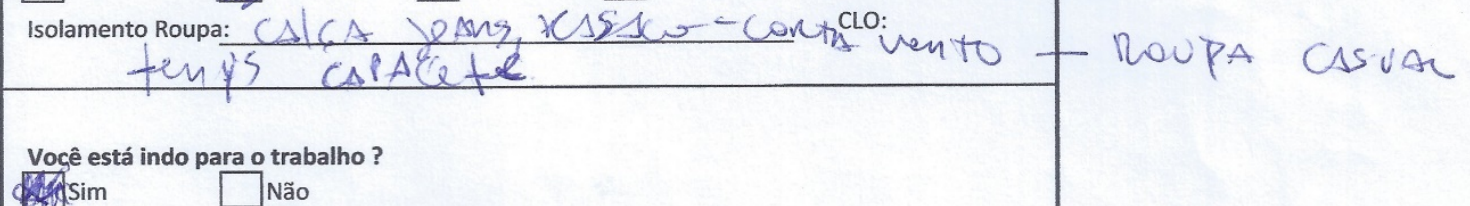

1. Neste exato momento, como você se sente com relação à temperatura ?

$\square$ Muito Frio $\square$ Frio $\quad$ Cenfortável $\square$ Calor $\square$ Muito Calor

2. Em relação à temperatura, você está ?

Sed Satisfeito $\square$ Insatisfeito

3. Como você gostaria de estar se sentindo em relação à temperatura ?

$\square$ Muito mais frio $\square$ Mais frio $\square$ (Sem mudança $\square$ Mais quente $\square$ Muito mais quente

5. Em relação ao sol, você gostaria que estivesse ?

$\square$ Mais sol 19 indiferente $\square$ Mais sombra

4. Em relação ao vento, você gostaria que estivesse ?

$\square$ Mais fraco

6. O que te desencoraja a usar a bicicleta ?

Calor
Muito calor

7. Há quanto tempo você iniciou este percurso?

$\square$ menos de $15 \mathrm{~min} \square$ 15-30 minutos $\square$ 30-45 minutos $\square$ 45-60 minutos $\square$ mais de 60 min

8. Há quanto tempo você está em SP ?
$\square$ Menos de 6 meses
Entre $6 \mathrm{~m}$. e 1 ano
Mais de 1 ano 


\section{QUESTIONÁRIO LEVANTAMENTO DE CAMPO}

Data: $19 / 06-\operatorname{seg} \ln D \Delta$ Feres
Horário: $7: 31$
identificaçãro número: ciclista:

Sentido do ciclista:

DA Pinheiros/Lgo. Batata

Vila Olímpia

Gênero:

$\square$ Feminino Masculino

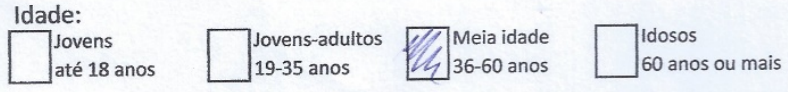

Peso:

$\square$ até $50 \mathrm{Kg} \quad \square 50-70 \mathrm{Kg} \quad \square 70-90 \mathrm{Kg} \quad 90 \mathrm{Kg}$ ou mais

Altura:

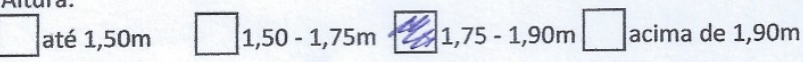

Atividade:

Atividade: $\quad \square$ Moderada $\square$ Pesada $\square$ Extenuante

Isolamento Roupa: tenis, BermubA, LUVA, CLO: zogings Rele e camisetA, CAPACote

Você está indo para o trabalho ?

Sim

1. Neste exato momento, como você se sente com relação à temperatura ?

$\square$ Muito Frio $\square$ Frio

2. Em relação à temperatura, você está ?

Satisfeito $\square$ Insatisfeito

3. Como você gostaria de estar se sentindo em relação à temperatura ?

$\square$ Muito mais frio $\square$ Mais frio

5. Em relação ao sol, você gostaria que estivesse ?

$\square$ Mais sol Indiferente $\square$ Mais sombra

4. Em relação ao vento, você gostaria que estivesse ?

Mais fraco $\square$ Mais forte

6. 0 que te desencoraja a usar a bicicleta ?

Calor
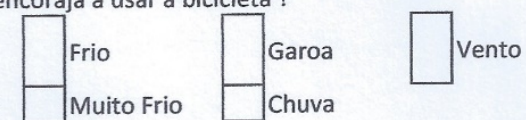

$\square$ Sol (ausência

usaria de qualqu forsma

7. Há quanto tempo você iniciou este percurso ?

$\square_{\text {menos de } 15 \text { min }} \square_{15-30 \text { minutos }} \square^{30-45}$ minutos $\square$ 45-60 minutos $\square$ mais de 60 min

8. Há quanto tempo você está em SP ?

Menos de 6 meses

Entre $6 \mathrm{~m} . \mathrm{e} 1$ ano

Mais de 1 ano 
QUESTIONÁRIO LEVANTAMENTO DE CAMPO

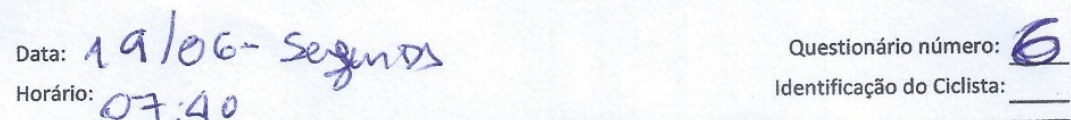

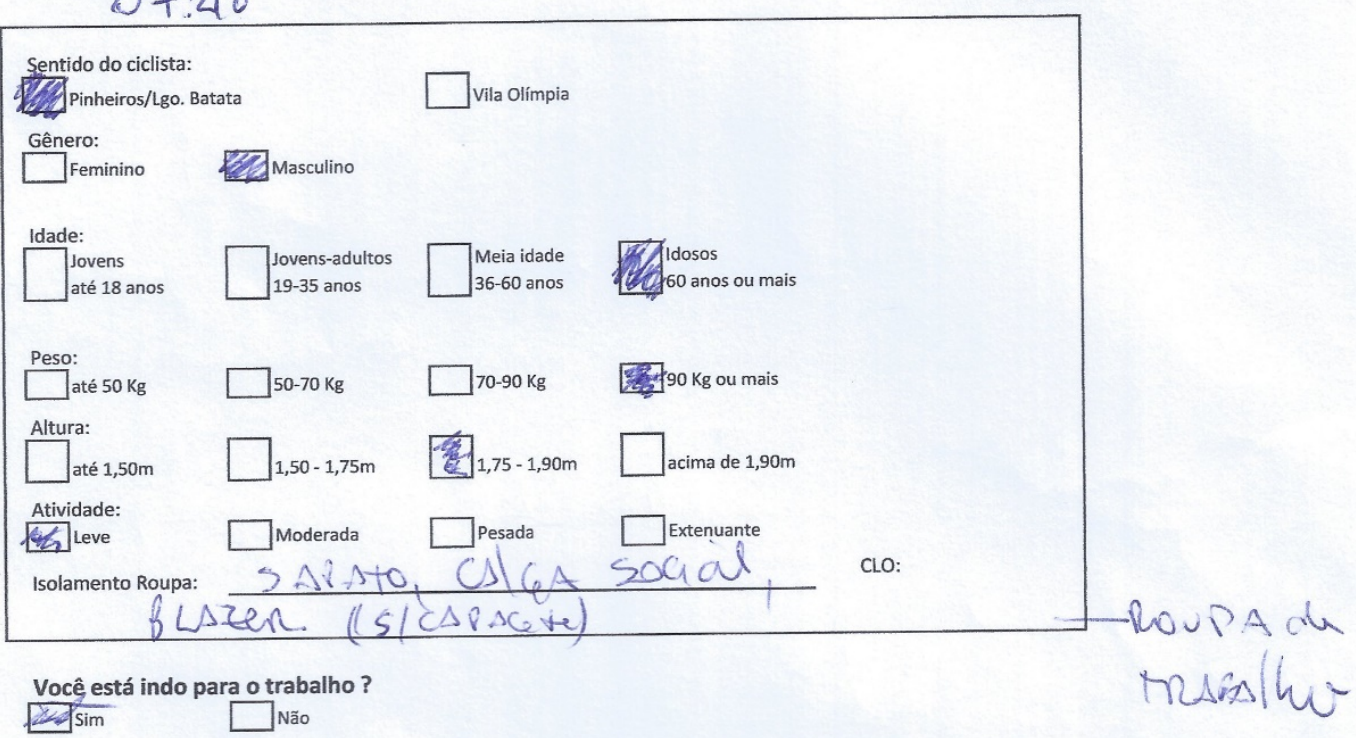

1. Neste exato momento, como você se sente com relação à temperatura ?

$\square$ Muito Frio $\quad \square$ confortável $\square$ calor $\square$ Muito Calor

2. Em relação à temperatura, você está ?

$\square$ satisfeito 1 insatisfeito

3. Como você gostaria de estar se sentindo em relação à temperatura ?

$\square$ Muito mais frio $\square$ Mais frio $\square$ sem mudança ${ }^{\text {Ma }}$ Mais quente $\square$ Muito mais quente

5. Em relação ao sol, você gostaria que estivesse ?

$123^{\circ \prime \prime}$ - Falou!

Minais sol $\square$ Indiferente $\square$ Mais sombra

4. Em relação ao vento, você gostaria que estivesse ?

$\square$ Mais fraco

\begin{tabular}{l} 
6. O que te desencoraja a usar a bicicleta ? \\
$\begin{array}{lll}\text { Calor } \\
\text { Muito calor }\end{array}$ Muito Frio \\
\hline Crio
\end{tabular}

7. Há quanto tempo você iniciou este percurso ?

$\square$ menos de 15 min $\square$ 15-30 minutos $\square$ 30-45 minutos $\square$ 45-60 minutos $\square$ mais de 60 min

8. Há quanto tempo você está em SP ?

$\square$ Menos de 6 meses $\square$ Entre 6 m. e 1 ano $\square$ Mais de 1 ano 


\section{QUESTIONÁRIO LEVANTAMENTO DE CAMPO}

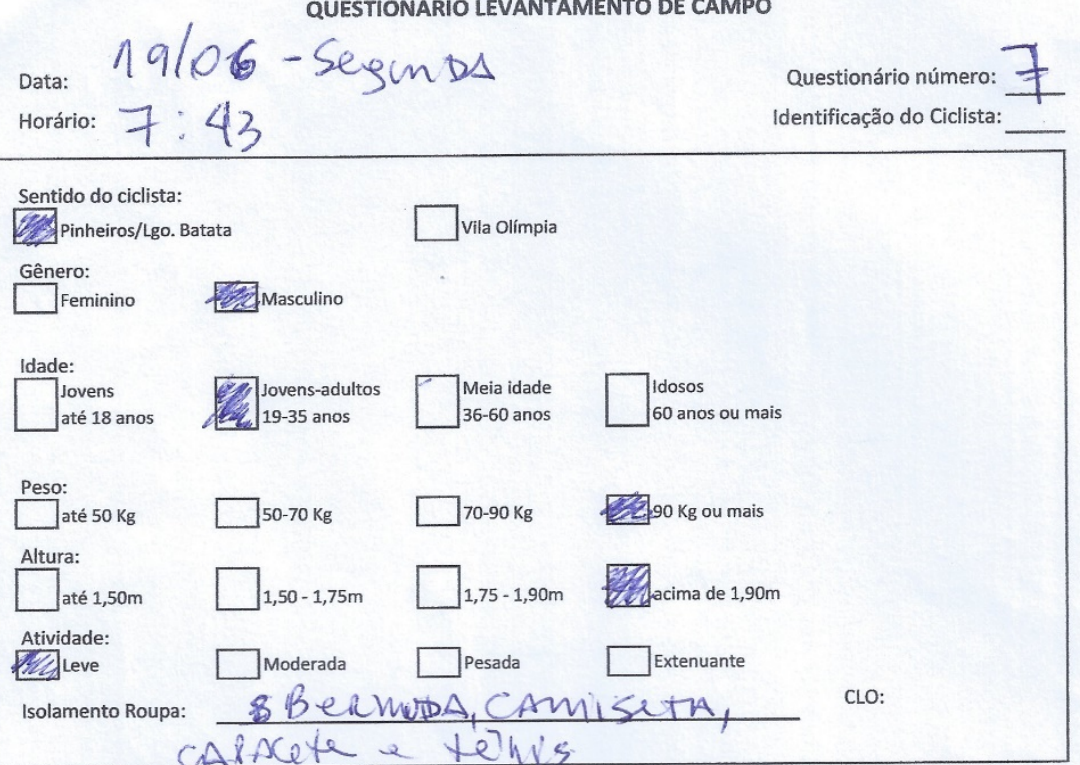

Você está indo para o trabalho ?

Hint

บão

1. Neste exato momento, como você se sente com relação à temperatura ?
Muito Frio
Qunfrio
$\square$ Confortável
Calor
Muito Calor

2. Em relação à temperatura, você está ?

W Satisfeito $\square$ Insatisfeito

3. Como você gostaria de estar se sentindo em relação à temperatura ?

$\square$ Muito mais frio $\square$ Mais frio $\quad \square$ Muito mais quente

5. Em relação ao sol, você gostaria que estivesse ?

fin

4. Em relação ao vento, você gostaria que estivesse ?

$\square$ Mais fraco

6. O que te desencoraja a usar a bicicleta ?
$\square$ Calor $\quad$ Frio $\square$ vento $\square$ sol (ausência de sombra)

Muito calor $\quad$ Muito Frio

7. Há quanto tempo você iniciou este percurso ?

$\square$ menos de 15 min $\square$ 15-30 minutos $\square$ 30-45 minutos $\square$ 45-60 minutos $\square$ mais de 60 min

8. Há quanto tempo você está em SP ?

$\square$ Menos de 6 meses $\square$ Entre 6 m. e 1 ano $\square$ Mais de 1 ano 
142

QUESTIONÁRIO LEVANTAMENTO DE CAMPO

oata: 19 log-segunts ferrs

Questionário número:

Horário: $\theta * 42$

Identificação do Ciclista:

Sentido do ciclista:

Pinheiros/Lgo. Batata

Gênero:

Feminino Masculino

Idade:

A

jovens

Peso:

Altura:

até $1,50 \mathrm{~m}$

Atividade:

Leve

Isolamento Roupa:

Moderada

ovens-adultos

Meia idade

Idosos

60 anos ou mais

CLO:

upa esfonte

Extenuant

capacetre ferus

Necêestá indo para o trabalho?

E. $\mathrm{sim}$

Não

1. Neste exato momento, como você se sente com relação à temperatura ?

Muito Frio

$\square$ Frio

20.

Calor

Muito Calor

2. Em relação à temperatura, você está ?

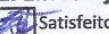

Insatisfeito

3. Como você gostaria de estar se sentindo em relação à temperatura ?

Muito mais frio $\square$ Mais frio

Isem mudança

Mais quente

Muito mais quente

5. Em relação ao sol, você gostaria que estivesse ?

Mais sol

4. Em relação ao vento, você gostaria que estivesse ?

Mais fraco $\square$ Como está $\square$ Mais forte

6. 0 que te desencoraja a usar a bicicleta ?

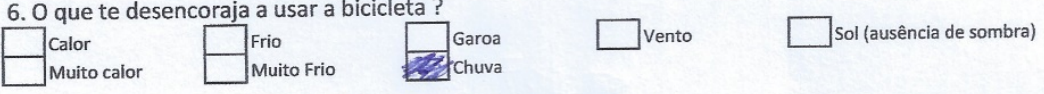

7. Há quanto tempo você iniciou este percurso?

$\square$ menos de 15 min $\square$ 15-30 minutos $\square$ 30-45 minutos $\square$ 45-60 minutos $\square$ mais de 60 min

8. Há quanto tempo você está em SP ?

Menos de 6 meses $\square$ Entre 6 m. e 1 ano $\square$ Mais de 1 ano 


\section{QUESTIONÁRIO LEVANTAMENTO DE CAMPO}

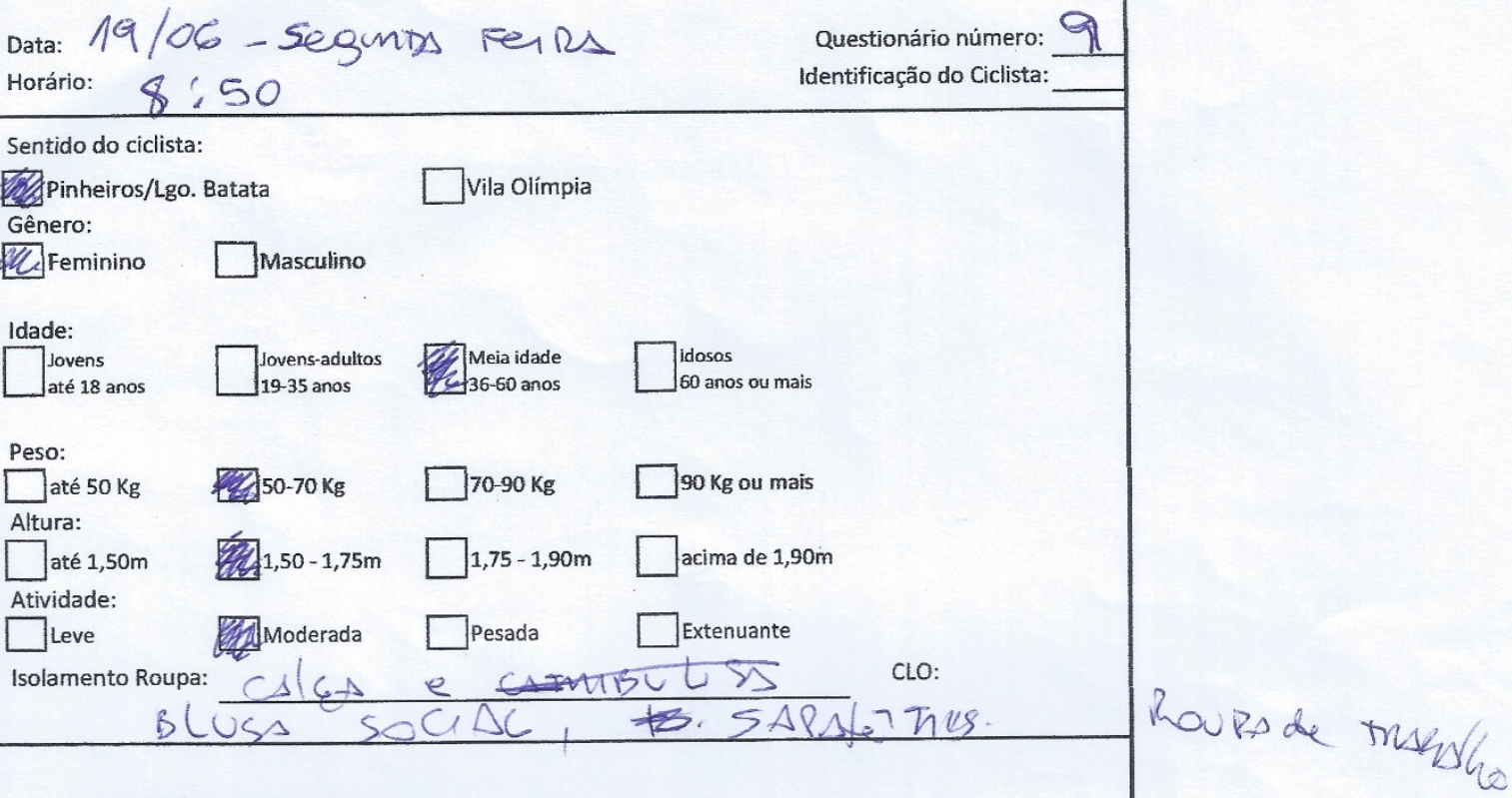

Você está indo para o trabalho?

W. $\operatorname{sim} \square$ Não

1. Neste exato momento, como você se sente com relação à temperatura ?

$\square$ Muito Frio $\square$ Frio $\quad \square$ Confortável $\square$ Calor Muito Calor

2. Em relação à temperatura, você está ?

2. Satisfeito $\square$ Insatisfeito

3. Como você gostaria de estar se sentindo em relação à temperatura ?

$\square$ Muito mais frio $\square$ Mais frio $\quad \square$ sem mudança $\square$ Mais quente $\square$ Muito mais quente

5. Em relação ao sol, você gostaria que estivesse?

$\square$ Mais sol

4. Em relação ao vento, você gostaria que estivesse?

$\square$ Mais fraco $\square$ Mais forte

6. O que te desencoraja a usar a bicicleta?
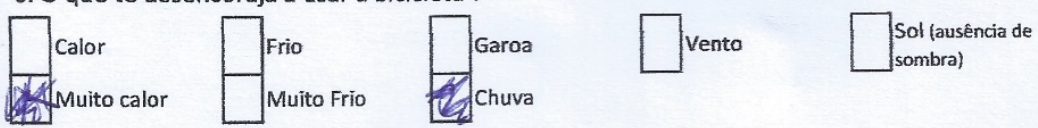

7. Há quanto tempo você iniciou este percurso ?

$\square$ menos de 15 min $\square$ 15-30 minutos $\square$ 30-45 minutos $\square$ 45-60 minutos $\square$ mais de 60 min

8. Há quanto tempo você está em SP ?

$\square$ Menos de 6 meses $\square$ Entre 6 m.e 1 ano $\square$ Mais de 1 ano 


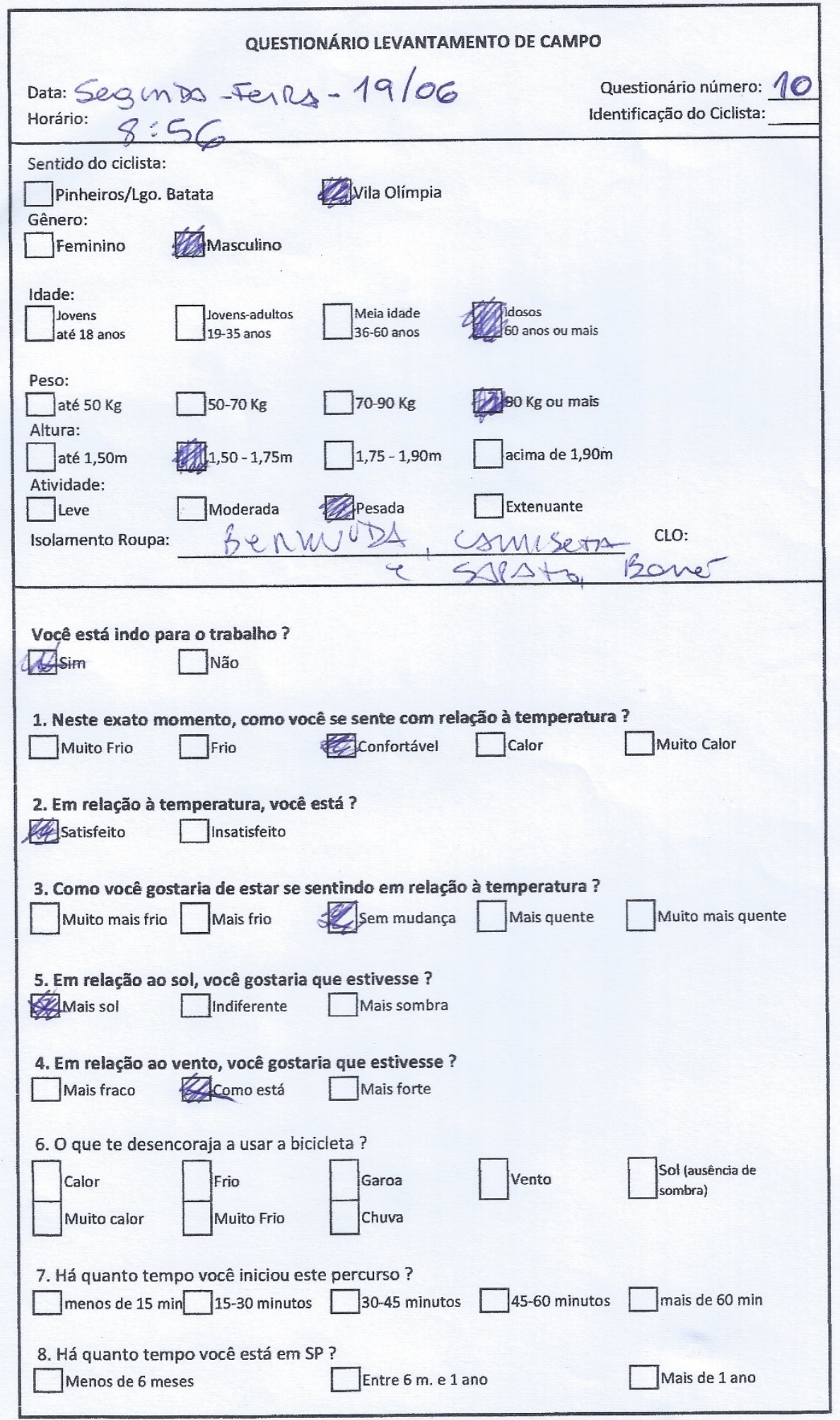




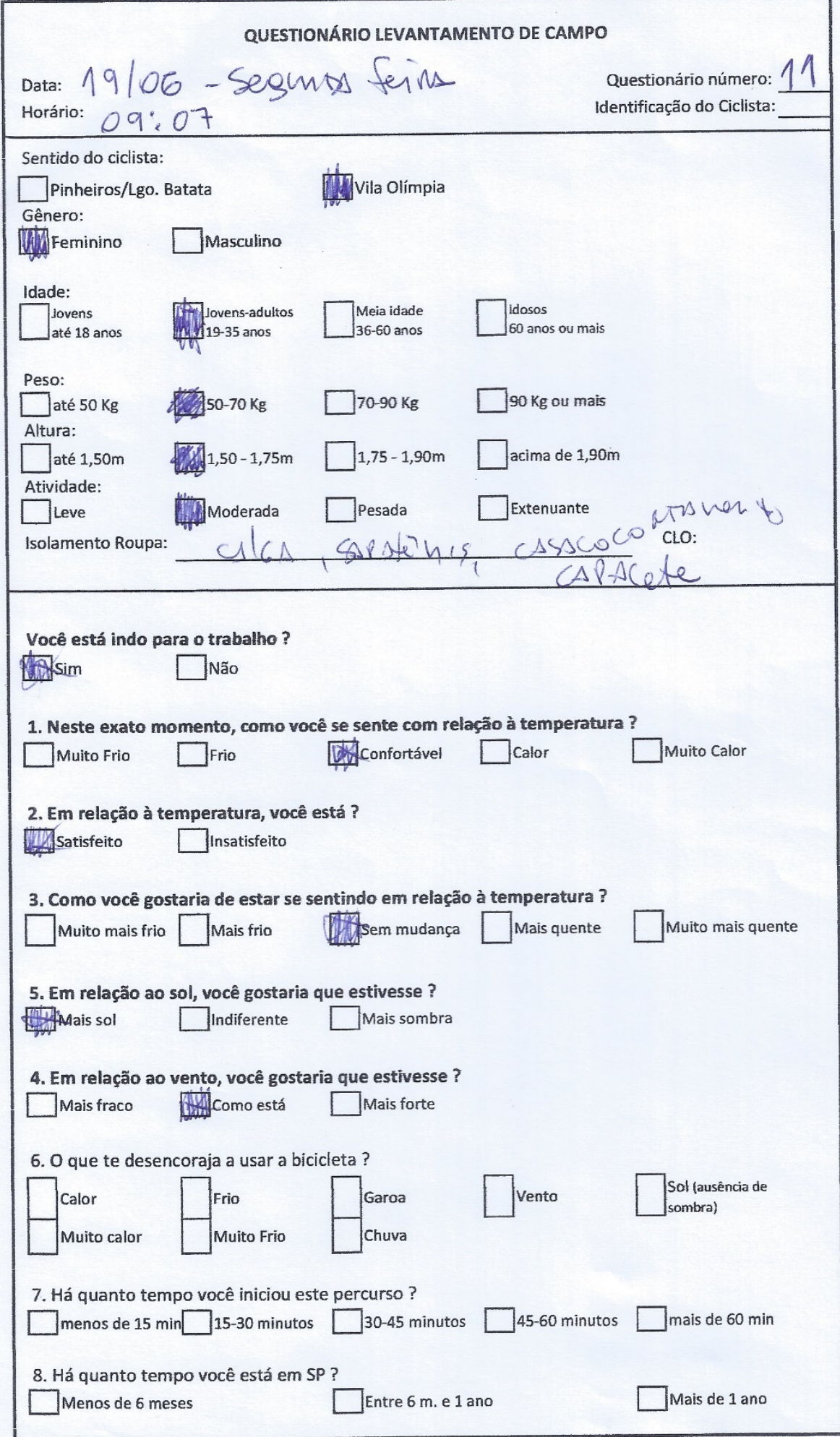




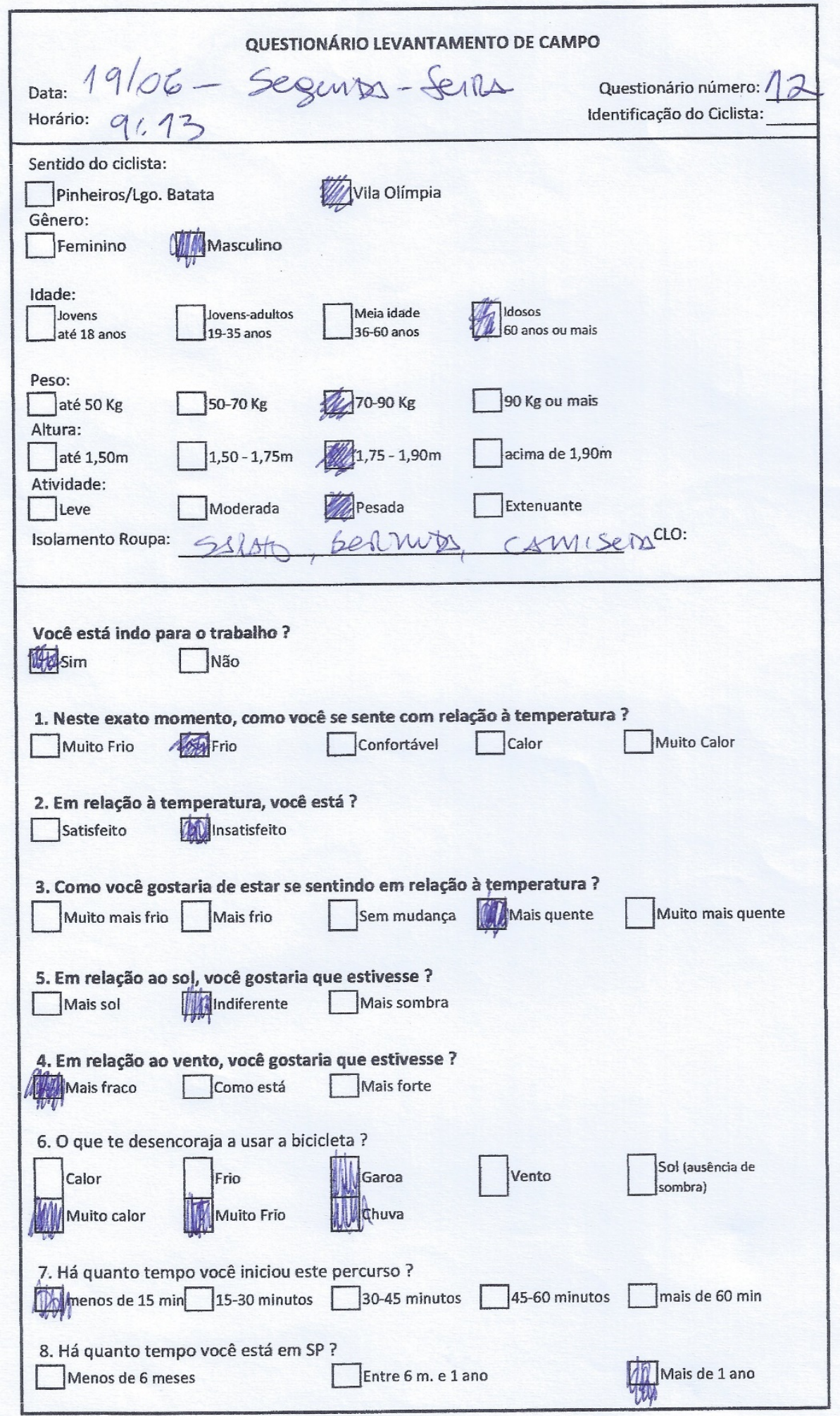




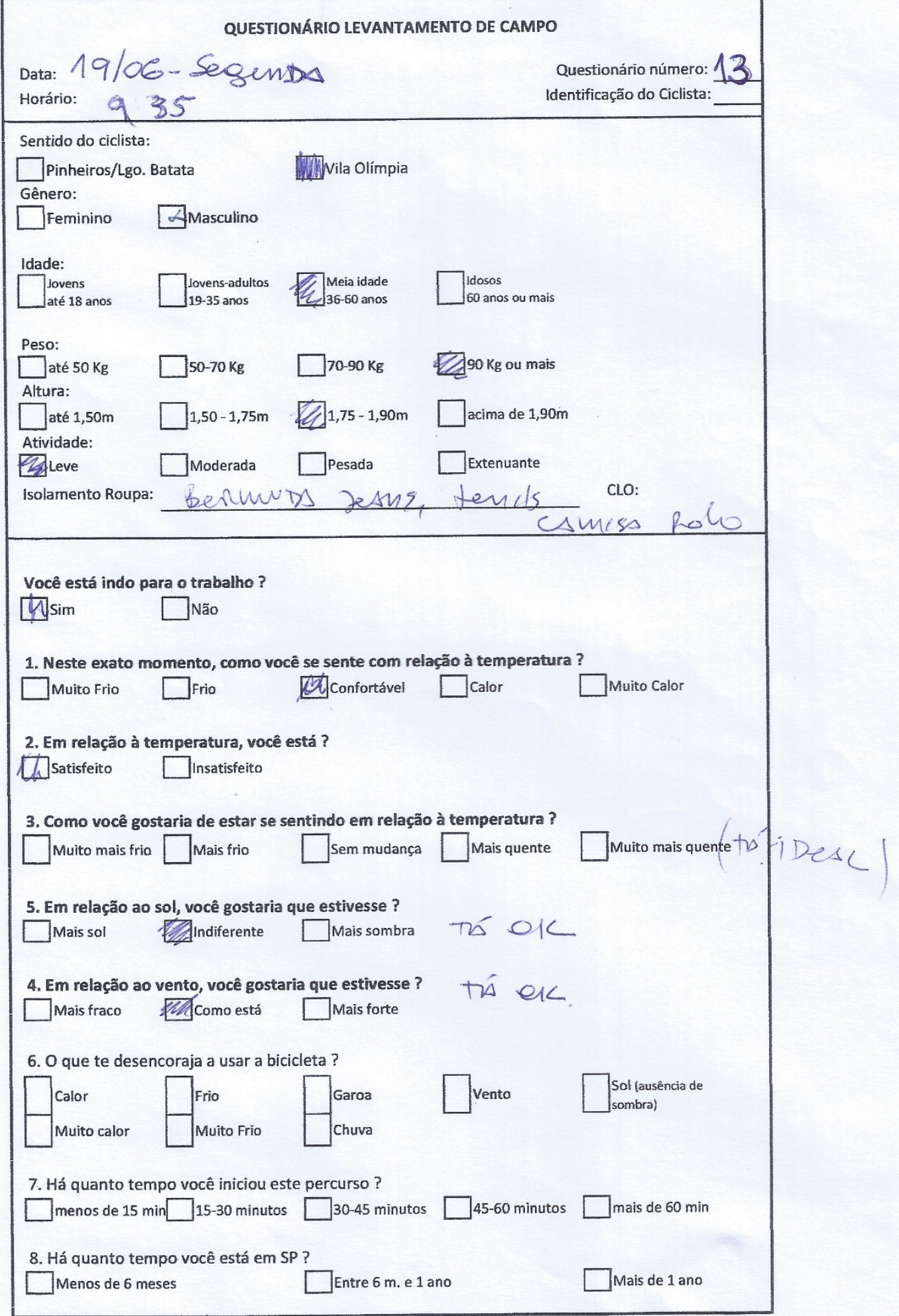




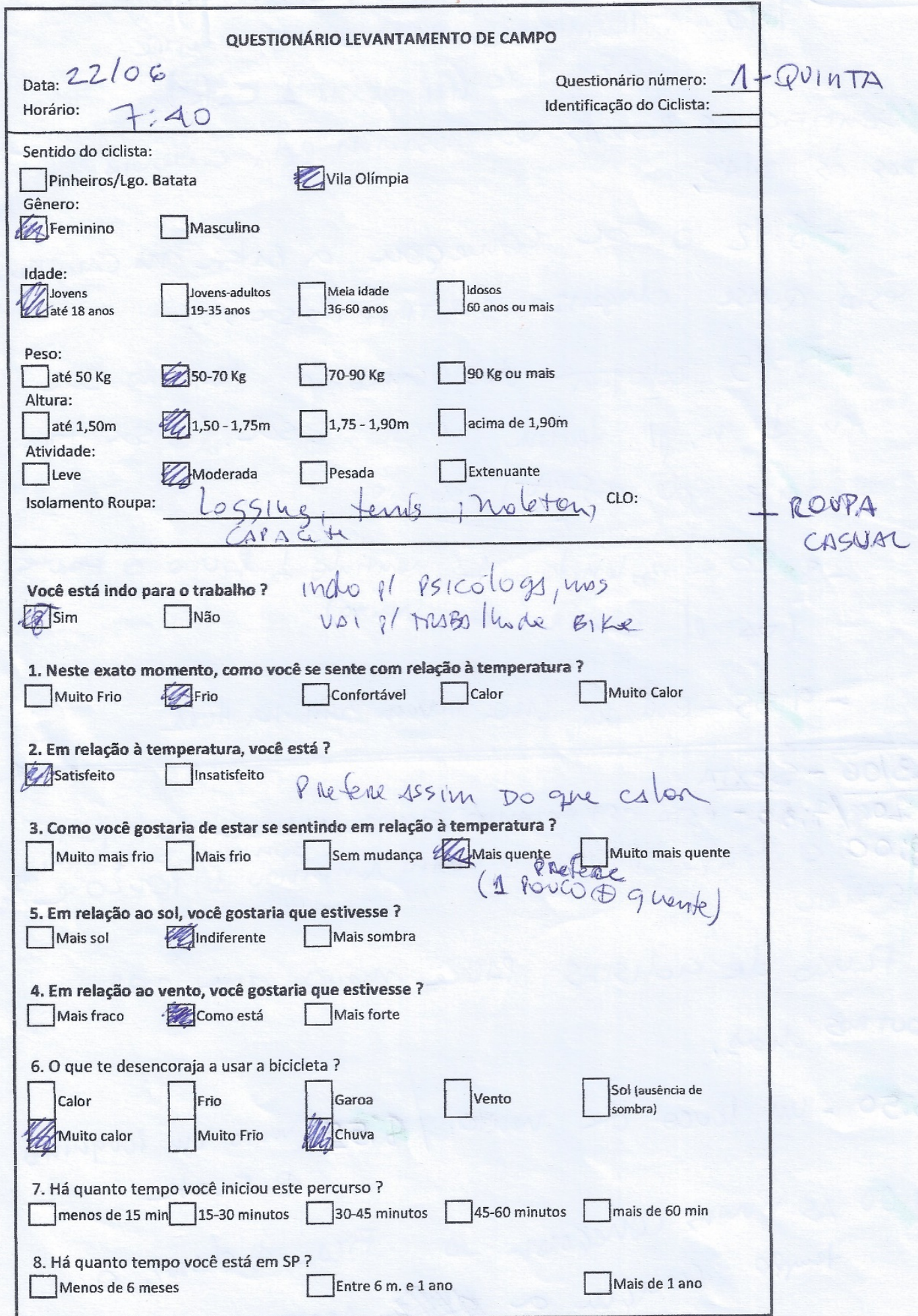




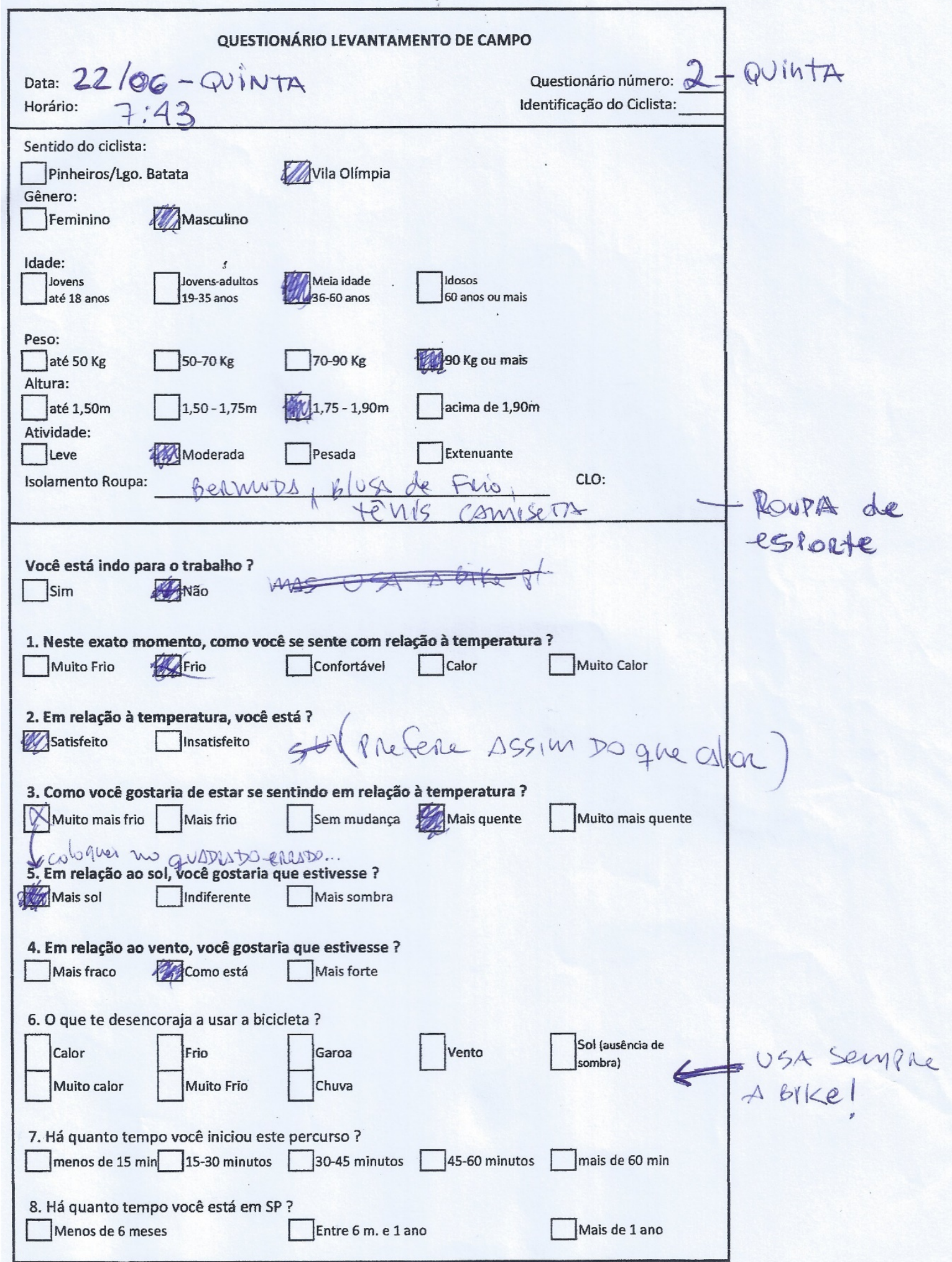




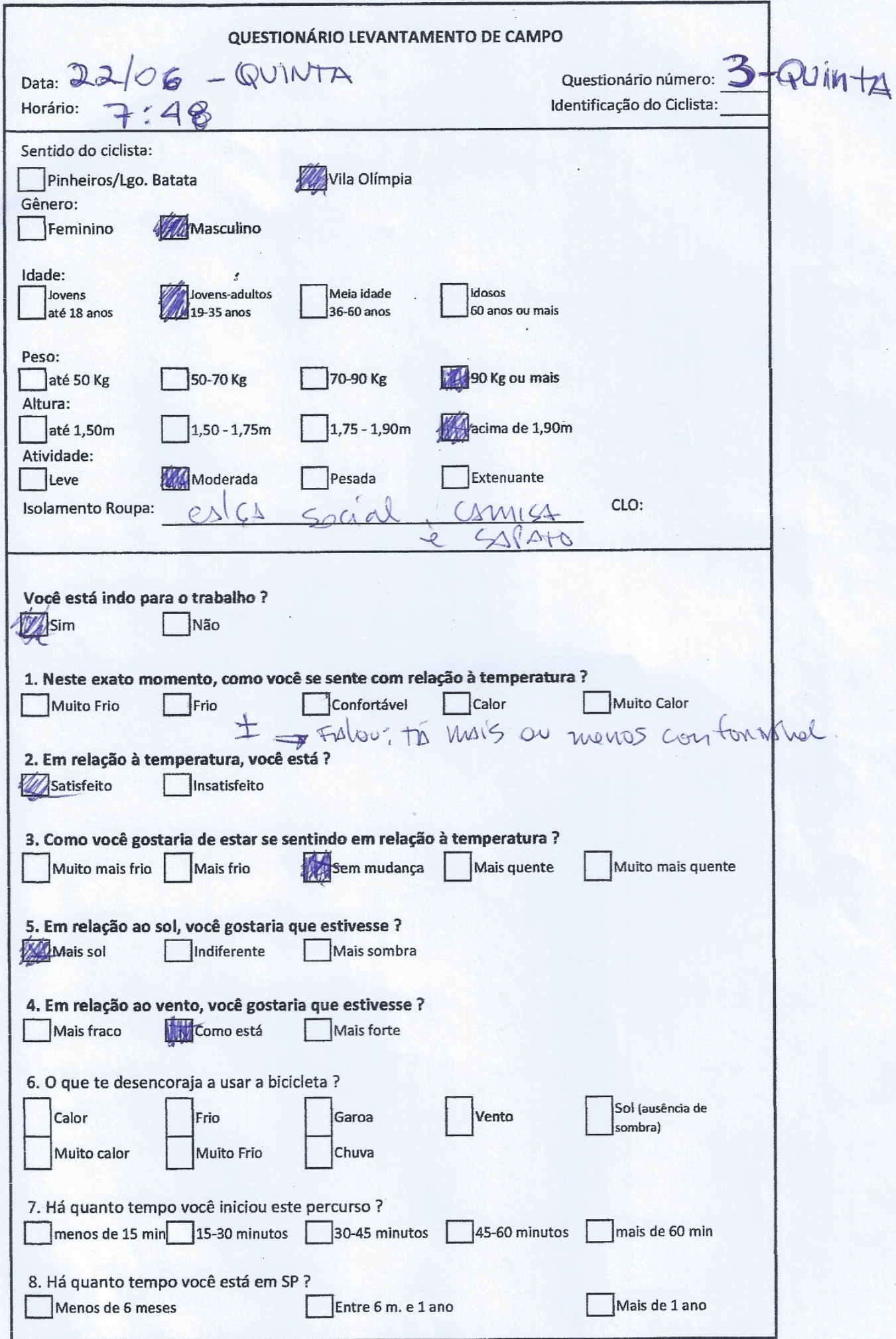




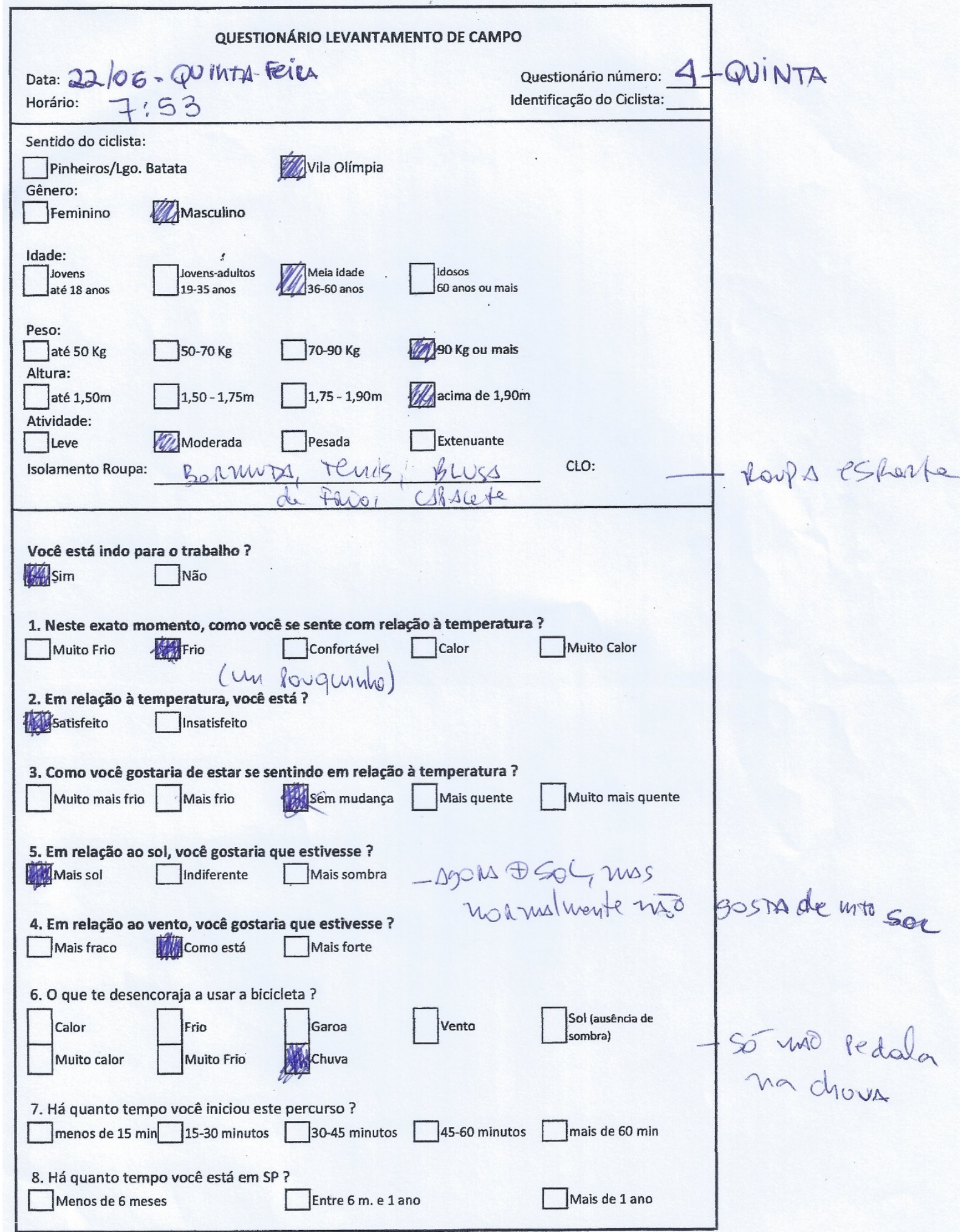




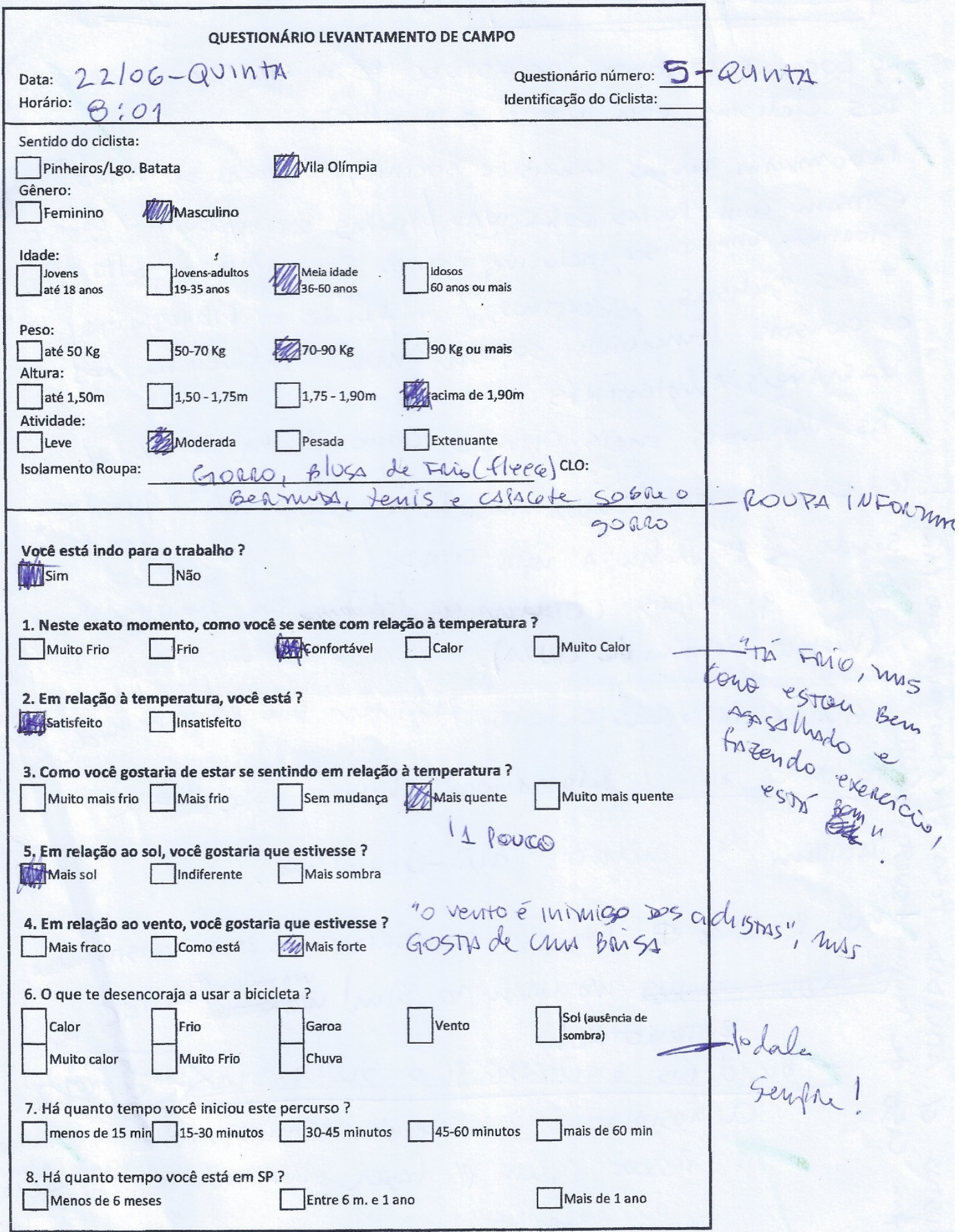


QUESTIONÁRIO LEVANTAMENTO DE CAMPO

Data: $22106-$ QuinTA

Questionário número: Identificação do Ciclista:

Horário: $8: 40$

Sentido do ciclista:

$\square$ Pinheiros/Lgo. Batata

\section{Tila Olímpia}

Gênero:

$\square$ Feminino $\quad$ Masculino

Idade:

\begin{tabular}{|c|c|c|c|}
\hline $\begin{array}{l}\text { lade: } \\
\text { Jovens } \\
\text { até } 18 \text { anos }\end{array}$ & $\begin{array}{l}\stackrel{3}{\text { lovens-adultos }} \\
19-35 \text { anos }\end{array}$ & Meia idade & $\square^{l d o s o s} 60$ anos ou mais \\
\hline
\end{tabular}

Peso:

$\square$ até $50 \mathrm{Kg} \quad \square 50-70 \mathrm{Kg} \quad \square 70-90 \mathrm{Kg} \quad \square 90 \mathrm{Kg}$ ou mais

Altura:

$\square$ até $1,50 \mathrm{~m}$

Atividade:

$\square$ Leve

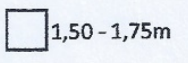

$\square 1,75-1,90 m$

III Tacima de $1,90 \mathrm{~m}$

Isolamento Roupa: woleton, Bermots

Extenuante

CLO:

tenis

Você está indo para o trabalho ?

$\square \operatorname{sim} \sqrt{4 \text { Não }}$

1. Neste exato momento, como você se sente com relação à temperatura ?

$\square$ Muito Frio $\quad$ 边Frio $\quad \square$ confortável $\quad \square$ calor $\quad \square$ Muito Calor

2. Em relação à temperatura, você está ?

$\square$ satisfeito $\quad$ Insatisfeito

3. Como você gostaria de estar se sentindo em relação à temperatura ?

$\square$ Muito mais frio $\square$ Mais frio $\square$ sem mudança $\quad 4$ Mais quente $\square$ Muito mais quente 1 Reoguinh

5. Em relação ao sol, você gostaria que estivesse ?

OUVinde

morsics

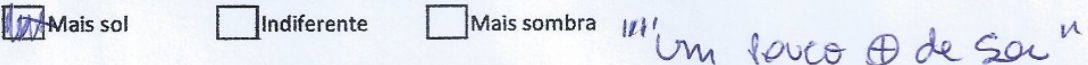

4. Em relação ao vento, você gostaria que estivesse ?

पMais fraco $\square$ Como está $\square$ Mais forte

6. 0 que te desencoraja a usar a bicicleta ?

$\square_{\text {Muito calor }}^{\text {Calor }} \square_{\text {Muito Frio }}^{\text {Frio }} \square_{\text {Chuva }}^{\text {Garoa }} \quad \square$ Vento $\quad \square$ sol (auséncia de

7. Há quanto tempo você iniciou este percurso ?

$\square$ menos de 15 min $\square$ 15-30 minutos $\square$ 30-45 minutos $\square$ 45-60 minutos $\square$ mais de 60 min

8. Há quanto tempo você está em SP ?
$\square$ Menos de 6 meses
Entre $6 \mathrm{~m}$. 1 ano
Mais de 1 ano 


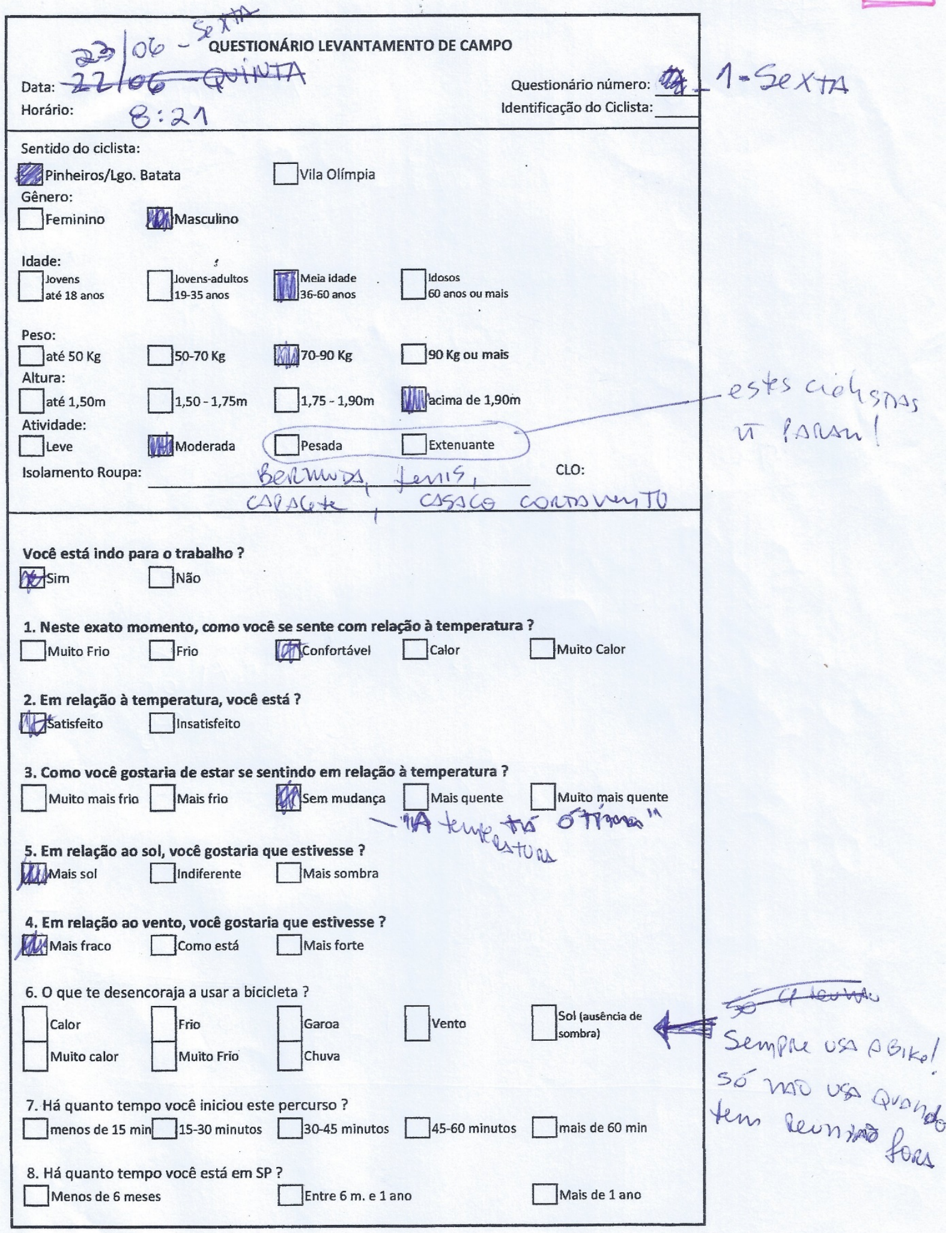




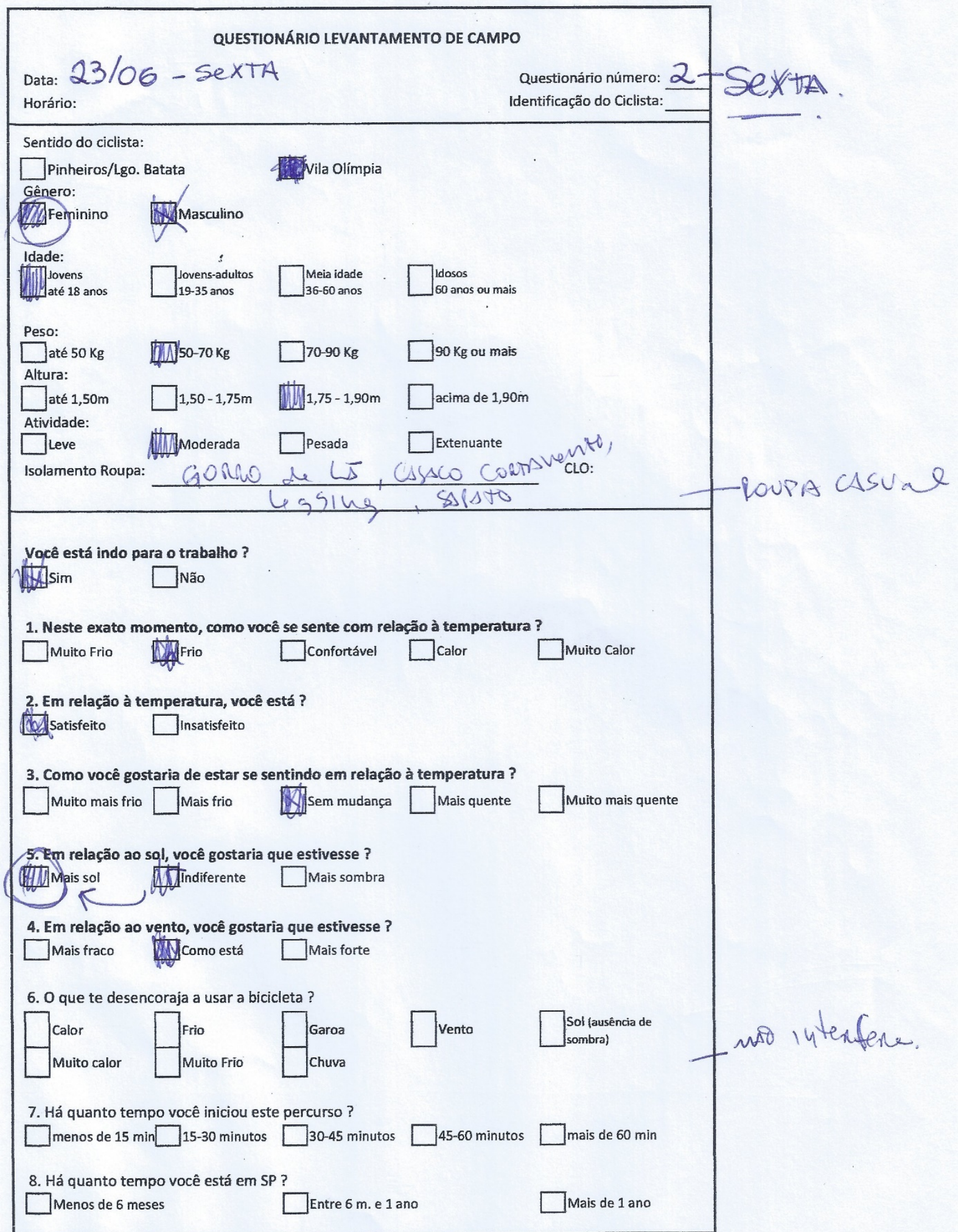




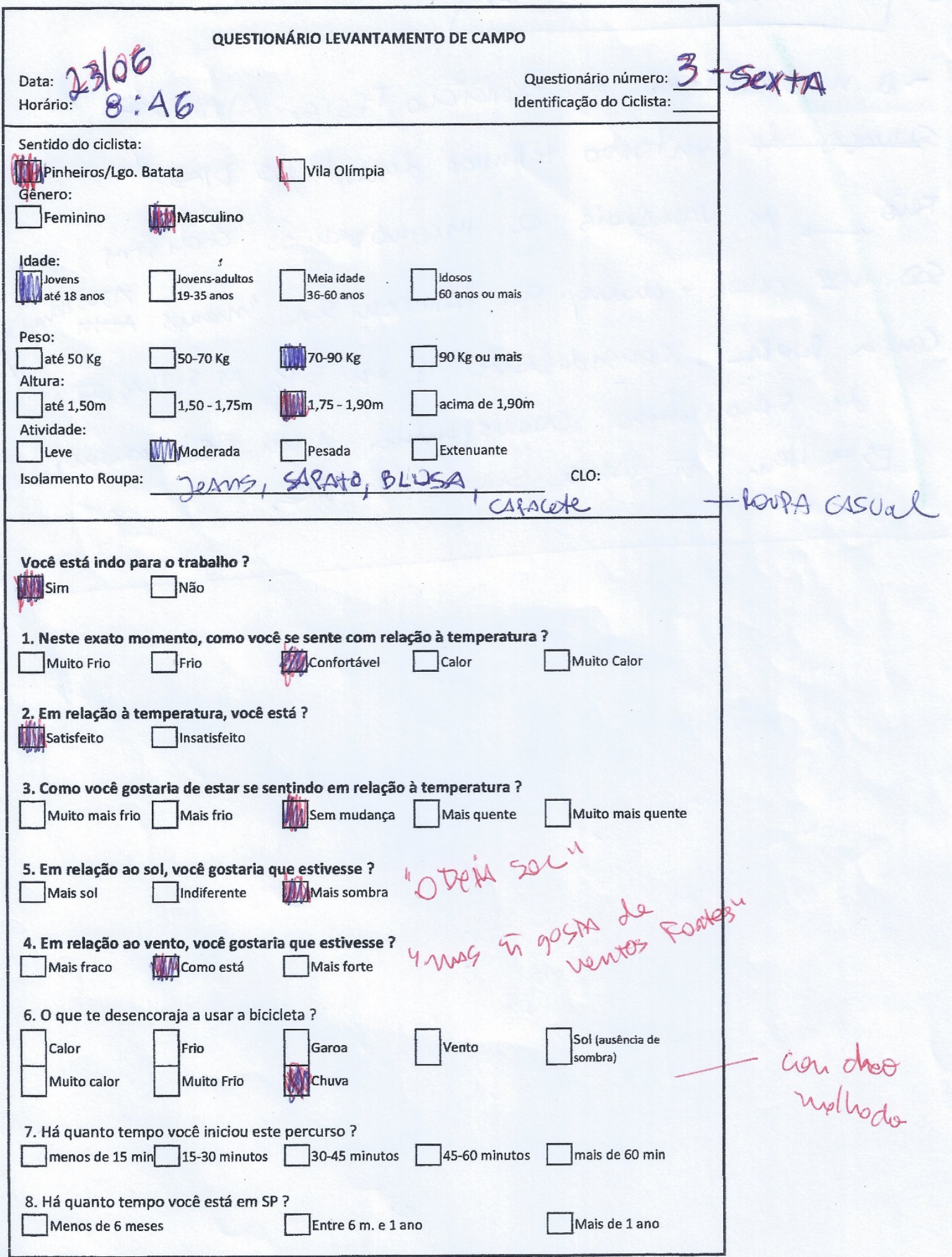




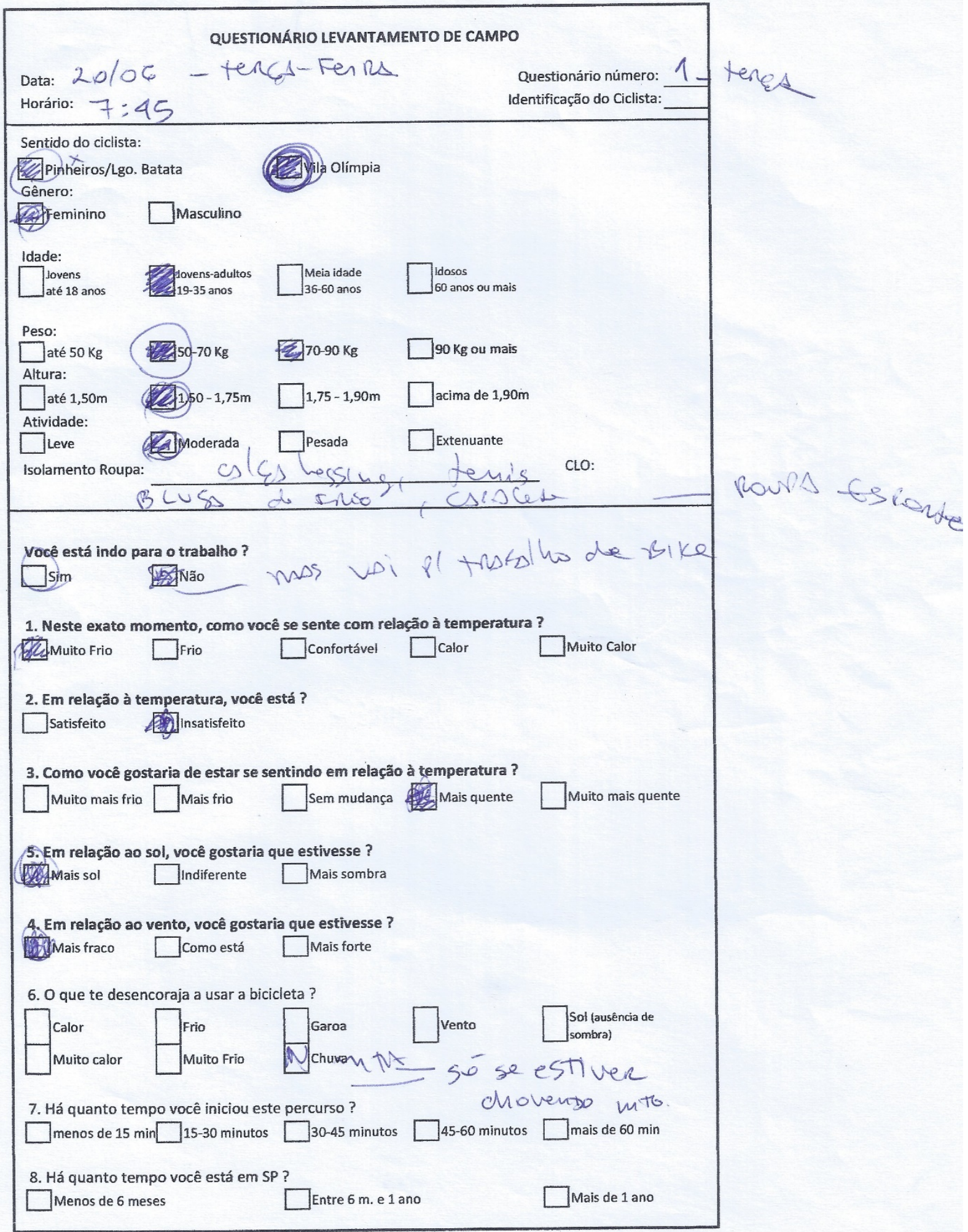




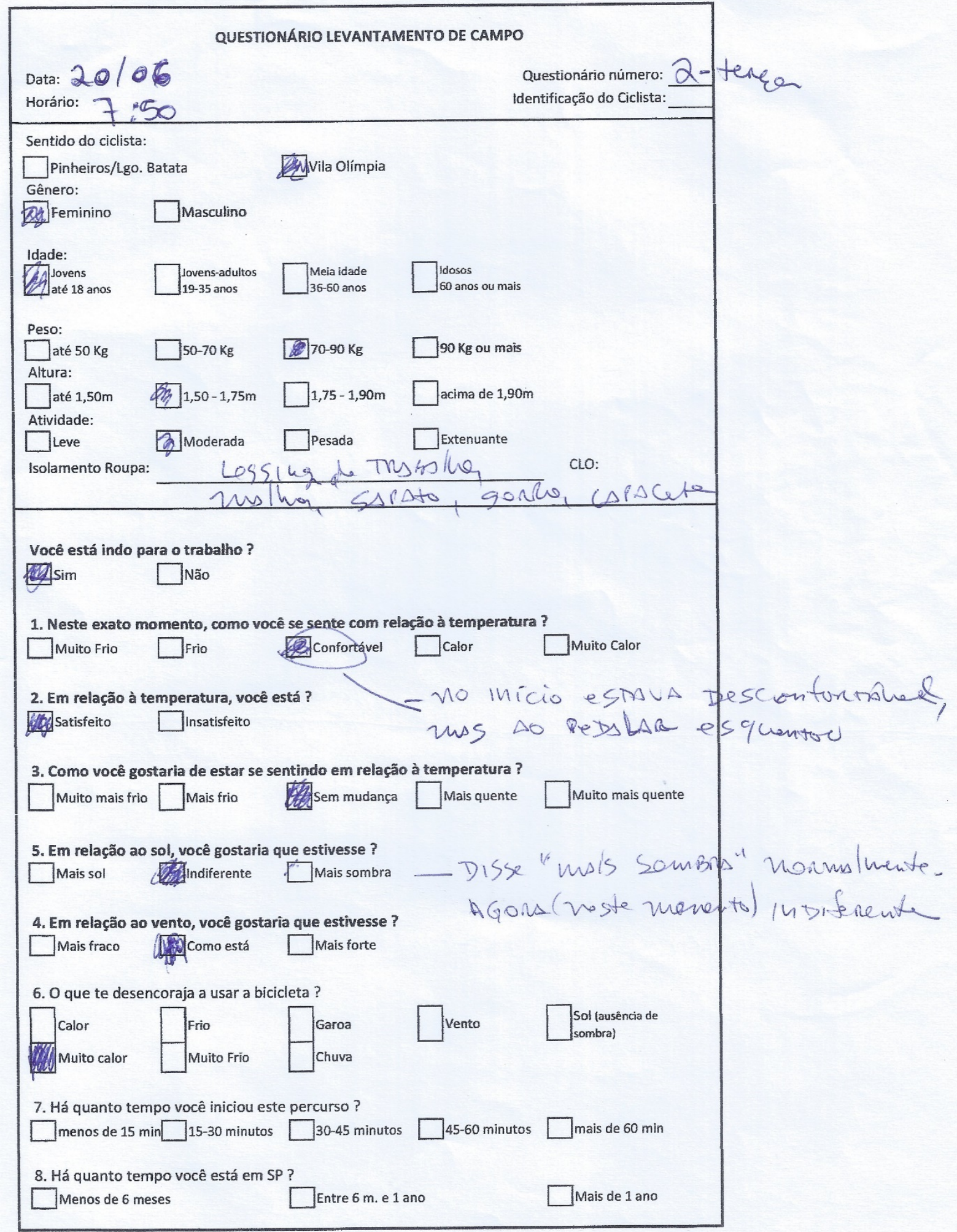




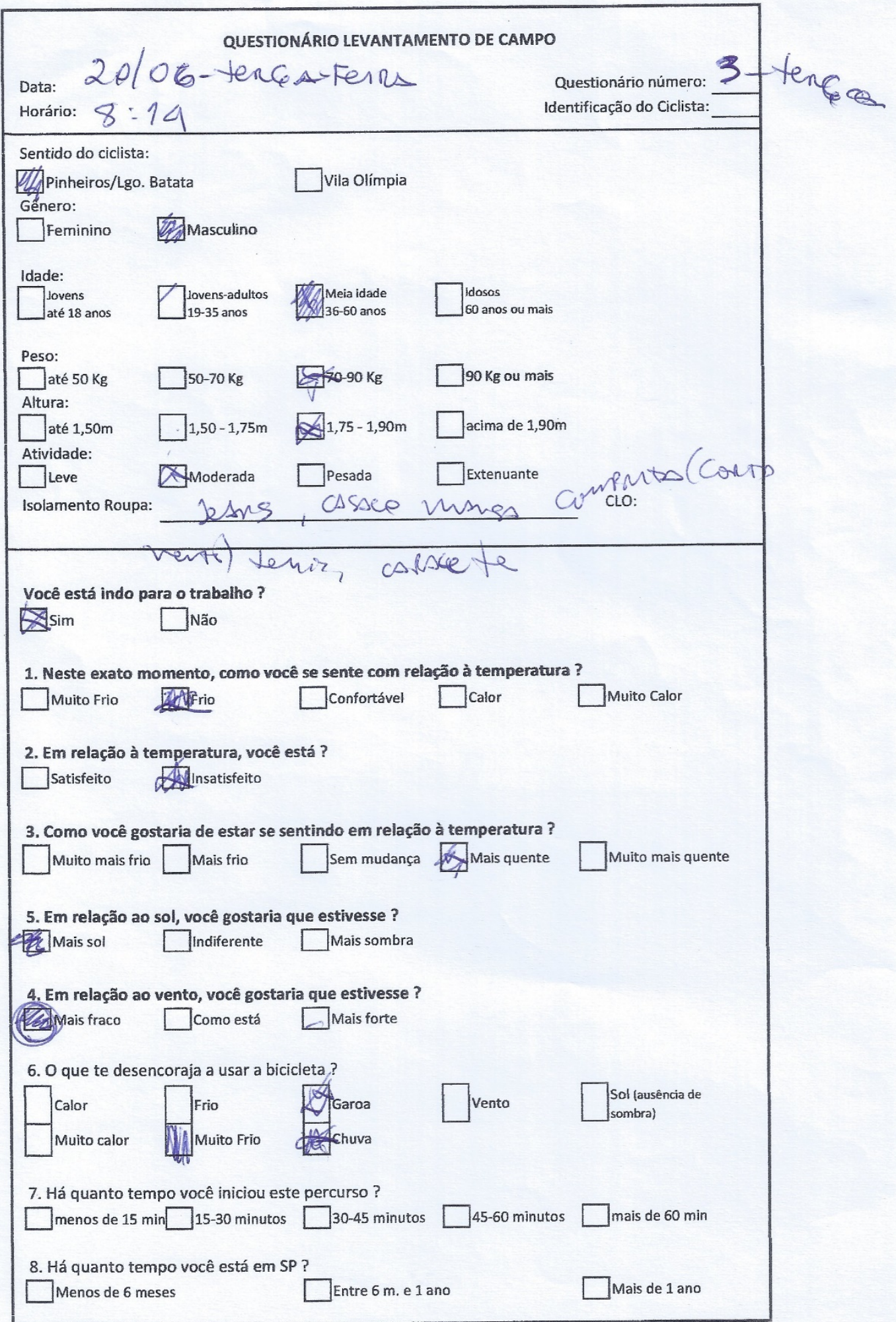

